\title{
Job autonomy, well-being, and health : a study among Dutch health care workers
}

Citation for published version (APA):

de Jonge, J. (1995). Job autonomy, well-being, and health : a study among Dutch health care workers. [Doctoral Thesis, Maastricht University]. Rijksuniversiteit Limburg. https://doi.org/10.26481/dis.19960125jj

Document status and date:

Published: 01/01/1995

DOI:

10.26481/dis.19960125jj

Document Version:

Publisher's PDF, also known as Version of record

\section{Please check the document version of this publication:}

- A submitted manuscript is the version of the article upon submission and before peer-review. There can be important differences between the submitted version and the official published version of record.

People interested in the research are advised to contact the author for the final version of the publication, or visit the DOI to the publisher's website.

- The final author version and the galley proof are versions of the publication after peer review.

- The final published version features the final layout of the paper including the volume, issue and page numbers.

Link to publication

\footnotetext{
General rights rights.

- You may freely distribute the URL identifying the publication in the public portal. please follow below link for the End User Agreement:

www.umlib.nl/taverne-license

Take down policy

If you believe that this document breaches copyright please contact us at:

repository@maastrichtuniversity.nl

providing details and we will investigate your claim.
}

Copyright and moral rights for the publications made accessible in the public portal are retained by the authors and/or other copyright owners and it is a condition of accessing publications that users recognise and abide by the legal requirements associated with these

- Users may download and print one copy of any publication from the public portal for the purpose of private study or research.

- You may not further distribute the material or use it for any profit-making activity or commercial gain

If the publication is distributed under the terms of Article $25 \mathrm{fa}$ of the Dutch Copyright Act, indicated by the "Taverne" license above, 
JOB AUTONOMY, WELL-BEING, AND HEALTH:

A STUDY AMONG DUTCH HEALTH CARE WORKERS 
Cㄷ 1995 by J. de Jonge.

All rights reserved. No part of this publication may be reproduced, stored in a retrieval system, or transmitted, in any form or by any means, electronic, mechanical, photocopying, recording, or otherwise, without the prior written permission from the publisher.

Cover design by Karel van den Hurk and Jan de Jonge.

Lay-out by Karel van den Hurk.

Printed and bound by Datawyse B.V. I Universitaire Pers Maastricht.

Printed in the Netherlands.

CIP-DATA KONINKLIJKE BIBLIOTHEEK, DEN HAAG

Jonge, Jan de

Job autonomy, well-being, and health: a study among Dutch health care workers / Jan de Jonge. - [S.I. : s.n.]. - III., fig., tab.

Thesis Rijksuniversiteit Limburg, Maastricht. - With ref. With summary in Dutch and German.

ISBN 90-9008948-9

Subject headings: job autonomy / workstress / health care. 


\section{JOB AUTONOMY, WELL-BEING, AND HEALTH:}

\section{A STUDY AMONG DUTCH HEALTH CARE WORKERS}

\section{PROEFSCHRIFT}

ter verkrijging van de graad van doctor

aan de Rijksuniversiteit Limburg te Maastricht,

op gezag van de Rector Magnificus, Prof, mr. M.J. Cohen, ingevolge het besluit van het College van Dekanen,

in het openbaar te verdedigen op

donderdag 25 januari 1996 om 14.00 uur

door

Jan de Jonge 


\section{Promotor:}

Prof. dr. F.J.N. Nijhuis

\section{Co-promotor:}

Dr. J.A. Landeweerd

\section{Beoordelingscommissie:}

Prof. dr. H. Philipsen (voorzitter)

Prof. dr. M.P.F. Berger

Dr. N.P.G. Boumans

Prof. dr. M.A.J. Kompier (Katholieke Universiteit Nijmegen)

Prof. dr. W.B. Schaufeli (Universiteit Utrecht) 
"He who loves practice without theory is like the sailor who boards ship without a rudder and compass and never knows where he may be cast."

Leonardo da Vinci (1452-1519). 

Contents 
1 General introduction

1.1 Modern working life: a worker's meat or poison?

1.2. Research problem and aims of the study

1.3 Overview of the thesis

\section{Job autonomy}

2.1 Introduction

2.2 The nature of job autonomy

2.3 Job autonomy: concept, measurement, and assessment

2.3.1 A typology of the job autonomy concept

2.3.2 Towards a definition of job autonomy

2.3.3 The measurement of job autonomy

2.3.4 Objective versus subjective assessment of job autonomy 18

2.4 Concluding remarks

3 Job autonomy and psychological outcomes

3.1 Introduction

3.2 The Task Characteristics Approach

3.3 Hackman and Oldham: The job Characteristics Model

3.3.1 Model description

3.3.2 Empirical evidence for the model

3.4 Karasek and colleagues:

The Job Demand-Control Model and the Demand-Control-Support Model

3.4.1 Model descriptions

3.4.2 Empirical evidence for the models

3.5 Warr: The Vitamin Model

3.5.1 Model description

3.5.2 Empirical evidence for the model

3.6 Research questions and conceptual framework

\section{Method}

4.1 Introduction

4.2 Design of the study

4.3 Population of the study

4.4 Sample design and sample procedure

4.5 Fieldwork and respondents 53

4.6 Summary 
5 Psychometric analysis 63

5.1 Introduction 63

5.2 Description and operationalization of the variables 63

5.2.1 Introduction 63

5.2.2 Job characteristics 64

5.2.3 Psychological outcomes 66

5.2.4 Demographic characteristics 68

$\begin{array}{lll}5.3 & \text { Data analysis } & 68\end{array}$

5.3 .1 Introduction $\quad 68$

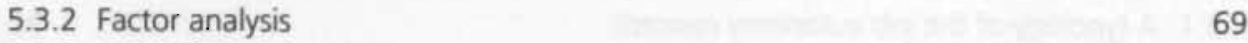

$\begin{array}{ll}5.3 .3 \text { Reliability analysis } & 71\end{array}$

$\begin{array}{lll}5.4 & \text { Results } & 73\end{array}$

5.4 .1 Introduction

5.4.2 Cross-sectional results

5.4 .3 Longitudinal results $\quad 82$

$\begin{array}{lll}5.5 & \text { Summary and conclusions } & 87\end{array}$

6 Cross-sectional analysis 93

6.1 General introduction 93

6.2 Preliminary analysis 93

6.3 Group and individual assessment of job characteristics

$\begin{array}{ll}6.3 .1 \text { Introduction } & 98\end{array}$

6.3.2 Data analysis 100

$\begin{array}{ll}6.3 .3 \text { Results } & 103\end{array}$

6.4 Testing the Demand-Control-Support Model 110

$\begin{array}{ll}6.4 .1 \text { Introduction } & 110\end{array}$

6.4.2 Data analysis 111

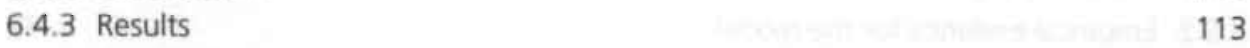

6.5 Testing the Vitamin Model 116

6.5.1 Introduction 116

6.5.2 Data analysis 116

$\begin{array}{ll}6.5 .3 \text { Results } & 117\end{array}$

$\begin{array}{lll}6.6 & \text { Summary } & 122\end{array}$

$7 \quad$ Longitudinal analysis $\quad 127$

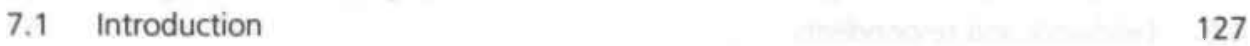

$\begin{array}{ll}\text { 7.2. Preliminary analysis } & 127\end{array}$

7.3 Structural equation modelling of longitudinal panel data $\quad 129$

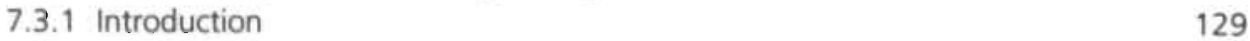

$\begin{array}{lr}\text { 7.3.2 Data-analysis } & 130\end{array}$

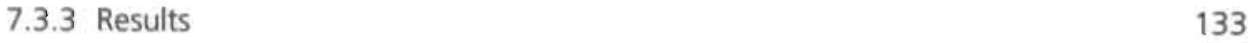

$\begin{array}{lll}7.4 & \text { Summary } & 137\end{array}$ 
8 General discussion 141

8.1 Introduction 141

8.2 Summary of the main findings 141

8.2.1 Introduction 141

8.2.2 The conceptualization and operationalization of the variables 141

8.2.3 Individual and group assessment of job characteristics 142

8.2.4 The relationship between job characteristics and psychological outcomes $\quad 143$

8.3 Methodological considerations 144

$\begin{array}{lll}8.4 & \text { Theoretical implications } & 148\end{array}$

8.4.1 Introduction 148

8.4.2 Job autonomy: conceptualization, measurement, and assessment 148

8.4.3 Job characteristics, well-being, and health: tests of theories 151

8.4.4 The particular role of demographic characteristics 158

8.4.5 Towards a heuristic model of job characteristics and psychological outcomes $\quad 158$

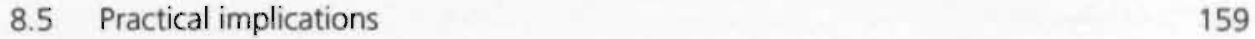

8.6 Directions for future research 162

$\begin{array}{lll}8.7 & \text { Final remarks } & 164\end{array}$

$\begin{array}{ll}\text { Summaries } & 167\end{array}$

$\begin{array}{ll}\text { Summary } & 169\end{array}$

Summary in German $\quad 170$

General outline in Dutch 172

$\begin{array}{ll}\text { References } & 177\end{array}$

$\begin{array}{ll}\text { Appendices } & 193\end{array}$

$\begin{array}{ll}\text { Acknowledgements } & 209\end{array}$

$\begin{array}{ll}\text { Curriculum Vitae } & 211\end{array}$ 
Chapter 



\section{GENERAL INTRODUCTION}

\subsection{Modern working life: a worker's meat or poison?}

In modern Western society work occupies a prominent role in the lives of many people. Present-day work fulfils a series of important functions. Not only does it provide income, but it also provides social status, personal identity, experienced meaningfulness, self-realization and growth. As a social phenomenon, work can also provide social contacts, thus functioning as a major psychosocial resource (Baker \& Green, 1991).

At the same time, however, today's work claims more and more from its employees. There is a shift in the modern industrial world away from old-fashioned manufacturing, metals, chemicals, and other industries to work characterized by knowledge and delivery of services (Johnson \& Hall, 1994; Offermann \& Gowing, 1990). Consequently, new sources of work stress' are emerging, psychosocial risk factors in particular. For instance, new 'bad' jobs might be characterized by little freedom to perform even the most basic tasks, nothing to be learned, high quality demands, long periods of intense time pressure, and social isolation (df. Houtman \& Kompier, 1995; Karasek \& Theorell, 1990).

In this ever-changing environment, increasing social, technological and economic pressures may cause physical, chemical or biological hazards. What is more, various psychosocial risk factors have an increasing influence on employees' well-being and health. It is therefore not surprising that working life within modern complex organizations proves to be a primary source of work stress exposures (Carayon, 1993; Johnson, Hall, Stewart, Fredlund \& Theorell, 1991).

One of the fast growing service industries that employs vast numbers of people is health care, in which many employees are exposed to - modern - risk factors at work. Several important developments are changing the face of health care (cf. De Jonge, Janssen \& Landeweerd, 1994; Schaefer \& Moos, 1993). The first is concerned with rapidly expanding medical technology and the increasing job complexity and ethical dilemmas associated with it. Cost containment programmes which restrict the resources staff have available is a second key development. A third change concerns the completion of new care delivery systems, which have important consequences for the method of working in health care. Finally, people are getting older and older, which increases the number of potential patients. Health care is confronted with new diseases, not only those of old age, but also new viral and infectious diseases. Consequently, there is a trend towards more 'care' instead of more 'cure'.

Although health care settings are very diverse, many health care workers are working in relatively large institutions. Because of the bureaucratic and professional nature of these institutions, the structure and the functioning of their organization are important sources of work stress (e.g., Lindström, 1992; Parkes \& Von Rabenau, 1993). For example, cost containment programmes and hierarchical decision making can increase job demands and may limit the worker's freedom. In addition, health care employees have often been termed 
"dependent practitioners" because of their reliance on physicians and, consequently, relative lack of job autonomy (Jonas, 1990).

Finally, health care workers are faced with a number of risk factors which are inherent to the specific nature of their job. Health care workers are "people-processing", and they deal with their patients in situations of suffering and death (cf. Hingley \& Cooper, 1986; Payne \& Firth-Cozens, 1987). These close care provider-recipient relationships can be fraught with emotional strain, possibly leading to occupational burnout (Maslach \& Schaufeli, 1993).

For the past decade there has been a growing interest for a greater understanding of psychosocial risk factors at the workplace. For example, the International Labour Office urged concern for physical and psychosocial risk factors by commissioning 19 stress prevention studies in nine countries (for a review, see Karasek, 1992). Action to combat work stress also include legislative responses by national governments. The Dutch Work Environment Act, for instance, comprises several provisions (article 3 in particular) which take account of physical and psychosocial risk factors in the workplace (cf. Kompier, De Gier, Smulders \& Draaisma, 1994).

With regard to psychosocial risk factors in the workplace, existing evidence supports the case that at least two key properties of the job are critical with respect to well-being and health (e.g. Hackman \& Oldham, 1980; Karasek \& Theorell, 1990; Landsbergis \& VivonaVaughan, 1995; Schnall, Landsbergis \& Baker, 1994): (1) psychological job demands; and (2) job autonomy (or related concepts like job control, job decision latitude and job discretion). Today the main problem seems not that one should resist the inevitable demands of work, but rather develop strategies to enhance job-related resources for controlling these demands. That is a reason why the concept of job autonomy has been recognized more and more as an important determinant of employee's well-being and health (e.g., Johansson \& Aronsson, 1991; De Jonge, 1992; Kahn \& Byosiere, 1994; Karasek, 1990; Sauter \& Hurrell, 1989).

In work and organizational literature, the job autonomy concept can be placed under the wide-ranging umbrella of job control research (see figure 1.1). Many of the research studies concerning job autonomy have been formulated in terms of job control (Evans \& Fischer, 1992: Ganster, 1989; Spector, 1986). Genera!ly, job control can be defined as the opportunity to exert some influence over one's work (cf. Frese, 1989; Ganster, 1989). Having influence means being able to take job-related decisions. If the work environment does not provide the freedom to decide, the employee does not have any job conitrol. As shown in figure 1.1, the concept of job control has been central in two prominent research traditions, namely (1) research on participative decision-making and (2) research on job redesign (cf. Evans \& Fisher, 1992; Ganster, 1989; Jackson, 1989; Landsbergis \& VivonaVaughan, 1995; Spector, 1986). Spector (1986), for instance, reviewed the literature and subsumed employee participation and job autonomy under a second-order job control factor. In addition to this, he found that both variables were associated with a number of psychological outcomes (like job satisfaction and emotional distress). We will briefly discuss the two research traditions. 


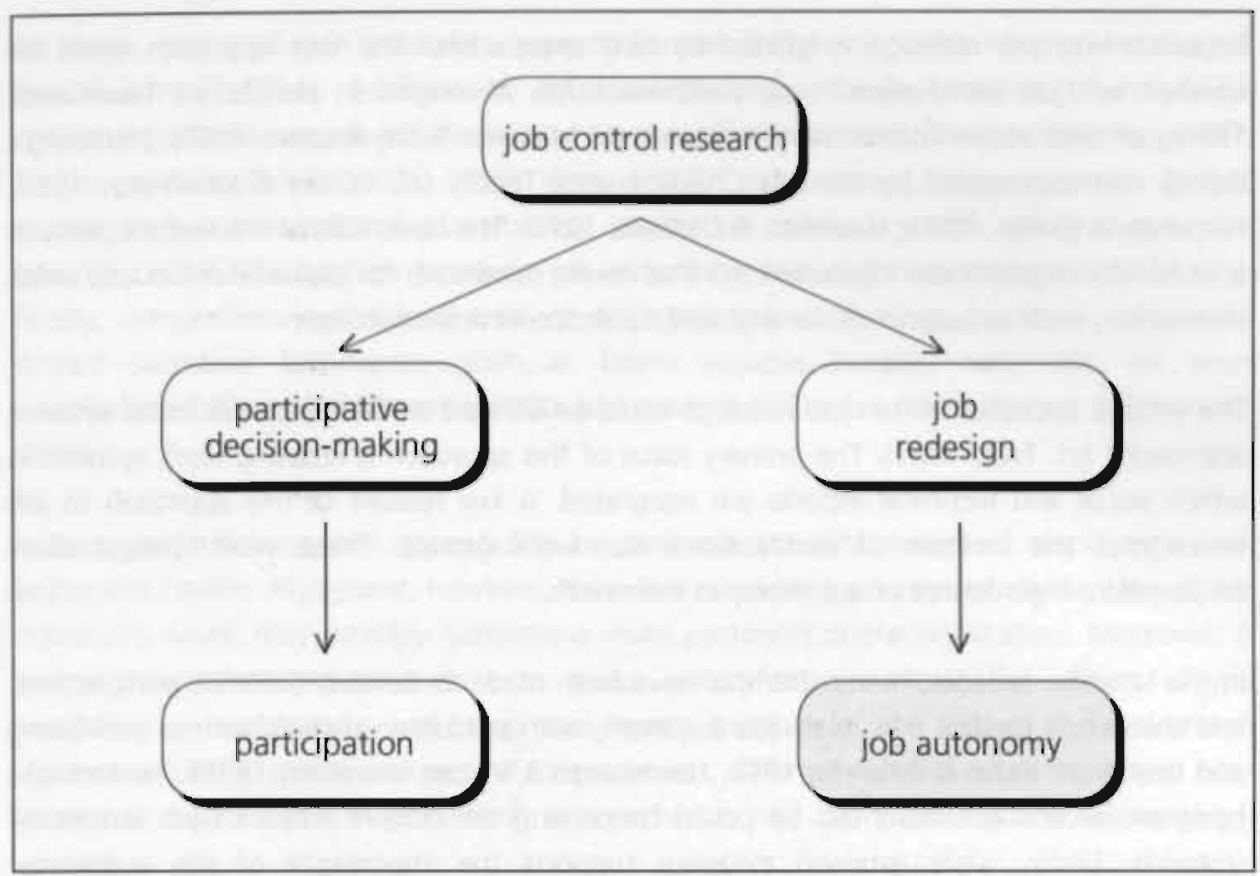

Figure 1.1 The structure of job control research

Participative decision-making, or $\mathrm{PDM}^{2}$, is a method of joint decision-making to motivate employees, which may lead to increased satisfaction and productivity. The central concept of PDM, employee participation, refers to the amount of involvement in the process of reaching decisions (Ganster, 1989; Locke \& Schweiger, 1979; Monge \& Miller, 1988). PDM is relevant to job control to the extent that employees who participated in making decisions have (more) influence in processes, regarding the workplace (Ganster \& Fusilier, 1989). Inextricably linked to the notion of job control appeared to be the concept of job autonomy. If job autonomy is restricted only to the first part of the most commonly cited definition (Hackman \& Oldham, 1975, p. 162), as relating to '... freedom, independence, and discretion to the individual in scheduling the work ...', then it measures a type of individual control in a specified domain - that of the worker's tasks (cf. Aronsson, 1991; Ganster, 1989; Hodson, Creighton, Sorenson Jamison, Rieble \& Welsh, 1994).

As a consequence, job autonomy has been one of the most important characteristics within the job redesign tradition (e.g., Hackman \& Oldham, 1980). Job redesign is a reaction to the job design paradigm (e.g., Smith, 1776; Taylor, 1911). The central idea of job redesign is projecting jobs so that they offer more intrinsic rewards to the worker, like intrinsic work motivation and job satisfaction. Instead of the division of labour and work simplification as indicated by job design, a wider range of tasks must be included in jobs and more autonomy should be granted to employees over the execution of work (Wall \& Martin, 1987). 
Research into job redesign is guided by two approaches. The first approach could be labelled as "job enrichment". Job enrichment has its origins in Herzberg's Two-Factor Theory of satisfaction and motivation (Herzberg, Mausner \& Snyderman, 1959). Herzberg's theory was superseded by the Job Characteristics Theory (cf. Turner \& Lawrence, 1965; Hackman \& Lawler, 1971; Hackman \& Oldham, 1976). The basic idea of this latter approach is to build into jobs those characteristics that create conditions for job satisfaction and work motivation, such as autonomy, variety, and the scope of responsibility.

The second approach within job redesign could be labelled as the "socio-technical systems approach" (cf. Trist, 1981). The primary focus of this approach is creating work systems in which social and technical aspects are integrated. A key feature of this approach to job redesign is the creation of semi-autonomous work groups. These work groups allow employees a high degree of autonomy in their work.

In the last two decades, many attempts have been made to develop theories, perspectives, and theoretical models that relate job autonomy with outcome variables such as well-being and health (cf. Kahn \& Byosiere, 1994; Landsbergis \& Vivona-Vaughan, 1995). Increasingly, however, several questions can be posed concerning the current status of job autonomy research. Firstly, while growing evidence supports the importance of job autonamy, fundamental questions remain as to the conceptualization and operationalization of this construct. The definition of job autonomy (or its related concepts) usually follows that used by most job redesign researchers: mostly in a narrow manner suggestive of Hackman and Oldham's (1975) definition of job autonomy (see also chapter 2). Many job autonomy studies, in practice, have failed to treat this job characteristic with any level of breadth and depth (Breaugh, 1985; Ganster, 1989; Ganster \& Fusilier, 1989). Additionally, several recent - measurement instruments appear to be too general and too vague to be usefui in describing this specific characteristic of the work setting. Moreover, they appear to overlap with other job characteristics like skill variety and task independence, which seem theoretically distinct from job autonomy (ć. Breaugh, 1985; Ganster \& Fusilier, 1989; De Jonge, Landeweerd \& Van Breukelen. 1994; Kasl, 1989; Sauter \& Hurrell, 1989: Spielberger \& Reheiser, 1995).

Secondly, a variety of methodological difficulties have been observed, making precise and robust conclusions very hard (e.g., Ganster, 1989; Kasl, 1987, 1989; Spector, 1992). For instance, different ways of objective as well as subjective assessments of job autonomy have been used in the prediction of psychological outcomes (e.g., expert ratings, occupational grouping, and self-reports). Another methodological issue concerns the kind of relationship between job autonomy and psychological outcomes. While there is some general agreement that several relationships do exist, there is still some disagreement about the specific nature and the magnitude of the associations (e.g., De Jonge, 1992; Karasek, 1989; Parkes, Mendham \& Von Rabenau, 1994; Warr, 1994). For example, existing evidence has shown that job autonomy acts not only as an independent variable, but also combines with other job characteristics to affect well-being and health - so-called interaction effects (e.g., 
De Jonge, Janssen \& Van Breukelen, in press; Karasek \& Theorell, 1990; Parkes, Mendham \& Von Rabenau, 1994). Additionally, empirical findings provide evidence of non-linear relationships between job autonomy and psychological outcomes (Fletcher \& Jones, 1993; De Jonge, Schaufeli \& Furda, 1995; Warr, 1990b). Furthermore, many research designs appear to be cross-sectional. Longitudinal studies are relatively scarce, which means that (strong) causal relationships between job autonomy and outcome variables are lacking. Finally, comprehensive empirical tests of all postulated relationships by means of sophisticated statistical techniques, such as latent variable models, have not yet been accomplished (Karasek \& Theorell, 1990; Muntaner \& O'Campo, 1993; Parkes, 1989; Warr, 1994).

In sum, job autonomy has appeared to be an important determinant of employee's wellbeing and health. At present, however, there is a need for a conceptual clarification of this construct, which may possibly generate a more profound operationalization. Moreover, it seems dangerous and premature to make generalizations about the effects of job autonomy on employee's well-being and health, because of the lack of theoretical and conceptual clarity, global and narrow measurement, different ways of assessment, and nonsystematic and superficial (statistical) approaches to the particular kind of relationships.

\subsection{Research problem and aims of the study}

The present study focuses on job autonomy primarily in the context of job redesign, and elaborates the issues discussed earlier. Despite what is already known about the theoretical and practical implications of job autonomy, there are several unresolved questions. We need therefore to know something about (1) the concept of job autonomy and (2) the processes. by which job autonomy affects well-being and health. As a consequence, the first issue of this thesis concerns the conceptualization, operationalization and assessment of job autonomy. The second issue deals with the specific function of job autonomy in the associations between job characteristics and psychological outcomes like well-being and health.

As expressed in the subtitle of this thesis, this is a study among health care workers, rather than health care as a topic per se. We chose health care workers as study population for several reasons. For instance, job autonomy is a key issue in many of the new combined management and care delivery systems in health care. In addition, health care workers are a relatively heterogeneous group, which may lead to sufficient statistical variance and diversity in observations (cf. Fox, Dwyer \& Ganster, 1993).

The following general research problem is evaluated in this thesis:

"What is the role of job autonomy in the relationship between job characteristics on the one hand, and well-being and health on the other?" 
The aim of the study is twofold accordingly. First, the main emphasis is to gain more insight into, and understanding of the concept of job autonomy. The second aim is to gain a better understanding of the specific nature and magnitude of the effects of job autonomy (whether or not in combination with other job characteristics) on well-being and health. We intend to study the job autonomy-outcomes relationships in a meaningful way. Therefore, job autonomy is embedded in three prominent theoretical models (i.e., the Job Characteristics Model, the Demand-Control-Support Model, and the Vitamin Model). In addition to this, we will employ sophisticated statistical techniques which allow for multivariate, simultaneous, and comprehensive tests of the postulated relationships in these models.

Based on its results, the study should contribute to further theory development in job autonomy research and, more generally, in job characteristics research. Furthermore, the study could produce a few suggestions for implementing organizational policy (particularly in health care) with respect to job redesign and employees' well-being and health.

\subsection{Overview of the thesis}

The present thesis consists of eight chapters. Chapter 2 examines various conceptualizations of job autonomy, followed by a discussion about the measurement and assessment of job autonomy. Chapter 3 extends this theoretical reflection from a stand-alone job autonomy term to the embedding of job autonomy in three theoretical models. We will therefore use the Task Characteristics Approach as classification system. The research method is presented in chapter 4. That is, the study design, the population, and the procedures involved will be discussed. Chapter 5 is devoted to a study of the psychometric properties of the measurement instruments used. Chapters 6 and 7 address the results of the analyses on the cross-sectional and longitudinal data, respectively. Finally, chapter 8 concludes this thesis by means of a discussion of the findings. Additionally, this chapter presents several theoretical and practical implications as well as some recommendations for further research.

NOTES

1. The term "work stress" is used in this thesis to refer to a range of job risk factors and their mechanisms that affect employee's outcomes in terms of well-being and health.

2. Appendix 1 gives a list of abbreviations used in this thesis. 


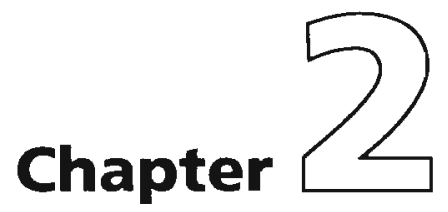




\section{JOB AUTONOMY}

\subsection{Introduction}

This chapter deals with the concept, measurement, and assessment of job autonomy. Anyone who proposes to study job autonomy has to look for a theoretical definition of job autonomy (cf. Farh \& Scott, 1983). Therefore, this common language term has to be more precisely defined or redefined. Accordingly, the first section begins with the etymology of the word "autonomy" and its general definition in several English dictionaries. In the next section, the concept of "job autonomy" is presented, followed by several prominent definitions within the job redesign tradition. In addition, this section addresses some salient measurement scales of job autonomy within the area of job redesign. The last part of this section discusses the way job autonomy has been - or could be - assessed in the prediction of well-being and health: either objectively or subjectively. This chapter ends with some concluding remarks, followed by a few recommendations for the development of a new job autonomy measurement scale.

\subsection{The nature of autonomy}

Regarding the etymology of the concept of autonomy, we have to go back to the old Greece. The Greek term for autonomy is "autonomia". Autonomia is derived from the word "autonomos"; "autos" means self and "nomos" means habit, principle, rule or law (Dworkin, 1988; Van Veen, 1993). Nomos itself comes from the Greek verb "nemein", which means more or less to take or to manage (Van Veen, 1993).

Autonomy has to be viewed in the historical context of city law (cf. Dworkin, 1988). In Greece, there were several city states like Athens and Sparta. A city had autonomia, or selfgovernment, when its free citizens had the opportunity to make their own laws, as opposed to being under control of another city state.

One of common contemporary definitions of autonomy still relates to the old Greek concept of self-government; that is, having the opportunity to make its own laws and to administer its own affairs. A consultation of several dictionaries (e.g., the 1961 Oxford English Dictionary, the 1971 Webster's Third New international Dictionary, the 1991 Collins English Dictionary) revealed, however, that autonomy has more meanings, such as:

- self-determination (physical, psychological): the opportunity or freedom to appoint one's own actions or behaviour;

- independence (philosophical, biological): moral or organic independence;

- freedom (metaphysical): liberty to follow one's will, personal freedom.

Thus, autonomy comes from the Greek and played a major role in Greek city law. However, used in everyclay language, autonomy has acquired different meanings depending on the field in which the term has been used. 


\subsection{Job autonomy: concept, measurement, and assessment}

\subsubsection{A typology of the job autonomy concept}

Schwab (1980) has emphasized that a clear conceptual understanding of a variable is critical for its proper operationalization. As mentioned earlier, autonomy is a term derived from the vernacular and has many different meanings in different - research - fields. Therefore, it requires a more precise definition before it can serve effectively in scientific discourse (Farh \& Scott, 1983).

Many of the job autonomy studies may be placed under the job redesign tradition (see chapter 1). The job redesign literature has revealed a broad spectrum of definitions, descriptions and operationalizations of job autonomy. Yet, it is striking that all efforts have not resulted in a clear integrative concept of job autonomy (Breaugh, 1985; Farh \& Scott, 1983; Ganster \& Fusilier, 1989; De Jonge, 1992; De Jonge, Landeweerd \& Van Breukelen, 1994; Kiggundu, 1983). A comprehensive study of the literature has resulted in a typology of job autonomy, which represents the framework of the next subsections. On the basis of relevant studies (e.g., Bailyn, 1985; Breaugh, 1985; Frese \& Zapf, 1988; Ganster, 1989) the following typology of job autonomy was generated:

1) job autonomy as an absolute or a relative concept;

2) job autonomy as a global (undifferentiated) or a multi-facet (differentiated) construct;

3) general level (unidimensional) versus multi-level (multidimensional) job autonomy;

4) objective versus subjective job autonomy.

These criteria are not mutually exclusive: combinations of aspects do occur. For example, job autonomy as a relative concept requires more than one single task element. Additionally, subjective assessment of job autonomy might be unidimensional as well as multidimensional. We will discuss these aspects in the next three subsections.

\subsubsection{Towards a definition of job autonomy}

The pioneering work of Turner and Lawrence (1965) provided researchers with rudimentary instruments to assess job characteristics. Turner and Lawrence developed șix Requisite Task Attributes (RTAs), among which was job autonomy. They viewed job autonomy as '... the discretion the worker is expected to exercise (assumed in the design of the job) in carrying out the assigned task activities' (Turner \& Lawrence, 1965, p. 21). According to the Job Characteristics Theory (see chapters 1 and 3), Turner and Lawrence considered job autonomy as an objective property, or characteristic, of the job. Hackman and Lawler (1971) noted, however, that autonomy as viewed by Turner and Lawrence seemed to tap the degree to which workers feel personal responsibility for their work [italics added]. Such a definition is of little use because it refers to a behavioural effect rather than to a characteristic of a job (Farh \& Scott, 1983). Consequently, Hackman and Lawler (1971, p. 265) defined job autonamy in a more objective way as '... the extent to which employees have a major say in scheduling their work, selecting the equipment they will use, and deciding on procedures to be followed' [italics ours].

One of the most commonly cited definitions of job autonomy is that formulated by Hackman and Oldham (1975, p. 162). They defined job autonomy as '... the degree to 
which the job provides substantial freedom, independence and discretion to the individual in scheduling the work and in determining the procedures to be used in carrying it out'. This. is a more restrictive and precise definition than that of Hackman and Lawler (1971), but the circumstances under which a job provides "substantial freedom" remain obscure (Farh \& Scott, 1983). In addition to this, Breaugh and Becker have criticized this conceptualization of job autonomy (Breaugh, 1985, 1989; Breaugh \& Becker, 1987). They noted that Hackman and Oldham's job autonomy definition comprises of two different concepts, namely discretion and independence. This is surprising because Turner and Lawrence (1965), on whom their work has initially been based, viewed job autonomy solely in terms. of discretion. Turner and Lawrence introduced the job characteristic "required interaction" to encompass employee independence. Kiggundu (1983) and Breaugh (1985) argued that job autonomy and task independence are distinct constructs and should be conceptualized as such. Finally, an ambiguity is seen in the last part of the definition. If the job performer determines the procedures to be used, it is hardly possible that two people could be regarded as doing the same job. In that way, job autonomy cannot be viewed as. independent of other job characteristics like, for example, skill variety (Farh \& Scott, 1983). The same ambiguity can be found in the definition of Hackman and Lawier (1971).

So far, it is remarkable that job autonomy had been considered too much as an absolute and, consequently, global phenomenon (cf. Breaugh, 1985; Ganster, 1989; Mok, 1980). in practice, job autonomy boils down to the question: 'Who in the end determines the work situation?'. The only facets, or elements, which have been delineated are work scheduling and work procedures (cf. Breaugh, 1985).

In a relative sense, job autonomy refers also to the opportunity workers have to determine several elements of their - direct - work situation. In this context, job autonomy is also a relative term, and is more or less restricted to facets of the worker's task (Mok, 1980). For example, Chung (1977) discussed job autonomy in terms of the degree to which a worker is able to determine several task elements, like the work method, the work schedules and the pace of work. In addition, DeCatiis and Koys (1980) viewed job autonomy as self-determination with respect to work procedures; goals and priorities. Finally, Breaugh's (1985) definition of job autonomy pertained to the degree of control or discretion a worker is able to exercise with respect to some work facets (i.e., method, scheduling and criteria).

In sum, autonomy as a job characteristic is mostly described in terms of self-determination, discretion and freedom. These descriptions come close to the psychological and metaphysical meaning of everyday autonomy. Following the same train of thought, job autonomy can be theoretically defined as the worker's self-determination, discretion or freedom, inherent in the job, to determine several task elements.

The next logical step is to specify which task elements can be differentiated. Some of them have been already mentioned, namely method of working, pace of work, procedures, scheduling and work criteria. Other relevant elements mentioned in the literature are work goals, workplace, work evaluation, working-hours, kind of work and amount of work (cf. Breaugh, 1985; Chung, 1977; DeCotiis \& Koys, 1980; Ganster, 1988, 1989; Van Hoof, 1963; Karasek, 1979; Warr, 1987). 
In addition to the different elements of job autonomy, the literature reveals several levels, or dimensions, of job autonomy (Aronsson, 1989a, 1989b; Bailyn, 1985; Bazerman, 1982; Breaugh, 1989; Ganster \& Fusilier, 1989). In order to understand this multi-level job autonomy, we will venture into the hierarchy within organizations and the corresponding personnel structure.

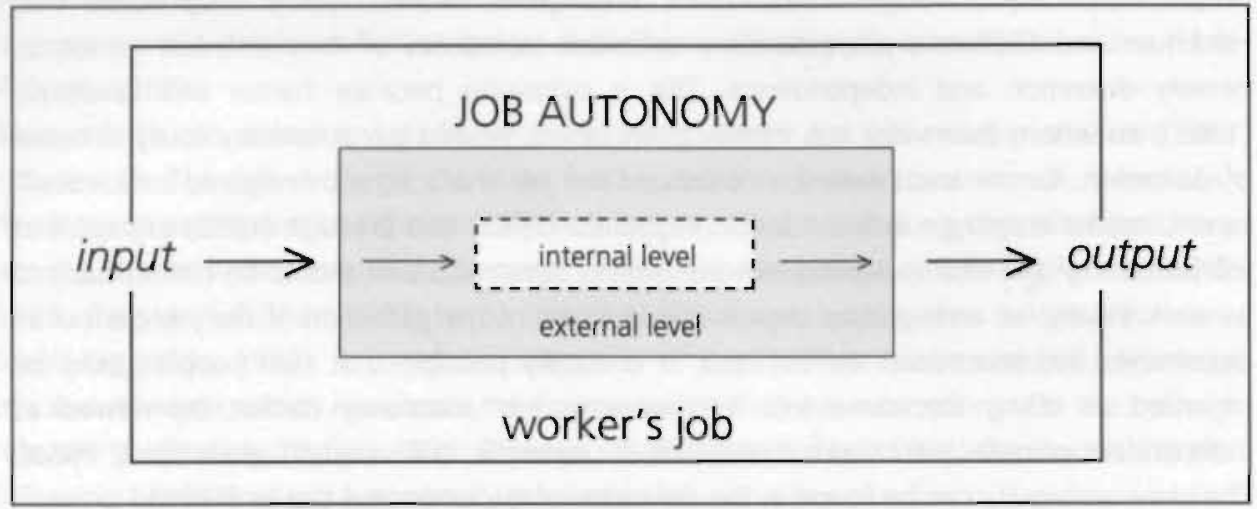

Figure 2.1 Multi-level job autonomy

Control within organizations includes an interplay of forces between the management and the employees (Van Dijck, 1987; In 't Veld, 1981). In other words, both management and employees will attempt to exercise control. The management wants to ensure that a predictable level and type of performance is attained and maintained; most employees want opportunities to determine their work (cf. Child, 1984). Frequently, a worker has various opportunities to carry out his tasks in different ways, depending on the outcome of the interplay of forces between management and employees.

In this situation, two levels of job autonomy can be distinguished, as shown in figure 2.1: (1) an external level; and (2) an internal level. It should be noted, however, that job autonomy is still restricted to direct task elements. The external level of job autonomy concerns the employee's opportunities to determine several input and output requirements of his tasks. In other words, this level of job autonomy refers to the norms of a part of the production process; that is, the worker's job. We will therefore speak about the "contextual aspects" of job autonomy. To pause in the work whenever the employee wants ancl to determine the amount of work are iwo examples of these contextual aspects. On the other hand, the internal level bears upon the opportunities within given job standards, which will be called the "content aspects" of job autonomy. Examples of these content aspects are to evaluate the work yourself and to determine the method of working yourself.

In a similar vein, Bailyn (1985) distinguished between strategic autonomy (the freedom to set one's own agenda). and operational autanomy (the freedom, once a problem has been set, to attack it by means determined by oneself, within given constraints). Bazerman (1982) argued as well that two critical levels of work-related control ("job autonomy') should be distinguished: (1) control over outcomes; and (2) control over activities (see alsa Jackson, 1989). The former is defined as the degree to which outcomes are contingent on 
performance; the latter refers to the discretion to use methods and activities chosen in carrying out the job, which is analogous to Breaugh's work method autonomy. Another quite similar - distinction was made by Aronsson (1989a, 1989b), namely control over and within a work situation'. Control over a situation means power to change the existing rules, while control within a situation means to be master of several work aspects within the existing situation.

Taken together, the whole spectrum of a worker's job autonomy consists of (1) external opportunities (i.e., contextual autonomy, strategic autonomy, control over outcomes, or control over work), and (2) internal opportunities (i.e., content autonomy, operational autonomy, control over activities, or control within work). The breadth of this spectrum is related to the chosen analytical level, or subsystem, by the management. For example, when an individual worker is the subsystem to be studied, the internal opportunities, and especially the external opportunities are limited. If the unit or work group is selected as subsystem, there are more opportunities to determine task elements, and even more kinds. of task elements. Within a unit or group context, an individual worker derived his opportunities from those afforded to the unit or group, and he can expand his job autonomy in line with his skills, needs and hierarchical position (e.g., Gardell, 1982; Jackson, 1989; In 't Veld, 1981).

Socio-technical researchers in particular have a very good grasp of this idea: the opportunities within a semi-autonomous work group are more widespread, and, hence, may provide for a higher degree of job autonomy (cf. Gardell, 1977, 1982; Susman, 1976; In 't Veld, 1981).

\subsubsection{The measurement of job autonomy}

The instruments described in this subsection are designed to measure autonomy as a characteristic of jobs themselves. In their compendium and review of measurement instruments, Cook, Hepworth, Wall and Warr (1981) reported a number of instruments reflecting some kind of job autonomy. Additionally, a study of the literature revealed some other job autonomy instruments. These measurement instruments and those mentioned by Cook, Hepworth, Wall and Warr (198.1) will be discussed below.

Turner and Lawrence (1965) developed 18 scales to measure the six task attributes, each assessed by the investigators. Job autonomy was operationalized using five items, with aspects like work methods, work sequence and work pace. The measurement scale was designed to range from 1 to 9 , using a 5-point response format. In addition, the Requisite Task Attributes were combined into a single RTA-index because of the highly positive association with one another. That is the reason why it is not possible to evaluate the psychometric properties of this autonomy measurement scale.

Hackman and Lawler (1971) created the Yale Job Inventory (Yji). This self-report: questionnaire opened up job characteristics, research to the survey methods (Taber \& Taylor, 1990). A 3-item measurement scale was provided for job autonomy (7-point response rating scale). The operationalization of the three items included words like autonomy, independence and freedom. Hackman and Lawler did not report any factor-analytic results of their scales. Internal consistency reliabilities (Cronbach's alpha, or $\alpha$ ) of the YJl autonomy 
scale were .68 for supervisor ratings and .77 for employee ratings. The interjudge reliability for the researchers' assessments was 89 .

Stone (1974) designed the 13-item Job Scope instrument as an improvement upon the scales of Turner and Lawrence (1965) and Hackman and Lawler (1971). Five job characteristics were constructed, one of which was autonomy. Autonomy contains four different items (i.e., method, order, speed and tools) with responses upon a 5-point continuum. The items of all characteristics are combined to an overall measure of Job Scope. Similar to the scale of Turner and Lawrence, it is therefore not possible to evaluate the psychometric properties of the Job Scope autonomy scale.

One year later, Hackman and Oldham (1975) published the Job Diagnostic Survey (JDS). The JDS consists of five scales measuring several core job characteristics like job autonomy and feedback from job (see also chapter 3). Job autonomy was operationalized by three items, of which one item was negatively worded. In addition, the items had different response formats (i.e., 7-step rating format or 7-point Likert scale).

Based on the results of 48 samples (cf. Fried, 1991; Fried \& Ferris, 1987), the internal consistencies (Cronbach's $\alpha$ ) of the JDS autonomy scale ranged from 35 to 90 . Test-retest coefficients ranged from .55 to .81 , with retest intervals varying from one to five months (Taber \& Taylor, 1990).

Many studies have examined the dimensionality of the JDS, and the results indicated different factor solutions. With regard to job autonomy, unstable factor results were found (cf. De Jonge, 1992; Taber \& Taylor, 1990). For example, Dunham (1976) found a fourfactor structure, in which one factor was comprised of autonomy and variety. In addition, one factor of Fried and Ferris' (1986) three-factor structure was defined by autonomy, variety and identity.

A number of explanations for this inconsistency were mentioned in the literature (e.g., Boumans, 1990; Breaugh, 1989; Dunham, Aldag \& Brief, 1977; Harvey, Billings \& Nilan, 1985; Idaszak \& Drasgow; 1987; Roberts \& Glick, 1981). First, the factor structure could be dependent on specific kinds of study populations (homogeneous versus heterogeneous samples). Second, the content of items overlapped with other job characteristics, due to inaccuracy of items. Third, negatively-worded items caused the conflicting findings. Finally, the use of different response formats was a reason for the different factor solutions.

Sims, Szilagyi and Keller (1976) developed a measure of six job characteristics, the Job Characteristics Index (JCl). The $\mathrm{JCl}$ can be considered as an extension of the Hackman and Lawler (1971) measurement approach. The JCI was undertaken parallel to - but separate from - the work of Hackman and Oldham (1975, 1976). Sims and colleagues retained Hackman and Lawler's (1971) initial set of six job elements. Job autonomy was defined in the same way as Hackman and Lawler's definition. The JCl autonomy scale, however, consisted of six items with responses on two different 5-point formats. The JCl was also subject to investigation in Fried and Ferris' meta-analytic studies (Fried, 1991; Fried \& Ferris, 1987). Based on 15 samples, Fried and Ferris reported internal consistencies of JCI job autonomy ranging from .56 to .99 . Only Sims (1977) described an average test-retest. 
reliability of .73 (6-month time interval) with regard to all subscales. Sims, Szilagyi and Keller (1976), Brief and Aldag (1978), and Pierce and Dunham (1978) reported an exact confirmation of the $\mathrm{JCl}$ job autonomy factor structure.

Cammann, Fichman, Jenkins and Klesh (1979) reported the Michigan Organizational Assessment Questionnaire. Module 3, entitled Task, Job and Role Characteristics, contains two scales with two different response formats to tap some kind of autonomy: (1) Freedom (three items, $\alpha=75$ ); and (2) Pace Control (three items, $\alpha=83$ ). The items possess words like freedom, responsibility, control, and self-determination, and seem to reflect several different constructs. Factor analysis showed that the six items load on a general factor rather than on two separate factors.

A 4-item autonomy instrument was designed by Bacharach and Aiken (1976). The scale measures the degree to which a worker's freedom of action is constrained, responding to a 4-point scale from 4 "true" to 1 "false". Bacharach and Aiken reported Cronbach's alphas of .65 and .66, obtained in two subgroups of one single study ( $N=860)$.

Beehr (1976) adapted four items from Quinn and Shepard (1974) to construct an autonomy measurement scale. The items include statements such as "a lot of say", "enough authority", "make a lot of decisions", and finally "enough freedom". The response scale is ranging from 4 "very true" to 1 "not at all true". In a study among 651 workers, al reliability coefficient of .74 was recorded. Cook, Hepworth, Wall and Warr (1981) noted, however, that two out of four items possess a so-called evaluative qualifier. More specifically, the inclusion of the word "enough" may inflate the correlations of job. autonomy with several psychological outcomes. Beehr's autonomy scale is particularly of interest, because the decision authority scale in the work of Karasek and colleagues has been extracted from the same questionnaire (see chapter 3 ).

Finally, Breaugh (1985) developed a job autonomy instrument designed to measure three facets of job autonomy (i.e., method, scheduling and criteria). Breaugh's scale consisted of nine items (three items for each facet), and was answered on a 7-point response scale. Based on several studies, Breaugh and Becker (Breaugh, 1985, 1989; Breaugh \& Becker, 1987) reported internal consistencies ranging from .77 (criteria autonomy) to .97 (method and scheduling autonomy). Test-retest reliabilities ranged from .65 to .76 (one study, 1month time interval). Factor analyses supported the three-dimensionality of the instrument in all studies. Brady, Judd and Javian (1990) tried to replicate the three-dimensional autonomy structure. However, using a 5-point response format, they could only isolate a single factor "total autonomy" $(\alpha=.94)$. It appeared that the three subscales were not independent (average intercorrelation: .73). In a two-wave longitudinal study among 169 service professionals, Lee and Ashfort (1993) reported Cronbach's alphas of .75 and .80 for the total scale (7-point response scale). In addition to this, they found a test-retest reliability of . 66 (8-month time interval). Van der Linden (1992) created a Belgian version of Breaugh's autonomy scales by translating the items. In a study among 197 people, Van der Linden used both the three subscales and the total scale (5-point response format). Reliability coefficients of method, scheduling and criteria autonomy were .78, .75 and .39 , respectively. 
The internal consistency of total autonomy was .78. Finally, the average intercorrelation between the three subscales was .40. Van der Linden concluded that Breaugh's autonomy scales did not come up to expectations because of (1) the less good discrimination between the three subscales, and ( 2 ) the low internal consistency of criteria autonomy.

To summarize these instruments briefly, it appears that the measurement of job autonomy cannot count on robust measurement scales. Some operational problems of the instruments were caused by conceptual issues mentioned earlier. Moreover, except for Breaugh's autonomy scale, none of the instruments had undoubtedly proven their psychometric properties in terms of factorial validity and internal consistency, regardless they had been investigated or not. Test-retest reliabilities showed, however, that job autonomy is a relatively stable characteristic over time.

\subsubsection{Objective versus subjective assessment of job autonomy}

In general, almost any theory developed in the behavioural and social sciences can be described as either "situation-centred" or "person-centred" (Gergen \& Gergen, 1982; Warr, 1987). In situation-centred theories explanations focus on factors or events outside the person. Theories of the latter type seek explanations in the person whose actions are being studied (e.g., cognitions, habits, feelings and needs). Within these categories, a further distinction may be made between accounts which are "enabling" and those which are "controlling". Theories which are both situation-centred and enabling, for instance, focus mainly on environmental influences, but include the assumption that people can alter these influences in different ways. On the other hand, situation-centred as well as controlling theories allow little individual freedom of action.

Underlying organizational research is a traditional model that can be primarily considered as situation-centred. This model mainly focuses on the objective characteristics of employees' jobs, which impinge upon the individual worker and cause perceptions (cf. Hackman \& Oldham, 1980; Spector, 1992; Spector, Dwyer \& Jex, 1988). These perceptions lead in turn to attitudinal and behavioural reactions. Job Characteristics Theory can be considered a version of this traditional model (see also chapter 3 ). The reason for this is that if it is demonstrated that objective job characteristics produce health and well-being, it makes sense to redesign work.

The question is, however, what is meant by objective job characteristics. Objective job characteristics are usually defined as ones which are assessed independently of the employee (cf. Griffin, 1987; Spector, 1992; Warr, 1987). Examples are physical and social characteristics of the work environment.

However, a methodological problem in the study of job characteristics is that most variables are hypothetical constructs and, consequently, are not easily measured without human judgement (Spector, 1992). The question is how such job characteristics should be identified in operational terms; by means of measures that aim at objectivity or by means of subjective measures $^{2}$ ? We shall see that a great part of objective assessment of job characteristics has been carried out through (1) direct independent measurement and (2) observers' ratings. The latter seems to be objective in the sense of independent of employees' assessments, but 
is subjective in the sense that these ratings depend on human judgement (Semmer, Zapf \& Greif, in press; Warr, 1987). Additionally, most observers were peers or supervisors, who may have shared biases with job incumbents (Spector \& Jex, 1991).

Turner and Lawrence (1965), two pioneers of Job Characteristics Theory, were primarily interested in the relationship between objective job characteristics and satisfaction oi absenteeism. They considered job characteristics as objective properties of jobs, built into their designs. In their study, these objective job characteristics were measured using observers' ratings for 47 job classifications in 11 companies

Hackman and Lawler (1971) started their study with an interest in the effects of objective job characteristics on employee's behaviour. However, they quickly added that '.. it is not their objective state which affect employee attitudes and behaviour, but rather how they are experienced by the employees' [italics added] (p. 265). According to Hackman and Lawler, objective job characteristics are important too, because they do affect the perceptions of the employees. In line with Gergen and Gergen's (1982) classification, this approach can be denoted as situation-centred and enabling. This means that objective job characteristics affect the employees, but these individuals are viewed as being able to mould the influence of job characteristics. In addition to this, job characteristics were measured using both job ratings (i.e., superiors, researchers) and employee self-report questionnaires. The JCM proposed by Hackman and Oldham $(1975,1976,1980)$ assumes that employee attitudes and behaviour are determined by perceptions of job characteristics. They noted, however, that these perceptions also reflect objective job properties. In addition, the JCM in its present form does not differentiate between objective and subjective job characteristics, and it is not known whether employee attitudes and behaviour derive primarily from objective or from perceived job characteristics (Hackman \& Oldham, 1980). As a result, Hackman and Oldham used multiple sources (i.e., employees, supervisors, researchers and members of the management) to obtain job descriptions, and studied their degree of agreement.

The use of perceived job characteristics as indicators of objective characteristics assumes that there is a reasonably strong correspondence between the two measures. More specifically, paper and pencil measures of job autonomy will be expected to vary to the extent that properties of the worksite vary (Evans \& Fischer, 1992). This assumption can be explored by two types of analysis (Fried \& Ferris, 1987; Spector, 1992; Spector, Biranrick \& Coovert, 1989). The first analysis investigates the question whether objective changes in the job affect the perception of job characteristics in the direction of the implemented change. Taber and Taylor (1990), for instance, conducted meta-analyses separately for experimental laboratory studies as well as experimental field studies, relating objective job properties to subject perceptions. With respect to JDS job autonomy, they showed an average effect size ( $r$ ) of .39 for laboratory studies $(N=13)$, and .18 for field studies $(N=6)$. For example, Farh and Scott's (1983) laboratory study showed that students working in a manipulated autonomous situation reported significantly higher job autonomy (i.e., JDS) than did students working in a semi-autonomous or non-autonomous situation. 
A second type of analysis is the degree of agreement between employee job perceptions and alternative 'objective' sources (e.g., ratings by other people, job analysis). Based upon 15 studies, Fried and Ferris (1987) reported a moderate to good overlap between employees' self-reports and observers' ratings. The median of overall median correlations was .56. Unfortunately, separate coefficients of concordance between employees' selfreports and observers' ratings for the subscales (especially autonomy) were not reported. A few studies showed, however, coefficients of concordance for job autonomy ranging from .28 to .85 (e.g., Boumans \& Landeweerd, 1993; Hackman \& Lawler, 1971; Hackman \& Oldham, 1975).

Fried and Ferris' meta-analysis has been conducted with the individual as the unit of analysis. There are also studies which have used aggregated data, that is, the comparison of aggregated judgements of outsiders (e.g., experts, observers) with aggregated self-report data. Spector (1992) conducted a meta-analysis of 16 convergence studies. It appeared that the convergent validity at aggregated level was rather large, especially for job autonomy $(r=0.71)$. At the individual level, modest convergence has been achieved for job autonomy $(r=0.30)$. Spector concluded that sources agree reasonably well at aggregated level, as a consequence of removing variance due to idiosyncratic job conditions and individual differences.

Similarly, several attempts have been made to use job analysis data to assess the job characteristics (cf. Spector, Brannick \& Coovert, 1989). Experienced job analysts have been compared with other raters, such as job incumbents and supervisors. Convergent validities (r) ranged from 47 to 94 .

If we may briefly summarize, it is evident that, while many studies distinguish the concepts objective and subjective, the corresponding operationalizations mostly do not. However, a respectable degree of agreement has been shown between objective job properties and employees' self-reports of job autonomy. To be specific, experimental laboratory studies have shown that changes in enrichment manipulation cause a significant change in JDS job autonomy. The six field experiments, however, generally did provide weak evidence for the expected linkage between objective changes (e.g., job enrichment) and JDS job autonomy In addition, with regard to alternative 'objective' sources like ratings by other people, convergence at both the individual level and particularly the aggregated level has been reasonable.

\subsection{Concluding remarks}

The most widely used job autonomy conceptualizations and operationalizations have been criticized for several reasons. First, most conceptualizations of job autonomy are either too narrow or too global in focus (Breaugh, 1985, 1989; Ganster, 1988, 1989; Ganster \& Fusilier, 1989). To be more specific, job autonomy had been mainly considered as an absolute, global and general construct.

Second, despite some authors discuss distinct elements of job autonomy, the concept has been rarely operationalized as such. According to discussions in the literature (e.g., Chung, 
1977; DeCotiis \& Koys, 1980), only Breaugh and his team have made empirical attempts to enhance the number of task elements, but they got stuck in three facets (i.e., method, scheduling and criteria autonomy).

Third, there is still disagreement over the objective or subjective assessment of job characteristics, including job autonomy. Breaugh and Becker (1987) noted that it seems unwise to argue that a particular kind of assessment should always be used. If the primary focus lies upon job redesign, reliance on objective assessment seems most appropriate. However, if one is interested in understanding the workers' attitudes and behaviour, subjective assessment will be preferred (see also Hackman \& Oldham, 1975). In light of these considerations it is astonishing that ratings by other people are often regarded as 'objective' measures. In general, empirical studies showed, however, a fair degree of agreement between 'objective' and subjective indicators of job autonomy. This could mean that some of the variance in self-reports is attributable to the objective environment (cf. Spector, 1992) Finally, the psychometric properties of some measurement scales were subject to criticism too. A number of researchers have tried to elucidate the measurement and psychometric problems. As described earlier, research on the psychometric problems concerning the job autonomy measurement scales has primarily focused upon at least four areas of attention (cf. Breaugh, 1985; De Jonge, 1992):

1) content overlap of items with other job characteristics, due to inaccuracy of items;

2) the different wordings of the items: positive and negative wordings at the same time;

3) the use of different response scale formats;

4) the use of different study populations: homogeneous versus heterogeneous groups.

In conclusion, it seems important to think of job autonomy in a more differentiated way than is usually done. Firstly, job autonomy is not simply an absolute concept, but also a relative one. Consequently, job autonomy as a multi-facet job characteristic can be more or less restricted to various elements of the worker's task. Secondly, although job autonomy can be primarily considered as a unidimensional construct, it may also be explored by two distinct levels (i.e., (1) external or contextual autonomy, and (2) internal or content autonomy). Finally, job autonomy as a job characteristic may fall within the theoretical category of situation-centred and enabling. The environment is taken as point of departure, but people are viewed as having some power to influence the work environment. Objective as well as subjective assessment of job autonomy need to be reconsidered with respect to the primary focus of job redesign research. In other words, there is a need for alternative sources to reflect the job conditions. Several sources, and a more concrete and easily measured job autonomy variable are needed to explore the accuracy of reports.

NOTES

1. Aronsson (1989a, 1989b) has defined job autonomy as control over boundary tasks, planning and execution.

2. Both objective and subjective assessment of job characteristics have theoretical as well as methodological advantages and disadvantages. These aspects will be extensively discussed in chapter 6 . 


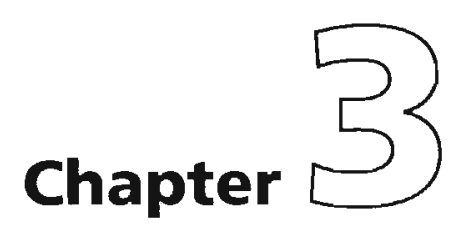




\section{JOB AUTONOMY AND PSYCHOLOGICAL OUTCOMES}

\subsection{Introduction}

The present chapter' describes how job characteristics, and especially job autonomy, may be associated with psychological outcomes like well-being and health. As already mentioned in chapter 1 , it seems scarcely possible to study job autonomy without an adequate theoretical framework. In the first section, a theoretical classification system will be introduced for the purpose of defining and describing job characteristics and, consequently, their relationship with psychological outcomes. The following sections deal with three theoretical models on which much of the job characteristics research has been based. A description of the models as well as their empirical evidence will be discussed. The chapter concludes with some summarizing remarks on the current state of job characteristics research, resulting in a general framework and several research questions.

\subsection{The Task Characteristics Approach}

Several attempts have been made to develop theoretical models of how job characteristics influence workers' well-being and health. Before studying job characteristics and their relationship with human behaviour and attitudes effectively, we need to conceptualize and classify these job characteristics. In other words, we need a tool that increases our ability to interpret and predict: a so-called classification system (cf. Fleishman, 1975; Fleishman \& Quaintance, 1984).

Many different taxonomic approaches were described at length in Fleishman and Quaintance (1984). An important classification system which is in line with job characteristics research is the "Task Characteristics Approach", or TCA (Farina \& Wheaton, 1973) The TCA is based upon a particular conceptualization of tasks, or of a conglomeration of tasks (i.e., jobs). Contrary to other classification systems (e.g., the Behaviour Description Approach or the Ability Requirements Approach), this classification is not based upon the task performer, but upon the task itself (De Jonge \& Furda, in press). The basic assumption is that tasks can be classified in terms of intrinsic, so-called 'objective' properties of the job. A task is therefore reflected by a set of stimulus situations or antecedent conditions that elicit performance (Farina \& Wheaton, 1973). These conditions are imposed on the employee and have an independent existence apart from: (1) the activities they may trigger (behaviour description); (2) the functions they may call into play (behaviour requirements); and (3) the abilities they may require.

The corresponding train of thought is that job characteristics in their own right represent a potent class of predictor variables (Algera, 1991; Fleishman \& Quaintance, 1984). Furthermore, if job characteristics are considered important determinants of the workers behaviour and attitudes, it seems necessary to classify job characteristics in quite different terms than the outcome variables (Hackman, 1969). Consequently, appropriate descriptive 
terms are those that focus on the objective properties of the task per se. Otherwise, we might be faced with conceptual overlap between these kinds of variables which renders the empirical association rather trivial (Kasl, 1989).

In sum, it is theoretically and methodologically wise to describe job characteristics in terms of intrinsic properties of the task itself. From this perspective, the TCA offers promising points of application through the added advantage of describing the job characteristics in terms other than the outcome variables to be predicted (cf. Algera, 1991; Hackman, 1968). The definition of a task by Hackman (1968, p. 12) reflects this view:

\begin{abstract}
'A task is assigned to a person (or group) by an external agent or is self-generated, and consists of a stimulus complex and a set of instructions which specify what is to be done vis-à-vis the stimuli. The instructions indicate what operations are to be performed by the performer(s) with respect to the stimuli and/or what goal is to be achieved.'
\end{abstract}

There are a number of theoretical and practical points which have to be taken into account when the TCA is adopted ( $c f$. De Jonge \& Furda, in press). For example, salient questions concern the selection of those components to be described, the relevant operationalizations of these components, and finally the type of relationships between these components and the workers' attitude and behaviour. Several theoretical models reflect the TCA. Each of these models has its own perspective on the questions mentioned above. The models of Hackman and Oldham (1975, 1976, 1980), Karasek and his team (e.g., Johnson \& Hall, 1988; Karasek, 1979; Karasek \& Theorell, 1990), and Warr (1986, 1987, 1994) are probably the most representative and promising of attempts to pursue the TCA (De Jonge \& Furda, in press). We will discuss these theoretical models in the next three sections.

\title{
3.3 Hackman and Oldham: The Job Characteristics Model
}

\subsubsection{Model description}

To date, a model that has received the widest attention in job characteristics research is Hackman and Oldham's Job Characteristics Model (JCM). The JCM summarizes and integrates much of the earlier work in the job redesign area (see chapter 1).

Hackman and Oldham (1975, 1976, 1980) have built their model of internal work motivation, as shown in figure 3.1. Basically, the JCM suggests that there are three key conditions that must be present simultaneously, which affect personal and organizational outcomes. These three conditions, also labelled the "critical psychological states", are defined as:

1) experienced meaningfulness of the work: employees must feel that the work is important, worthwhile, and valuable;

2) experienced responsibility for work outcomes: employees must feel personally responsible and accountable for the results of the work they perform;

3) knowledge of the actual results of the work activities: employees must receive regular feedback concerning the quality of their performance. 
The three critical psychological states are internal to persons and, therefore, not directly manipulable (Hackman \& Oldham, 1980). They are activated by five core job dimensions (or job characteristics). which are defined as '... objective, measurable, changeable properties of the work itself ...' (Hackman \& Oldham, 1980, p. 77). These five job characteristics are (1) skill variety, (2) task identity, (3) task significance, (4) autonomy, and (5) feedback from job. The first three characteristics are believed to influence the experienced meaningfulness of the work, as depicted in figure 3.1. The fourth characteristic (autonomy) influences the experienced responsibility, whereas the fifth characteristic (feedback) contributes to the knowledge of the actual results.

Hackman and Oldham combine the five core job dimensions into a single index, the socalled "Motivating Potential Score (MPS)". The formula for the MPS has been derived from the assumptions of the JCM, and can be calculated as follows (formula 3.1):

(variety $\mathrm{x}$ identity $\mathrm{x}$ significance)

MPS =

$x$ autonomy $x$ feedback

3

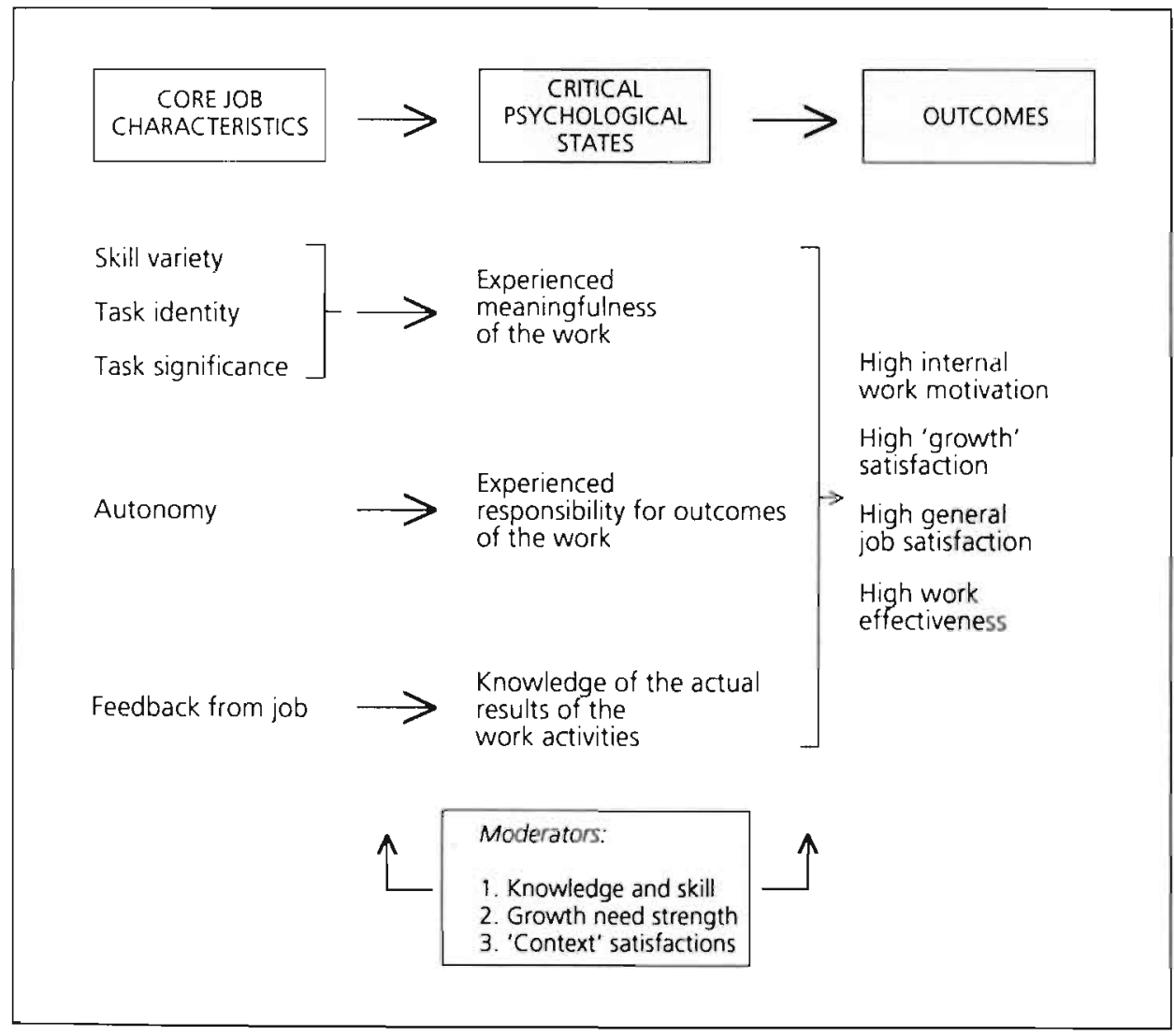

Figure 3.1 The Job Characteristics Model (J. Richard Hackman and Greg R. Oldham, Work Redesign (p. 90), (C) 1980 by Addison-Wesley Publishing Co., Inc. Reprinted with permission of the publisher) 
The MPS reflects the extent to which employees see their jobs as motivating. The basic assumption is that autonomy and feedback from the job especially contribute to the motivating potential.

The critical psychological states then determine a variety of outcomes. Internal work motivation is a key outcome of the model, but other outcomes do exist. Hackman and Oldham (1980) classified two types of outcome variables: (1) personal outcomes; and (2) organizational outcomes. The personal outcome variables are internal work motivation, growth satisfaction and general job satisfaction. Only one organizational outcome is described, namely work effectiveness.

The original Task Characteristics Approach has not been designed to assess individual differences. It assumes that everyone will respond to job conditions in a similar fashion. Some researchers, however, explore the role of individual differences among employees (e.g., Hulin \& Blood, 1968). This perspective, which may be called the "Individual Differences Approach", allows for the possibility of variation in people's reactions (De Jonge \& Furda, in press).

The JCM has been expanded to include explicit consideration of individual differences in employee responses to a job as well. According to Hackman and Oldham, individual differences between people play also an important role in the JCM. Three factors are introduced to account for whether a person will or will not respond positively to jobs with a high motivating potential; these are (1) knowledge and skill, (2) growth need strength, and (3) satisfaction with the work context (viz., pay, security, co-worker and supervision). For example, individual workers with strong needs for growth will respond more positively to the opportunities provided by job enrichment than those workers with low growth need strength will.

\subsubsection{Empirical evidence for the model}

To test the Job Characteristics Model, Hackman and Oldham developed the Job Diagnostic Survey, or JDS (see also chapter 2). This questionnaire measures employee perceptions of job characteristics, the critical psychological states, personal and organizational outcomes, and finally growth need strength.

Empirical research using the Job Characteristics Model does not yield unqualified, favourable results (Algera, 1991; Steers, 1991). As is the case with any theoretical model, providing for a comprehensive test is difficult. Besides, there are several studies that have been designed to test the model as a whole (e.g., Algera, Van der Flier \& Van der Kamp, 1986; Hackman \& Oldham, 1976; Hogan \& Martell, 1987; Wall, Clegg \& Jackson, 1978). These studies generally failed to support the comprehensive model. Especially the mediating role of the critical psychological states was not demonstrated. Alternative models postulating direct relationships between the job characteristics and the outcome variables account for a significantly higher proportion of variance than the original model does. Boumans (1990) stated that most JCM studies tested the relationships between job characteristics and outcome variables on the one hand, and the effects of the individual moderators on the other. It is possible to briefly summarize the research on the validity of 
the model with the help of several review studies and meta-analytic studies (e.g. Aldag, Barr \& Brief, 1981; Algera, 1989; Cook, Hepworth, Wall \& Warr, 1981; Fried, 1991; Fried \& Ferris, 1987; Loher, Noe, Moeller \& Fitzgerald, 1985; Roberts \& Glick, 1981).

In general, the job characteristics tend to show moderate to strong relationships with personal outcomes (e.g., work motivation and job satisfaction), and much weaker relationships with organizational outcomes (e.g., job performance). In the following paragraphs we will present some results regarding the central job characteristic of this thesis, that is job autonomy.

The meta-analytic study of Loher, Noe, Moeller and Fitzgerald (1985) showed correlations between each job characteristic and job satisfaction. The correlation for job autonomy, after correction for statistical artefacts, was .46. In addition, Fried and Ferris (Fried, 1991; Fried \& Ferris, 1987) reported corrected correlations between job autonomy on the one hand, and growth satisfaction and overall job satisfaction on the other of .35 and .71 , respectively. Furthermore, the corrected correlation between job autonomy and internal work motivation was .42. in contrast, job autonomy had no relationship with the organizational measure "job performance" (Fried \& Ferris, 1987).

The JCM in its current form deals only with positive outcome variables. One reason for this is that the JCM reflects a theory of individual motivation (Hackman \& Oldham, 1980). Several authors, however, extended the collection of outcomes with variables such as mental health (Wall, Clegg \& Jackson, 1978), general health complaints (Algera, 1983; Boumans, 1990), and mental complaints (Algera, 1983; Broadbent, 1985). To summarize these studies briefly, job autonomy appeared to show much weaker, although meaningful, relationships with these outcome variables. Boumans (1990), for instance, showed a significant correlation of -.20 between job autonomy and health complaints after correction for several demographic characteristics.

The JCM has tried to promote interest in individual differences as moderators of the relationship between job characteristics and outcomes. Initially, the main focus was on the variable "growth need strength", or GNS. Much basic research showed inconclusive results regarding the moderating role of GNS (cf. Fried \& Ferris, 1987; Wall \& Martin, 1987). For example, two meta-analytic studies demonstrated some confidence that GNS acts as a moderator. Loher, Noe, Moeller and Fitzgerald (1985) showed that the corrected overall correlation between all five job characteristics and satisfaction was .68 for persons with high GNS, and about 38 for employees with low GNS. Additionally, Spector (1985) examined the moderating role of the GNS in 20 research populations. Regarding job autonomy, moderating effects were found for five out of ten outcome variables (job satisfaction in particular). On the other hand, the results from Fried and Ferris' (1987) meta-analysis showed that moderator effects were largely artefacts. The difference between the conclusions reached by the two 1985 meta-analyses and the 1987 meta-analysis may lie in the fact that the latter study was based upon a larger sample of studies and has controlled for at least one statistical artefact (Tiegs, Tetrick \& Fried, 1992).

Overall, the research makes it clear that inconsistent moderating effects of GNS are apparent. 
What can be said about the direction of causation in the JCM research? It is generally assumed that the causal flow in the JCM is unidirectional, where job characteristics affect psychological outcomes, and not vice versa (Hackman \& Oldham, 1980). This assumption, however, has been questioned by several researchers (e.g., Frese \& Zapf, 1988; James \& Jones 1980; James \& Tetrick, 1986; Kohn \& Schooler, 1983; O'Brien, 1986; Spector, 1992). They have argued that outcome variables may affect job perception. For instance, job satisfaction can predispose people's perceptions of their jobs. In addition, an employee's competence may affect the kind of job that is performed. O'Brien (1986) stated that this phenomenon does not invalidate the evidence that supports a causal relationship from job characteristics to psychological outcomes. It may indicate that perceptions and outcomes influence each other reciprocally rather than unidirectional (cf. Warr, 1987). Hence, a few studies have demonstrated that simultaneous reciprocal causality does occur (e.g., James \& Jones, 1980; James \& Tetrick, 1986; Kohn \& Schooler, 1983). Furthermore, evidence suggested that these reciprocal relationships do not appear to be symmetric. The outcomes tended to occur after job perceptions, rather than vice versa (Warr, 1987).

A final issue regarding the JCM is whether the objective ${ }^{2}$ job characteristics-outcomes relationships are similar to the perceived job characteristics-outcomes relationships. As in section 2.3 in chapter 2 , two types of research will be examined.

First, several studies have compared the effects of objective, manipulated, job characteristics versus perceived job characteristics on outcome variables (for a review, see Fried \& Ferris, 1987). These studies revealed similar directions for the relationships mentioned above. Orpen (1979), for instance, found that employees whose jobs were enriched were more satisfied, more motivated, and more involved with their jobs than employees whose jobs remained the same. Similarly, perceived job characteristics were related to these outcome variables too. However, questions may be raised with respect to the differences in magnitude of the cited results. In general, the former type of relationships accounted for less variance than the latter type, due to, for example, method variance, statistical artefacts and restriction of range (Fried \& Ferris, 1987).

Second, a comparison of different rating methods was investigated in regard to some outcome variables; that is, ratings by employees or ratings by other people (e.g., researchers or supervisors). According to Fried and Ferris (1987), these studies showed a trend toward the same relationships of different rating methods to outcome variables. Besides, the differences in magnitude were not systematically biased in favour of a specific group of raters. In sum, both objective job characteristics-outcomes relationships and perceived job characteristics-outcomes relationships do exist, although the latter type usually is stronger and more consistent than the former

Altogether, the evidence for the Job Characteristics Model is inconclusive. In particular the mediating role of the critical psychological states is not demonstrated. Additionally, empirical support for moderating effects of growth need strength is not consistent. Alternative models that postulate direct (i.e., linear additive) relationships between job characteristics and psychological outcomes seem to be more valid. 


\subsection{Karasek and colleagues: The Job Demand-Control Model and the Demand-Control-Support Model}

\subsubsection{Model descriptions}

Karasek and his team developed two models, known as (1) the Job Demand-Control Model and (2) the Demand-Control-Support Model. The latter is an expanded version of the former. In order to understand the basic ideas of both models, we will first discuss the Job Demand-Control Model.

The Job Demand-Control Model (JD-C Model), developed by Karasek (1979), can be considered a synthesis of two well-known lines of research, namely the job redesign tradition (e.g., Hackman \& Oldham, 1980) and the occupational stress tradition (e.g., Caplan, Cobb, French, Harrison \& Pinneau, 1975; Kahn, 1981). The aim of the JD-C Model is to provide a theoretical framework for the development of guidelines for the enhancement of the quality of working life. In addition to reducing work-related strains, work motivation and growth can be promoted. It is postulated that the model will predict a wide range of consequences of the structure of work with regard to health and well-being.

The Job Demand-Control Model is a two-dimensional model, as shown in figure 3.2. Similar to the Task Characteristics Approach, the JD-C Model postulates that the primary sources of stress lie within two basic characteristics of the job itself (Baker, 1985). The JD-C Model emphasizes the need to categorize these job characteristics as demands or control, and does not simply list all job features as potential stressors (Schnall, Landsbergis \& Baker. 1994). Psychological strains are a consequence of the joint effects of the demands of a job and the range of job control available to the employee, also called interaction effects (Karasek, 1979). Job demands are defined as psychological stressors, present in the work environment (e.g., not having enough time to do work, working hard and working fast). Karasek (1979, pp. 289-290) defines his measure of job control, also labelled job decision latitude or job discretion, as '... the working individual's potential control over his tasks and conduct during the working day'. Job control comprises two theoretically distinct constructs: (1) the worker's authority to make decisions on the job ("decision authority", or 'autonomy'); and (2) the breadth of skills used by the worker on the job ("skill discretion"; cf. Karasek \& Theorell, 1990).

In addition, four different kinds of psychosocial work situations may result from four combinations between high and low levels of psychological job demands and job control. Karasek (1979) uses the following terms for the four kinds of work situations: (1) high strain jobs; (2) active jobs; (3) low strain jobs; and (4) passive jobs.

The first major prediction of the JD-C Model is that the strongest aversive job-related strain reactions (like exhaustion, anxiety and health complaints) will occur when job demands are high and worker's control is low (cell 1 in figure 3.2). High job demands produce a state of arousal which is normally accompanied by increased heart rate and adrenaline excretion. If there is also an environmentally-based constraint (e.g., low control), the arousal cannot be converted into an effective coping response. Such conditions produce a more extensive 
reaction for a longer period, a so-called damaging, unused residual strain. The opposite situation is presented in cell 3: a low strain job, in which worker's control is high and job demands are low. In this situation the model predicts lower than average levels of residual strain. The - sometimes overlooked - second prediction of the model is that motivation, learning and personal growth will occur in situations where both job demands and worker's control are high (cell 2 in figure 3.2). The opposite of this situation can be found in cell 4: a passive job, in which skills and abilities may atrophy, similar to "learned helplessness" (cf. Abramson, Seligman \& Teasdale, 1978; Lennerlöf, 1988).

There are two independent diagonals: the strains-diagonal (A) and the active-diagonal (B). This results in a model which reconciles the mechanistic stress tradition with the insights of social learning theory and adult education theory (Landsbergis, 1988). The two general psychological mechanisms mentioned above may result in a variety of outcome variables, such as exhaustion, anxiety, psychosomatic complaints, cardiovascular diseases and absenteeism on the one hand, and work motivation, learning and job satisfaction on the other.

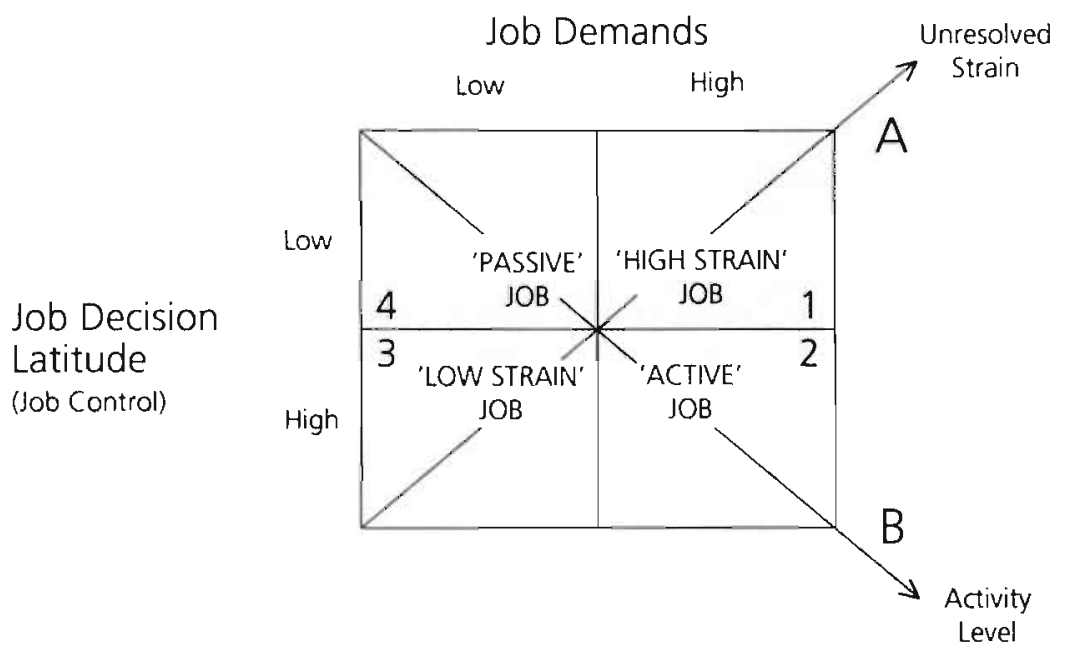

Figure 3.2 The Job Demand-Control Model (Reprinted from "Job Demands, Job Decision Latitude, and Mental Strain: Implications for Job Redesign" by Robert A. Karasek Jr., published in Administrative Science Quarterly, 24, 2, 1979, p. 288, by permission of Administrative Science Quarterly) 
Job control, however, is not the only resource available for coping with job demands (cf. Johnson \& Hall, 1988; Johnson, 1989). For example, workplace social support may also function as a moderator of job demands ${ }^{3}$ (Johnson, 1989). Karasek and Theorell (1990) defined this workplace social support as overall levels of helpful social interaction available on the job

In the late eighties, Johnson and Hall (1988) redefined the JD-C Model adding workplace social support. This expanded model, called the Demand-Control-Support Model (DCS Model), is a three-dimensional model (see figure 3.3).

Both the strains-diagonal and the active-diagonal are split up into isolated and collective. conditions, thereby redefining the process of job strain (indicated by the diagonal arrows of figure 3.3). Accordingly, eight instead of four kinds of work situations are modelled:

a) four types of work situations in combination with low social support;

b) four types of work situations in combination with high social support.

The DCS Model was developed to examine the joint - interactive - effects of three basic characteristics of the work organization, namely job demands, job control and workplace social support.

PSYCHOLOGICAL JOB DEMANDS

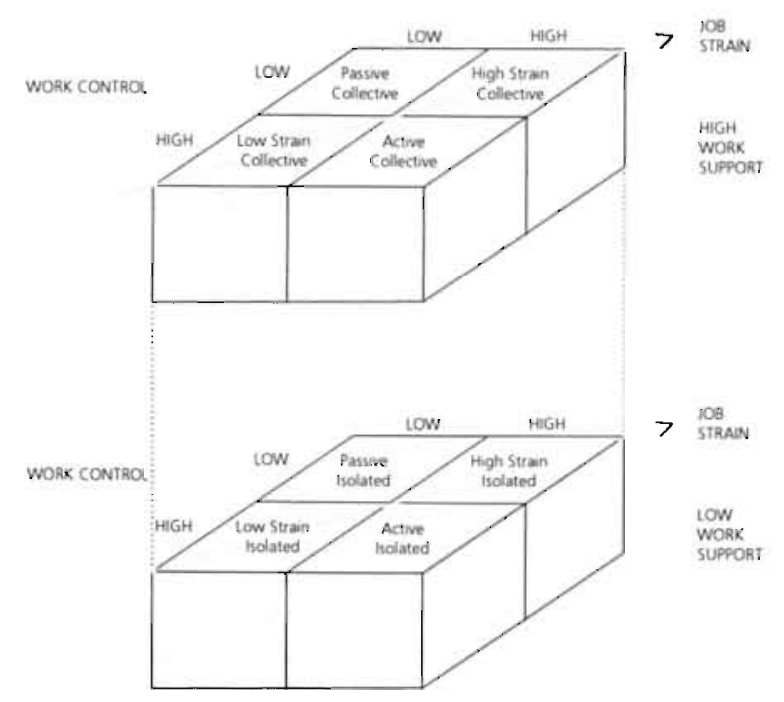

Figure 3.3 The Demand-Control-Support Model (Reprinted from "Job Strain, Work Place Social Support, and Cardiovascular Disease: A Cross-Sectional Study of a Random Sample of the Swedish Working Population" by Jeffrey V. Johnson and Ellen M. Hall, published in American Journal of Public Health, 78, 10,1988, p. 1336, by permission of the American Public Health Association) 


\subsubsection{Empirical evidence for the models}

First of all, it is obvious that most studies which tested the DCS Model are brased upon the JD-C Model. So, in testing the DCS Model they are implicitly testing the JD-C Model. In order to make the empirical evidence of both models quite clear, we will discuss the DCS studies separately from the JD-C studies. We have to keep in mind, however, that the 'demand-control'-part of the DCS studies is able to support the JD-C Model. Significant findings regarding the interaction between job demands and job control within DCS studies will be particularly mentioned.

Tests of the JD-C Model can be roughly divided into two categories, namely (1) multioccupation (epidemiological) studies and (2) single-occupation studies (De Jonge \& Furda, 1995). The former kind of studies mainly focuses on cardiovascular diseases (CVD); the latter refers to attitudinal outcomes (e.g., job satisfaction and work motivation), behavioural outcomes (e.g., absenteeism and smoking consumption), and physiological outcomes (e.g., blood pressure and muscle tension).

Both longitudinal and cross-sectional studies have been carried out. Most of the performed JD-C studies are reviewed by Ganster and Fusilier (1989). Karasek (1989), Karasek and Theorell (1990), Ganster and Schaubroeck (1991), De Jonge (1992), Schnall, Landsbergis and Baker (1994), and finally Kristensen (1995). Several conclusions might be drawn from these reviews. First, the overall support for the JD-C Model is mixed. The - early - epidemiological studies provide more evidence for the JD-C Model than research at single-occupation level does. Besides, there is little evidence in support of the postulated interactions in any of the studies due to, for instance, the mathematical formulation of this interaction term (a further discussion of this topic can be found in chapter 6).

A second conclusion is that the effects of job demands and job control may be confounded with socio-economic status, health behaviour or personality, particularly in the multioccupation studies. Jobs concomitantly high in demands and low in control are likely overrepresented by employees of low socio-economic class and low health behaviour who share other risks for CVD (e.g., Siegrist, Peter, Junge, Cremer \& Seidel, 1990). Added to this, personality characteristics such as negative affectivity or neuroticism appear to influence the magnitude of observed correlations between self-reported stressors and strains (cf. Burke, Brief \& George, 1993).

Finally, there is some doubt as to the conceptualization and operationalization of the measure of job control. The construct reflects the term "job autonomy" as it is used in job redesign research, but the construct also contains elements like skill level, variety and even complexity (Frese, 1989; Ganster, 1988, 1989). So, job control may be confounded with other job characteristics, particularly in the multi-occupation studies.

During the past decade, the DCS Model has been the subject of many studies. In particular Johnson and colleagues have tested this model extensively using large-scale, multioccupation, databases (e.g., Johnson, 1986; Johnson \& Hall, 1988, 1994; Johnson, Hall, Stewart, Fredlund \& Theorell, 1991; Johnson, Hall \& Theorell, 1989). Johnson (1986), for instance, found that workers with low control, low support and high demands had an age- 
adjusted relative risk of CVD prevalence of 2.17 (95\% confidence interval: 1.32-3.56), compared with workers with high control, high support and low demands. In the eighties; Johnson (1986) constructed a variable called "iso-strain" (for isolation strain). Iso-strain is a product term for the standardized demands, control and support indicators. A study by Johnson, Hall and Theorell (1989) showed that a high iso-strain group had a higher progression of cardiovascular death risk with increasing age than a low iso-strain group. Furthermore, it was found that workers who experienced high levels of iso-strain reported symptoms earlier and tended to develop cardiovascular diseases sooner than a low iso-strain group.

There are also small-scale as well as large-scale single-occupation studies testing the DCS Model. For instance, Landsbergis, Schnall, Deitz, Friedman and Pickering (1992) tested the DCS Model among 297 men. They found empirical support for the DCS Model for job dissatisfaction, using a three-way multiplicative interaction model. In addition, a Demands $x$ Support interaction was observed for negative attributional style. However, a study among 267 female social workers showed no evidence for the DCS Model. Only main effects regarding job satisfaction and burnout were found (Melamed, Kushnir \& Meir, 1991). De Jonge and Landeweerd (1993, see also 1992b) did a secondary data analysis using five databases from various sectors in Dutch health care $(n=1226)$. The results showed little support for the DCS Model as well as the JD-C Model. Only 4 out of 24 possible multiplicative interaction terms, or about 17 per cent, were statistically significant. It should be noted that a significant Demands $x$ Autonomy interaction was observed for psychosomatic health complaints in the direction predicted by the model.

As stated before, providing for a comprehensive test of a theoretical model is difficult. As far as we are aware, at least two studies have tried to test the complete DCS Model with sophisticated statistical techniques. First, Knox, Theorell, Svensson and Waller (1985) did a path-analysis (LISREL) of cross-sectional data on 89 young Swedish males. Only main effects of the model were tested with regard to physiological outcomes. The results revealed that high plasma adrenaline levels were associated with a poor social network as well as restricted learning possibilities. Added to this, plasma renin activity was negatively related with job control. A second study estimated all relationships in the DCS Model simultaneously by means of a structural equation model (LISREL) in a study among 249 health care professionals (De Jonge, Janssen \& Van Breukelen, in press). Although the statistical model provided an acceptable fit, the researchers could not confirm the DCS Model as a whole. However, the results partially support the JD-C Model. High levels of job autonomy appeared to attenuate the increase of emotional exhaustion (burnout) due to job demands. In addition, high levels of social support proved to attenuate the increase of emotional exhaustion due to job autonomy.

Finally, Parkes, Mendham and Von Rabenau (1994) found some evidence in support of the DCS Model in a heterogeneous sample of 145 health care workers. Somatic symptoms were significantly predicted by the interactive effects of job demands, job control and social support. 
Longitudinal single-occupation studies using the DCS Model as theoretical framework are scarce. Parkes (1982), for instance, describes a natural experiment among 164 student nurses. Correlational analyses showed that an increase in social support was associated with decreases in affective symptoms. Added to this, increases in job discretion were associated with an increase in job satisfaction and a decrease in depressive symptoms. Increases in job dernands, however, were not related to changes in anxiety.

Kawakami, Haratani and Araki (1992) conducted a three-year prospective study among 468 male blue-collar workers in Japan on the effects of job characteristics on depressive symptoms. They found that only poor work-related human relations ('social support') and skill under-utilization were significant risk factors for long-lasting depressive symptoms. Job overload and lack of control, however, did not seem to be risk factors over time. In a Dutch sample of 115 administrative employees, some support was observed for the DCS Model. According the buffer hypothesis of social support (cf. Cohen \& Wills, 1985), interaction effects of changes in demands and support for health complaints as well as recovery complaints were found (Furda, De Jonge, Le Blanc, Meijman, Schreurs \& Scheenen, 1994). Parkes, Mendham and Von Rabenau (1994) reported a second study which examined the DCS Model with longitudinal data. In a homogeneous sample of 180 university graduates, Parkes and colleagues detected the same three-way interaction as they found in their crosssectional study mentioned above. Time 2 somatic symptoms were predicted by the Demands $\times$ Control $x$ Support interaction, controlling for time 1 levels of somatic symptoms.

As in JCM research (see section 3.3), a methodological point of attention is the use of objective ${ }^{2}$ versus subjective job characteristics as predictors for outcome variables. Karasek and Theorell (1990) stated that the primary interest of the two models is the objective work environment, which have to be the basis of job redesign. They noted that self-report questionnaires have been the most common method of gathering data. However, the problem with self-report measurement scales is that they are subject to many problems, such as common method variance, positive information bias, conceptual overlap and causality problems. In addition, alternative measurement strategies, like observers' ratings of jobs, present several problems as well (see in detail Frese \& Zapf, 1988; De Jonge, Van Breukelen, Landeweerd \& Nijhuis, 1995; Kristensen, 1995; Semmer, Zapf \& Greif, in press). Karasek and his team coped with this matter by means of a method called "occupational mapping": all workers with the same job title are given the average values of the responses given by workers with that particular job. According to them, occupational grouping seems a measure of objective differences in jobs relevant to job redesign. They stated that occupations could be located using the basic dimensions of the DCS Model. This method should indicate some evidence for the objective validity of the measurement scales. Schwartz, Pieper and Karasek (1988), for example, compared occupation scores of job control to analogous scales from the U.S. Dictionary of Occupational Titles (DOT, U.S. Department of Labor, 1981). The correlation of perceived job control with the DOT measure of occupational self-direction (i.e., some kind of job control) was .76, indicating a reasonably high association. Added to this, Karasek and Theorell (1990) showed that job control is better discriminated by occupation for men than take-home pay is. On the other 
hand, however, job demands and workplace social support are discriminated very poorly between occupation for men as well as occupation for women.

Finally, two recent studies deserve some attention. Muntaner, Eaton and Garrison (1993) compared the JD-C scales with a set of factorial scales derived from the DOT. A major finding was that Karasek's job control scale overlapped substantially with the substantive complexity construct from the DOT. Substantive complexity can be defined as the degree to which the work, in its very substance, requires thought and independent judgement (cf. Kohn \& Schooler, 1983). Johnson and Stewart (1993) have developed a job exposure matrix to assign exposure scores retrospectively to occupational groups. The matrix consisted of mean estimates of - among other things - job control, job demands and social support of 261 occupations. It appeared that the matrix scores were significantly related with the corresponding individual self-report scores.

In sum, there is evidence for some objective validity of the job characteristics, particularly of job control.

A few JD-C and DCS studies have tested the relationship between objective job measures and outcomes. For example, in a laboratory experiment of Perrewé and Ganster (1989) among 125 undergraduate students, the impact of objective job demands and job control on experienced strain generally was non-existent. In addition, perceived demands and control appeared to be predictors of psychological and physiological strains. Finally, perceived control moderated the perceived demands-anxiety relationship.

Dwyer and Ganster (1991) found significant interactions between job control and objective job demands in a sample of 90 male manufacturing employees. The results indicated that these demands were associated with a higher number of sick days and higher levels of tardiness behaviour. Moreover, they reported also two significant interaction effects between job control and subjective demands with respect to job satisfaction and absenteeism.

In the study of Kawakami, Haratani and Araki (1992) mentioned above, three objective measures of job stress were related to depressive symptoms, namely shift work, recent job change (i.e., change of job position within the preceding six months), and overtime (i.e., hours per month). None of these objective measures were significantly related with depressive symptoms.

Fox, Dwyer and Ganster (1993) reported a test of the JD-C Model among 136 registered nurses. The workload-related objective stressors, patient load and patient contact time, showed significant correlations with physiological outcomes (e.g., blood pressure and cortisol levels), even if age, body weight and caffeine consumption were controlled for. However, control perceptions generally did not moderate the effects of these stressors. Only 1 out of 27 interactions tested was significant, which is below chance level.

Finally, Johnson and Stewart (1993) showed that the job control element of their job exposure matrix (see above) followed a similar pattern of association as the individual self-report job control score with regard to chronic disease prevalence. 
Altogether, the overall support for the Job Demand-Control Model as well as the DemandControl-Support Model is mixed. Comprehensive, simultaneous tests of both models in combination with longitudinal studies are scarce. Added to this, there is little evidence in support of the assumed interactions due to, for instance:
1) different kinds of mathematical formulation of the interaction term;
2) probable confounding effects of, for example, socio-economic status;
3) the indirect conceptualization and operationalization of job control;
4) sampling: homogeneous versus heterogeneous samples;
5) objective versus subjective assessment of job characteristics.

\subsection{Warr: The Vitamin Model}

\subsubsection{Model description}

The models discussed so far assume linear relationships between job characteristics and outcome variables. One aspect that has received little attention in this line of research is the possible non-linear relationships between job characteristics and psychological outcomes. A theoretical model that suggests such non-linear relationships is Warr's $(1986,1987)$ Vitamin Model (VM) of environmental features and mental health.

The VM proposes that mental health is affected by environmental psychological features such as job characteristics in a way that is analogous to the non-linear effects that vitamins are supposed to have on physical health. Warr's overall framework has three principal parts:

1) the processes whereby environmental features effect mental health;

2) a categorization of the environmental features into nine broad types;

3) the interaction between persons and situations.

The VM is intended to have application to all existing environments in the real world. Warr talks about a broad-ranging model that can be applied to, for instance, work and unemployment. In this thesis, we will restrict the discussion of the model to the work situation.

Vitamins exert a particular influence on the human body. That is, vitamin deficiency produces bodily impairment and, consequently, may lead to physical illness ('deficiency disease'). Generally, vitamin intake initially improves health and physical functioning, but beyond a particular level of intake no further improvement is observed. Continued intake of vitamins may lead to two different kinds of effects, as shown in figure 3.4. Firstly, additional doses of vitamins have a constant effect: health neither improves, nor noxious consequences are observed that impair the individual's physical health. According to Warr (1987, 1994), vitamins C and E might have a suchlike effect on the human body. Therefore, the label CE ('Constant Effect') at the right-hand side of figure 3.4 is used to denote this particular relationship. Secondly, an overdose of vitamins leads to a toxic concentration in the body, which is called a 'hypervitaminosis'. This situation results in harmful effects, and causes poor bodily functioning and ill-health. Among others, vitamins $A$ and $D$ are known to be toxic, when taken in large quantities. For that reason Warr has used the label $A D$ ('Additional Decrement') to denote the inverted U-shaped relationship as shown in figure 3.4. 


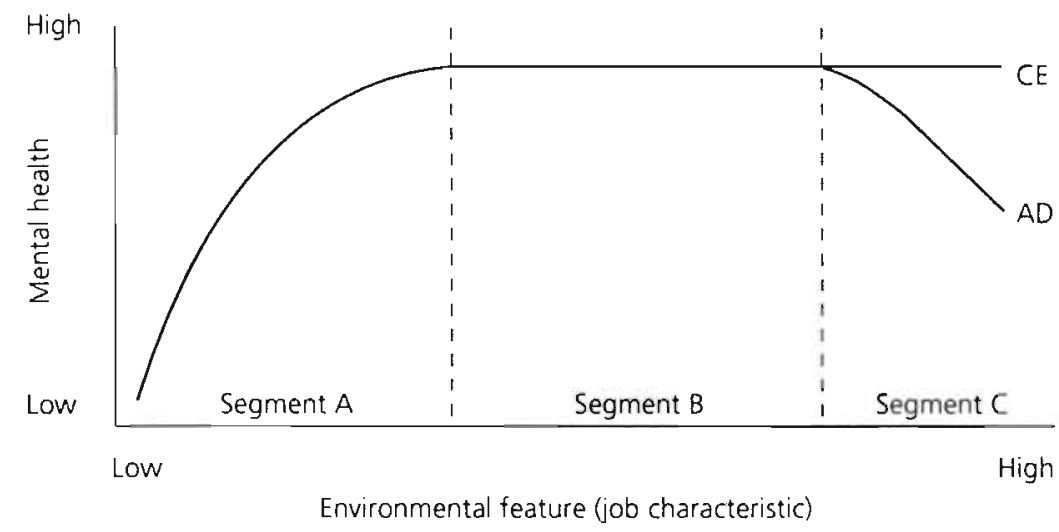

Figure 3.4 The Vitamin Model (Reprinted from "Work, Unemployment, and Mental Health" by Peter B. Warr, 1987, p. 234, by permission of Oxford University Press)

Warr $(1987,1994)$ argues that the effects of job characteristics upon mental health parallel the way in which vitamins act upon the human body. Following this line of reasoning we could refer to Warr's vitamins as 'work vitamins' (De Jonge, Schaufeli \& Furda, 1995). According to Warr (1987), the presence of job characteristics initially has a beneficial effect on employee mental health, whereas their absence impairs mental health (segment $\mathrm{A}$ ). Beyond a certain level, vitamin intake has no positive effect anymore: a plateau has been reached and the level of mental health remains constant (segment 8 ). Further increase of job characteristics may have two kinds of effects (segment $C$ ). Some job characteristics may be harmful and impair mental health (analogously to the vitamins $A$ and D). Other job characteristics may produce a constant effect, similarly to the vitamins $C$ and $E^{4}$. As we shall see, the type of effect depends upon the particular job characteristic under investigation. Moreover, Warr (1994) maintains that the curvilinear AD pattern is likely to vary across different kinds of mental health outcomes. For instance, a less pronounced mid-range plateau is expected for job-related well-being and an inverted U-shaped relationship is postulated.

After a thorough review of the literature, Warr $(1987,1994)$ came up with nine job characteristics that act as potential determinants of job-related mental health (see table 3.1). Not surprisingly, these characteristics include - amongst others - those that are featured in the JCM and the DCS Model. Warr $(1987,1994)$ assumes that six job characteristics have effects similar to vitamins $A$ and $D$. The remaining three job characteristics are supposed to follow the CE pattern. The reflected patterns are also summarized in table 3.1. 
Table 3.1 The nine job characteristics of the Vitamin Model (cf. Warr, 1994, p. 87)

\begin{tabular}{ll}
\hline CE ('constant effect') & AD ('additional decrement') \\
job characteristics & job characteristics \\
\hline - salary & - job autonomy \\
- safety & - job demands \\
- task significance & - social support \\
& - skill utilization \\
& - skill variety \\
& - task feedback \\
\hline
\end{tabular}

Warr (1994) argues that these nine job characteristics are all related to job-related mental health. Moreover, it is important to know that the VM postulates that job characteristics influence mental health, rather than the other way around (Warr, 1994). Job autonomy, for instance, is assumed to follow the inverted U-shape or AD pattern: very high levels of job autonomy might be potentially harmful for the employee's level of mental health since it implies uncertainty, difficulty in decision making and high job responsibility (Warr, 1987). Additionally, too much variety in the work may create problems in controlling attention efficiently. However, this suggested causal patterns have yet to be empirically confirmed or disconfirmed.

The VM implies that variations in the job characteristics between many kinds of jobs are of no psychological consequence for mental health because a great part of these jobs falls in segment B of figure 3.4. Instead of this, it is more important to concentrate upon jobs which fall at the extremes of the job characteristics. In other words, one should look for effects in either segment $A$ or segment $C$ of figure 3.4 .

\section{Job-related affective well-being}

One aspect of Warr's approach that deserves particular attention is its comprehensive and multi-component view of mental health. Warr (1987, 1994) distinguishes five main components of mental health: (1) affective well-being; (2) competence; (3) autonomy; (4) aspiration; and (5) integrated functioning. Psychological research mainly focuses on affective well-being as an indicator of job-related mental health. Following similar frameworks of Russell (1980) and Watson and Tellegen (1985), this job-related affective well-being is made up of two orthogonal dimensions of "pleasure" and "arousal". The former dimension is located on the horizontal axis of figure 3.5, while the latter is situated on the vertical axis. In addition, two separate axes were located diagonally: "anxious-comfortable" and "depressed-actively pleased".

In order to measure job-related affective well-being empirically three principal axes are used: (1) "discontented-contented"; (2) "anxious-comfortable"; and (3) "depressed-actively pleased". The vertical arousal dimension is not considered to be an empirical indicator of well-being and is therefore not labelled. Negative aspects of well-being are shown at the left-hand side of figure 3.5, whereas positive aspects are depicted at the right-hand side. The elongated shape of figure 3.5 suggests that the pleasure dimension is more important than the arousal dimension in constituting affective well-being 


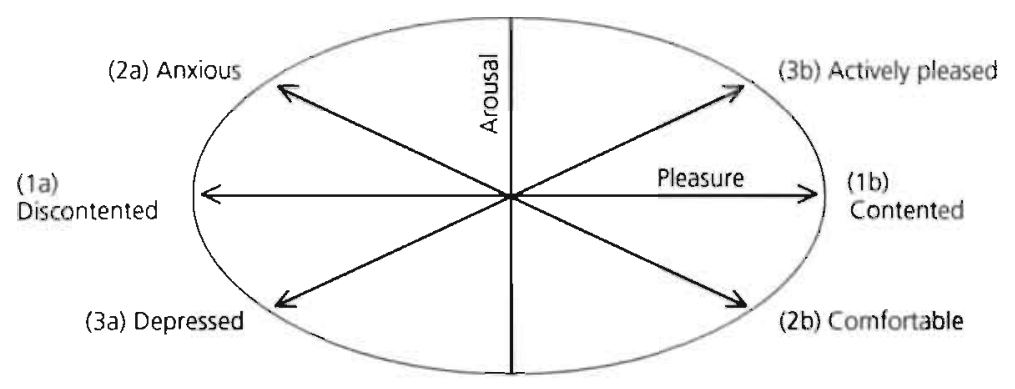

Figure 3.5 Job-related affective well-being: Three principal axes of measurement (Reprinted from "Work, Unemployment, and Mental Health" by Peter B. Warr, 1987, p. 41, by permission of Oxford University Press)

Warr (1990a) has developed measurement scales of all aspects of mental health, including job-related affective well-being (see also Schalk, Keunen \& Meijer, 1995; Sevastos, Smith \& Cordery, 1992). The scales for job-related affective well-being cover the full range of the two principal axes (numbers 2 and 3 in figure 3.5), and seem to be psychometrically quite acceptable. Consistent with the position of the axes in figure 3.5, the scores on the dimensions of affective well-being are expected to be positively correlated; that is, the angles between the axes are less than 90 degrees. In occupational settings, the first axis (i.e., discontented-contented) has mostly been operationalized through measures of job satisfaction, but measures of job attachment and organizational commitment have been used as well (Warr, 1987). The second axis (i.e., anxious-comfortable) is usually tapped through measures of job-related anxiety, job-related tension and job-related strain. Finally, the third axis (i.e., depressed-actively pleased) is assessed by such measures as occupational burnout, job-related depression, job boredom and fatigue.

Finaliy in this section, the interaction between persons and situations will be discussed. Essentially, the VM is situation-centred in that it focuses on characteristics of the work environment rather than the experience of the worker. However, Warr (1987) also describes the model as enabling in that people are assumed to be able to shape the character of their work environment and to influence the impact upon them (see also chapter 2). As a consequence, individual characteristics are viewed as possible moderators of main effects of job characteristics on mental health. Warr (1994) mentions three categories of individual characteristics: (1) abilities; (2) values; and (3) baseline mental health.

Abilities include all kinds of personal skills (i.e., intellectual and psychomotor skills), and can be viewed as relatively stable characteristics (see also Feather, 1990). The second category values - deals with all types of specific value orientations, such as preferences, motives and attitudes. The last category, labelled "baseline mental health", covers dispositions like negative affectivity.

Two kinds of effects are postulated, namely (1) direct effects and (2) moderating effects. In the former case, affective well-being is directly influenced by one of more stable 
individual characteristics. According to the latter situation, individual characteristics modify the relationship between job characteristics and affective well-being. This moderating effect will be expected especially in the case of a so-called 'matching' individual characteristic (Warr, 1994). In other words, individual characteristics that match particular job characteristics will cause a stronger, moderating, effect than those which lack this matching property. Consider for example job autonomy: one matching individual characteristic might be "need for autonomy". It is assumed that need for autonomy is a moderator for the relationship between job autonomy and, for instance, job satisfaction (cf. Warr, 1987).

\subsubsection{Empirical evidence for the model}

In presenting a sound summary of empirical support with respect to several aspects of the VM, Warr (1987, 1994) showed that his nine job characteristics do act in isolation as predicted by the model. But as far as we know, a comprehensive empirical test of - parts of this model is lacking (see also Warr, 1994).

In recent years, a few cross-sectional studies investigated the proposed patterns of the VM (Fletcher \& Jones, 1993; De Jonge, Schaufeli \& Furda, 1995; Parkes, 1991; Warr, 1990b). Most notably Warr's own study among nearly 1,900 people confirmed the postulated curvilinear relationships (Warr, 1990b). Significant - curvilinear - relationships were found between job demands on the one hand, and job satisfaction, job-related anxiety and jobrelated depression on the other. Regarding job autonomy, a curvilinear association was shown with job satisfaction. The latter relationship was the only one found to be significant in a study of Fletcher and Jones (1993) in a large heterogeneous sample of about 1,300 men. Parkes (1991), however, did not find any curvilinear relationship in her sample of almost 600 civil servants. Contrarily, De Jonge, Schaufeli and Furda (1995) detected four curvilinear relationships in their study among about 250 health care professionals. Firstly, they demonstrated a similar curvilinear relationship between job demands and job satisfaction as reported by Warr (1990b). Secondly, a curvilinear association was found between job autonomy and emotional exhaustion, an occupational burnout component. Finally, two curvilinear relationships were detected between social support and particular aspects of job-related burnout (i.e., emotional exhaustion and reduced personal accomplishment). However, these curvilinear patterns did not match expectations. Instead of a U-shaped ('AD') curve, an inverted U-shape was found.

Few investigators have examined the moderating effect of individual characteristics on the relationship between job characteristics and mental health. Warr (1987) has summarized empirical support for significant person-situation interactions in respect of job satisfaction. Possible matching individual characteristics for each job characteristic were presented. However, Warr could only report results from linear analyses. Non-linear relationships within this particular kind of research have remained unexplored.

To summarize these studies briefly, the results of the few studies that have - partially tested the VM are inconclusive. Comprehensive as well as longitudinal studies have not been reported yet. Furthermore, there has been no empirical evidence for the interactions between individual and job characteristics within the multi-faceted VM. 
Most importantly, however, all studies have failed to take account of the possible multifaceted ways in which job characteristics may affect job-related affective well-being. The VM seems to provide a useful framework in predicting new forms of relationships between job characteristics and mental health.

This concludes our discussion of three prominent theoretical models in line with the Task Characteristics Approach. Each of these models has postulated a particular role of job autonomy in the relationship between job characteristics and psychological outcomes. The three sections described the models and reviewed their empirical evidence. At present, we may conclude that some salient questions still need to be answered. The current study will address some of these questions, focusing primarily on job autonomy.

\subsection{Research questions and conceptual framework}

This study deals specifically with the conceptualization and operationalization of the term "job autonomy", and investigates its relationship (whether or not in combination with other job characteristics) with well-being and health. In chapter 2, it was concluded that most conceptualizations and particularly most operationalizations of job autonomy may be further improved. Job autonomy accordingly has to be considered in a more differentiated way. Moreover, the assessment of job autonomy in the prediction of psychological outcomes needs to be reconsidered as well. In chapter 2 , we suggested using alternative sources to reflect the properties of a task. We will therefore use group assessments in order to reflect job autonomy (cf. Frese, 1985, 1989; Frese \& Zapf, 1988; Spector, 1992). By group assessments we mean that the scores of job incumbents with the same job and working in nearly identical workplaces are aggregated into one general score (see also chapter 6).

In the present chapter, three theoretical models were considered to be most relevant for the study of job autonomy and its relationship with psychological outcomes. This relationship was reflected by three potential associations (i.e., linear additive, linear interactive and curvilinear). However, empirical evidence for these different types of relationships is mixed, due to, for instance, theoretical, conceptual and methodological problems. In addition, longitudinal research is relatively scarce, meaning that little can be said about the direction of causation in job characteristics research, in particular with respect to the DCS Model and the Vitamin Model. Based on the current state of job characteristics research reflected in the first part of this study, we are now able to address three main research questions:

1) "How can job autonomy be clearly and precisely operationalized, and what are the psychometric properties of the corresponding measurement scale?"

11) "Can well-being and health be better predicted by individual assessment of job autonomy or by an alternative (group) assessment of job autonomy?"

III) "What is the particular form and direction of the relationship between job autonomy (whether or not in combination with other job characteristics) and wellbeing and health?" 
At this point, we will introduce our conceptual framework and we will discuss its elements. This framework is shown in figure 3.6. The basic elements consist of job characteristics, psychological outcomes and demographic characteristics. It should be noted that our main research questions are embedded in this general framework, mainly based upon the theoretical models discussed.

The selection of the specific variables within this framework is based upon the three theoretical models, as described earlier in this chapter. Not surprisingly, agents for the job characteristics are job autonomy, job demands and social support. These three variables are the central characteristics of the Demand-Control-Support Model. In addition, job autonomy is a core characteristic of the Job Characteristics Model as well. Finally, these wintes sem to be important psychological work vitamins as hypothesized by Warr (1987. 1992, 1994).

The choice of the - four - psychological outcomes is guided by the three theoretical models t5\%. work motwation, job satisfaction, emotional exhaustion and job-related anxiety. Firstly, Warrs thres-axial measurement of affertive well-being might be reflected through three corresponding agents of outcomes, namely (1) job satisfaction, (2) job-related anxiety, and (3) occupational burnout. Secondly. work motivation and to a lesser extent job satisfaction are key outcomes of the Job Characteristics Model. At the same time, both outcomes reflect the active-diagonal of the two Karasek models. Lastly, the strains-diagonal of Karasek's models is represented by the occupational bumaut-component "emotional exhaustion "and by job-relatad anxiety. These wo strain variables have been often used for testing the job Demand-Control Model as weil as he Demand-Control-Support Model le.g. Karasek. 1979; Karasek 8 Theorell, 1990, Landsbergis, 1988; Melamed, Kushnir \& Meir, 1991; Parkes, 1982). Moreover, occupational bumout is an important research topic in today's fursing (e.g. Cordes \& Dougherty, 1993; Landsbergis, 1988; Schaufeli \& lanczur, 1994). Since demographic variables such as gender and age may confound the results, both warbles are included in our study as well. For instance, wornen tend to repont greater job satisfaction than men, and they also tend to report more psychosomatic symptoms (e.g. Rosentield, 1989; War, 1987). Simlarly, Kasl (1989) noted that age may play an important

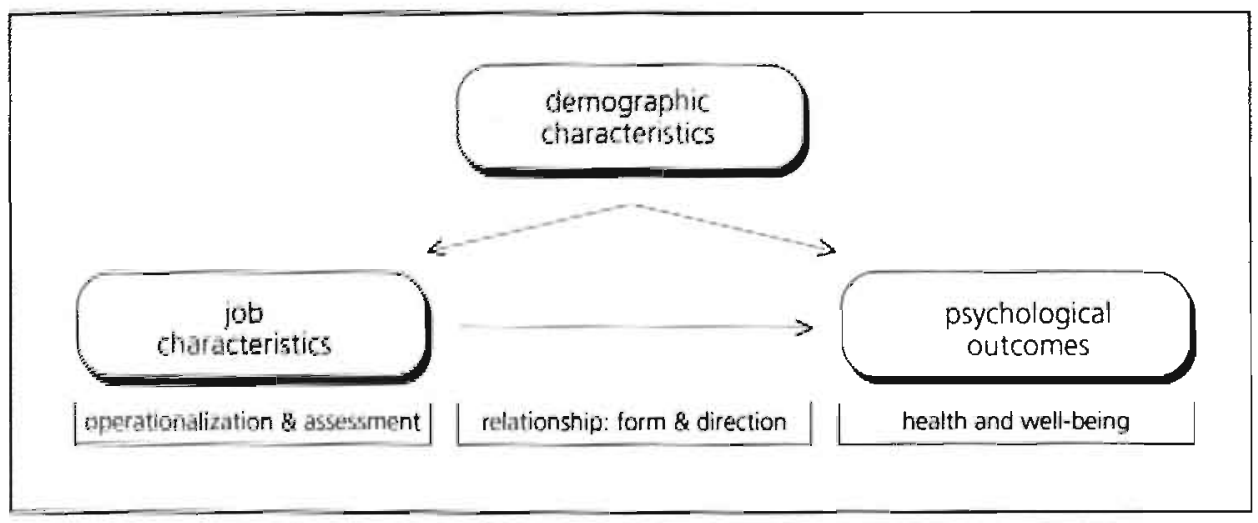

Figure 3.6 Conceplual framework of the present research 
role: older people report more health problems than younger people do (see alsa Warr, 1992). In addition. Schwartz, Pieper and Karasek (1988) argued that age generally is negatively related to job strain. Moreover, they showed that job characteristics were systematically related to demographic variables. For example, it should not be surprising that (1) older women tend to have less demanding jobs, and (2) men's average level of job autonomy seems to be markedly higher than women's. In a similar vein, Johnson and Hall (1988) noted that among women workplace social support was a more important predictor for adverse health outcomes than job autonomy.

In view of our conceptual framework and main research questions, several specific questions (QS) and hypotheses (Hs) can be formulated.

As discussed in chapter 2, research question I addresses the operationalization of job autonomy and the development of a new measurement scale.

Research question II concerns the assessment of job autonomy in the prediction of wellbeing and health. Regarding the exploratory nature of this question, it seems inappropriate, and premature, to generate detailed hypotheses. Instead, this main question has led to three specific research questions. We will compare individual data and group data (i.e., aggregated individual data) in the light of the following three questions:

Q1) "To what extent can individual data on job characteristics explain health (i.e., emotional exhaustion, job-related anxiety) and well-being (i.e., job satisfaction, work motivation)?"

Q2) "To what extent can aggregated individual data on job characteristics explain health and well-being?"

Q3) "Do aggregated individual data add explained variance to the explained variance by individual variables with respect to health and well-being?"

Because these questions have been based on the Job Demand-Control Model of Karasek (1979), and are to be published separately (see De Jonge, Van Breukelen, Landeweerd \& Nijhuis, 1995), we extend - and partly integrate - our questions by means of the following hypothesis:

H1) "Job autonomy and job demands have an interaction effect with respect to health on the one hand, and well-being on the other."

This hypothesis bridges the first part of our third main research question (III). That is, the particular form of the relationship between job autonomy and the psychological outcomes will be investigated. According to the three theoretical models described, three forms of relationships can be postulated:

1) Job autonomy has a linear additive relationship with the psychological outcomes (cf. Hackman \& Oldham, 1980);

2) Job autonomy has a linear interactive relationship (i.e., in combination with other job characteristics) with the psychological outcomes (cf. Johnson \& Hall, 1988; Karasek, 1979);

3) Job autonomy has a curvilinear relationship with the psychological outcomes (cf. Warr.1987). 
These forms of relationships can hardly be studied separately from other - related - job characteristics. For example, at least two job characteristics are needed for studying linear interactive relationships. We will therefore embed the postulated job autonomy-outcomes relationships in the theoretical models

The present chapter has shown that the popular belief of linear additive relationships is challenged by Karasek and Warr. As a consequence, the main question is whether both a linear interactive model and a curvilinear model are superior to a model that only includes linear additive relationships (on the condition that linear additive relationships exist). Two salient hypotheses can be formulated accordingly, such that the first postulated relationship is reflected by the null hypotheses that no interactive or no curvilinear relationships exist. In other words, if these two null hypotheses are not rejected, then linear additive relationships, as predicted by Hackman and Oldham (1980), might be further investigated. An integration of job autonomy in the DCS Model of Johnson and Hall (1988) results in the following hypothesis:

H2) "Job autonomy, job demands and workplace social support have an interaction effect with respect to health on the one hand, and well-being on the other."

The third relationship follows the assumptions of Warr (1987, 1994). An integration of job autonomy in the Vitamin Model leads to the following hypothesis:

H3) "Job autonomy, job demands and workplace social support are curvilinearly associated with health and well-being."

The second part of our third main research question (III) addresses causal relationships. To be more specific, the direction of the relationship between job characteristics (and job autonomy in particular) and the outcome variables will be investigated. Our theoretical models generally assume that the causal pattern is unidirectional; that is, job characteristics influence psychological outcomes, and not vice versa. Consequently, our central hypothesis is formulated as follows:

H4) "Job characteristics at measurement 1 influence health and well-being at measurement 2."

Alternatively, several researchers have questioned this assumption by stating that outcome variables may affect perceptions of job characteristics (see section 3.3). For instance, employees who believe they are satisfied with their job tend to rate their jobs as higher in job autonomy than those who express job dissatisfaction - even though satisfied and dissatisfied people perform the same job.

However, these two seemingly conflicting assumptions are not mutually exclusive. It was also suggested earlier in this chapter that job characteristics and psychological outcomes influence each other reciprocally. Moreover, these reciprocal relationships appeared to be 
asymmetric. As you will recall, Warr (1987) mentioned that the outcomes tended to occur after job perceptions, rather than vice versa. Consequently, in addition to our central fourth hypothesis, two final research questions can be formulated:

Q4) "Do health and well-being at measurement 1 affect perceptions of job characteristics at measurement 2?"

Q5) "Do job characteristics and health and well-being mutually influence each other in an asymmetric way?"

The next chapter will deal with the basic methodological conditions for answering our three main research questions; that is, the research method.

\section{NOTES}

1. Several parts of this chapter are based upon: De Jonge (1992); De Jonge and Furda (in press); De Jonge, Janssen and Van Breukelen (in press); De Jonge, Janssen and Landeweerd (1994); De Jonge, Schaufeli and Furda (1995); De Jonge and Schaufeli (1995).

2. As noted in chapter 2, 'objective' means an assessment independently of the employee.

3. Next to workplace social support, several other characteristics were added to the model, like physical exertion, job insecurity and hazardous exposure ( $c$. Karasek \& Theorell, 1990). A discussion of these characteristics is beyond the scope of this thesis.

4. Warr's description of vitamin overdose is only partly correct. Hypervitaminosis is mostly a consequence of misuse of vitamin preparations. Vitamin intake by food hardly ever causes hypervitaminosis. Only fatsoluble vitamins (i.e., A, D, E and $K$ ) have the potential for toxicity, because they cannot be excreted easily. On the other hand, water-soluble vitamins like $B$ and $C$ are readily excreted once their concent ration surpasses the renal threshold. In other words, toxicities are quite rare (cf. Devlin, 1992).

Being a fat-soluble vitamin, E has the potential for toxicity. However, it does appear to be least toxic of fat-soluble vitamins (Devlin, 1992). Thus, strictly speaking, vitamin E appears to possess AD features rather than CE features. 


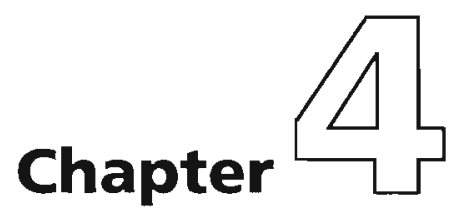




\section{METHOD}

\subsection{Introduction}

In the last part of chapter 3 we discussed the general framework and the specific research questions. Before we will conduct the statistical analyses and will present the corresponding results, chapter 4 addresses the research method. More specifically, the study design, the population, and the procedures involved will be discussed, as well as an analysis of nonresponse. Section 4.6 is a summary of this chapter.

\subsection{Design of the study}

The research design is twofold. The first part of the study involves a cross-sectional design. To a large extent, the data were collected at one measurement point in time. The second part is referred to as a longitudinal design or panel design with two panel waves: subjects supplied the data at two measurement points in time.

There are a number of advantages to panel designs compared to cross-sectional designs (cf. Dooley, 1984; Hagenaars, 1990; Hsiao, 1986; Verbeek, 1991). First, panel data sets have statistical advantages with regard to model building and testing. For instance, panel data may produce more efficient and more robust model estimators than cross-sectional data do. Second, if panel data are available additional parameters might be identifiable, and the effects of omitted variable bias might be reduced. Third, it is possible to follow attitudinal and behavioural changes on the individual level over time. Finally, the causal order and causal predominance of variables can be established more reliably than in cross-sectional designs (see chapter 7).

However, problems can also arise in panel studies. A major difficulty for panel data is the risk of losing respondents, a problem referred to as "attrition" or "subject mortality". Another problem is that respondents may strive to be consistent across interviews. This phenomenon can be particularly troublesome in studies which measure respondents' attitudes and behaviour. Finally, the initial questionnaire may sensitize people to the issue under investigation, which can influence the answers in the second interview. This problem is referred to as "panel conditioning". Nonetheless, the availability of panel data introduces new possibilities for model building and testing.

\subsection{Population of the study}

The population of this study consisted of health care workers from general hospitals and combined nursing homes' in the Netherlands. We expressly chose health care workers as study population, because health care professions are suitable for testing our theoretical models for several reasons (cf. Fox, Dwyer \& Ganster, 1993; De Jonge, Janssen \& Van 
Breukelen, in press; Kristensen, 1995). First, job autonomy is an important tool in presentday care delivery systems. Second, health care workers seem to be subject to stressful work conditions (i.e., high job demands). Third, because of different types of health care areas and different specialties, health care workers are a relatively heterogeneous group. Fourth, because of the small variance in social class, socio-economic status will not act as a confounder. Finally, units within general hospitals and nursing homes can be clearly defined and traced, which allow multi-level modelling (Bryk \& Raudenbush, 1992; see aiso chapter 6).

\subsection{Sample design and sample procedure}

A primary goal in explanatory research is to observe associations between variables or to observe differences between groups in terms of causal models. An important prerequisite to achieve this goal is sufficient variance and diversity in observations (cf. Kristensen, 1995). In order to obtain optimal variance and diversity, and to minimize or control errors, we have to make use of sampling survey techniques. Sampling techniques allow for all the variety of a large heterogeneous population to be portrayed. It has also other advantages, such as reduction of time, costs, and manpower (cf. Polit \& Hungler, 1987; Yates, 1981).

In the light of the research problem of the present study, several sampling criteria have to be drafted.

1) In order to investigate higher-order effects (i.e., interaction and non-linear effects), the approximate sample size needs to be determined to achieve a desired level of statistical power (cf. Cohen, 1988).

2) We have to make use of supplementary information of subpopulations in our study population, because we are primarily interested in intergroup comparisons. If necessary, stratified random sampling will take us in the right direction (increasing precision).

3) The accuracy of the parameter estimates mainly relies on sample size and less on sampling fraction (e.g., Stuart, 1984; Yates, 1981). In the case of stratification, it is therefore desirable to have an equal number of institutions within each stratum. This is called "disproportional stratified sampling" (Polit \& Hungler, 1987).

4) Representativeness of the (whole) sample is of secondary importance, because we want to study (causal) relationships between the phenomena under investigation (Kristensen, 1995; Philipsen, 1969; Sturmans, 1986).

With respect to the demands of the statistical analysis, the requisite sample size to achieve a recommended power of 80 for testing higher-order effects would be at least 520 subjects (cf. Cohen, 1988; Jaccard, Turrisi \& Wan, 1990; De Jonge \& Landeweerd, 1993). Because of the desirability to employ double cross-validation procedures, at least a sample of 1,040 subjects would be a sufficient number (e.g., Cudeck \& Browne, 1983; Kleinbaum, Kupper \& Muller, 1988). 
Furthermore, possible bias due to, for instance, regional spreading and personnel supply problems was controlled for by stratifying the population. To be more specific, the number of relevant institutions within the Western industrial region of the Netherlands is higher than that in the Eastern - more agricultural - region: 122 and 96, respectively. Moreover, the Western region had more personnel supply problems, which may lead to a significant imbalance between the employee and the work environment (Van der Windt, 1992).

Accordingly, the Netherlands were divided in two strata: a Western and an Eastern region. Within each stratum (West versus East) two disproportional random samples were taken: 1) a sample from the sampling frame "general hospitals including a psychiatric unit" $(\mathrm{N}=57)$;

2) a sample from the sampling frame "combined nursing homes" ( $N=161$; Bartels, 1992). This sampling technique yielded 16 general hospitals and 16 combined nursing homes. The institutions were numbered according to the sequence of entry into the sample. Institutions of both kinds which received even numbers were selected in the study (i.e., eight hospitals and eight nursing homes). Institutions with odd numbers were held in reserve. In this way, refusals could be immediately replaced by odd-numbered institutions.

Letters to the management of 16 institutions were sent out in March 1993. In order to achieve a relatively heterogeneous group of health care providers, different kinds of units were asked to participate in the study: intensive care units (ICUs), psychiatric units, internal units and surgical units in hospitals, and somatic units and psycho-geriatric units in nursing homes. Added to this, the management was told that each member of staff within a specific unit had to complete a questionnaire which would take approximately 30 minutes. After data collection and data analyses were finished, the institutions would receive a research report with results and practical implications ${ }^{2}$.

Twelve out of 16 institutions were willing to participate in the study: one general hospital and three nursing homes declined their cooperation. Reasons for refusal were, for instance, participation on other research projects, time pressure, and unstable work situations (like. reorganizations).

After this, four randomly chosen odd-numbered institutions were approached (i.e., one general hospital and three nursing homes). This time, one general hospital and one nursing home approved participation. Finally, we randomly chose two nursing homes from the remaining odd-numbered institutions and sent letters to their management. These last two letters resulted in the cooperation of these two institutions. In sum, eight general hospitals (four from West and East, respectively) and eight combined nursing homes (the same spread) participated in the present study.

\subsection{Fieldwork and respondents}

First of all, meetings were arranged with members of the management, heads of the nursing department, coordinating nursing managers, and senior nursing officers. information was given about the research topic and purpose, the data collection procedure, 
and the research report. After this, the four participating units were, if possible, randomly chosen and informed likewise.

The questionnaires were administered in three possible ways, namely (1) group administration, (2) individual administration, and (3) a combination of (1) and (2). As far as possible, the questionnaires were personally presented to the respondents. In a clinical setting like nursing, this method is often efficient and likely to yield a high rate of completed questionnaires (cf. Boumans, 1990; De Jonge \& Landeweerd, 1992a). The questionnaires were distributed in a uniform main envelope with the name of the respondent on it. This envelope included a questionnaire, administration instructions, and a stamped, addressed return envelope. Moreover, the panel questionnaires contained an administration number for second round identification.

Table 4.1 Time schedule of the two measurement points

\begin{tabular}{llll}
\hline activity & institutions & start & end \\
\hline first measurement & $\begin{array}{l}\text { eight general hospitals } \\
\text { eight nursing homes }\end{array}$ & April 1993 & December 1993 \\
\hline second measurement & $\begin{array}{l}\text { one general hospital } \\
\text { three nursing homes }\end{array}$ & April 1994 & june 1994 \\
\hline
\end{tabular}

In line with the research design, the study involved two measurement points as shown in table 4.1. We will briefly discuss both.

The first questionnaires were distributed from April 1993, and the final questionnaires returned in December 1993. In general, the interval between hand out and return was about three weeks.

During the first meetings the management was asked if they wanted to participate twice. Most of them were hesitant to make the commitment of costs and time necessary to complete such an additional project. No more than four institutions participated in the second measurement, one general hospital and three nursing homes. Therefore, their first measurement started in April 1993. The aim was to have about a one-year interval between the two measurements (table 4.1). This time appears to be long enough for possible changes in individual scores, but not too long for too much non-response (see also Frese \& Zapf, 1988; Vermaat, 1994). Moreover, possible season fluctuations in work and test-retest effects were controlled for (Hagenaars, 1990). In practice, the real interval between the two measurement points ranged from 11 to 13 months.

The total sample consisted of 1,806 health care workers from 64 units, including registered nurses, student nurses, nurse's aides, activity therapists, secretaries, and kitchen staff. After ten days, a reminder was sent to all participants. The number of respondents who returned the questionnaire was 1.489, yielding a response rate of 82 per cent. Both types of institutions had about the same response rate (see table 4.2). At institutional level, the response ranged from 69 per cent to 94 per cent. At unit level, the range was from 58 per cent to 100 per cent. 
Table 4.2 Response rate of the first measurement

\begin{tabular}{llcl}
\hline first measurement & lowest rate & highest rate & general rate \\
\hline institutional level $(N=16)$ & $69 \%$ & $94 \%$ & $82 \%$ \\
unit level $(N=64)$ & $58 \%$ & $100 \%$ & $82 \%$ \\
\hline general hospitals $(n=8)$ & $74 \%$ & $94 \%$ & $83 \%$ \\
nursing homes $(n=8)$ & $69 \%$ & $91 \%$ & $82 \%$ \\
\hline
\end{tabular}

Thirteen employees from non-caring professions (e.g., activity therapists and secretaries) were excluded from the final sample, since the content of their jobs differs greatly from that of health care providers. Furthermore, only workers who had been employed for more than three months were included in the final sample, in order to ensure valid and reliable observations of the work situation ( $f$. Katz, 1978a, 1978b). Both restrictions reduced the final sample to 1,437 'real' and 'experienced' health care workers.

Table 4.3 Description of the first measurement sample ( $n=1,437$; standard deviations in parentheses)

\begin{tabular}{llll}
\hline first measurement & $\begin{array}{l}\text { hospitals } \\
(n=692)\end{array}$ & $\begin{array}{l}\text { nursing homes } \\
(n=745)\end{array}$ & $\begin{array}{l}\text { total sample } \\
(n=1,437)\end{array}$ \\
\hline percentage of women & $75 \%$ & $91 \%$ & $83 \%$ \\
mean age & $31.1 \mathrm{y} .(7.9)$ & $30.3 \mathrm{y} .(8.9)$ & $30.7 \mathrm{y} .(8.4)$ \\
mean work experience & $11.3 \mathrm{y} .(7.3)$ & $9.1 \mathrm{y} .(7.1)$ & $10.2 \mathrm{y} .(7.2)$ \\
percentage full-time & $45 \%$ & $46 \%$ & $46 \%$ \\
\hline
\end{tabular}

Table 4.3 gives a brief description of the first measurement sample. Eighty-three per cent of the respondents were women, and the age ranged from 17 to 59 years ( $M=30.7, S D=8.4$ ). The mean work experience was 10.2 years $(S D=7.2)$, and 46 per cent of the respondents worked full-time. The demographic characteristics of our sample appeared to be quite similar to other large-scale surveys in the Netherlands (e.g., Le Blanc, 1994; Boumans, 1990). A closer look at the two types of institutions reveals two significant differences between them. First, it appeared that the percentage of women working in nursing homes is significantly higher than the percentage women working in hospitals $\left(\chi^{2}(1)=69.42, p \leq .001\right)$. Second, respondents in the hospitals have a significantly higher mean work experience within the organization than those working in the nursing homes (Mann-Whitney $Z=6.64, p \leq 001$ ) To examine the robustness of the models under investigation, a double cross-validation procedure is followed that has been suggested by Browne and Cudeck (Browne \& Cudeck, 1993; Cudeck \& Browne, 1983; see also chapter 5). Two independent subsamples from the parent-sample were involved: (1) a calibration sample; and (2) a validation sample. The calibration sample is usually employed for model development and model derivation; the validation sample is used for evaluating the ultimate model (Diamantopoulos, 1994; Hayduk, 1987). In order to ensure that both hospital workers and nursing home workers were equally represented in both subsamples, the parent-sample was stratified accordingly. Within each stratum (i.e., type of institution), all respondents were randomly assigned to the calibration sample or to the validation sample. No significant differences between the two split-samples were found with respect to demographic characteristics (see table 4.4). 
Table 4.4 Description of the calibration sample and the validation sample (first measurement; standard deviations in parentheses,

\begin{tabular}{llll}
\hline first measurement & calibration $(n=719)$ & validation $(n=718)$ & total sample $(n=1,437)$ \\
\hline hospital workers & 346 & 346 & 692 \\
nursing home workers & 373 & 372 & 745 \\
\hline percentage of women & $83 \%$ & $83 \%$ & $83 \%$ \\
mean age & $30.8 \mathrm{y} \cdot(8.4)$ & $30.6 \mathrm{y} .(8.5)$ & $30.7 \mathrm{y} .(8.4)$ \\
mean work experience & $10.2 \mathrm{y} .(7.2)$ & $10.1 \mathrm{y} .(7.3)$ & $10.2 \mathrm{y} .(7.2)$ \\
percentage full-time & $44 \%$ & $47 \%$ & $46 \%$ \\
\hline
\end{tabular}

The questionnaires for the second measurement were distributed in April 1994, and the last one returned in June 1994. With the exception for non-caring professions, all health care workers in the units (i.e., both participants in the first measurement and new subjects) were asked to participate in the second measurement. Subjects were given the same questionnaire to fill in. Irrelevant demographic items were left out and the order of items was changed to diminish test-retest effects. Together 454 health care workers received the questionnaires, and 363 respondents returned the questionnaire by post $80 \%$ response rate). Again, only those health care workers who had been employed for more than three months were included in the sample (i.e., 358 employees).

Table 4.5 Description of the second measurement sample ( $n=358$; standard deviations in parentheses)

\begin{tabular}{llll}
\hline second measurement & hospital $(n=75)$ & nursing homes $(n=283)$ & total group $(n=358)$ \\
\hline percentage of women & $80 \%$ & $90 \%$ & $88 \%$ \\
mean age & $33.6 \mathrm{y} .(9.5)$ & $31.3 \mathrm{y} .(8.4)$ & $31.8 \mathrm{y} .(8.7)$ \\
mean work experience & $12.5 \mathrm{y} .(8.1)$ & $9.5 \mathrm{y} .(7.0)$ & $10.1 \mathrm{y} .(7.3)$ \\
percentage full-time & $40 \%$ & $39 \%$ & $39 \%$ \\
\hline
\end{tabular}

A brief description of the second measurement sample is given in table 4.5. Eighty-eight per cent of the respondents were women. The age ranged from 19 to 58 years $(M=31.8$, $S D=8.7$ ), and the mean work experience was 10.1 years $(S D=7.3)$. Full-time workers accounted for 39 per cent of the respondents. Table 4.5 reflects the same trends as table 4.3. Similarly, a significantly higher percentage of women were shown to be working in nursing homes $\left(\chi^{2}(1)=5.23, p \leq 05\right)$. The mean work experience of the hospital workers is also significantly higher than that of the nursing home workers (Mann-Whitney $Z=2.75$, ps.01).

Compared with the first measurement sample $(n=1,437$, table 4.3), three significant differences between the two samples were observed. First, there are significantly more women present in the second measurement sample $\left(\chi^{2}(1)=4.35, p \leq .05\right)$. Second, the second measurement sample is significantly older as well $(t=-2.11, p \leq .05)$. Finally, the latter sample has a significantly lower percentage full-time workers $\left(\chi^{2}(1)=5.07, p \leq .05\right)$. Some of these differences might caused by the higher percentage nursing home workers in the second measurement sample. The difference in age is rather trivial because of the one-year interval between the two measurement points 
As we mentioned earlier in this chapter, panel data are more subject to non-response than cross-sectional data sets are. Two special cases of non-response will be considered in this study, namely (1) wave non-response and (2) attrition (Verbeek, 1991). Wave non-response occurs when subjects do not respond for (one of) the two measurements. Attrition arises when persons participate in the first measurement and then leave (drop out) the panel group.

Table 4.6 Participation and non-response of the panel study

\begin{tabular}{|c|c|c|c|c|c|c|c|c|c|c|c|}
\hline & \multirow{2}{*}{$\begin{array}{l}\text { recipients } \\
\mathrm{N}\end{array}$} & \multicolumn{2}{|c|}{$\begin{array}{l}\text { wave } \\
\text { response }\end{array}$} & \multicolumn{2}{|c|}{$\begin{array}{l}\text { continuous } \\
\text { participants }\end{array}$} & \multicolumn{2}{|c|}{$\begin{array}{l}\text { wave } \\
\text { non-response }\end{array}$} & \multicolumn{2}{|c|}{$\begin{array}{l}\text { excluded } \\
\text { respondents\# }\end{array}$} & \multicolumn{2}{|c|}{ drop-outs } \\
\hline & & $\mathrm{n}$ & $\%$ & $n$ & $\%$ & $\mathrm{n}$ & $\%$ & $n$ & $\%$ & $\mathrm{n}$ & $\%$ \\
\hline first measurement & 457 & 380 & 83 & 380 & 83 & 77 & 17 & 19 & 4 & 72 & 19 \\
\hline second measurement & 454 & 363 & 80 & 261 & 57 & 91 & 20 & 5 & 1 & & \\
\hline
\end{tabular}

\# people working less than or equal to three months, and non-caring professions

Table 4.6 represents both kinds of non-response. The second column shows the number of subjects that received a questionnaire. The wave response of both measurements is shown in the third column. The fourth column reflects those persons who continuously participated at the measurements. After the second measurement, 57 per cent of the initial group had completed both questionnaires, which is not an unusual percentage (cf. Hagenaars, 1990). Column five demonstrates the wave non-response. The wave non-response at both measurements is remarkably low (17\% and $20 \%$, respectively). So, hardly any problems could be expected with respect to the relatively low wave non-response (e.g., Hagenaars, 1990; Verbeek, 1991).

In order to evaluate selection problems due to attrition, the 261 continuous participants (the panel group) were compared with the information available from the drop-outs (table 4.7). Seventy-two participants out of 380 subjects of the first measurement, or 19 per cent, did not return in the second measurement. In order to make a fair comparison between the panel group and the drop-outs, only those 64 workers who had been employed for more than three months were included in the analysis (see table 4.7 ). It should be noted that the demographic variables of the first measurement were used in the comparison.

Table 4.7 Comparison of the panel group with the drop-outs (first measurement; standard deviations in parentheses)

\begin{tabular}{lll}
\hline & panel group $(n=261)$ & drop-outsi $(n=64)$ \\
\hline percentage of women & $87 \%$ & $92 \%$ \\
mean age & $31.9 y \cdot(8.5)$ & $29.1 \mathrm{y} .(9.8)$ \\
mean work experience & $10.7 \mathrm{y} \cdot(7.2)$ & $7.5 \mathrm{y} .(8.0)$ \\
percentage full-time & $45 \%$ & $55 \%$ \\
\hline
\end{tabular}


Significant differences between both groups were found in age and work experience. The panel group is significantly older $(t=2.04, p \leq .05)$, and has a significantly higher mean work experience as well (Mann-Whitney $Z=4.02, p \leq .001$ ). These results are not astonishing. because a substantial number of the drop-outs are (young) student nurses, who changed unit twice a year.

In conclusion, analyses of non-response showed some comparatively small differences between panel group and drop-outs. Younger and less experienced people (e.g., student nurses) are slightly under-represented in the panel group. It seems therefore that our panel data do not suffer from serious selection problems with respect to demographic background ${ }^{3}$.

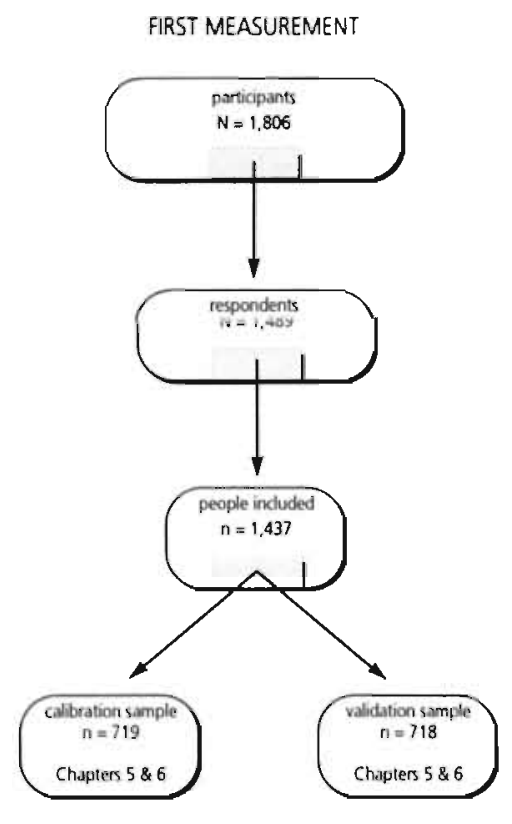

SECOND MEASUREMENT

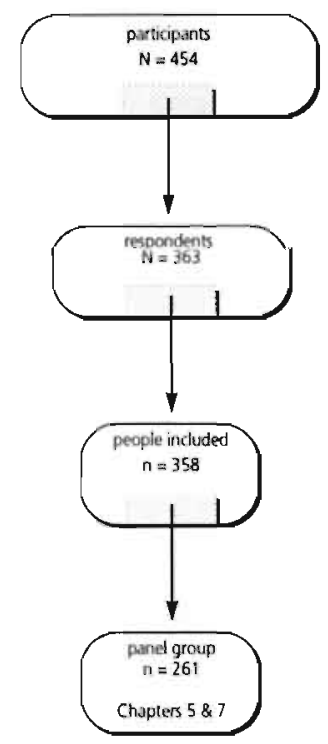

Figure 4.1 Subsamples to be used in the next three chapters

This concludes our description and comparison of the demographic characteristics of the groups under study. We will use this information in the light of the results of this study. Taken together, three subsamples will be used in the forthcoming analyses in the next three chapters, as indicated in figure 4.1. All subsamples will be used in the psychometric analyses in chapter 5 . The analyses in chapters 6 and 7 consist of the first measurement subsamples and the second measurement subsample, respectively. 


\subsection{Summary}

In this chapter several parts of the research method have been discussed. The research design of the present study includes a cross-sectional design (i.e., one measurement point) as well as a longitudinal design (i.e., two measurement points). A disproportional stratified random sample was drawn from general hospitals and combined nursing homes in the Netherlands. Eight hospitals and eight nursing homes participated in the study. Health care workers were asked to complete a questionnaire.

The first measurement sample consisted of 1,489 health care workers from 64 units ( $82 \%$ response rate). In order to investigate the robustness of the theoretical models, the sample was divided in a calibration sample and a validation sample. Moreover, 363 health care workers from four institutions participated in the second measurement sample $180 \%$ response rate).

Longitudinal data are sensitive to non-response. A comparison of continuous participants with drop-outs showed, however, that our data do not appear to suffer from serious selection problems.

The chapter concluded by presenting those subsamples which will be involved in the analyses.

\section{NOTES}

1. Combined nursing homes are nursing homes with somatic units as well as psycho-geriatric units.

2. These results and practical implications were reported in several internal memoranda and two articles in a professional nursing journal (De Jonge, Landeweerd, Nijhuis \& Boumans, 1994; De Jonge, Landeweerd \& Nijhuis, 1994; De Jonge, Boumans, Landeweerd \& Nijhuis, 1995a, 1995b).

3. The question whether disappearance from the sample is not an outcome of a causal dynamic that is different from that of the survivors is answered in chapter 7. 
$\operatorname{chapter} \square$ 


\section{PSYCHOMETRIC ANALYSIS}

\subsection{Introduction}

This chapter deals with the specification and evaluation of the measurement instruments used. We will describe the definitions of the variables, the corresponding operationalizations, and their response scale formats. For this study, we searched for existing measurement scales which have proved to be psychometrically sound. Additionally, we tried to construct new instruments for existing instruments which were badly designed. Finally, we wanted to make a profound study of the psychometric properties of all instruments used.

Before we discuss the outline of this chapter, it is valuable to consider briefly the nature of measurement. Measurement can be defined as a process by which a concept is linked to latent factors, and these are in turn linked to observed variables (Bollen, 1989). In other words, latent factors are the representations of concepts in measurement models. Once a concept is specified, at least five general steps in the measurement process can be considered (cf. Bollen, 1989):

1) to give a meaning to a concept by developing a theoretical definition;

2) to identify one or more elements to represent the concept;

3) to form measures depending on the theoretical definition, sometimes referred to as the operational definition;

4) to construct the measurement model by specifying the relationships between the measures and the latent factor(s);

5) to estimate and to evaluate the measures in terms of their validity and reliability.

The outline of this chapter follows these five steps. The first three steps are discussed in section 5.2; descriptions and operationalizations are. given of the variables used. With regard to step four, section 5.3 reviews our method of scale construction and evaluation. This is followed by an evaluation of the psychometric properties of the measurement instruments in section 5.4. Finally, the chapter concludes with a summary of the findings and with several conclusions.

\subsection{Description and operationalization of the variables}

\subsubsection{Introduction}

This section gives an overview of the measurement instruments used. More specifically, a description of the variables is given, directly followed by the corresponding operationalization. The selection of the variables is based upon the three theoretical models, as described at the end of chapter 3 . The variables can be classified into three categories: (1) job characteristics; (2) psychological outcomes; and (3) demographic characteristics. We will discuss them in the next three subsections accordingly. 


\subsubsection{Job characteristics}

\section{JOB AUTONOMY}

In chapter 2 it has been stated that most job autonomy measurement scales could be improved conceptually and psychometrically. Therefore, we have made an effort to construct a new measurement instrument for job autonomy. Following the theoretical definition, as described in chapter 2 (p. 13), the definition of job autonomy will be extended to cover the worker's opportunity or freedom, inherent in the job, to determine a variety of task elements, like the method of working, the pace of work and the work goals. In fact, this definition overlaps with the way Breaugh (1985) and Chung (1977) defined job autonomy (see chapter 2). Our definition, however, allows an expansion of the number of task elements as, for instance, defined by Ganster (1988, 1989). Furthermore, this definition allows for a multi-level construct as well; that is, some task elements belong to the external level, and some others belong to the internal level.

Our job autonomy instrument should meet the recommendations mentioned earlier. In other words:

1) the job autonomy instrument should cover as many task elements as possible, and at the same time these elements should be theoretically defensible;

2) item content should be checked accurately and, consequently, may not overlap with other job characteristics;

3) all items should be worded into the same direction (i.e., positive or negative);

4) all items should have the same response scale format;

5) indicators of job autonomy should be defined not only precisely, but also in neutral terms - in other words, items should require a minimum of cognitive processing and avoid global judgements;

6) the measurement instrument should be valid in both homogeneous and heterogeneous samples.

An extensive review of the literature yielded a great number of task elements and corresponding items ( $C$. De Jonge, 1992; De Jonge, Landeweerd \& Van Breukelen, 1994). The challenge was to achieve a relatively exhaustive enumeration of these job autonomy elements and items. Furthermore, several experts had checked these elements and items for content validity. As a result, ten elements and corresponding items withstood the scrutiny of criticism. Table 5.1 shows the final items.

These ten items were submitted to a thorough psychometric analysis, and resulted therefore in a new measurement scale: the Maastricht Autonomy Questionnaire, abbreviated MAQ (cf. De Jonge, Landeweerd \& Van Breukelen, 1994). All items were positively worded, and the response format consisted of the same 5 -point Likert scales ranging from 1 "very little" to 5 "very much". Added to this, the respondents were instructed to try to remain aloof from their work situations when they answered the questionnaire, in order to reduce the likelihood of scoring subjectivity (cf. Frese \& Zapf, 1988; Wikman, 1991). 
Table 5.1 The Maastricht Autonomy Questionnaire (MAQ)

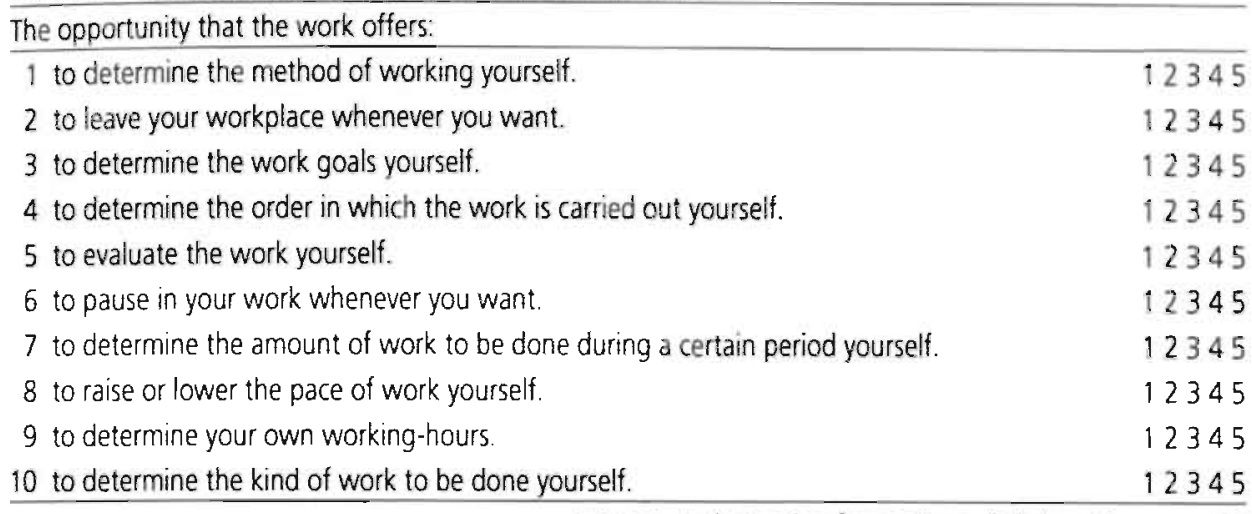

response scale ranging from 1 "very little" to 5 "very much"

The ten MAQ items are assumed to be represented by two latent factors (see also chapter 2):

1) contextual autonomy: the worker's opportunities to determine several input and output requirements of his tasks (i.e., items 2, 6, 7, 8, 9, and 10);

2) content autonomy: the worker's opportunities within given job standards (i.e., items 1 , 3, 4, and 5).

At the same time, a general latent factor job autonomy is expected to represent all ten items.

The results of a pilot study among 249 health care workers confirmed the validity as well as the reliability of the MAQ (De Jonge, Janssen \& Van Breukelen, in press; De Jonge, Janssen \& Landeweerd, 1994; De Jonge, Landeweerd \& Van Breukelen, 1994; De Jonge, Schaufeli \& Furda, 1995). For example, both the postulated two-factor and the one-factor structure had been confirmed in a heterogeneous group as well as three homogeneous, subgroups. Additionally, coefficient alphas ranging from .75 to 86 , and test-retest reliability coefficients ranging from .58 to .66 have been found for both kinds of factor structures (8-month time interval). Finally, construct validity of the MAQ had been successfully tested using several theoretical models (i.e., the Job Demand-Control Model, the Demand-Control-Support Model, and the Vitamin Model). For instance, job autonomy was positively related to work motivation and job satisfaction, and curvilinearly associated with emotional exhaustion (burnout).

\section{JOB DEMANDS}

Job demands can be defined as psychological stressors that are present in the work environment (Karasek, 1979). They can be described as either task requirements or task goals within a job. The job demands construct also includes workload, with task complexity or difficulty being referred to as qualitative workload, and the number of requirements within limited time space being referred to as quantitative workload (cf. Muntaner \& O'Campo, 1993; Warr, 1987). 
In this study, job demands were measured by an 8-item questionnaire with a 5-point response scale ranging from 1 "never" to 5 "always". The scale was developed by De Jonge, Landeweerd and Nijhuis (1993), and consists of a relatively wide range of both quantitative and qualitative demanding aspects, like working under pressure of time, working hard, strenuous work, and task complexity'. Results of a pilot study indicated a clear one-factor structure, and reported a coefficient alpha of .90 and a test-retest reliability of .48 (8-month time interval; De Jonge, Landeweerd \& Nijhuis, 1993; Vermaat, 1994).

\section{WORKPLACE SOCIAL SUPPORT}

Social support has been defined by Kahn and Antonucci (1980) as interpersonal transactions including one or more of the following aspects:

1) affect (e.g., expressions of love, respect or liking):

2) affirmation (expressions of agreement with or acknowledgement of the appropriateness of some act of another person);

3) aid (direct aid or assistance, including money, information, advice or things).

Consequently, social support at work refers to overall levels of social transactions available on the job from both supervisors and colleagues (cf. Karasek \& Theorell, 1990).

Workplace social support measures may be divided into three general categories: (1) network measures; (2) actually received support; and (3) perceived available support (Sarason \& Sarason, 1994). Our measure of workplace social support can be classed under the third category; that is, perceived available support. Perceived available support can be seen as a relatively stable characteristic that develops as a function of both earlier and present-day relationships. A number of studies have concluded that it is the perceived aspect of social support, rather than support actually received, that increases positive outcomes and diminishes negative outcomes (cf. Cohen \& Wills, 1985; Sarason \& Sarason, 1994). Accordingly, workplace social support has been measured by means of two 5 -item scales': (1) perceived social support from the senior nursing officer; and (2) perceived social support from colleagues. The scales were derived from a Dutch questionnaire on organizational stress ("Vragenlijst Organisatie Stress-Doetinchem" - VOS-D; Bergers, Marcelissen \& De Wolff, 1986). The items were scored on a 4-point response scale format, ranging from 1 "never" to 4 "always". A pilot study among about 250 health care professionals showed an obvious two-factor structure, with coefficient alphas of .92 and .76, respectively (De Jonge, Landeweerd \& Nijhuis, 1993). However, a one-factor structure seemed to be possible too (i.e., all ten items). The 10-item one-factor structure revealed a coefficient alpha of .82 and a test-retest reliability coefficient of 64 (8-month time interval; De Jonge, Janssen \& Landeweerd, 1994; Vermaat, 1994)

\subsubsection{Psychological outcomes}

\section{WORK MOTIVATION}

An individual's motivation for a specific task or job is determined by the work environment, personal characteristics, and their interrelationship (Kanfer, 1992; Thierry, 1990). In this study, work motivation will be considered as the extent to which the work drives the behavioural actions of the worker, resulting in, for instance, feelings of challenge, 
stimulation, interest and creativity (De Jonge, Landeweerd \& Nighuis, 1993; Thierry, 1990). It has become clearly established that these kinds of feelings can be important rewards themselves (cf. Lawler, 1980).

Work motivation was measured by five items in which the respondents were asked how stimulating, interesting and challenging their work is' (De Jonge, Landeweerd \& Nijhuis, 1993). The questions were answered on a 5 -point scale with a response scale ranging from 1 "strongly disagree" to 5 "fully agree". The pilot study which was mentioned above reported a coefficient alpha of .89 . The same study revealed a relatively low stability of the scale; the test-retest coefficient was .39 (8-month time interval).

\section{Job SATISFACTION (GENERAL MEASURE)}

The distinction between work motivation and job satisfaction is that the former refers to the energizing or directing of effort toward the attainment of outcomes (cf. Schneider, 1985), while the latter can be considered the sum of evaluations of the job elements (Locke, 1969). Although Locke's conceptualization has been an accepted description for the content of many job satisfaction instruments, a more specific and precise definition was presented by Bullock (1952, p. 7): 'Job satisfaction is considered to be an attitude which results from a balancing and summation of many specific likes and dislikes experienced in connection with the job. This attitude manifests itself in evaluation of the job and of the employing organization'. It appears that job satisfaction can be considered as a unidimensional and general construct, resulting from positive and negative work experiences.

In the present study, job satisfaction was assessed by one item: "I am satisfied with my present job". The question was answered on a 5-point scale, ranging from 1 "strongly disagree" to 5 "fully agree". Several researchers have shown that a global rating of overall job satisfaction is an inclusive measure of general job satisfaction (e.g., Scarpello \& Campbell, 1983; Weaver, 1980). Vermaat (1994) showed a test-retest reliability for this item of .52 (8-month time interval)

\section{EMOTIONAL EXHAUSTION (OCCUPATIONAL BURNOUT)}

The burnout concept was introduced by the psychiatrist Freudenberger in 1974 to symbolize a particular state of emotional exhaustion. According to Maslach and Jackson (1986, p. 1), burnout can be defined as '... a syndrome of emotional exhaustion, depersonalization and reduced personal accomplishment that can occur among individuals who do "people work" of some kind". Of the three dimensions of burnout, emotional exhaustion is closest to more traditional strain variables (Shirom, 1989). Similarly, Koeske and Koeske (1989) as well as Maslach and Jackson (1986) consider emotional exhaustion as the essence of occupational burnout.

Emotional exhaustion refers to feelings of being totally empty like a rundown battery. In other words, there are no emotional resources left. Emotional exhaustion has predominated much of the burnout research (Maslach, 1993).

We measured emotional exhaustion by means of the Dutch version of the Maslach Burnout Inventory (MBI): the MBI-NL (Schaufeli \& Van Dierendonck, 1993, 1994). The MBI-NL is particularly suitable for use in human services professions like nursing. In its original form, 
the scale consists of nine items, scored on a 7-point scale' (ranging from 0 "never" to 6 "always"). Because of insufficient factorial validity in earlier studies, the original item 16 ('Working with people directly puts too much stress on me') was eliminated in the Dutch version of the MBI (cf. Byrne, 1991; Schaufeli \& Van Dierendonck, 1993). The emotional exhaustion scale showed the best psychometric qualities of all subscales of both the $\mathrm{MB} \mid$ and the MBI-NL (cf. Schaufeli \& Van Dierendonck, 1993, 1994; Schaufeli, Enzmann \& Girault, 1993). Schaufeli and Van Dierendonck (1994), for instance, reported a coefficient alpha for the 8 -item scale of .87 . The test-retest reliability with a 1-month time interval was 77. Additionally, De Jonge, Schaufeli and Furda (1995) reported an alpha of .86 for the 8item scale in their study among about 250 health care workers

\section{JOB-RELATED ANXIETY}

Anxiety can be defined as a transitory emotional state with feelings of anxiety to match. As Bannister and Fransella (1980) pointed out, 'we become anxious when we can only partially construe the events which we encounter, and too many of their implications are obscure', it is the unknown aspects of those (job-related) things that give them their potency. Job-related anxiety may caused by the realization that existing resources are not adequate for coping with job demands (cf. Hingley \& Cooper, 1986).

Job-related anxiety was measured by means of a scale of the Dutch Organizational Stress Questionnaire ("Vragenlijst Organisatie Stress" - VOS; Reiche \& Van Dijkhuizen, 1979), asking respondents how they generally felt at work. The scale consists of four items with a response scale ranging from 1 "never" to 4 "always". The items reflect feelings of anxiety, nervousness, tenseness, and restlessness, respectively'. The factorial validity of the scale was proven in the study by De Jonge, Landeweerd and Nijhuis (1993) mentioned above. They reported a coefficient alpha of 68 . Added to this, Vermaat (1994) found a test-retest reliability of 34 (8-month time interval).

\subsubsection{Demographic characteristics}

Demographic characteristics refer to background factors such as gender, age, social class and education (Furnham, 1992). These characteristics are primarily related to the life career of employees, and may be relevant to job-related human behaviour (Roe, 1984).

Since gender and age may confound the results (see chapter 3 ), both variables are involved in the analyses described in chapters 6 and 7.

\subsection{Data analysis}

\subsubsection{Introduction}

Two kinds of statistical analyses were performed in order to investigate the psychometric properties of the measurement instruments: (1) factor analysis; and (2) reliability analysis. Another method for assessing model stability across different samples involves crossvalidation, which merits separate attention. We shall discuss these analyses below. 


\subsubsection{Factor analysis}

Factor analysis is a multivariable method intended to reduce observed measured variables ( $x$ or $y$ ) into a few underlying latent factors ( $\xi$ or $\eta)^{2}$. How these latent factors are measured in terms of the observed variables is specified in a measurement model (Jöreskog \& Sörbom, 1989)

There are many forms of factor analysis. One basic distinction is that between exploratory and confirmatory factor analysis (cf. Bernstein, Garbin \& Teng, 1988; Byrne, 1989; Jöreskog \& Sörbom, 1993a). In exploratory factor analysis (EFA), the aim is to explore the empirical data and to satisfy some mathematical criteria. Perhaps the most distinctive feature of EFA is that a detailed measurement model is not specified in advance. In confirmatory factor analysis (CFA), on the other hand, the measurement model is based on a priori information about the data structure. Here, the goal is to satisfy some substantive criteria based on knowledge from previous studies. It should be noted, however, that CFA can also be used in an exploratory fashion (see section 5.4). Because of the centrality of CFA in the present study, we will discuss the general CFA model here.

The measurement or factor equation for the variables (e.g., $x_{1}$ ) within CFA is given as equation 5.1.

$x_{i}=\lambda_{i 1} \xi_{1}+\lambda_{12} \xi_{2}+\ldots+\lambda_{i n} \xi_{n}+\delta_{i}$

The factor loadings, or in our terms the $\lambda$ coefficients, reflect the direct 'effects' of the latent factors on the observed variables. The term $\delta_{i}$ is often called the unique factor or measurement error in $x_{i}$, and is assumed to be uncorrelated with the latent factor(s).

In order to estimate and evaluate factor analytic models the LISREL approach will be employed. LISREL stands for Linear Structural RELations and, strictly speaking, is a computer programme for covariance structure analysis. However, these covariance structure models are more commonly known as LISREL models. In this investigation, we used the LISREL programme ${ }^{3}$ version $8.12 \mathrm{a}$ and the companion programme PRELIS, version $2.12 \mathrm{a}$ (Jöreskog \& Sörbom, 1993a, 1993b, 1993c).

Relations among the observed variables $x$ (or $y$ ) produce a sample variance-covariance matrix, symbolized $\mathrm{S}$. This matrix provides the basic data to estimate $\lambda$. The intercorrelations of the latent factors $\xi$ are contained in a matrix denoted $\Phi$. Finally, the error variances and covariances are contained in a matrix denoted $\Theta_{\delta}$ (or $\Theta_{\varepsilon}$ in case of an y-model).

Before estimation of the parameters can proceed, however, it is necessary to determine whether a unique solution exists for each parameter in the matrices. This is called the problem of identification ( $d$. Hayduk, 1987; Scott Long, 1983a). If any measurement model is not identified, it is impossible to identify, locate or determine unique estimates of the coefficients.

Once a structural equation model is identified, the parameters of the model can be estimated (cf. Diamantopoulos, 1994; Hayduk, 1987). LISREL is able to obtain several kinds of parameter estimates. In this case, Full Information Maximum Likelihood (FIML) estimation 
was used. FIML estimation assumes that all variables are multinormally distributed (Cf. Hayduk, 1987). The FIML estimation, however, is rather robust against nonnormally distributed variables (cf. Bollen, 1989; Boomsma, 1987).

Bollen and Scott Long (1993) recommend a mixture of fit indices in order to determine the overall fit of the model. In other words, one should not rely only on one single fit index. In accordance with the classification of proposed fit indices (Jöreskog, 1993) we tested the fit of the model by examining the chi-square statistic (Chi-2, or $\left.\chi^{2}\right)$, the LISREL adjusted goodness-of-fit index (AGFI), the non-normed fit index (NNFI; Bentler \& Bonett, 1980), and finally the root-mean-square error of approximation (RMSEA; Browne \& Cudeck, 1993; Steiger, 1990). We will briefly discuss these indices.

The chi-square statistic is a measure of overall fit of the model to the data. It tests the null hypothesis that the observed covariance matrix fits the hypothesized model, apart from sampling error. The chi-square statistic should more accurately be termed a "badness-of-fit index" (Jöreskog, 1993). A small chi-square corresponds to good fit and a large chi-square to bad fit; zero chi-square corresponds to a perfect fit.

The goodness-of-fit index adjusted for degrees of freedom (AGFI) is an overall measure of fit which takes into account the number of degrees of freedom. This fit statistic estimates the extent to which the sample variances and covariances fit the hypothesized model, while taking the parsimony of the model into account (Bollen \& Scott Long, 1993). Models with a larger number of unknown parameters are penalized by a lower AGFI. The value of this measure varies from zero to one, in which zero indicates a bad fit and one a good fit. A rule of thumb for evaluating the AGFI is to be concerned with values greater than or equal to 85 (Verschuren, 1991). Values around .95 indicate a good fit. However, the major disadvantage of the AGFI and particularly the chi-square statistic is that their value depends on sample size (cf. Anderson \& Gerbing. 1984; Marsh, Balla \& McDonald, 1988). Even minor deviation between sample and hypothesized population values can lead to statistically significant chi-square values (Hayduk, 1987).

As a result, additional fit indices that are not as sensitive in large samples have been proposed. Therefore, we computed also an alternative fit statistic: the non-normed fit index (NNFI). The NNFI, also known as the Tucker-Lewis index, can be called an incremental fit index. The NNFI has the advantage that it is hardly affected by sample size (e.g., Marsh, Balla \& McDonald, 1988). The NNFI measures how much better the model fits than an independent model, a so-called null model $\left(M_{0}\right)$ that assumes zero relationships between the variables ( $\Sigma$ is diagonal). Bentler (1990) argued that the value of the NNFI should be greater than .90 . Models with a poorer fit can usually be improved substantially.

Finally, Browne and Cudeck (1993) recommend that Steiger's (1990) root-mean-square error of approximation (RMSEA) can be used as a measure of the discrepancy per degree of freedom for the model. The RMSEA can give quite useful information for the assessment of the degree of approximation in the population, and has the potential to reward more parsimonious models. A value smaller than or equal to .05 indicates a close fit of the model in relation to the degrees of freedom. A value greater than .10 would suggest that the model should be discarded (cf. Browne \& Cudeck, 1993). 
We use the phrase "statistical fit index" to refer to the chi-square statistic, and the expression "practical fit indices" to refer to the AGFI, NNFI, and RMSEA, respectively. The former is based on a particular statistical distribution. whereas the latter are not test statistics in the usual sense, but heuristic indicators of how well a model performs (cf Cuttance, 1987).

\section{Cross-validation}

A generally accepted method for assessing model reliability or stability is that of crossvalidation (cf. Cudeck \& Browne, 1983; Kleinbaum, Kupper \& Muller, 1988). That is, how well will a solution, obtained by fitting a model to a given sample, fit an independent sample from the same population?

Cross-validation usually begins by randomly splitting the sample in half and forming two subsamples: (1) the calibration sample; and (2) the validation sample. A model is fitted to the calibration sample and the model estimates of the population are obtained. The next step does not involve estimation of a new model, but calculates a fit function $F$ using the validation sample when the model estimates are read in as fixed values. This fitting function, also called the two-sample cross-validation index (CVI), is a measure of the discrepancy between the fitted model estimates in the analysed sample and the covariance matrix of the other sample (cf. Browne \& Cudeck, 1993).

Optionally, this procedure can be repeated by reversing the roles of the two subsamples. That is, the second subsample becomes the calibration sample, and the first subsample the validation sample. This double cross-validation procedure yields a second set of CVis. If the same model yields the lowest CVI in each of the two sets, then this may be regarded as the most stable model (Cudeck \& Browne, 1983).

The CVI is not a conventional measure of model fit. It provides an estimate of overall discrepancy. Therefore, it is important to understand what factors contribute to that discrepancy. MacCallum and Tucker (1991) showed that, when considering the factor model after removing that portion of each variable that is not consistent with the mode!, the values of factor loadings were not influenced directly by sampling. This means that factor loadings will have the same values across different samples. However, (co)variances of latent factors and of unique factors appeared to vary from sample to sample. These findings are relevant to the issue of alternative strategies for cross-validation (cf. MacCallum, Roznowski, Mar \& Reith, 1994). When carrying out two-sample crossvalidation, a reasonable strategy would be to fit the estimated model to the validation sample with all factor loadings being constrained (i.e., set to the estimated values obtained in the calibration sample) and all other parameters allowed to be re-estimated. This partial cross-validation procedure, which is called the "fixed-loadings strategy", appears to be as theoretically sound as the conventional strategy.

\subsubsection{Reliability analysis}

Reliability is a major criterion for assessing quality and adequacy of an instrument. Essentially, reliability can be defined as the consistency of measurement (e.g., Bollen, 1989; Dooley, 1984; Polit \& Hungler, 1987). Reliability is that part of a measurement instrument 
that is free of purely random error. The particular estimate of reliability that one may use depends on the particular error-producing factors that one seeks to identify (Cronbach. Gleser, Nanda \& Rajaratnam, 1972). For example, if error factors associated with the use of different items are of interest, then internal consistency estimates may be used. If error terms associated with the passing of time are of interest, then test-retest methods may be used (Cortina, 1993).

In the rase of this study, two reliability measurement methods have been used, namely (1) coefficient alpha, or $\alpha$ (Cronbach, 1951), and (2) test-retest methods (Polit \& Hungler, 1987; Stommel, Wang, Given \& Given, 1992).

According to Cortina (1993), coefficient alpha is a lower bound of reliability and is a function of the extent to which items in a test have high communalities and thus low uniqueness (in other words, a function of interrelatedness of items).

A difficulty with the use of coefficient alpha is that there seems to be no real metric for an adequate level of internal consistency. The reason for this is that coefficient alpha is affected by, for example, the number of items, the item intercorrelations, and the scale dimensionality. Cortina (1993) stated that in a unidimensional scale with at least three items an average item intercorrelation of .50 yields alphas that are acceptable by convention (i.e., greater than .75 ), regardless of test length. However, most recent studies that have used coefficient alpha imply that alphas of .70 or better will be adequate (see also Nunnally. 1978; Polit \& Hungler, 1987).

In the light of our panel design, two test-retest methods can be employed here. The first test-retest method is a test of factorial invariance. The question is whether the factorial properties of a measurement instrument are the same over time. If the factor model holds over time, change scores will reflect changes in the tasks or subjects rather than changes in the internal composition of the scale (cf. Stommel, Wang, Given \& Given, 1992). Different nested" factor models across groups and/or time can be compared with a likelihood ratio test (cf. Bentler \& Bonett, 1980; Jöreskog \& Sörbom, 1993a). The difference between nested models has itself a chi-square distribution with degrees of freedom equal to the corresponding difference in the degrees of freedom of the separate models. Critical values of the chi-square distribution are taken as evidence that additional constraints (e.g., equal factor loadings) would be preferred or not.

The second test-retest method is referred to as "test-retest reliability". The same measurement instrument is administered to the same subjects at two points in time. The reliability coefficient for test-retest estimates is approximately the correlation coefficient between the two sets of scores. A problem of this test-retest approach is that many variables of interest (like job characteristics, attitudes and moods) do change over time, independently of the test-retest reliability of the measure. On the whole, test-retest coefficients tend to be higher for short-term retests than for long-term retests (i.e., longer than six months). The reason for this is that the true score may change over time. Hence, perfect stability of the true score (i.e., 1.00) is hardly possible.

As a general rule of thumb, test-retest reliabilities above .50 are considered moderate. Values above .70 are considered satisfactory (cf. Bollen, 1989; Polit \& Hungler, 1987). 


\section{$5.4 \quad$ Results}

\subsubsection{Introduction}

The results are described in two subsections. First, the cross-sectional results of the psychometric analyses will be discussed in subsection 5.4.2. Second, the corresponding longitudinal results of these analyses will be presented (5.4.3). All measurement instruments have passed through earlier stages of scale construction (see section 5.2). This is the reason why we mainly rely on confirmatory analysis rather than exploratory analysis.

Finally, it should be mentioned that all analyses have been based on cases with valid observations. In other words, missing observations were handled by listwise deletion, assuming there is a global missing value code for all items.

\subsubsection{Cross-sectional results}

First of all, univariate normality of the items was considered with as criteria the approximate range from -1.00 to 1.00 for both skewness and kurtosis (cf. Byrne, 1991; Muthén \& Kaplan, 1985). Univariate skewness ranged from -1.05 to 1.15 , and univariate kurtosis ranged from -.95 to 1.69 . Given univariate skewness and kurtosis values within the range mentioned above, most items were considered to approximate a normal distribution ${ }^{5}$. Multicategory items, like Likert scales, can spuriously influence factor analytic results (cf. Bernstein, Garbin \& Teng, 1989; Bernstein \& Teng, 1989). For example, extreme differential categorization can produce false evidence for multidimensionality. Items were therefore checked for extreme item response distributions (i.e., more than 70 per cent of the respondents score in the lowest or upper response category). In general, the results showed that less than 56 per cent of the respondents scored in one of the extreme response scale categories. Given these non-extreme item distributions, no problems were expected with regard to the performing (factor) analyses.

Tables 5.2 to 5.7 show the cross-sectional results of the CFA. Covariance matrices were used in order to analyse the CFA models. All the CFA models hypothesized that:

1) responses to the measurement instruments could be explained by one or two latent factors ( $\xi$ or $\eta$ ) per instrument;

2) each of the observed variables ( $x$ or $y$ ) loads on only one latent factor;

3) the latent factors are standardized (i.e., a variance of one);

4) latent factors are allowed to be correlated (i.e., an oblique model);

5) the error terms ( $\delta$ or $\varepsilon$ ) are initially uncorrelated (i.e., the basic models $M_{1}$ or $M_{2}$ in the tables)

The results of the CFA with respect to job autonomy are reported in table 5.2. Two a priori models are specified: a general job autonomy one-factor model $M_{1}$ (ten items), and a model $\mathrm{M}_{2}$ with two specific latent factors (i.e., contextual autonomy and content autonomy). These models are compared with the most restrictive model: the null model, or $M_{0}$, which was mentioned above. The fit indices of the models are shown for the calibration sample as well as the validation sample. 
Table 5.2 Comparison of job autonomy factorial models (calibration sample and validation sample)

\begin{tabular}{|c|c|c|c|c|c|c|}
\hline Model & Chi-2\# & $d f$ & AGFI & RMSEA & NNFI & $\mathrm{CV}]$ \\
\hline \multicolumn{7}{|c|}{ Calibration sample $(n=665)$} \\
\hline Null model $\left(\mathrm{M}_{0}\right)$ & $1639.04 * * *$ & 45 & .42 & .23 & & 2.68 \\
\hline One-factor $\left(M_{1}\right)$ & $334.02^{\star * \star}$ & 35 & .83 & .12 & .76 & .42 \\
\hline$M_{1}$-respecified & $144.68^{* * *}$ & 31 & .92 & .08 & .90 & .26 \\
\hline Two-factor $\left(\mathrm{M}_{2}\right)$ & $175.81^{\star \star *}$ & 34 & .91 & .08 & .88 & .23 \\
\hline $\mathrm{M}_{2}$-respecified & $92.34^{* * *}$ & 33 & .95 & .05 & .95 & .18 \\
\hline \multicolumn{7}{|c|}{ Validation sample $(n=667)$} \\
\hline Null model $\left(\mathrm{M}_{0}\right)$ & $1708.25^{\star \star \star}$ & 45 & .40 & .24 & & 2.59 \\
\hline One-factor $\left(M_{1}\right)$ & $263.99 * \star *$ & 35 & .87 & .10 & .82 & .53 \\
\hline$M_{1}$-respecified & $134.29 * \star \star$ & 31 & .92 & .07 & .91 & .25 \\
\hline Two-factor $\left(\mathrm{M}_{2}\right)$ & $136.98 * * *$ & 34 & .93 & .07 & .92 & .29 \\
\hline$M_{2}$-respecified & $97.80^{\star \star \star}$ & 33 & .95 & .06 & .95 & .17 \\
\hline
\end{tabular}

${ }^{*} p \leq .05^{\star *} p \leq .01 * \star * p \leq .001$

\# for a list of abbreviations used, see appendix 1

As shown in table 5.2, the fit of the models is poor from a statistical perspective: all chi-square statistics are highly significant. However, the $\chi^{2}$ is proportional to the sample size, and small model specification errors may therefore yield large $\chi^{2}$-values if $n$ is large. The practical fit indices indicate a reasonable fit for the basic models $M_{1}$ and $M_{2}$. Some values of the NNFIs are smaller than .90 , indicating that the models may be improved. As described earlier, CFA can also be used in an exploratory way. To facilitate improvement of model fit, LISREL provides for each fixed parameter what is called a "Modification Index" (MI), that shows how much the model fit will improve if a parameter which was fixed to a specific value a priori (e.g. zero) is set free and is estimated from the data. According to Hayduk (1987), these model modifications should be nine-tenths theory driven and only one-tenth data driven. The process of respecification based upon the Mls can be repeated until the model fit is acceptable. A closer inspection of the Mls showed significantly correlated error terms. In other words, a unique factor affecting one observed variable is related with a unique factor affecting some other observed variable (see also Scott Long, 1983a). Such correlated errors can be substantially meaningful in reflecting small group factors or item similarity (cf. Byrne, 1989; Gerbing \& Anderson, 1984). Stepwise relaxing the corresponding parameters $\left(\Theta_{\delta} \mathrm{s}\right)$ led to respecified models and improved model fit. The model modifications followed a consistent modification pattern in both subsamples, and are theoretically defensible. For instance, there might be a close relationship between the opportunity to pause in your work (item 6) and the opportunity to leave the workplace (item 2).

Both models $\mathrm{M}_{2}$-respecified indicate an acceptable fit. Finally, the calculated CVIs show that model $\mathrm{M}_{2}$-respecified of the validation sample is the most stable model in the case of a twofactor solution.

Figure 5.1 shows the factor solution of the CFA model of the validation sample; all factor loadings were significant ( $p \leq .05$ ). 
It should be noted that both observed and latent variables are standardized in the figure (i.e., a completely standardized solution). The $\Phi$-matrix shows an estimated correlation of .71 between the two latent factors. This means that a general latent factor "job autonomy" needs to be considered as well. In the case of a one-factor solution, moclel $\mathrm{M}_{1}$-respecified of the validation sample is most robust and indicates a reasonable fit. Figure 5.2 shows the corresponding factor solution. Again, all factor loadings were significant ( $p \leq 05$ ). In addition to this, several significantly correlated error terms are shown in the figure.

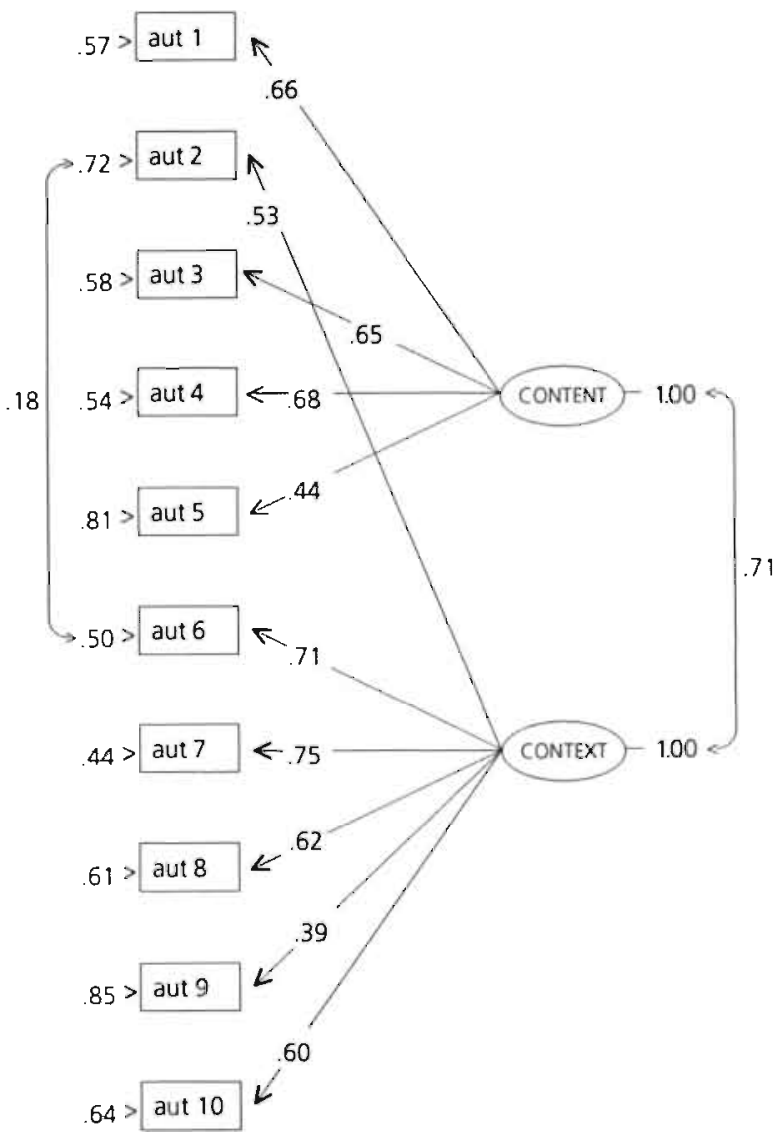

Figure 5.1 Two-factor solution of job autonomy CFA model (completely standardized solution; validation sample) 


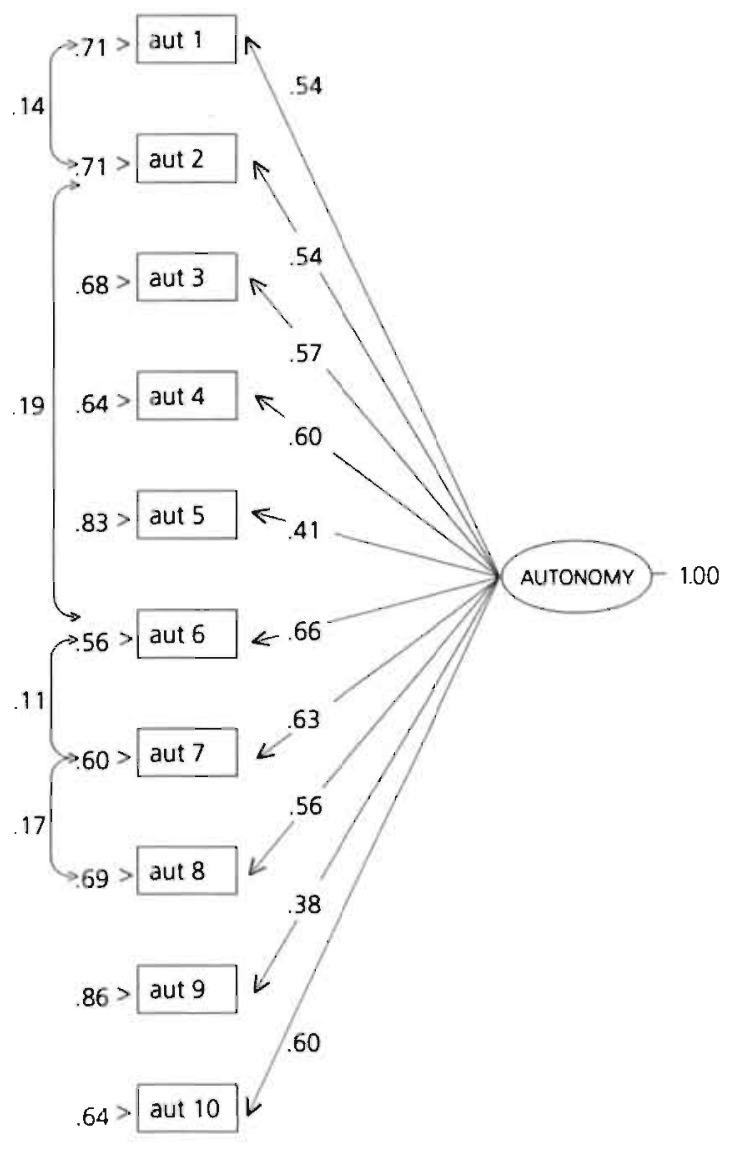

Figure 5.2 One-factor solution of job autonomy CFA model (completely standardized solution; validation sample)

Table 5.3 presents the findings of the CFA with respect to job demands (eight items; one-factor structure). Again, most chi-square statistics are highly significant, indicating a poor model fit. The other fit indices, however, report a reasonable model fit for the basic models $\left(M_{1}\right)$. Following the Mls, two error parameters were relaxed in both subsamples, yielding a relatively good fit for the respecified models. These Mis are theoretically reasonable. For instance, the items 7 and 8 reflect qualitative demands. Cross-validation shows that the respecified model $M_{1}$ in the calibration sample is the most robust model. Figure 5.3 shows the corresponding one-factor solution. 
Table 5.3 Comparison of job demands factorial models (calibration sample and validation sample)

\begin{tabular}{|c|c|c|c|c|c|c|}
\hline Model & Chi-2 & $d f$ & AGFI & RMSEA & NNFI & $\mathrm{CVI}$ \\
\hline \multicolumn{7}{|c|}{ Calibration sample $(n=665)$} \\
\hline Null model $\left(\mathrm{M}_{0}\right)$ & $2491.59 * * *$ & 28 & .21 & .37 & & 3.81 \\
\hline One-factor $\left(M_{1}\right)$ & $166.82^{\star \star \star}$ & 20 & .89 & .11 & .92 & .29 \\
\hline$M$, -respecified & $69.34^{* * *}$ & 18 & .95 & .07 & .97 & .15 \\
\hline \multicolumn{7}{|c|}{ Validation sample $(n=667)$} \\
\hline Null model $\left(M_{0}\right)$ & $2421.05^{\star \star \star}$ & 28 & .22 & .37 & & 3.86 \\
\hline One-factor $\left(M_{1}\right)$ & $165.26^{\star \star \star}$ & 20 & .89 & .11 & .92 & .28 \\
\hline$M_{1}$-respecified & $64.30^{\star \star}$ & 18 & .95 & .06 & .97 & .19 \\
\hline
\end{tabular}

* $p \leq 05^{* \star} p \leq .01 * * * p \leq .001$

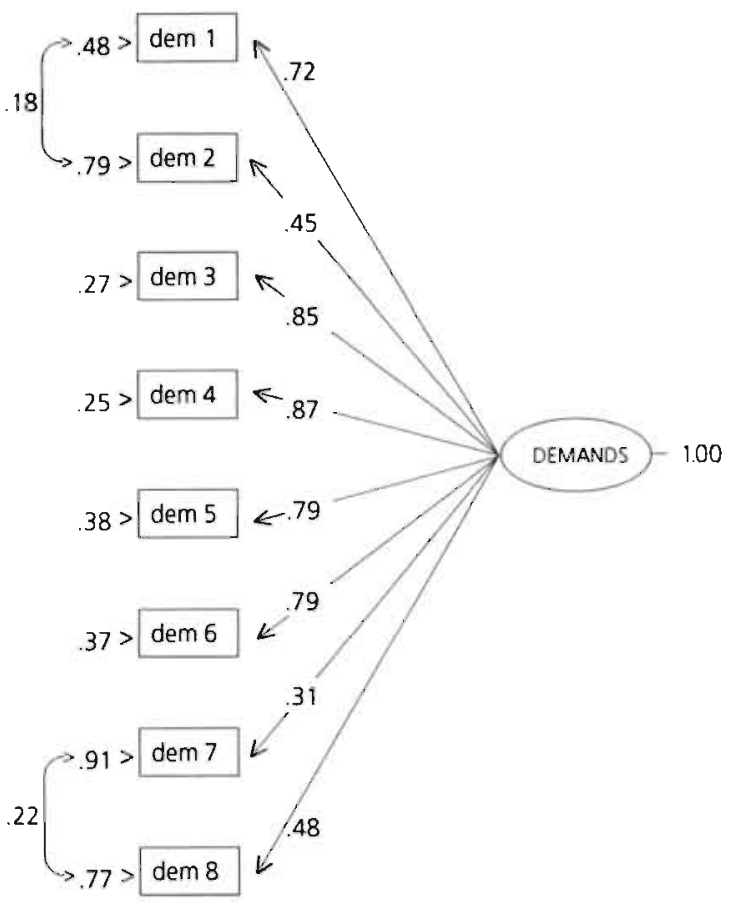

Figure 5.3 Factor solution of job demands CFA model (completely standardized solution; calibration sample)

The results of the CFA regarding workplace social support (ten items; two factors) are reported in table 5.4, in which the fit indices of the models are shown for both the calibration sample and the validation sample. Again, all chi-square statistics are highly significant, which means a poor absolute fit. The practical fit indices show in the first instance a bad fit as well. According to the small NNFIs $(<.90)$ and the Mls, the models are capable of improvement. Relaxing the same five error covariances in both subsamples 
clearly indicate an acceptable model fit. Not surprisingly, these error covariances reflect method effects due to the item resemblance associated with the two subscales. The double cross-validation procedure showed that model $\mathrm{M}_{2}$-respecified of the calibration sample is the most stable model. The factor solution of this model is shown in figure 5.4. The signs of the loadings are all in the expected direction. Note that the $\Phi$-matrix reports an intercorrelation of 32 between the two factors. This intercorrelation is possibly attributable to an underlying general support construct, which will be discussed theoretically as well as methodologically in the next chapter.

Table 5.4 Comparison of social support factorial models (calibration sample and validation sample)

\begin{tabular}{lcccccc}
\hline Model & Chi-2 & df & AGFI & RMSEA & NNFI & CVI \\
\hline Calibration sample $(n=665)$ & & & & & & \\
\hline Null model $\left(M_{0}\right)$ & $2451.96^{\star \star \star}$ & 45 & .41 & .29 & & 3.52 \\
Two-factor $\left(M_{2}\right)$ & $654.04^{\star \star \star}$ & 34 & .75 & .17 & .66 & 1.89 \\
$M_{2}$-respecified & $108.11^{\star \star \star}$ & 29 & .94 & .07 & .95 & .16 \\
\hline Validation sample $(n=667)$ & & & & & & \\
\hline Null model $\left(M_{0}\right)$ & $2266.84^{\star \star \star}$ & 45 & .43 & .27 & & 3.80 \\
Two-factor $\left(M_{2}\right)$ & $590.92^{\star \star \star}$ & 34 & .77 & .16 & .67 & 1.99 \\
$M_{2}$-respecified & $73.91^{\star \star \star}$ & 29 & .96 & .05 & .97 & .22 \\
\hline
\end{tabular}

${ }^{*} p \leq .05^{* *} p \leq .01 * * * p \leq .001$

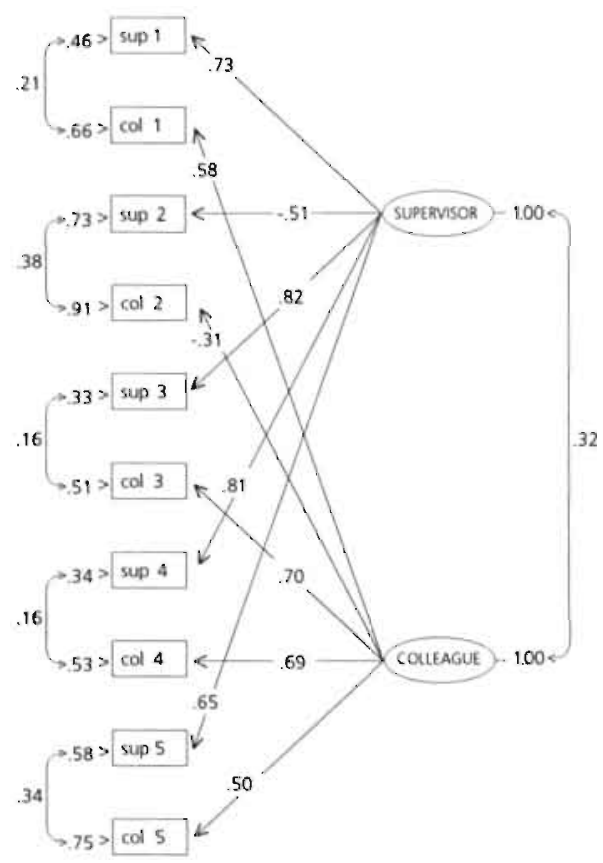

Figure 5.4 Factor solution of social support CFA model (completely standardized solution; calibration sample) 
Next, the CFA model fit of work motivation (five items; one-factor structure) is examined, as shown in table 5.5. Firstly, the chi-square statistics show a poor model fit, as was the case with the earlier instruments. Secondly, however, the AGFls, the RMSEAs, and the NNFIs show a good fit. Inspection of the Mls revealed that no further model improvements could be made. Finally, the CVIs show that $M_{1}$ of the validation sample is the most robust model. The corresponding factor solution is presented in figure 5.5 .

Table 5.5 Comparison of work motivation factorial models (calibration sample and validation sample)

\begin{tabular}{lcrrrrr}
\hline Model & Chi-2 & df & AGFI & RMSEA & NNFI & CVI \\
\hline Calibration sample $(\mathrm{n}=665)$ & & & & & & \\
\hline Null model $\left(\mathrm{M}_{0}\right)$ & $1435.12^{\star \star \star}$ & 10 & .16 & .46 & & 2.11 \\
One-factor $\left(\mathrm{M}_{1}\right)$ & $17.81^{\star *}$ & 5 & .97 & .06 & .98 & .05 \\
\hline Validation sample $(\mathrm{n}=667)$ & & & & & & \\
\hline Null model $\left(\mathrm{M}_{0}\right)$ & $1389.37^{\star \star \star}$ & 10 & .18 & .46 & & 2.17 \\
One-factor $\left(\mathrm{M}_{1}\right)$ & $26.23^{\star \star \star}$ & 5 & .95 & .08 & .97 & .04 \\
\hline
\end{tabular}

${ }^{\star} p \leq .05^{\star \star} p \leq .01^{\star \star \star} p \leq .001$

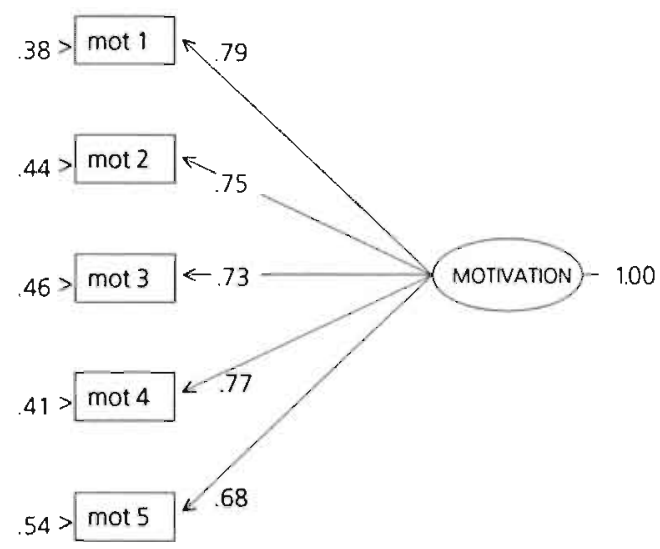

Figure 5.5 Factor solution of work motivation CFA model (completely standardized solution; validation sample)

The outcomes of the CFA regarding the occupational burnout component emotional exhaustion (eight items; one factor) are contained in table 5.6. The statistical tests resulted in significant chi-square statistics, but the other fit indices suggest that the models have an acceptable fit. No further improvements of the models could be made. Model $M_{1}$ of the calibration sample yields the smallest CVI, indicating the most stable model. Figure 5.6 shows the corresponding factor solution of this model. 
Table 5.6 Comparison of emotional exhaustion factorial models (calibration sample and validation sample)

\begin{tabular}{lrrrrrr}
\hline Model & Chi-2 & df & AGFI & RMSEA & NNFI & CVI \\
\hline Calibration sample $(n=665)$ & & & & & & \\
\hline Null model $\left(M_{0}\right)$ & $1894.99^{\star \star \star}$ & 28 & .27 & .32 & & 2.65 \\
One-factor $\left(M_{1}\right)$ & $88.27^{\star \star \star}$ & 20 & .94 & .07 & .95 & .15 \\
\hline Validation sample $(n=667)$ & & & & & & \\
\hline Null model $\left(M_{0}\right)$ & $1720.24^{\star \star \star}$ & 28 & .30 & .30 & & 2.94 \\
One-factor $\left(M_{1}\right)$ & $83.31^{\star \star \star}$ & 20 & .94 & .07 & .95 & .16 \\
\hline
\end{tabular}

${ }^{\star} p \leq .05^{\star \star} p \leq .01{ }^{\star \star \star} p \leq .001$

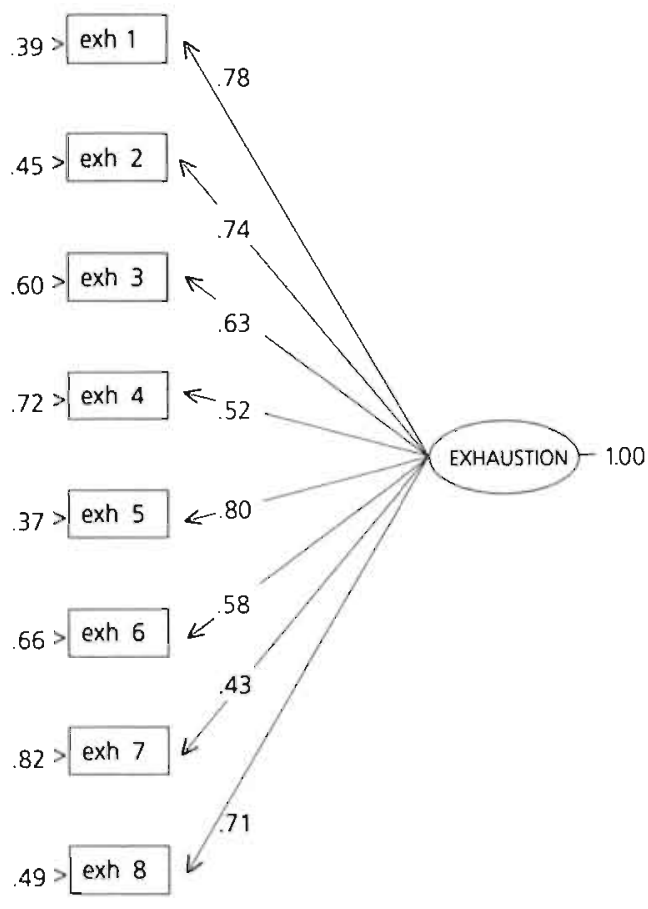

Figure 5.6 Factor solution of emotional exhaustion CFA model (completely standardized solution; calibration sample)

Finally, table 5.7 summarizes the fit indices of the job-related anxiety CFA models (four items, one factor). Once more, all chi-square statistics are highly significant, indicating a bad absolute fit. According to the practical fit indices the fit of the models is reasonable. The MIs suggested no further improvements in model fit. The outcomes of the CVIs imply that Model $\mathrm{M}_{1}$ of the calibration sample is most robust. Its factor solution is presented in figure 5.7 . 
Table 5.7 Comparison of job-related anxiety factorial models (calibration sample and validation sample)

\begin{tabular}{lcccccc}
\hline Model & Chi-2 & df & AGFI & RMSEA & NNFI & CVI \\
\hline Calibration sample $(n=665)$ & & & & & & \\
\hline Null model $\left(M_{0}\right)$ & $811.92^{\star \star \star}$ & 6 & .30 & .45 & & 1.09 \\
One-factor $\left(M_{1}\right)$ & $34.99^{\star \star \star}$ & 2 & .87 & .16 & .88 & .05 \\
\hline Validation sample $(n=667)$ & & & & & & \\
\hline Null model $\left(M_{0}\right)$ & $717.53^{\star \star *}$ & 6 & .36 & .42 & & 1.24 \\
One-factor $\left(M_{1}\right)$ & $28.49^{\star \star *}$ & 2 & .89 & .14 & .89 & .06 \\
\hline
\end{tabular}

* $p \leq 05$ ** $p \leq 01$ *** $p \leq 001$

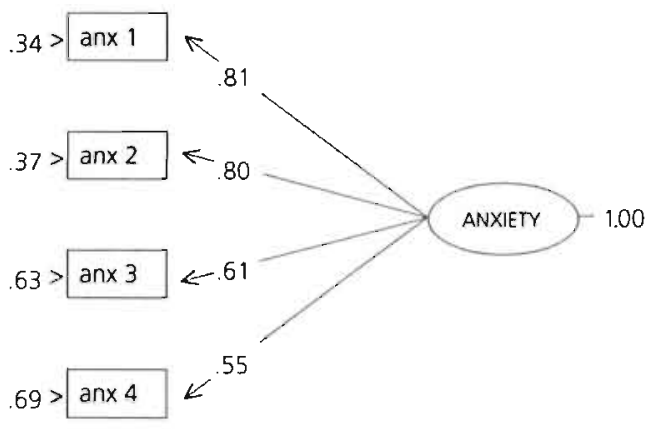

Figure 5.7 Factor solution of job-related anxiety CFA model (completely standardized solution; calibration sample)

An overview of the item intercorrelations and coefficient alphas of the scales is presented in table 5.8. Content autonomy and colleague support show reasonable internal consistencies; all other multiple-item scales yield acceptable internal consistencies. Additionally, both subsamples show similar levels of coefficient alphas, indicating stable internal consistency. Finally, the findings are consistent with results from earlier studies which were mentioned in section 5.2 . 
Table 5.8 Average item-item correlations and coefficient alphas of the measurement scales (calibration sample and validation sample)

\begin{tabular}{|c|c|c|c|c|c|}
\hline \multirow[b]{2}{*}{ Measurement scale } & \multirow[b]{2}{*}{ Nitems } & \multicolumn{2}{|c|}{ Calibration sample $(n=665)$} & \multicolumn{2}{|c|}{ Validation sample $(n=667)$} \\
\hline & & $r_{i}$ & $\alpha$ & $r_{i}$ & $\alpha$ \\
\hline Job Autonomy & 10 & .30 & .81 & .31 & .82 \\
\hline - contextual autonomy & 6 & .35 & .76 & .36 & .78 \\
\hline - content autonomy & 4 & .36 & .71 & 36 & .70 \\
\hline Job Demands & 8 & .45 & .87 & .44 & .86 \\
\hline Supervisor Support & 5 & .49 & .83 & .45 & .81 \\
\hline Colleague Support & 5 & .30 & .69 & 31 & .70 \\
\hline Job Satisfaction & 1 & & & & \\
\hline Work Motivation & 5 & .56 & .86 & .55 & .86 \\
\hline Emotional Exhaustion & 8 & .42 & .85 & .39 & 84 \\
\hline Job-related Anxiety & 4 & .48 & .79 & .44 & .76 \\
\hline
\end{tabular}

Taken together, the results of the cross-sectional analyses show acceptable psychometric properties of all measurement instruments. The hypothesized models are roughly confirmed by the results of CFA. Moreover, the double cross-validation procedure appears to be successful, yielding stable scales. Finally, most multiple-item scales have acceptable internal consistencies, which means that a large portion of the variance in the instruments is attributable to general factors.

\subsubsection{Longitudinal results}

Before we conducted the longitudinal psychometric analyses, univariate normality of the item scores within the panel group $(n=261)$ was investigated. Univariate skewness ranged from -1.08 to .95 , and univariate kurtosis ranged from -1.75 to 1.39 . Given univariate skewness and kurtosis values within the approximate range (i.e., from -1.00 to 1.00 ), the greater part of the items were considered to be approximately normally distributed ${ }^{\mathrm{s}}$.

Similar to the cross-sectional measurement instruments, the panel group items were checked for extreme item response distributions. The results showed that less than 52 per cent of the respondents scored in one of the extreme categories. So, problems of spurious multi-dimensionality were not to be expected.

As discussed before, two test-retest methods were performed: (1) factorial invariance; and (2) test-retest reliability. First, we begin with a discussion of the tests of factorial invariance over time. In general, tests of factorial invariance start with formulating several hypotheses in order to identify the sources of inequality (cf. Byrne, 1989; Byrne, Shavelson \& Muthén, 1989; Jöreskog \& Sörbom, 1989). That is, we will test for the invariance of factor loadings, measurement errors and, when possible, for the invariance of factor correlations. Three or, if necessary, four hypotheses are formulated: 
1) the overall inequality of all factorial components (reflected by model A);

2) the equality of factor loadings across time (reflected by model $B$; that is, $H_{0}: \Lambda_{1}=\Lambda_{2}$, where 1 and 2 are the two measurement points);

3) the equality of error variances across measurement occasions (reflected by model $C$; that is, $\left.\mathrm{H}_{0}: \Theta_{1}=\Theta_{2}\right)$;

4) if applicable (i.e., more than one factor), the equality of factor correlations across time (reflected by model $D$; that is, $H_{0}: \Phi_{1}=\Phi_{2}$ ).

Model $A$ is our basic model, and mirrors a kind of alternative hypothesis $\left(H_{1}\right)$. Covariance matrices which represent items of both measurement points were used in order to analyse the longitudinal CFA models.

Figure 5.8 shows an example of an invariance test of two CFA models across time. Each model contains two factors which in turn reflect four items. A model in which certain parameters are constrained to be equal across time is compared with a less restrictive model in which the same parameters are free to take on any value. For instance, equal factor loadings $\left(H_{0}: \Lambda_{1}=\Lambda_{2} ;\right.$ model $\left.B\right)$ are compared with unequal factor loadings $\left(H_{1}: \Lambda_{1} \neq \Lambda_{2}\right.$; model A). Subsequently, the difference in fit between a model and a less restrictive model is computed. If the difference in chi-square statistic ( $\Delta \mathrm{Chi}-2)$ is not significant, the hypothesis of an invariant pattern is considered tenable.

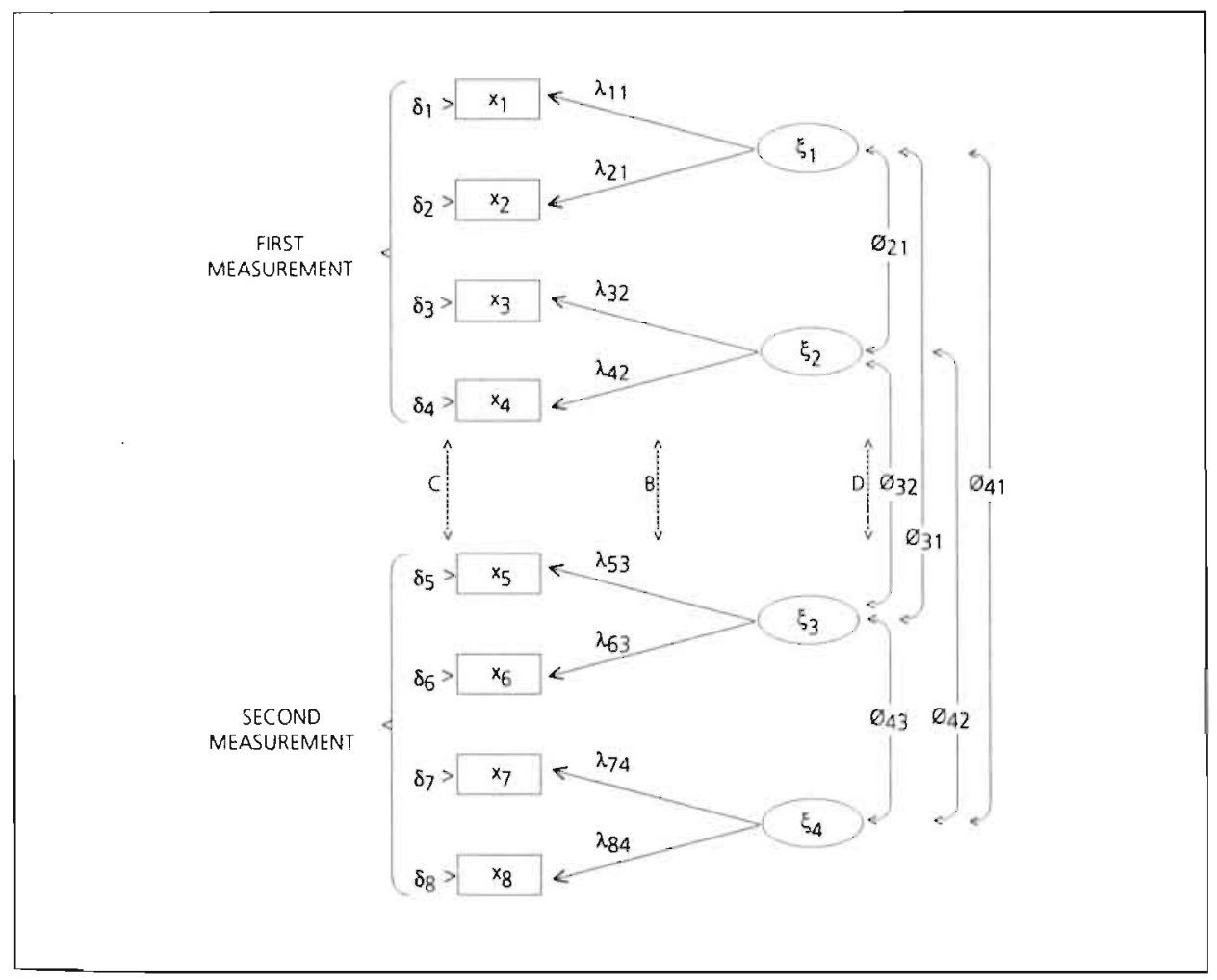

Figure 5.8 An example of a test of factorial invariance over time 
As a first step in the evaluation of the nested models regarding two-factor job autonomy, the overall chi-square statistics are presented (table 5.9). These values indicate highly significant differences between observed and estimated covariance matrices. However, it should be noted that in relatively large samples the chi-square statistic is sensitive to even minor deviations of sample data from the hypothesized model (in this case between the two measurements across time).

The hypothesis of an invariant pattern of factor loadings was tested by. comparing the chisquare values of model $A$ and $B$. The difference in chi-square between these models was not significant. Therefore, the hypothesis of an invariant pattern of factor loadings is tenable. In addition, the invariant pattern of error variances as well as the invariant pattern of factor correlations are defensible on theoretical grounds. Both chi-square differences were not significant (model $A$ versus model $C$, and model $A$ versus model $D$, respectively).

Table 5.9 Simultaneous tests of invariance for job autonomy (two-factor structure; panel group; $n=225$ )

\begin{tabular}{lllrr}
\hline Model & Chi-2 & df & $\Delta C h i-2$ & $\Delta$ df \\
\hline Model A & $512.69^{\star \star \star}$ & 164 & & \\
\hline Model B & $521.72^{\star \star \star}$ & 174 & 9.03 & 10 \\
Model C & $529.16^{\star \star \star}$ & 174 & 16.47 & 10 \\
Model D & $513.14^{\star \star \star}$ & 165 & .45 & 1 \\
\hline
\end{tabular}

${ }^{*} p \leq .05^{* *} p \leq .01 * * * p \leq .001$

Table 5.10 summarizes the tests of factorial invariance with regard to one-factor job autonomy. Similar to the two-factor structure tests, all differences in chi-square were not significant, indicating equality over time of factor loadings and measurement errors, respectively.

Table 5.10 Simultaneous tests of invariance for job autonomy (one-factor structure, panel group; $n=225$ )

\begin{tabular}{|c|c|c|c|c|}
\hline Model & Chi-2 & $d f$ & $\Delta$ Chi-2 & $\Delta d f$ \\
\hline Model A & $601.22 * * *$ & 169 & & \\
\hline Model B & $610.95^{* * *}$ & 179 & 9.73 & 10 \\
\hline Model C & $618.77^{* * *}$ & 179 & 17.55 & 10 \\
\hline
\end{tabular}

$* p \leq .05 * * p \leq .01 * * * p \leq .001$

The results of the analyses regarding job demands are reported in table 5.11. The analyses revealed that the factor loadings of job demands are equivalent across measurement occasions. The unique factors, however, showed a significant chi-square difference (model A versus model C). So, it appears that the unique factors are not invariant over time Workplace social support invariance tests are shown in table 5.12. The factor loadings invariance test proved to be significant. Thus, the factor loadings did not appear to be equal. In order to determine the specific source of loading variance, additional analyses 
were performed for the two support scales (i.e., supervisor support and colleague support, respectively). Model $B_{1}$ and model $B_{2}$ show the corresponding findings. Relaxing the supervisor support loadings indicated a significant difference in chi-square (model A versus model $B_{1}$ ). In contrast, relaxing the colleague support loadings demonstrated an invariant pattern of factor loadings (model $A$ versus model $B_{2}$ ). Thus, the inequality of the overall pattern of factor loadings was mainly caused by the supervisor support loadings. This result is not completely surprising, given that 3 out of 16 senior nursing officers (i.e., 19\%) changed of job between the two measurement points. This might led to different assessments of supervisor support and, probably as a consequence, to different factor loadings. Finally, table 5.12 shows that the overall unique factors and factor correlations are invariant across time since the differences in chi-square were not significant.

Table 5.11 Simultaneous tests of invariance for job demands (one-factor structure; panel group: $n=225$ )

\begin{tabular}{lllll}
\hline Model & Chi-2 & df & $\Delta$ Chi-2 & $\Delta d f$ \\
\hline Model A & $422.69^{* \star *}$ & 103 & & \\
\hline Model B & $426.28^{* * *}$ & 111 & 3.59 & 8 \\
Model C & $447.54^{* * *}$ & 111 & $24.85^{\star *}$ & 8 \\
\hline
\end{tabular}

${ }^{*} p \leq .05^{* *} p \leq .01^{* \star *} p \leq .001$

Table 5.12 Simultaneous tests of invariance for social support (two-factor structure; panel group; $n=225$ )

\begin{tabular}{|c|c|c|c|c|}
\hline Model & Chi-2 & $d f$ & $\Delta$ Chi-2 & $\Delta d f$ \\
\hline Model A & $502.54^{\star * *}$ & 164 & & \\
\hline Model B & $528.70 * \star \star *$ & 174 & $26.16^{* *}$ & 10 \\
\hline Model $B_{1}$ & $521.71 * \star \star$ & 169 & $19.17^{* *}$ & 5 \\
\hline Model $B_{2}$ & $510.72 * \star \star *$ & 169 & 8.18 & 5 \\
\hline Model C & $518.89 * * *$ & 174 & 16.35 & 10 \\
\hline Model D & $503.69 * * *$ & 165 & 1.15 & 1 \\
\hline
\end{tabular}

${ }^{*} p \leq .05^{* \star} p \leq .01^{* \star *} p \leq .001$

We proceeded next to test the invariance of each multiple-item outcome variable (i.e., work motivation, emotional exhaustion, and job-related anxiety). First, the hypotheses concerning work motivation were investigated (table 5.13). The hypothesis of an invariant pattern of factor loadings as well as the hypothesis of invariant measurement errors were not confirmed since the differences in chi-square were just significant ( $p \leq .05)$. In other words, the factor loadings and error covariances of work motivation appear to be unequal across time.

Second, with respect to the occupational burnout component emotional exhaustion, the chi-square statistics indicated equal factor loadings as well as equal error variances (table 5.14). In other words, there is evidence of invariance across the two measurement occasions with respect to emotional exhaustion. 
Table 5.13 Simultaneous tests of invariance for work motivation (one-factor structure; panel group; $n=225$ )

\begin{tabular}{lllll}
\hline Model & Chi-2 & df & $\Delta$ Chi-2 & $\Delta$ df \\
\hline Model A & $170.20^{\star \star *}$ & 34 & & \\
\hline Model B & $181.32^{\star * *}$ & 39 & $11.12^{*}$ & 5 \\
Model C & $182.83^{\star \star *}$ & 39 & $12.63^{*}$ & 5 \\
\hline
\end{tabular}

${ }^{*} p \leq .05^{* *} p \leq .01 * * * p \leq 001$

Table 5.14 Simultaneous tests of invariance for emotional exhaustion (one-factor structure; panel group; $n=225$ )

\begin{tabular}{llllc}
\hline Model & Chi-2 & df & $\Delta$ Chi-2 & $\Delta$ df \\
\hline Model A & $313.38^{\star \star *}$ & 103 & & \\
\hline Model B & $315.79^{\star \star \star}$ & 111 & 2.41 & 8 \\
Model C & $318.33^{\star \star \star}$ & 111 & 4.95 & 8 \\
\hline
\end{tabular}

${ }^{*} p \leq .05 * * p \leq .01 * * * p \leq .001$

Finally, we constrained the factor loadings and error covariances of job-related anxiety to be invariant over time (see table 5.15). These hypotheses were found to be tenable. Again, factor loadings and unique factors were found to be equivalent. Anxiety shows an invariant pattern over time as well.

Table 5.15 Simultaneous tests of invariance for job-related anxiety (one-factor structure; panel group;

\begin{tabular}{llllc}
\multicolumn{1}{c}{$n=225)$} & & & $\Delta$ Chi-2 & $\Delta$ df \\
\hline Model & Chi-2 & df & & \\
\hline Model A & $88.10^{\star \star \star}$ & 19 & 5.51 & 4 \\
\hline Model B & $93.61^{\star \star \star}$ & 23 & 2.34 & 4 \\
\hline Model C & $90.44^{\star * *}$ & 23 & &
\end{tabular}

${ }^{*} p \leq .05 * * p \leq .01 * * * p \leq .001$

After the factorial invariance tests, coefficient alphas were computed and test-retest reliability analyses of the measurement scales were performed. To approximate the testretest reliabilities, correlation coefficients between the scores of each measurement occasion were calculated. Table 5.16 presents the ultimate findings of these analyses. First, the coefficient alphas show satisfactory and consistent values. Only colleague support and, to a lesser extent, content autonomy do not satisfy criterion values, and show some inconsistency over time as well. Second, except for colleague support, all measurement scales reported moderate to satisfactory test-retest reliabilities. This means that most of the instruments are relatively stable over time. 
Table 5.16 Coefficient alpha and test-retest reliability of the measurement scales (panel group; $n=225$ )

\begin{tabular}{|c|c|c|c|c|}
\hline Measurement scale & $\mathrm{N}$ items & Time $1 \alpha$ & Time $2 \alpha$ & $r_{1}$ \\
\hline Job Autonomy & 10 & .81 & .84 & $.64^{* \star *}$ \\
\hline - contextual autonomy & 6 & .77 & 78 & $.65^{\star \star *}$ \\
\hline - content autonomy & 4 & .64 & .75 & $.51 * * *$ \\
\hline Job Demands & 8 & .88 & .89 & $.72^{\star \star \star}$ \\
\hline Supervisor Support & 5 & .81 & .89 & $.64^{\star \star \star}$ \\
\hline Colleague Support & 5 & .54 & .69 & $.46^{\star \star \star}$ \\
\hline Job Satisfaction & 1 & & & $.55^{\star \star \star *}$ \\
\hline Work Motivation & 5 & .86 & .86 & $.62^{* * *}$ \\
\hline Emotional Exhaustion & 8 & .85 & .85 & $.66^{* \star *}$ \\
\hline Job-related Anxiety & 4 & .75 & .78 & $.59 * \star \star$ \\
\hline
\end{tabular}

To summarize the longitudinal findings briefly, there is evidence that the internal composition of all but two of the scales holds over the two measurement occasions. To be more specific, the supervisor support factor loadings appear to be non-equivalent, probably due to job changes. Added to this, work motivation factor loadings and error covariances are not invariant over time. Furthermore, coefficient alphas appear to be acceptable for all but two of the measurement scales. Finally, the acceptable test-retest correlations indicate relatively stable measurement scales over time.

\subsection{Summary and conclusions}

In this chapter the definitions, operationalizations, and the corresponding psychometric properties have been discussed of the measurement instruments used in this study. The variables were classified into three categories: (1) job characteristics (i.e., job autonomy, job demands and workplace social support); (2) psychological outcomes (i.e., work motivation. job satisfaction, emotional exhaustion and job-related anxiety); and (3) demographic characteristics (i.e., gender and age).

Cross-sectional as well as longitudinal psychometric analyses were performed in order to test the psychometric qualities of the measurement instruments. The results of the crasssectional analyses showed acceptable psychometric properties of all measurement instruments. The hypothesized factor models were globally confirmed by the results of CFA. Moreover, the robustness of fit was successfully demonstrated in two independent subsamples. Finally, most multiple-item scales had acceptable internal consistencies. These findings were consistent with results from earlier studies among health care workers, which were mentioned in section 5.2 .

The findings of the longitudinal analyses showed evidence for the fact that the factor models of all but two of the scales held over the two measurement occasions. The supervisor support factor loadings appeared to be non-equivalent, probably due to job changes of several senior nursing officers. Additionally, the factor loadings as well as the 
error covariances of work motivation were not invariant over time. Furthermore, coefficient alphas appeared to be acceptable (and comparable over time) for all but two of the measurement scales. Finally, the test-retest reliabilities indicated relatively stable measurement scales across the two measurement points.

At the end of this chapter, several concluding remarks can be made on each of the measurement instruments.

1) The job autonomy instrument has adequate psychometric properties. CFA has shown that a two-factor structure as well as a one-factor structure are appropriate. Only the subscale content autonomy showed one small problem, namely slightly inconsistent coefficient alphas over time.

2) Job demands showed a clear unidimensional structure. The scale undoubtedly satisfies the psychometric criteria.

3) Workplace social support was measured by a Dutch questionnaire on organizational stress (VOS-D). The a priori subscales were less positively evaluated, both in terms of factorial invariance and internal consistency as well as test-retest reliability. Moreover, the two-factor solution showed significantly correlated error terms, indicating data covariation not explained by the factor model.

4) Work motivation could be measured in a satisfactory way and met all but one of the psychometric criteria.

5) Only the test-retest reliability of the 1-item job satisfaction instrument could be determined, and appears to be acceptable.

6) Emotional exhaustion was measured by a subscale of the Dutch version of the Maslach Burnout Inventory. This 8 -item subscale was positively evaluated and therefore not changed.

7) The original job-related anxiety scale of the Dutch Organizational Stress Questionnaire (VOS) has proven to be psychometrically sound. Therefore, this scale remained unchanged.

Generally, it appears that the extensive psychometric analyses have shown to be successful. All but one of the measurement instruments satisfy most psychometric criteria. Attention has to be paid particularly to the subscales of workplace social support. An additional psychometric analysis will therefore be performed in the next chapter in order to deal with the slightly unsatisfactory psychometric qualities of this measurement instrument.

Nonetheless, on the basis of the present results we may conclude that, but for the social support subscales, our measurement instruments are acceptable for use in successive analyses. The outcomes of these analyses will be discussed in chapters 6 and 7 . 


\section{NOTES}

1. See appendix 2 for full text of questionnaire.

2. The Greek symbols used are standard LISREL notation. We will shift to LISREL notation in discussing the factor models, because of the centrality of the LISREL analyses in this study. Appendix 3 gives an English translation of the symbols used.

3. Serial number: 8903 . Chicago: Scientific Software International.

4. A basic concept in LISREL is a nested model. To say that a model is nested in another (original) model means that the nested model is derivable from the original model by restricting a suitable set of parameters in the original model. In other words, the nested model is a special case of the original model.

5. Within LISREL, we usually are concerned about multinormality of the variables (i.e., multivariate skewness and multivariate kurtosis). One possible check for multinormality is to test the marginal distribution of each variable with univariate tests (Bollen, 1989). Univariate tests of normality have the advantage that they pinpoint specific variables that sharply deviate from a normal distribution. A limitation of these tests is that all variables may have normal marginal distributions but are not multinormally distributed. Consequently, an additional multivariate test was performed, namely Mardia's (1985) omnibus test of multinormality. The greater part of the corresponding test statistics, however, appeared to be significant, indicating - strictly speaking - a nonnormal multivariate distribution. Because joint multivariate normal distribution is required for FIML estimation, these results raise questions about the accuracy of the FIML-based $\chi^{2}$-tests. Therefore, we re-analysed the factor models with an alternative estimator that allows for nonnormality (i.e., the Weighted Least Squares - WLS estimator). The (FAs with WLS estimation showed the same patterns of results compared to FIML estimation, indicating that severe problems with respect to nonnormality were absent. 
Chapter 5 
chapter 


\section{CROSS-SECTIONAL ANALYSIS}

\subsection{General introduction}

In this chapter' the outcomes of the analyses on the cross-sectional data will be presented. We will use data from the health care workers of the first measurement sample, from eight general hospitals and eight nursing homes in the Netherlands (see also chapter 4).

Section 6.2 discusses some preliminary analyses, which pave the way for the forthcoming statistical analyses in the next three sections.

The rest of this chapter can be considered as a triptych and consists of three general parts accordingly. The first, section 6.3, deals with group and individual assessment of job characteristics, reflected in multi-level modelling. The Job Demand-Control Model (ID-C Model) of Karasek (1979) is the theoretical model used in this part. The second, section 6.4, discusses an overall test of the Demand-Control-Support Model ${ }^{2}$ (DCS Model; Johnson \& Hall, 1988), while the third part of this triptych reports a comprehensive test of - parts of - Warr's (1987) Vitamin Model $^{2}$, abbreviated VM (section 6.5). The DCS Model and the VM represent higher-order models, which are in statistical terms superior to first-order, linear additive, models (e.g., Aiken \& West, 1991; see also chapter 3). Consequently, both higher-order models are tested primarily, and are contrasted with the linear additive idea of Hackman and Oldham (1980) as postulated in their Job Characteristics Model (JCM). Section 6.6 summarizes the results.

\subsection{Preliminary analysis}

In this section, some preparatory statistical analyses are described in order to create conditions for further analysis. More specifically, we will discuss a second-order confirmatory factor analysis (CFA) and the computation of higher-order terms.

\section{SECOND-ORDER FACTOR ANALYSIS}

Part of the motivation for the performance of CFA in chapter 5 was the idea that a few latent factors may underlie a large number of items. Correlations among items are said to be explained in the sense that, if the effects of the latent factors were removed, the items would no longer be correlated. It is less widely recognized that more abstract latent factors may determine the "first-order" latent factors (cf. Benson \& Bandalos, 1992; Bollen, 1989; Gerbing \& Anderson, 1984).

We performed a second-order confirmatory factor analysis for both theoretical and methodological reasons. First, model building should be guided by the principle of parsimony (Bollen, 1989; Hayduk, 1987). In other words, if we judge several models to fit the data and to approximate reality, we should select the simplest model. Moreover, this principle of parsimony is closely linked up with our theoretical models. The DCS Model, for instance, focuses on three key job characteristics: job demands, job autonomy and 
workplace social support. Second, the intercorrelations between the two latent factors of job autonomy and, to a lesser extent, those of social support suggest that the first-order latent factors may be reduced to higher-order latent factors. Finally, high correlations between exogenous latent factors (e.g., the job autonomy subscales) may create collinearity problems (Bollen, 1989; Hayduk, 1987). Collinearity generally increases the standard errors of the coefficients of the collinear factors, which means greater uncertainty in the inferences we can make.

Table 6.1 Comparison of first-and second-order factorial models (calibration sample and validation sample)

\begin{tabular}{|c|c|c|c|c|c|c|}
\hline Model & Chi-2 & $d f$ & AGFI & RMSEA & NNFI & $\mathrm{CVI}$ \\
\hline \multicolumn{7}{|l|}{ Calibration sample $(n=665)$} \\
\hline Null model $\left(\mathrm{M}_{0}\right)$ & $6829.33^{* * *}$ & 378 & .39 & .17 & & 10.92 \\
\hline First-order model $\left(M_{1}\right)$ & $1337.54^{\star \star \star}$ & 340 & .84 & .07 & .83 & 2.30 \\
\hline$M_{1}$-respecified & $1167.99 * \star *$ & 339 & .86 & .06 & .86 & 2.03 \\
\hline Second-order model $\left(\mathrm{M}_{2}\right)$ & $1374.18^{\star \star \star}$ & 345 & .84 & .07 & .83 & 2.30 \\
\hline $\mathrm{M}_{2}$-respecified & $1203.93^{* \star \star}$ & 344 & 86 & .06 & .85 & 2.02 \\
\hline \multicolumn{7}{|l|}{ Validation sample $(n=667)$} \\
\hline Null model $\left(M_{0}\right)$ & $6616.87^{\star \star *}$ & 378 & .39 & .16 & & 10.76 \\
\hline First-order model $\left(M_{1}\right)$ & $1228.23^{\star * *}$ & 340 & 85 & .07 & .84 & 2.16 \\
\hline$M_{1}$-respecified & $1012.02^{\star \star \star}$ & 339 & 87 & .06 & .88 & 1.81 \\
\hline Second-order model $\left(\mathrm{M}_{2}\right)$ & $1268.93^{\star \star \star}$ & 345 & 85 & .07 & .84 & 2.15 \\
\hline$M_{2}$-respecified & $1054.80^{\star \star \star}$ & 344 & 87 & .06 & .87 & 1.80 \\
\hline
\end{tabular}

* $p \leq .05 * * p \leq .01 * * * p \leq .001$

Both first- and second-order CFAs with regard to job autonomy, job demands and workplace social support were conducted by specifying the LISREL parameters in terms of an "all y-model" (cf. Jöreskog \& Sörbom, 1989, p. 160). The first-order CFA consisted of five first-order latent factors, while the second-order CFA consisted of five first-order latent factors and three second-order latent factors. A covariance matrix based on all 28 items was computed for the calibration sample as well as the validation sample. Each item was constrained to load on only one factor. One loading on each factor was constrained to equal one, in order to set a metric for the five first-order latent factors ${ }^{3}$. Factor covariances were left free to be estimated. All error covariances were initially constrained to equal zero, because these covariances are hypothesized to be explained by the three second-order factors. The variances of the second-order latent factors were constrained to equal one, in order to set a metric for these factors. Finally, it might be theoretically reasonable to impose an equality restriction on the second-order factor loadings with regard to job autonomy and social support (i.e., $\gamma_{11}=\gamma_{21}$ and $\gamma_{43}=\gamma_{53}$ ). These restrictions were also needed to identify the factor model.

Table 6.1 reports the results of the first- and second-order CFAs. All chi-square statistics are highly significant, indicating a poor statistical fit. The practical fit indices, however, show a moderate fit. The Modification Indices (M/s) of the first- and second-order CFAs suggested 
only a meaningful modification in one error covariance; that is, a similar social support subscale item (see also chapter 5). Relaxing the corresponding parameter (i.e., the same $\Theta_{\varepsilon}$ in all models in both subsamples) led to respecified models and improved model fit.

As noted by Marsh and Hocevar (1985), the goodness-of-fit of a second-order factor model can never be better than that of the corresponding first-order factor model. This is because the second-order factors are merely trying to explain all the covariation among the firstorder factors in a more parsimonious way. In this sense, the first-order factor model provides a target (or optimum fit) for the second-order factor model. Marsh and Hocevar (1985) propose a new index of goodness-of-fit to summarize the fit of the second-order model relative to the first-order model. This index, called the Target Coefficient $(T)$, is the ratio of the chi-square of the first-order model to the chi-square of the second-order model. $T$ has an upper limit of 1.00 , which would occur if the covariation among the first-order factors could be completely accounted for by the second-order factor model. In the current application, the value of T was .97 for the calibration sample and .96 for the validation sample, based upon the chi-squares obtained for models $M_{1}$-respecified and $M_{2}$-respecified. Thus, 97 or 96 per cent of the covariation among the five first-order factors can be accounted for by three second-order factors

Both respecified second-order models show a passable fit. Furthermore, the double crossvalidation procedure with a fixed-loadings strategy (see chapter 5) shows that model $\mathrm{M}_{2}$ respecified of the validation sample is most stable $(C V I=1.80)$. The completely standardized factor solution of this model is presented in figure 6.1 .

Consider finally the coefficient alphas of the three measurement scales. The values of $\alpha$ for job autonomy, job demands and workplace social support are 81,87 , and 79 , respectively for the calibration sample, and $.82, .86$, and .79 , respectively for the validation sample. These values indicate acceptable internal consistencies.

We may conclude that the second-order three-factor solution of the job characteristics is a reasonable and more parsimonious representation of the five first-order latent factors. For the sake of parsimony, better psychometric qualities (social support in particular), and collinearity reduction, we will use this second-order three-factor solution in the forthcoming analyses of model testing.

\section{HigheR-ORDER ANALYSIS WITH INTERACTION TERMS}

Central to Karasek's JD-C Model is the notion that job demands and job decision latitude have an interactive effect on outcomes (Karasek, 1979, 1989; Karasek \& Theorell, 1990). However, as described in chapter 3 , evidence for the interactive model is not strong. Interactions have often proved to be statistically weak, or not of the predicted form and direction, and even non-significant (cf. De Jonge, 1992; Parkes, Mendham \& Von Rabenau, 1994: Schnall, Landsbergis \& Baker, 1994). Several methodological reasons for this modest support have been mentioned in the literature. We will discuss them below.

A first reason concerns the mathematical formulation of the interaction term (e.g. Fox, Dwyer \& Ganster, 1993; De Jonge, Janssen \& Van Breukelen, in press; Karasek, 1979, 1989; 


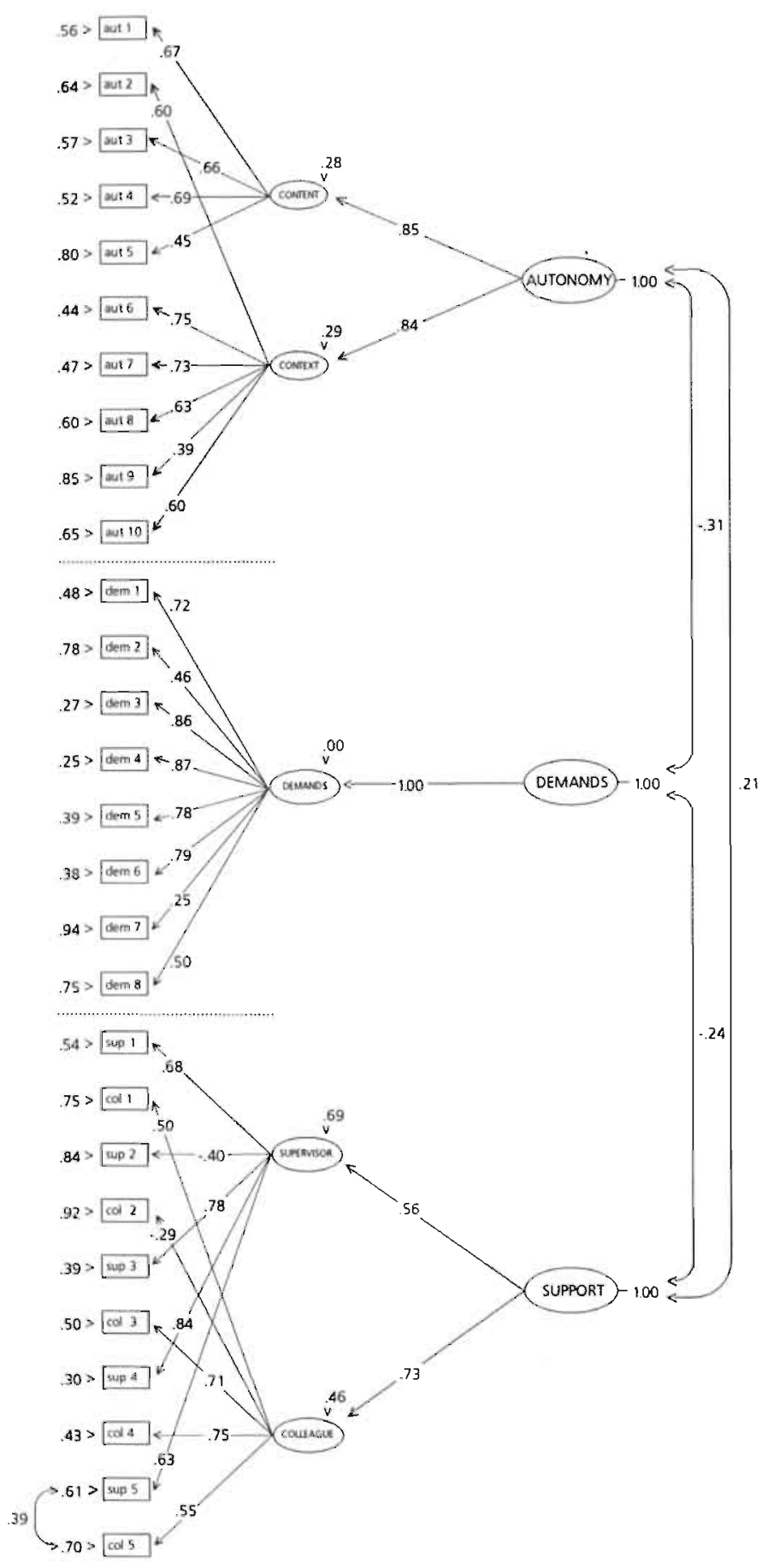

Figure 6.1 Factor solution of second-order CFA model of job characteristics (completely standardized solution; validation sample) 
Kasl, 1989; Sauter, 1989). Since the advent of the JD-C Model in 1979, the interaction term between job demands and job decision latitude has been operationalized primarily in four ways (Landsbergis, Schnall, Warren, Pickering \& Schwartz, 1994; Schnall, Landsbergis \& Baker, 1994).

Initially, the $\mathrm{JD}-\mathrm{C}$ interaction term referred to a subtractive term, a so-called "relative excess

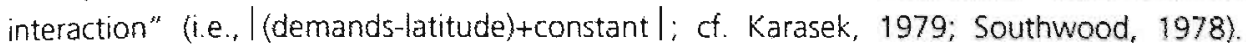
That is, job strain increases with the surplus of job demands over job decision latitude. A second procedure has been to define workers both above the median on job demands and below the median on job decision latitude as 'high strain' group. Third, several researchers have used a multiplicative interaction term controlling for main effects in order to investigate demand-control interactions. Finally, an approach has been to create another continuous variable - job demands divided by decision latitude.

A question is whether the results have been contaminated by the use of these four different kinds of interaction terms. Landsbergis, Schnall, Warren, Pickering and Schwartz (1994) investigated the four interaction terms in a sample of 262 full-time male employees. All four formulations were significantly associated with elevated ambulatory systolic blood pressure. They concluded that the demand-control interaction is consistent and robust across mathematical formulations of this risk factor, at least on systolic blood pressure. Additionally, research has shown that the relative excess term and the multiplicative interaction term lead to nearly the same results (e.g., Fletcher \& Jones, 1991; De Jonge \& Landeweerd, 1993; Payne \& Fletcher, 1983; Sauter, 1989; Schnall, Landsbergis \& Baker, 1994).

A second reason concerns the possible presence of non-linearity of associations (cf. Warr, 1987. 1990b). Lubinski and Humphreys (1990), for example, have suggested that a significant interaction effect may spuriously represent a curvilinear effect for either of the two variables. Finally, it is also possible that the inconsistent interactive findings could be due to one or more moderator variables influencing relations between job characteristics and outcomes. As stated in chapter 3, workplace social support may act like such a moderator variable.

The most widely used approach to the problem inherent in interactions between continuous or binary variables is the inclusion of multiplicative terms in the equations, thereby controlling for main effects (Cohen \& Cohen, 1983). In the case of two exogenous variables (i.e., job autonomy and job demands), one product term is needed to represent the interaction effect. In addition, when there are three predictors (i.e., job autonomy, job demands and social support), four multiplicative terms are needed to represent all possible interaction effects: three two-way interaction terms (i.e., (1) Demands x Autonomy; (2) Autonomy $x$ Support; (3) Demands $x$ Support) and one three-way term (i.e., Demands $x$ Autonomy x Support; (f. Aiken \& West, 1991; Jaccard, Turrisi \& Wan, 1990). If the DCS Model is to be supported, particularly the three-way interaction will have to be significant. Because of hierarchical statistical principles, all remaining interaction terms are also included in the model, including the interaction term between job demands and job autonomy (e.g., Bishop, Fienberg \& Holland, 1975). Testing the contribution of this term automatically is a test of the JD-C Model; in testing the DCS Model we are implicitly testing the JD-C Model. 
We performed two analytic steps accordingly (cf. Aiken \& West, 1991; Jaccard, Turrisi \& Wan, 1990):

1) the three job characteristics (i.e., job autonomy, job demands and workplace social support) were mean-centred ${ }^{4}$ in order to prevent multicollinearity,

2) the four interaction terms (i.e., cross-products) were computed from these centred variables.

\subsection{Group and individual assessment of job characteristics}

\subsubsection{Introduction}

In chapter 2 we gave prominence to the job redesign tradition, because many of the job autonomy studies may be headed under this tradition. Consequently, job autonomy was considered as a characteristic of the task (or job) itself. Underlying the corresponding kind of job characteristics research is a traditional causal model, which focuses on the objective characteristics of the job. In cases where the aim is to implement strategies that promote health and well-being, the primary focus on objective job characteristics seems to be heuristic. Linking outcomes to some objective indicators of job characteristics allows us to determine whether it is the characteristics of the job themselves that are important for health and well-being, or whether it is the predispositions that people bring with them to the workplace that account for health and well-being (Ganster \& Schaubroeck, 1991; Krahe, 1992). In other words, it provides a kind of yardstick.

In addition to this, Karasek (1992) reviewed some basic trends in 19 case studies of stress prevention programmes. He found that work environment restructuring has been more effective than person-based coping enhancement programmes. So, it may be easier to redesign the job than to alter well-established needs, values and abilities.

The question is, however, how job characteristics should be measured in the prediction of health and well-being: either objectively (in the sense that the assessment is independent of the employee) or subjectively (i.e., dependent on cognitive and emotional perceptions of job incumbents)?

Buth objective and subjective assessment of job characteristics have advantages and disadvantages. They may lead to various problems. We mentioned in chapter 2 that current objective assessment of job characteristics is carried out through (1) direct independent measurement and (2) observers' ratings. The main problem with direct measurement of objective characteristics is that some aspects are difficult to express in concrete physical terms (Warr, 1987). For example, job autonomy and job clarity do not provide usable general markers. The second approach seems to be 'objective' as mentioned above, but may be influenced by observer bias. The measurement yields incomplete and partially invalid information, due to limited observation time or space and the effects of the observation itself (Frese \& Zapf, 1988). Insufficient interrater reliability may be an additional problem. And finally, observers ratings seem to suffer from a stronger halo effect ${ }^{5}$ than employee assessments (Frese. 1985; Tsui \& Ohlott, 1988). 
However, subjective measurement of job characteristics by means of self-report questionnaires also has its problems (Algera, 1983, 1991; Frese, 1985; Frese \& Zapf, 1988; Kasl, 1989; Mackay \& Cooper, 1987; Soeters \& Nijhuis, 1988; Spector, 1992), such as:

1) conceptual overlap between independent and dependent measures in that both measures reflect the same construct;

2) common method variance, because the information is derived from the same source (e.g., central tendency, acquiescence):

3) influence of a third variable that causes a spurious relationship (e.g., a personal trait);

4) the potential influence - or alteration - of the estimation of job characteristics due to the presence of an outcome variable (e.g., health complaints);

5) possible effect of demand characteristics of the research context and experimenter effects, resulting in false correlations between job characteristics and outcome variables:

6) subjective measurement by means of questionnaires, which is more time-consuming (for the job incumbents) and more expensive (for the organization) than observations by a few independent observers are.

One way to avoid the above-mentioned problems as far as possible is to look for alternative sources to reflect the work conditions. So-called group assessments seem to be very useful in measuring job characteristics (Frese, 1985, 1989; Frese \& Zapf, 1988; Spector, 1992). By group assessments we mean that the scores of job incumbents with the same job and working in nearly identical workplaces are aggregated into one general score. The group assessments can be described as the group estimates of the respective job characteristic for each job incumbent. According to Frese and Zapf (1988), group assessments are more 'objective' measures in the sense that the influence of idiosyncratic - individual - perceptions and possibly illusory answers are reduced. In addition, the expertise of workers is taken into account and problems of brief periods of observation are avoided. Finally, group assessments seem not to be subject to methodological problems such as common method variance. Thus, group data are likely to be more reliable than individual assessments.

The claim that group assessment (i.e., aggregated data) is more 'objective' is corroborated by several empirical findings (see also chapters 2 and 3). For instance, a meta-analysis of 16 convergence studies conducted by Spector (1992) showed that aggregate-level correlations between job characteristics and outcomes were similar to individual-level correlations. Moreover, it appeared that the convergent validity at aggregated level was rather large, and even larger than at individual level.

The purpose of this section is to test Karasek's (1979) Job Demand-Control Model $\left.\right|^{6}$ using both group and individual indicators of job characteristics. We used group and individual assessments of job demands and job autonomy for two reasons. The first reason is that some of the measurement problems mentioned above (e.g., method variance) are not very problematic when group and individual assessments lead to nearly the same pattern of results. The second reason is that we want to find out whether aggregated job characteristics data significantly add explained variance to individual-level job characteristics data with regard to health and well-being. In other words, we want to study the relationship between 
aggregated job characteristics and health and well-being, after controlling for individuallevel job characteristics. This could mean that some of the explained variance of health and well-being is attributable to some - environmental - features outside the individual employee, which has important practical consequences for job redesign.

The question how job characteristics should be assessed has led to three exploratory research questions, which have been described earlier in chapter 3 . Firstly, we will compare aggregated data and individual data by means of the following questions:

Q1) "To what extent can individual data on job characteristics explain health (i.e., emotional exhaustion, job-related anxiety) and well-being (i.e., work motivation, job satisfaction)?"

Q2) "To what extent can aggregated individual data on job characteristics explain health and wellbeing?"

Q3) "Do aggregated individual data add explained variance to the explained variance by individual variables with respect to health and well-being?"

Secondly, we extend and partly integrate our questions by means of the following hypothesis, as described in chapter 3 :

H1) "Job autonomy and job demands have an interaction effect with respect to health on the one hand, and well-being on the other."

In order to keep the work situation roughly constant across individuals within a given unit, we only included health care workers with the same job level, namely registered nurses (cf. Thomas, 1986). This restriction reduces the whole sample to 895 registered nurses. Eightyfour per cent of the respondents were women, and the age ranged from 19 to 59 years $(M=30.7, S D=7.4)$. It should be noted that these demographic characteristics were not significantly different from the initial sample of 1,437 health care workers (gender: $\chi^{2}(1)=.09, p=n$. s.; age: $t=.02, p=n . s$.).

\subsubsection{Data analysis}

Much behavioural and social research involves hierarchical data structures. Conventional statistical techniques (e.g. ordinary regression analysis) ignore this hierarchy and may, therefore, lead to incorrect results (Bryk \& Raudenbush, 1992; Hox, 1994; Hox \& Kreft, 1994). In the multi-occupation studies regarding the JD-C Model, for example, occupational grouping was used as a measure of 'objective' differences between jobs relevant to job redesign (e.g., Karasek \& Theorell, 1990; Schwartz, Pieper \& Karasek, 1988). Although this method appears to be a slight improvement on the use of observers' ratings, it is still very conservative and too indirect to isolate the two job characteristics (Frese \& Zapf, 1988; Ganster \& Schaubroeck, 1991; Kasl, 1989). More specifically, information is lost if data are aggregated to mean group scores. There is a great deal of imprecision as a result of the inability to deal with variability in job characteristics within the group (Ganster \& Fusilier, 
1989; Landsbergis, Schurman, Israel, Schnall, Hugentobler, Cahill \& Baker, 1993). Consequently, the statistical analysis loses power (Hox, 1994). Furthermore, employees within the same occupational or organizational group tend to be similar to each other, because of, for instance, selection processes. As a result, the average (intra group) correlation between variables measured on employees from the same identity or organizational group will be higher than the average correlation between variables measured on employees from different groups. Conventional statistical techniques, however, lean heavily on the assumption of independence of observations. A common problem with these techniques is that the statistical dependence among the scores of employees within the same group is discounted. All observations are regarded as independent, when in fact there is dependence (Hox, 1994; Vancouver, Millsap \& Peters, 1994). Violation of the assumption of independence of observations may cause too small estimates of the standard errors of conventional statistical techniques (Bryk \& Raudenbush, 1992). This negative bias in turn may lead to spurious 'significant' findings.

A final problem is that in small groups, the group averages will have large standard errors. Conventional statistical analysis using group means will be unusable to separate systematic variation from sampling error (Vancouver, Millsap \& Peters, 1994).

Recent developments in statistical theory with regard to the estimation of hierarchical linear models allow us to take the hierarchy in data into account (Aitkin \& Longford, 1986). In this so-called "multi-level research", the data structure in the population is hierarchical, and the data are viewed as a multistage sample from this hierarchical population. For example, in organizational research, the population consists of organizations, units within these organizations, and employees within these units.

With the help of multi-level models we can formulate and test hypotheses about relationships occurring at different levels and even across levels. In the present study, a three-level model is used (cf. Bryk \& Raudenbush, 1992, chapter 8). First, the macro-level contains a random sample of 16 institutions. Second, there are 64 units at the meso-level. Finally, there are 895 nurses assumed to be randomly sampled per unit (micro-level).

The basic hierarchical regression model for a three-level data set can be formulated as equation 6.1:

$y_{i j k}=B_{0 j k}+B_{1 j k} x_{1 i j k}+B_{2 j k} x_{2 i j k}+\ldots+B_{i j k} x_{h i j k}+e_{i j k}$

in which the subscript $i$ refers to the micro-level, $j$ to the meso-level, and $k$ to the macrolevel. The subscript $h$ indexes the independent variable $x$ and the corresponding regression parameter $B$. Equation 6.1 is the general micro-level model. In the multi-level model, regression coefficients ( $B$ ) of micro-level predictors may vary across meso-level units (units) and across macro-level units (institutions), randomly and/or as a linear function of a mesolevel or macro-level fixed factor (see Bryk \& Raudenbush, 1992). In our model we assume (equation 6.2):

$B_{0 j k}=B_{0}+\sum^{5} \gamma_{0 q} z_{q}+u_{0 j k}+v_{0 k}$ 
in which $z_{1}$ to $z_{5}$ represent the dummy variables for type of unit (fixed factors), $u_{0 j k}$ the random effect of the factor unit within type of unit, and $v_{0 k}$ the random effect of the factor institution.

Explicit hypotheses about the interaction between our predictor variables on the one hand, and the random factors unit and institution on the other were absent. Therefore, we restricted our analyses to random variation between units and institutions in the intercepts only, which represents random (main) effects of the factors unit and institution. Thus, the other regression coefficients $\left(B_{1}\right.$ to $\left.B_{h}\right)$ are assumed to be constant across units and institutions, which implies non-interaction between fixed factors (xs) and random factors (unit and institution).

This results in a multi-level model in which the intercept may vary at two levels: units and institutions. Additionally, some meso-level and macro-level fixed factors can be introduced to explain variability. For our purpose we only included meso-level, aggregated, characteristics. Taken together, multi-level analysis has several advantages in comparison with conventional statistical techniques. First, data from more than one hierarchical level can be included in the analysis. Second, the statistical dependence is explicitly modelled in the hierarchical model. Finally, the multi-level model separates unsystematic sampling error from systematic variation due to group-level influences. This separation is especially important when sample sizes within groups are rather small.

In this study the multi-level models are estimated and fitted with the computer programme VARCL' (VARiance Component analysis by maximum Likelihood; Longford, 1993).

\section{Model building}

The strategy for model building within VARCL is to follow the questions and hypothesis, as described earlier. The first model that is fitted (model 1) is an empty model: a fully unconditional model without predictors at any level apart from the random effects of units and institutions. This model represents the (unexplained) variation of the outcome variables at each level (nurse, unit and institution). In case of significant unit and institution effects we will have to perform multi-level analyses rather than ordinary linear regression analyses. The second model includes all covariables; that is, gender, age and type of unit. The question is how much variance can first be explained by these variables. The third model contains the covariables of model 2 and the individual - micro-level - job characteristics. How much of the total variance can be explained by the individual job characteristics? The fourth model again includes the covariables of model 2, but now the aggregated job characteristics are added at the unit level. How much variance can be explained by these aggregated variables? The fifth model contains all covariables and predictors at both the micro-level and the meso-level. The questions are, first, whether the aggregated variables add explained variance to model 3, and, second, how much variance can be explained by both individual and aggregated variables. Finally, model 6 is a parsimonious model based upon the best fitting model (i.e., model 3 or model 5). Within this simplified model, non-significant interaction terms are deleted in order to interpret main effects (cf. Aiken \& West, 1991). 
In order to test the interaction hypothesis, we performed multi-level regression analyses including a multiplicative interaction term for all outcome variables. The multiplicative term was computed from the grand mean centred ${ }^{4}$ scores of job demands and job autonomy, for the individual variables (model 3) and aggregated variables (model 4), respectively ( $\mathrm{f}$. Aiken \& West, 1991; Kleinbaum, Kupper \& Muller, 1988).

\subsubsection{Results}

The means, standard deviations, empirical ranges and zero-order Pearson correlations of the study variables are presented in appendix 4, tables A4.1 and A4.2. Note that there are two covariables at the micro-level (i.e., gender and age) and five dummy variables at the mesolevel, controlling for the six types of units. The Intensive Care Unit (ICU) is the reference category and has the value zero on all five dummy variables. At the meso-level, the predictor variables job demands and job autonomy consist of aggregated individual data (i.e., the mean group score per unit).

The first model within VARCL is an empty model with only one fixed effect, namely the intercept (the average individual mean) and two random effects of the factors units and institutions. Significance of the random effects of units and institutions within VARCL was tested by computing the deviance (D) for the ordinary regression model (a regression model without these random effects). The difference between this deviance and the deviance of our multi-level null model has a $\chi^{2}$-distribution with two degrees of freedom under $\mathrm{H}_{0}$ such that there are neither unit nor institution effects (e.g., Bryk \& Raudenbush, 1992; Kleinbaum, Kupper \& Muller, 1988). For all outcome variables, the results showed that the difference between the two deviances is significant, which means that $\mathrm{H}_{0}$ was rejected. We may conclude that there are differences between units and/or institutions with respect to all outcome variables. The variance in these variables is mainly a function of individual differences (at least $85.7 \%$ ), but unit and institution differences together explain some of the variance (at least 5.6\%). So, multi-level regression analyses rather than ordinary regression analyses have to be performed.

The results of the multi-level regression analyses with emotional exhaustion as outcome variable are given in table 6.2. In the second model of table 6.2, all covariables are entered including (1) gender and age at the individual level, and (2) the five unit dummy variables at the unit level.

Different models can be compared with respect to predictive power by a likelihood ratio test (Bosker \& Snijders, 1990; Bryk \& Raudenbush, 1992). Deviance (D) is computed for each model and the difference between the deviance statistics $(\Delta D)$ is used to test the hypotheses. If one model is a special, reduced, version of the other model, this difference has a $\chi^{2}$-distribution under $\mathrm{H}_{0}$ that the extended model does not predict better than the reduced model. Critical values of the $\chi^{2}$-statistic mean that the - reduced - model is too simple a description of the data (e.g., Kleinbaum, Kupper \& Muller, 1988). After entering the covariables, the overall model fit improved $(\Delta D(7)=16.70, p \leq .05)$. This implies that 
Table 6.2 Results of the multi-level regression analyses with respect to emotional exhaustion (p-values based on approximate Standard Errors provided by VARCL)

\begin{tabular}{|c|c|c|c|c|c|c|}
\hline Model & 1 & 2 & 3 & 4 & 5 & 6 \\
\hline Grand mean $\left(B_{0}\right)$ & 1.76 & 1.69 & 1.76 & 1.83 & 1.78 & 1.76 \\
\hline Individual level & $b$ & $b$ & $\underline{b}$ & $b$ & $b$ & $b(B)$ \\
\hline gender & & -.12 & -.10 & -.13 & -.09 & -.10 \\
\hline age & & -.01 & -.00 & -.00 & -.00 & -.00 \\
\hline job demands & & & $.73^{*}$ & & $.71^{\star}$ & $.73^{\star}(47)$ \\
\hline job autonomy & & & -.04 & & -.04 & $-.04(-.03)$ \\
\hline dem $x$ aut & & & -.02 & & .01 & \\
\hline Unit level & b & $b$ & b & $b$ & $\mathrm{~b}$ & $b$ \\
\hline job demands & & & & $.81^{*}$ & .10 & \\
\hline job autonomy & & & & -.10 & -.07 & \\
\hline dem $x$ aut & & & & -.64 & -.65 & \\
\hline \multicolumn{7}{|l|}{ type of unit \# } \\
\hline psychiatric & & $.52^{*}$ & $.55^{\star}$ & $.52^{\star}$ & $.52^{\star}$ & $.56^{\star}$ \\
\hline internal & & $.30^{\star}$ & .12 & .12 & .11 & .11 \\
\hline surgical & & $.46^{\star}$ & $.24^{\star}$ & $.24^{\star}$ & $.23^{\star}$ & $.24^{\star}$ \\
\hline somatic & & $.37^{\star}$ & .06 & -.01 & -.01 & .07 \\
\hline psycho-geriatric & & $.36^{\star}$ & $.20^{\star}$ & .17 & .17 & $.20^{*}$ \\
\hline Variance decomposition & $\sigma_{e}^{2}$ & $\sigma_{e}{ }^{2}$ & $\sigma_{e}^{2}$ & $\sigma_{e}^{2}$ & $\sigma_{e}^{2}$ & $\sigma_{e}^{2}$ \\
\hline individual level & .680 & .678 & .561 & .676 & .560 & .561 \\
\hline unit level & .071 & .038 & .011 & .003 & .010 & .012 \\
\hline institution level & .013 & .023 & .002 & .000 & .000 & .002 \\
\hline \multicolumn{7}{|l|}{ Model fit } \\
\hline deviance $(D)$ & 2256.30 & 2239.60 & 2040.54 & 2193.51 & 2035.99 & 2040.62 \\
\hline$\Delta$ model $1(\Delta D)$ & & $16.70^{\star}$ & & & & \\
\hline$\Delta$ model $2(\Delta D)$ & & & $199.06^{\star}$ & $46.09^{*}$ & & \\
\hline$\Delta$ model $3(\Delta D)$ & & & & & 4.55 & .08 \\
\hline$\Delta d f$ & & 7 & 3 & 3 & 3 & 1 \\
\hline$R^{2}$ & & $3.3 \%$ & $24.9 \%$ & $11.1 \%$ & $25.4 \%$ & $24.7 \%$ \\
\hline
\end{tabular}

model 2 has a better fit than model 1 and that the covariables have to be taken into account in our subsequent analyses. The total modelled, or explained, proportion of variance $\left(R^{2}\right)$ is 3.3 per cent. For a random intercept model this parameter can be estimated as the proportional reduction in mean squared prediction error due to predictor variables (see also Snijders \& Bosker, 1994).

Entering individual variables in model 2 again improved the overall model fit $(\Delta D(3)=199.06$, $p \leq .05$ ). This means that model 3 has a better fit than model 2 , and reduces unexplained variance at all three levels (modelled variance: $24.9 \%$ ). The interaction term of job demands and job autonomy, however, is not significant. 
In our next model aggregated variables were entered instead of individual variables in order to explain differences in emotional exhaustion. The results are presented in table 6.2, model 4. Model 4 shows a better fit than model $2(\Delta D(3)=46.09, p \leq .05)$. The aggregated variables contribute to the explanation of emotional exhaustion as well. The modelled variance is 11.1 per cent, which reduces unexplained variance at the unit and institution level. Again, the interaction term is not significant.

Model 5 examines whether aggregated variables add variance to model 3 . Table 6.2 shows that model 5 does not have a better fit than model $3(\Delta D(3)=4.55, p=n .5)$. The elfects. of the aggregated variables in model 5 appear to be modest. Model 6 shows the best fitting model (i.e., model 3) with an eliminated non-significant interaction term at the individual level. In order to interpret the linear additive relationships correctly, the standardized regression coefficients (Bs) are presented in parentheses in the last column of tables 6.2 to 6.5 (cf. Aiken \& West, 1991; Hox, 1994; Jaccard, Turrisi \& Wan, 1990). It appears that the individual job demands have a significant positive relationship with emotional exhaustion. in other words, higher levels of individual job demands are associated with higher levels of emotional exhaustion.

Table 6.3 presents the results of the multi-level regression analyses with job-related anxiety as the outcome variable. Model 2 contains the results for the covariables. Entering these variables improved model fit $(\Delta D(7)=18.55, p \leq .05)$. The modelled variance $\left(R^{2}\right)$ is 3.2 per cent. The individual variables were entered in the next model (model 3 ). This model shows a better fit than model $2(\Delta D(3)=44.48, p \leq .05)$, which indicates that the individual variables contribute to the explanation of anxiety. More specifically, model 3 reduces unexplained variance at the individual and unit levels (modelled variance: $8.5 \%$ ). In our fourth model only the aggregated variables were entered. Once more the aggregated variables contribute to the explanation of the outcome variable $(\Delta D(3)=25.15, p \leq .05)$. Entering the aggregated variables in the model reduces unexplained variance at the unit level in particular (modelled variance: $6.3 \%$ ).

Compared with model 3, model 5 does not lead to an improvement in model fit $(\Delta \mathrm{D}(3)=6.07, p=n . s$.). This means that the remaining unexplained variance in model 3 cannot be explained by the aggregated variables. The total modelled variance is 9.1 per cent. Finally, the parsimonious model (i.e., model 6 ) shows that the individual job demands have a significant positive association with anxiety. That is, higher levels of individual job demands are related to higher levels of job-related anxiety.

The results of the multi-level regression analyses with work motivation are presented in table 6.4. Entering the covariables in model 2 improved model fit $(\Delta D(7)=29.87, p \leq .05)$. In model 3 the individual variables were entered. The individual variables contribute significantly to the explanation of work motivation $(\Delta D(3)=29.04, p \leq .05)$. The whole modelled variance at all three levels is 10.6 per cent. The three aggregated variables instead of the individual variables were entered in the fourth model. Model 4 has a better fit than model 2 
Table 6.3 Results of the multi-level regression analyses with respect to job-related anxiety (p-values based on approximate Standard Errors provided by VARCL)

\begin{tabular}{|c|c|c|c|c|c|c|}
\hline Model & 1 & 2 & 3 & 4 & 5 & 6 \\
\hline Grand mean $\left(B_{0}\right)$ & 1.47 & 1.52 & 1.54 & 1.56 & 1.55 & 1.54 \\
\hline Individual level & $b$ & $\mathrm{~b}$ & $b$ & $\mathrm{~b}$ & $\mathrm{~b}$ & $b(B)$ \\
\hline gender & & -.02 & -.01 & -.01 & -.01 & -.01 \\
\hline age & & -.00 & .00 & -.00 & -.00 & -.00 \\
\hline job demands & & & $.18^{*}$ & & $.15^{\star}$ & $.18^{*}(.23)$ \\
\hline job autonomy & & & .01 & & .00 & $.01(.01)$ \\
\hline dem $x$ aut & & & -.05 & & -.03 & \\
\hline Unit level & $b$ & $b$ & $\mathrm{~b}$ & $b$ & $\mathrm{~b}$ & $b$ \\
\hline job demands & & & & $.25^{\star}$ & .10 & \\
\hline job autonomy & & & & .01 & .01 & \\
\hline dem $x$ aut & & & & -.31 & -.28 & \\
\hline \multicolumn{7}{|l|}{ type of unit \# } \\
\hline psychiatric & & $.23^{\star}$ & $.23^{\star}$ & $.22^{\star}$ & $.22^{\star}$ & $.24^{\star}$ \\
\hline internal & & .04 & .00 &. .01 & -.01 & -.00 \\
\hline surgical & & .05 & .00 & -.01 & -.01 & .00 \\
\hline somatic & & .01 & -.06 & .09 & -.09 & -.05 \\
\hline psycho-geriatric & & .00 & -.04 & -.04 & -.05 &. .03 \\
\hline Variance decomposition & $\sigma_{e}{ }^{l}$ & $\sigma_{e}^{2}$ & $\sigma_{\rho}^{2}$ & $\sigma_{e}{ }^{2}$ & $\sigma_{8}^{2}$ & $\sigma_{e}^{2}$ \\
\hline individual level & .178 & .178 & .173 & .177 & .172 & .173 \\
\hline unit level & .011 & .005 & .000 & .000 & .000 & .000 \\
\hline institution level & .000 & .000 & .000 & .000 & .000 & .000 \\
\hline \multicolumn{7}{|l|}{ Model fit } \\
\hline deviance (D) & 1031.60 & 1013.05 & 968.57 & 987.90 & 962.50 & 969.91 \\
\hline$\Delta$ model $1(\Delta \mathrm{D})$ & & $18.55^{\star}$ & & & & \\
\hline$\Delta$ model $2(\Delta \mathrm{D})$ & & & $44.48^{*}$ & $25.15^{\star}$ & & \\
\hline$\Delta$ model $3(\Delta \mathrm{D})$ & & & & & 6.07 & 1.34 \\
\hline$\Delta d f$ & & 7 & 3 & 3 & 3 & 1 \\
\hline $\mathrm{R}^{2}$ & & $3.2 \%$ & $8.5 \%$ & $6.3 \%$ & $9.1 \%$ & $8.5 \%$ \\
\hline
\end{tabular}

* $\mathrm{p} \leq .05$ regression coefficients: $b=$ unstandardized and $B=s$ tandardized \# reference category: ICU

$(\Delta D(3)=16.29, p \leq .05)$, indicating that the aggregated variables explain some of the variance of work motivation, particularly at the unit level (modelled variance: $10.4 \%$ ).

Model 5 provides a significant improvement in model fit compared with model 3 $(\Delta D(3)=11.71, p \leq .05)$. The aggregated variables are able to explain some variance that cannot be explained by the individual variables. The entire modelled variance is 12.8 per cent. Finally, model 6 shows a significant positive interaction effect at the individual level. Added to this, the aggregated job demands have a significant negative relationship with work motivation. In other words, higher levels of aggregated job demands are associated with lower levels of work motivation. 
Table 6.4 Results of the multi-level regression analyses with respect to work motivation ( $\rho$-values based on approximate Standard Errors provided by VARCL)

\begin{tabular}{|c|c|c|c|c|c|c|}
\hline Model & 1 & 2 & 3 & 4 & 5 & 6 \\
\hline Grand mean $\left(B_{0}\right)$ & 3.77 & 4.31 & 4.31 & 4.23 & 4.25 & 4.24 \\
\hline Individual level & $b$ & $\mathrm{~b}$ & $\mathrm{~b}$ & b & $b$ & $b(B)$ \\
\hline gender & & .09 & .10 & .09 & .10 & .11 \\
\hline age & & -.01 & -.01 & -.01 & -.01 & -.01 \\
\hline job demands & & & .02 & & .07 & .07 \\
\hline job autonomy & & & $.21^{*}$ & & $.20^{*}$ & $20^{*}$ \\
\hline dem $x$ aut & & & $.14^{*}$ & & $.13^{*}$ & $.14^{*}$ \\
\hline Unit level & $b$ & $b$ & $\mathrm{~b}$ & $b$ & $\mathrm{~b}$ & $\mathrm{~b}$ \\
\hline job demands & & & & $-.24^{*}$ & $-.31 *$ & $-.33^{*}(-.16)$ \\
\hline job autonomy & & & & $39 \star$ & .19 & $.13(.05)$ \\
\hline dem $x$ aut & & & & .52 & .36 & \\
\hline \multicolumn{7}{|l|}{ type of unit \# } \\
\hline psychiatric & & $-.29^{\star}$ & $-.31^{\star}$ & $-33^{\star}$ & $-.32^{\star}$ & $-.34^{\star}$ \\
\hline internal & & -.18 & -.20 & -.15 & -.16 & -.14 \\
\hline surgical & & -.17 & -.16 & -.08 & -.08 & -.07 \\
\hline somatic & & $-.47^{\star}$ & $-.40^{*}$ & $-.24^{\star}$ & $-.24^{\star}$ & $-26^{\star}$ \\
\hline psycho-geriatric & & $-.44^{\star}$ & -.41 * & $-.34^{\star}$ & $-.34^{*}$ & $-.34^{*}$ \\
\hline Variance decomposition & $\sigma_{e}^{2}$ & $\sigma_{e}^{2}$ & $\sigma_{e}^{2}$ & $\sigma_{e}^{2}$ & $\sigma_{e}^{2}$ & $\sigma_{e}^{2}$ \\
\hline individual level & .403 & .397 & .386 & .397 & .385 & 385 \\
\hline unit level & .046 & .036 & .034 & .024 & .025 & .026 \\
\hline institution level & .021 & .004 & .000 & .000 & .000 & .000 \\
\hline \multicolumn{7}{|l|}{ Model fit } \\
\hline deviance (D) & 1796.80 & 1766.93 & 1737.89 & 1750.64 & 1726.18 & 1727.28 \\
\hline$\Delta$ model $1(\Delta \mathrm{D})$ & & $29.87^{\star}$ & & & & \\
\hline$\Delta$ model $2(\Delta \mathrm{D})$ & & & $29.04^{\star}$ & $16.29^{*}$ & & \\
\hline$\Delta$ model $3(\Delta \mathrm{D})$ & & & & & $11.71^{\star}$ & \\
\hline$\Delta$ model $5(\Delta D)$ & & & & & & 1.10 \\
\hline$\Delta d f$ & & 7 & 3 & 3 & 3 & 1 \\
\hline$R^{2}$ & & $7.0 \%$ & $10.6 \%$ & $10.4 \%$ & $12.8 \%$ & $12.6 \%$ \\
\hline
\end{tabular}

* $p \leq 05$ regression coefficients: $b=$ unstandardized and $B=$ standardized $\quad$ \# reference category. ICU

The technique for examining the interaction between job demands and job autonomy is plotting the equations (cf. Aiken \& West, 1991). Following the method of Cohen and Cohen (1983), values of the predictor variables were chosen one standard deviation below and above the mean. Simple regression lines were then generated by entering these values in the regression equation. The results of the computations of these simple regression equations are given in figure 6.2 . 


\section{WORK MOTIVATION}

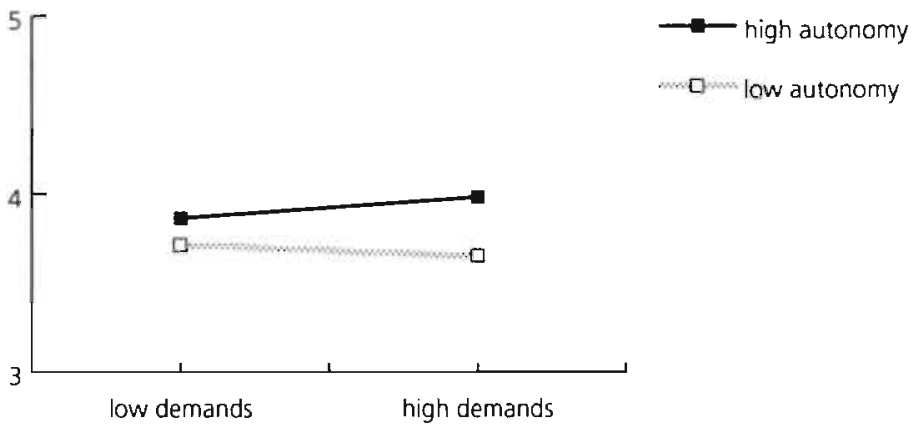

Figure 6.2 Graphical representation of the interaction among job demands and job autonomy in the prediction of work motivation (individual level)

The interaction term at individual level with regard to work motivation shows that job demands and work motivation are slightly positively related at high levels of autonomy. At the same time, however, demands and motivation are slightly negatively associated in the case of low levels of autonomy.

Finally, table 6.5 shows the results of the multi-level regression analyses with job satisfaction. The model fit improved significantly when the covariables are entered in the model $(\Delta D(7)=23.62, p \leq .05)$. The modelled variance is 4.7 per cent. Model 3 includes the three individual variables, and shows a significant improvement in model fit $(\Delta D(3)=37.50$, $p \leq 05)$. Model 3 reduced unexplained variance at all three levels; the total explained variance is 10.4 per cent. The fourth model contains the three aggregated variables, and shows a significant improvement in model fit compared with model $2(\Delta D(3)=24.60, p \leq .05)$. The entire explained variance of model 4 is 10.9 per cent.

Furthermore, the unit variables were added to model 3 , and led to a significant increment in fit of model $5(\Delta D(3)=12.14, p \leq .05)$. Once more the aggregated variables explain some variance that is not explained by the individual variables. The entire modelled variance is 13.2 per cent. Finally, the simplified sixth model shows a significant positive interaction effect at the unit level. Job demands and job autonomy at individual level have a significant negative and positive association with job satisfaction, respectively. That is, higher levels of individual job demands are related to lower levels of job satisfaction. Conversely, higher levels of job autonomy are associated with higher levels of job satisfaction.

Figure 6.3 shows the graphical representation of the interaction between job demands and job autonomy at unit level with regard to job satisfaction. It appears that job demands and job satisfaction are positively associated in the case of high levels of job autonomy. At low levels of job autonomy, however, job demands and job satisfaction are negatively related. 
Table 6.5 Results of the multi-level regression analyses with respect to jab satisfaction ( $p$-values based on approximate Standard Errors provided by VARCL)

\begin{tabular}{|c|c|c|c|c|c|c|}
\hline Model & 1 & 2 & 3 & 4 & 5 & 6 \\
\hline Grand mean $\left(B_{0}\right)$ & 3.88 & 3.97 & 3.96 & 3.90 & 3.93 & 3.93 \\
\hline Individual level & $b$ & $\mathrm{~b}$ & b & $\mathrm{b}$ & $\mathrm{b}$ & $b(B)$ \\
\hline gender & & $.23^{\star}$ & $.23^{\star}$ & $.21^{\star}$ & $22^{*}$ & $.21^{\star}$ \\
\hline age & & -.00 & -.00 &. .00 & -.00 & -.00 \\
\hline job demands & & & $-.22^{\star}$ & & $-.18^{\star}$ & $-.19 *(-.12)$ \\
\hline job autonomy & & & $.16^{\star}$ & & $15^{\star}$ & $.15^{\star}(.10)$ \\
\hline dem $\times$ aut & & & .15 & & .12 & \\
\hline Unit level & $\mathrm{b}$ & $\mathrm{b}$ & $\mathrm{b}$ & b & $\mathrm{b}$ & $\mathrm{b}$ \\
\hline job demands & & & & $-.40^{\star}$ & -.22 & -.22 \\
\hline job autonomy & & & & $.50^{\star}$ & .35 & .35 \\
\hline dem $x$ aut & & & & $1.25^{\star}$ & $1.12^{\star}$ & $1.26^{\star}$ \\
\hline \multicolumn{7}{|l|}{ type of unit \# } \\
\hline psychiatri & & $-.52^{\star}$ & $-.54^{\star}$ & $-.53^{\star}$ & $-.53^{\star}$ & $-.53^{\star}$ \\
\hline internal & & -.09 & -.05 & .05 & -.05 & -.05 \\
\hline surgical & & -.22 & -.15 & -.09 & -.09 & -.09 \\
\hline somatic & & -.31 & -.17 & .04 & .04 & .03 \\
\hline psycho-geriatric & & -.19 & -.12 & .04 & -.03 & -.04 \\
\hline Variance decomposition & $\sigma_{e}^{2}$ & $\sigma_{e}^{2}$ & $\sigma_{e}^{2}$ & $\sigma_{e}{ }^{2}$ & $\sigma_{e}{ }^{2}$ & $\sigma_{e}{ }^{\prime}$ \\
\hline individual level & .628 & .621 & .604 & .620 & .602 & .604 \\
\hline unit level & .085 & .049 & .035 & .026 & .028 & .027 \\
\hline institution level & .024 & .032 & .021 & .011 & .010 & .010 \\
\hline \multicolumn{7}{|l|}{ Model fit } \\
\hline deviance $(D)$ & 2197.32 & 2173.70 & 2136.20 & 2149.10 & 2124.06 & 2126.29 \\
\hline$\Delta$ model $1(\Delta D)$ & & $23.62^{\star}$ & & & & \\
\hline$\Delta$ model $2(\Delta D)$ & & & $37.50^{\star}$ & $24.60^{\star}$ & & \\
\hline$\Delta$ model $3(\Delta D)$ & & & & & $12.14^{\star}$ & \\
\hline$\Delta$ model $5(\Delta D)$ & & & & & & 2.23 \\
\hline$\Delta d f$ & & 7 & 3 & 3 & 3 & 1 \\
\hline$R^{2}$ & & $4.7 \%$ & $10.4 \%$ & $10.9 \%$ & $13.2 \%$ & $13.0 \%$ \\
\hline
\end{tabular}

* $p \leq 05$ regression coefficients: $b=$ unstandardized and $B=5$ tandardized \# reference category: ICU

In multi-level literature, our aggregated variables are considered to be contextual effects (Bosker \& Snijders, 1991; Raudenbush, 1989). The classic formulation of a contextual effect model involves a regression equation including both the individual variable(s) and the group variable(s). However, such a model might suffer from high collinearity, leading to poor precision in model fit (Aitkin \& Longford, 1986).

Our models 5 (tables 6.2 to 6.5 ) are such contextual effect models. To test whether the models are subject to high collinearity, we carried out ordinary regression analyses of model 5 with all four outcome variables. Collinearity was checked by means of the variance 


\section{JOB SATISFACTION}

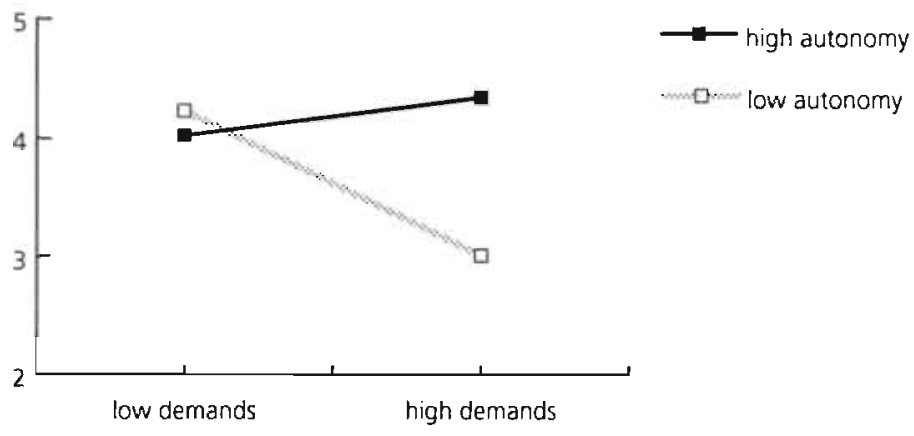

Figure 6.3 Graphical representation of the interaction among job demands and job autonomy in the prediction of job satisfaction (unit level)

Inflation Factor (VIF). A rule of thumb for evaluating VIFs is that one should be concerned about any value larger than 10.0 (Kleinbaum, Kupper \& Muller, 1988). The VIFs in our analyses did not exceed 3.3, which indicates that no collinearity problems are to be expected. All in all, it can be concluded that our contextual effect models do not suffer from high collinearity.

\subsection{Testing the Demand-Control-Support Model}

\subsubsection{Introduction}

In this section we will test Johnson and Hall's (1988) Demand-Control-Support Model. As we mentioned in chapter 3 , there are few studies available in which all the relationships in the DCS Model were estimated simultaneously. Therefore, we will try to evaluate the model by means of covariance structure modelling, as is described in the next subsection (6.4.2). We will not perform multi-level covariance structure modelling because: (1) this rather complex technique is still in its infancy (for examples, see Hox, 1994; Muthén, 1994); (2) unit as well as institutional random effects in MLA appeared to be small, especially after entering covariables and predictor variables; and (3) the multi-level models 3 and 6 fitted nearly equal (see also section 6.3). Subsection 6.4 .3 deals with the results of the hypothesized structural equation models. We intend to test the DCS Model by means of the following hypothesis:

H2) "Job autonomy, job demands and workplace social support have an interaction effect with respect to health (i.e., emotional exhaustion, anxiety) on the one hand, and well-being (i.e., job satisfaction, work motivation) on the other." 
Note that this model is tested against the null hypothesis that no interactive relationships exist. In other words, no rejection of the null hypothesis means that linear additive effects of the three job characteristics might be further examined, as postulated by Hackman and Oldham (1980)

\subsubsection{Data analysis}

Structural equation modelling (SEM) can be used to study causal models like the DCS Model. SEM can be considered a covariance structure analysis; that is, a multivariate technique which combines methodological and statistical contributions from the psychometric theory as well as the econometric theory (Diamantopoulos, 1994; Scott Long, 1983b). Basically, covariance structure analysis contains two components: (1) the measurement or factor-analytic model, which reduces observed variables to a smaller number of latent factors; and (2) the structural equation model, which defines (causal) relationships among these latent factors (cf. Jöreskog \& Sörbom, 1989: Scott Long, 1983b). In general, full covariance structure models consist of an integration of these two models. The present chapter simplifies the covariance structure model by assuming that the latent and observed variables are identical (i.e., each construct had only one operationalization). In other words, there are no specified measurement models in the analyses. The measurement models used have proved to be valid and reliable (see chapter 5 and section 6.2).

The basic objective of SEM is to provide a means of simultaneously testing hypothesized substantive models to account for a pattern of covariation among the (latent) variables (cf. Ecob \& Cuttance, 1987). Accordingly, the general latent variable model ${ }^{9}$ can be written as equation 6.3:

$\eta=B \eta+\Gamma \xi+\zeta$

where $B$ is a matrix of structural parameters relating the endogenous factors to one another, $\Gamma$ is a matrix of structural parameters relating the exogenous factors to the endogenous factors, and $\zeta$ is a vector of random disturbance terms, sometimes called errors in equations. The latter represent a summary of all known and unknown influences of the $\eta$ s which are uncorrelated with the $\xi$ s. Furthermore, $\Phi$ represents the covariance matrix of $\xi$, and $\Psi$ reflects the covariance matrix of $\zeta$ (Jöreskog \& Sörbom, 1989; Scott Long, 198b). Just as latent factors and unique factors are assumed to be uncorrelated in the measurement model, the exogenous variables and the errors in equations are assumed to be uncorrelated in the structural equation model.

The statistical model used in SEM is based on the fundamental premise that the corresponding theoretical model has been specified completely prior to any data analysis (Bentler \& Chou, 1987). In other words, the entire structure should be theoretically derived. If the empirical data are examined a priori, and hypotheses are formed after this examination, the statistical model may become incorrect because one may be capitalizing on chance data associations. 
So, the analysis is primarily confirmatory in nature: it investigates to what extent the postulated structure is actually consistent with the data. This is done by computing the estimated covariance matrix implied by the hypothesized model and comparing it to the covariance matrix based on the empirical data.

The corresponding covariance structure analysis was performed using the LISREL 8 computer programme (Jöreskog \& Sörbom, 1993a, 1993b). Jöreskog (1993) indicated several fit indices to investigate the overall fit of the model, namely the chi-square statistic (Chi-2, or $\chi^{2}$ ), the LISREL adjusted goodness-of-fit index (AGFI), the root-mean-square error of approximation (RMSEA; Browne \& Cudeck 1993; Steiger, 1990), the non-normed fit index (NNFI; Bentler \& Bonett, 1980), and finally the cross-validation index (CVI; Browne \& Cudeck, 1993; Cudeck \& Browne, 1983). The programme as well as the fit indices were extensively described in chapter 5 , and are therefore not repeated here.

First of all, gender (dummy variable) and age were introduced into the structural model as potential confounders. Therefore, they have to be labelled as exogenous variables (cf. Bollen, 1989, p. 126), and all other variables have to be labelled as endogenous variables (i.e., job characteristics and outcomes). Furthermore, it is theoretically hardly defensible to assume associations from gender and age to interactive terms. Consequently, these - eight relationships have initially been left out.

Next, four structural equation models were fitted to the two subsample covariance matrices in three steps. First, the specified model $M_{1}$ was compared with a very restrictive (null) model $\left(M_{0}\right)$ and a less restrictive (null) model $\left(M_{01}\right)$. The former $\left(M_{0}\right)$ is an independent model that assumes zero relationships between all variables, whereas the latter $\left(M_{01}\right)$ is less restrictive in the sense that only $B$ parameters were fixed to zero. In order to study the existence of linear additive relationships, the nested models $M_{1}$ and $M_{0}$, were compared by a likelihood ratio test, as mentioned in chapter 5 and section 6.3. Second, two models with and without interaction terms were compared $\left(M_{2}\right.$ and $M_{1}$, respectively). Accordingly, hypothesis $H_{1}$ (i.e., interactive relationships exist) was tested against the null hypothesis $H_{0}$ that there are no interaction effects (i.e., only linear additive relations exist).

Finally, in order to examine the robustness of the final model, a cross-validation procedure was followed that has been suggested by Browne and Cudeck (1993). We employed a double cross-validation in combination with a so-called "fixed-weights strategy" (cf. Cudeck \& Browne, 1983; Diamantopoulos, 1994; MacCallum, Roznowski, Mar \& Reith, 1994). Both split-sample covariance matrices were used to fit the proposed model and were mutually cross-validated. The fixed-weights strategy implies that only those parameters which represent the model-structure will be constrained (i.e., all linear weights). All variances and covariances (including error and residual terms) are allowed to be re-estimated. The rationale for this approach is that theoretical weights are identical for every individual in the population and are therefore not affected by sampling. On the other hand, (co)variances reflect (co)variation within a given group and, hence, are affected by sampling. 


\subsubsection{Results}

Prior to the LISREL analyses, the means, standard deviations, empirical ranges and zeroorder Pearson correlations of the variables were calculated (see appendix 4, tables A4.3 and A4.4). Covariance matrices were used in order to analyse the SEMs. Figure 6.4 shows the hypothetical structural equation model with interactive effects. The parameters to be estimated are: (1) regression coefficients linking gender and age with job characteristics as well as outcomes ( $\Gamma$ matrix); (2) regression coefficients linking job characteristics with psychological outcomes (B); (3) covariances between the exogenous variables $(\Phi)$; (4) residual covariances between the job characteristics $(\Psi)$. In addition, errors in equations predicting the four outcome variables $(\Psi)$ are allowed to correlate. Error caused by misspecification of the model would be reflected by these correlations. Such misspecifications might be caused by the existence of an additional variable that is not included in the model, but nevertheless is necessary to explain more fully the outcome variables (cf. MacCallum. Wegener, Uchino \& Fabrigar, 1993; Scott Long, 1983b).

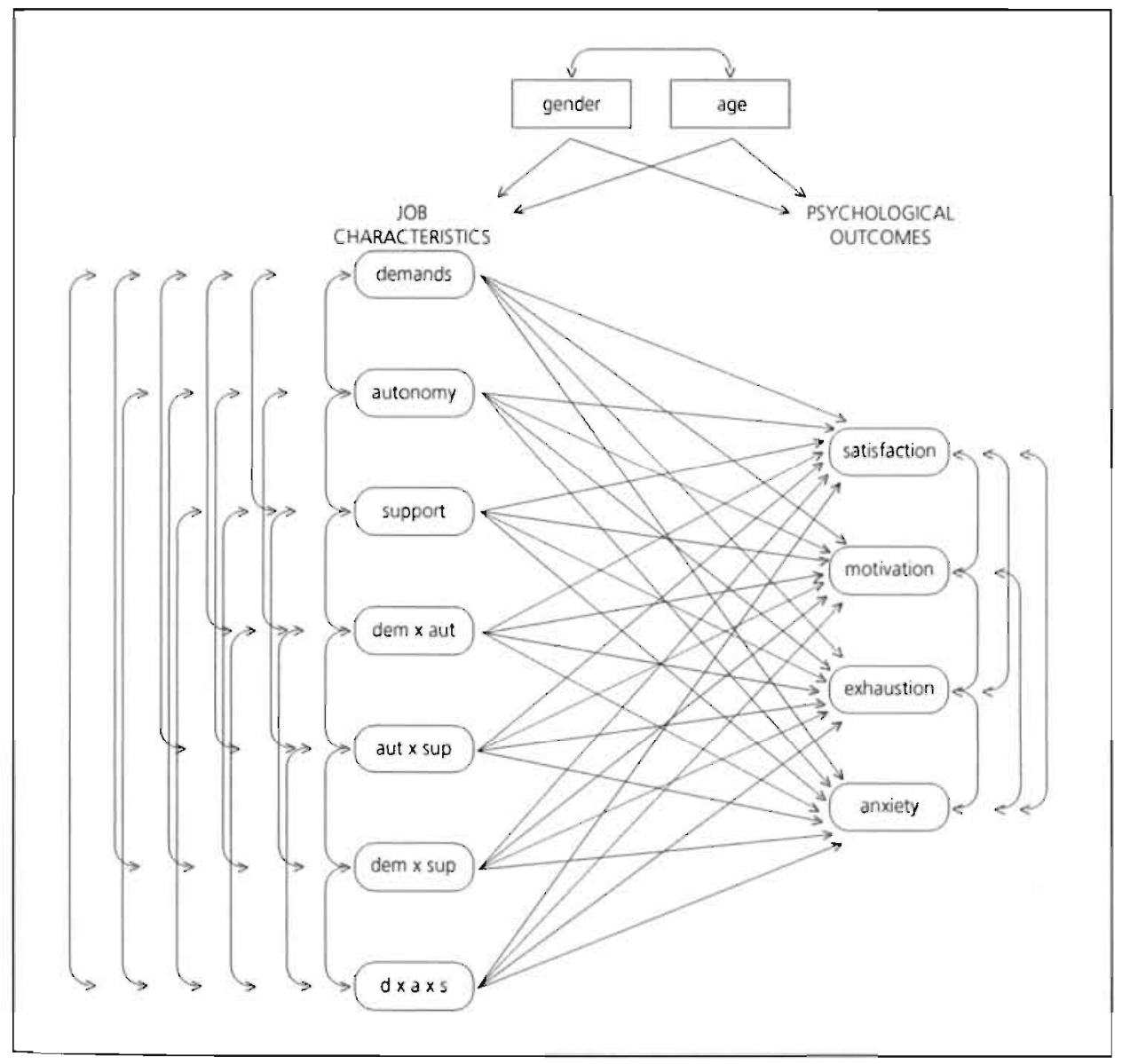

Figure 6.4 The hypothesized Demand-Control-Support (structural equation) Model 
After successful model identification tests ${ }^{10}$ have been performed, estimation of the model parameters can proceed. First, we will investigate whether linear additive relationships exist at all. The results of the nested models that address the linear additive relationships (i.e., $\mathrm{M}_{01}$ and $\mathrm{M}_{1}$ ) are presented in table 6.6. The hypothesis tests showed that the linear additive model $M_{1}$ has a better statistical fit than the model without linear additive relationships $\left(M_{01}\right)$ in both the calibration sample and the validation sample $\left(\Delta \chi^{2}(12)=296.47, p \leq .001\right.$, and $\Delta \chi^{2}(12)=266.59, p \leq .001$, respectively). Thus, we can proceed with the next analyses with regard to interactions.

The results of the nested models that address the interaction effects are presented in table 6.6 as well. Consider first the models with $\left(M_{2}\right)$ and without interaction effects $\left(M_{1}\right)$ of the calibration sample. The hypothesis test showed that the difference between the two chisquares is not significant $\left(\Delta \chi^{2}(16)=20.54, p=n . s\right.$.), which means that $H_{0}$ cannot be rejected". In the calibration sample, the additive model has a better statistical fit than the interactive model. Consider next the two competitive models (i.e., $M_{1}$ and $M_{2}$ ) of the validation sample. Again, the likelihood ratio test did not exceed a significant critical value $\left(\Delta \chi^{2}(16)=17.27, p=n .5\right.$.). indicating again that $H_{0}$ cannot be rejected. The additive model fits better than the interactive model in the validation sample.

Furthermore, model $M_{1}$ in both subsamples shows an acceptable fit as far as the practical fit indices are concerned. The NNFls are above .90 , indicating that, strictly speaking, model modifications are not necessary. Finally, we consider the cross-validation indices for the models in both subsamples. The findings show that the additive model $\left(M_{1}\right)$ in the calibration sample has the smallest discrepancy function value ( $C V I=.12)$; that is, this model appears to be most stable.

Table 6.6 Goodness-of-fit indices of nested structural models and squared multiple correlations of the four psychological outcomes (Demand-Control-Support Model)

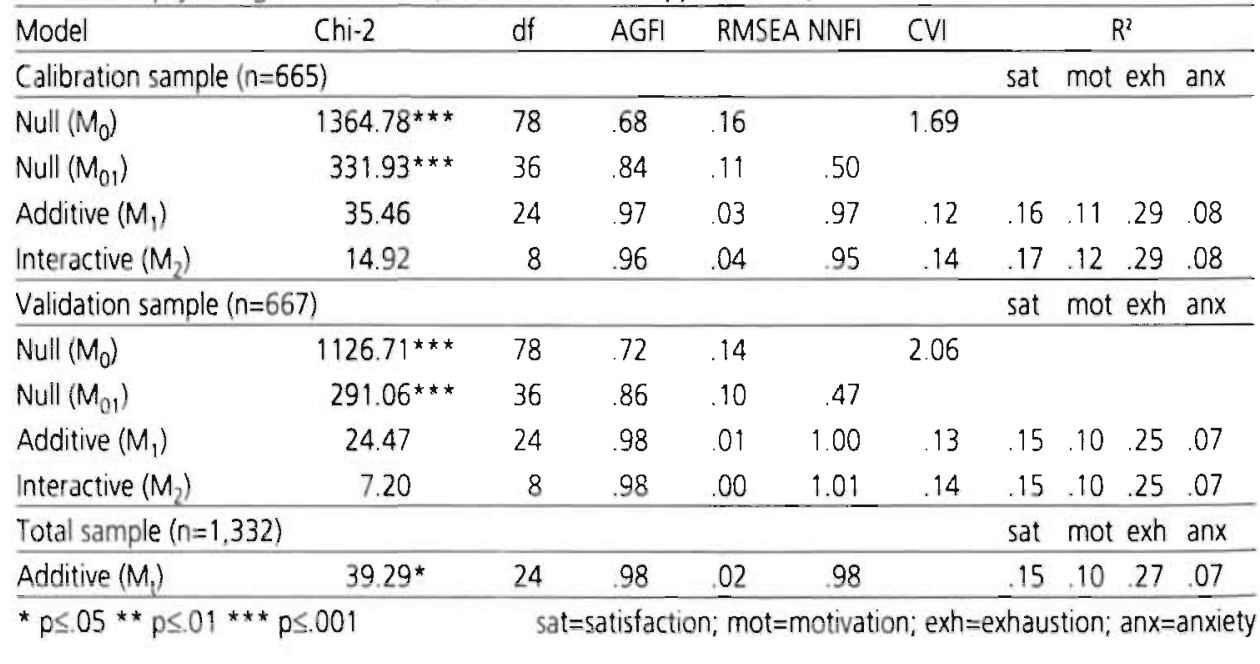




\section{INTERPRETING STRUCTURAL COEFFICIENTS}

The SEMS performed have shown that the additive models $\left(M_{1}\right)$ in both subsamples have the best fit indices and are most stable. In order to interpret the structural coefficients of these models as reliably as possible, raw data of both subsamples were combined into a single covariance matrix $(n=1,332)$. The chi-square statistic of the overall additive model $M_{t}$ was just significant ( $p \leq .05$ ), which means a poor statistical fit (table 6.6). The practical fit indices, however, show an acceptable fit. The magnitude of the squared multiple correlations $\left(\mathrm{R}^{2}\right)$ of the outcome variables ranges from .07 for job-related anxiety to .27 for emotional exhaustion (see model $M_{p}$ ).

Figure 6.5 shows the estimated structural coefficients of the overall additive model. This figure includes only the three job characteristics, the four psychological outcomes, and the two covariables. In other words, the four higher-order terms have been left out. The estimated structural coefficients can be interpreted as direct effects on the outcome variables. For example, $B_{i j}$ indicates that a unit change in the outcome variable $\eta_{j}$ results in a change of $\beta_{11}$ units in $\eta_{i}$, all other variables being held constant (Scott Long, 1983b). It should be noted that only significant relationships between job characteristics and psychological outcomes are shown'2. Added to this, in order to interpret the associations correctly, the standardized coefficients are presented in the figure (cf. Aiken \& West, 1991; Jaccard, Turrisi \& Wan, 1990).

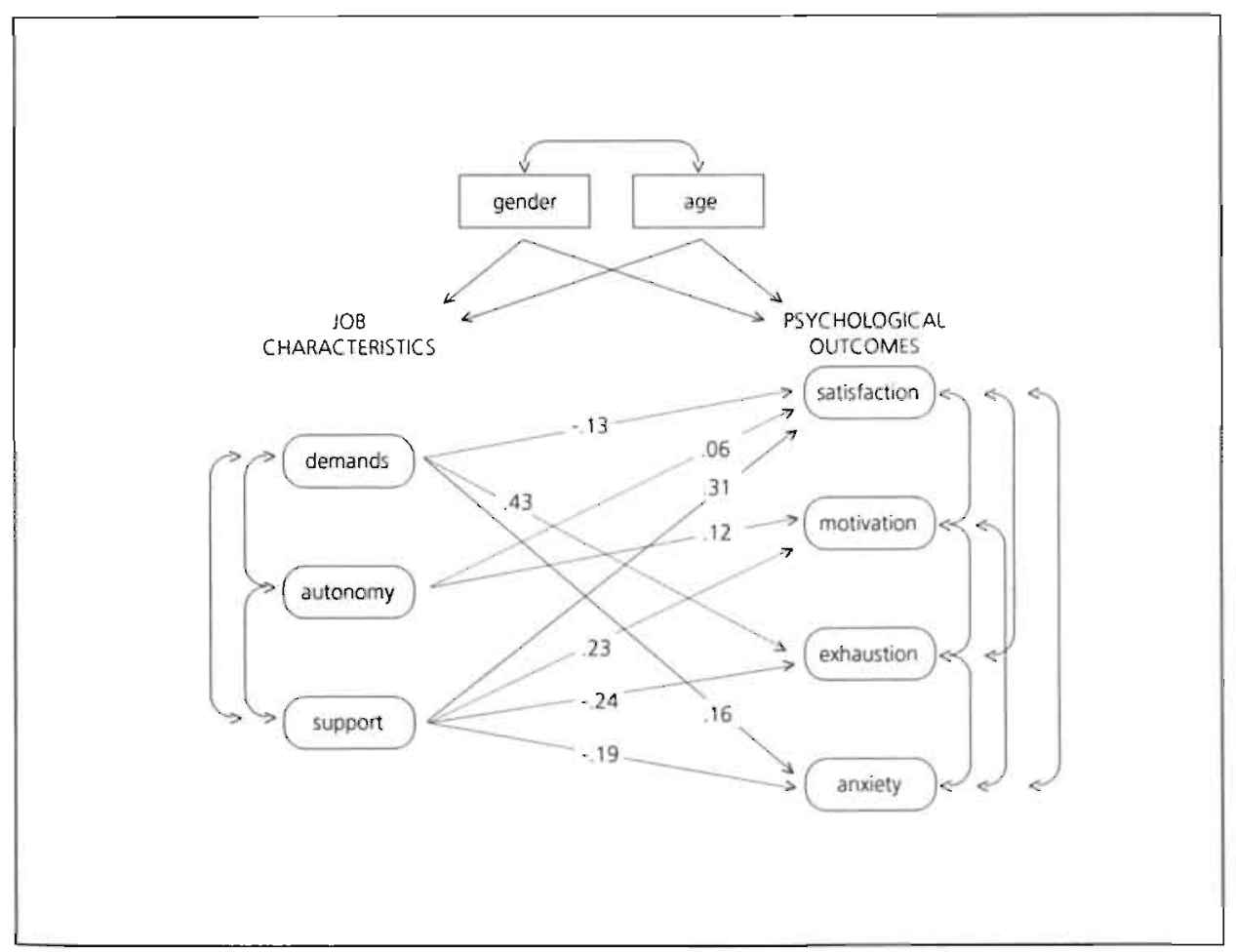

Figure 6.5 Linear additive (structural equation) model with significant standardized coefficients ( $p \leq 05$, two-tailed; total sample: $n=1,332$ ) 
Regarding the estimated and significant parameters, it appears that job autonomy is positively related with job satisfaction and work motivation. To be specific, high levels of job autonomy are associated with high levels of job satisfaction and work motivation. Additionally, job demands are positively related with emotional exhaustion and anxiety, and negatively related with job satisfaction. In other words, high levels of job demands are related to (1) high levels of emotional exhaustion and anxiety, and (2) low levels of job satisfaction. Finally, workplace social support shows significant relationships with all four outcome variables. High levels of social support are associated with high levels of job satisfaction and work motivation, and with low levels of emotional exhaustion and anxiety.

\subsection{Testing the Vitamin Model}

\subsubsection{Introduction}

So far, SEM indicated no evidence for interactive relationships between job characteristics and psychological outcomes. In this section we will test various aspects of the Vitamin Model (VM) of Warr (1987). More specifically, the question is whether job characteristics do act like psychological 'vitamins' in ways as predicted by the model. In line with the VM, we hypothesize that:

H3) "Job autonomy, job demands and work-related social support are curvilinearly associated with health (i.e., exhaustion, anxiety), and well-being (i.e., job satisfaction, work motivation)."

According to the categorization of job characteristics in $C E$ features and $A D$ features (see chapter 3, table 3.1), AD patterns (U-shaped) are expected in the case of all three job characteristics. Again, if the null hypothesis cannot be rejected, linear additive relationships might be further investigated. The computation of higher-order terms (i.e., non-linear terms) will be discussed in subsection 6.5.2. Finally, subsection 6.5.3 deals with the results of the structural equation modelling

\subsubsection{Data analysis}

Warr (1994) stated that multivariate and simultaneous tests of the VM are badly needed. We will therefore employ a comprehensive structural equation model that allows for a :minultaneous test of various aspects of the model. Analogous to section 6.4. SEM with double cross-validation was performed in order to test the multi-variable VM. Four structural models were fitted to the two subsample covariance matrices in three steps. First, a linear additive model $M_{1}$ was compared with two (null) models $M_{0}$ and $M_{01}$, and tested against the latter by means of a likelihood ratio test (see also sections 6.3 and 6.4). Second, a model $M_{2}$ with non-linear effects was specified. Hypothesis $H_{1}$ (i.e., non-linear relationships exist) was tested against the null hypothesis $H_{0}$ that there are no non-linear relationships (i.e.. only linear additive relations exist). Accordingly, the two nested models $M_{2}$ and $M_{1}$ were compared by a likelihood ratio test. Finally, the models fitted were refitted to the covariance matrix of the other subsample, and vice versa. 
Again, gender (dummy variable) and age were introduced into the structural model as potential confounders. Therefore, they have to be labelled as exogenous variables (cf. Bollen, 1989, p. 126), and all other variables have to be labelled as endogenous variables (i.e., job characteristics and psychological outcomes).

In addition, the VM suggests curvilinear relationships between job characteristics and psychological outcomes. Such relationships are appropriately modelled by including a linear as well as a squared term of a particular variable (Bollen, 1989; Hayduk, 1987; Kenny \& Judd, 1984). This was done by performing two analytic steps (cf. Aiken \& West. 1991; Jaccard. Turrisi \& Wan, 1990): (1) the three job characteristics (i.e., job autonomy, job demands and workplace social support) were mean-centred ${ }^{4}$ in order to prevent multicollinearity; (2) the squared terms of the job characteristics were computed from these centred variables. Finally, it is theoretically scarcely defensible to postulate associations from gender and age to curvilinear terms. Similar to the former model test (section 6.4), these - six - relationships have initially been left out.

\subsubsection{Results}

First of all, means, standard deviations, empirical ranges and zero-order Pearson correlations of the studied variables were computed (see appendix 4, tables A4.5 and A4.6). Again, covariance matrices were used in order to analyse the SEMs. The hypothetical structural equation model with non-linear relationships is shown in figure 6.6. The parameters to be estimated are: (1) regression coefficients linking gender and age with job characteristics as well as psychological outcomes ( $\Gamma$ matrix); (2) regression coefficients linking the job characteristics with the outcomes $(B)$; (3) covariances between the exogenous variables $(\Phi) ;(4)$ residual covariances between the job characteristics $(\Psi)$. In addition, errors in equations predicting the four outcome variables $(\Psi)$ are allowed to correlate.

The structural models were identified ${ }^{10}$ successfully; therefore, we are able to estimate the model parameters. Again, we will first investigate whether linear additive relationships exist at all. The results of the models that deal with the linear additive relationships (i.e., $M_{01}$ and $M_{1}$ ) are shown in table 6.7. The hypothesis tests showed that the linear additive model $M_{1}$ has a better statistical fit than the model without linear additive relationships $\left(M_{01}\right)$ in the calibration sample as well as the validation sample $\left(\Delta \chi^{2}(12)=296.48, \quad p \leq .001\right.$, and $\Delta \chi^{2}(12)=266.58, p \leq .001$, respectively). So, we can continue with the non-linear analytic tests.

Table 6.7 also summarizes the results of the nested models that include non-linear effects Consider first the models without $\left(M_{1}\right)$ and with non-linear effects $\left(M_{2}\right)$ of the calibration sample. The hypothesis test showed that the difference between the two chi-squares is significant $\left(\Delta \chi^{2}(12)=37.16, p \leq .001\right)$, which means that $H_{0}$ is rejected". The non-linear model has a better statistical fit than the linear model in the calibration sample. Consider next the linear $\left(\mathrm{M}_{1}\right)$ and non-linear model $\left(\mathrm{M}_{2}\right)$ of the validation sample. Again, the likelihood ratio test exceeded a significant critical value $\left(\Delta \chi^{2}(12)=27.12, p \leq 01\right)$, indicating that $H_{0}$ is rejected. Thus, the non-linear model fits better than the linear model in the validation sample as well. 


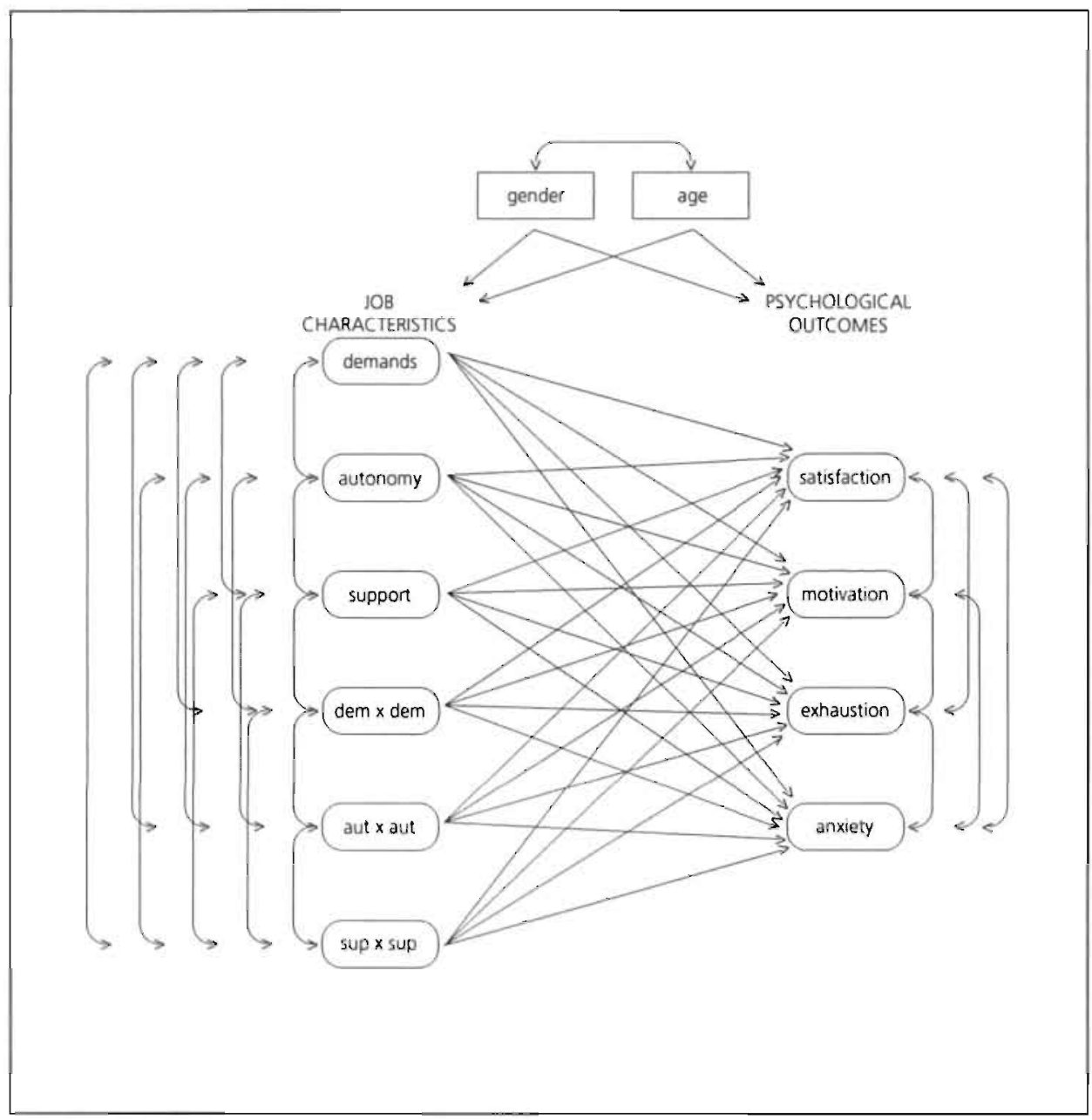

Figure 6.6 The hypothesized Vitamin (structural equation) Model

However, values of NNFI are still below .90, which means that the models can be further improved. The Modification Indices (Mls) of all four models revealed that one of the largest Mls refers to the fixed parameter connecting age to the cross-product of job autonomy. Since age is significantly correlated with the cross-product of job autonomy (see appendix 4 , table A4.6), the corresponding parameter has been relaxed in all models, resulting in four respecified models (see table 6.7). It appears that the modified non-linear models $\mathrm{SM}_{2}$ respecified) yield a non-significant chi-square value, which means a statistically good fit. Moreover, all respecified models show acceptable practical fit values, and all NNFls are greater than or equal to .90 .

Finally, we consider the cross-validation indices for the modified models in both subsamples. The results show that model $M_{1}$-respecified in the calibration sample has the smallest discrepancy function value (CVI=.14), indicating the most stable model. 
Table 6.7 Goodness-of-fit indices of nested structural models and squared multiple correlations of the four psychological outcomes (Vitamin Model)

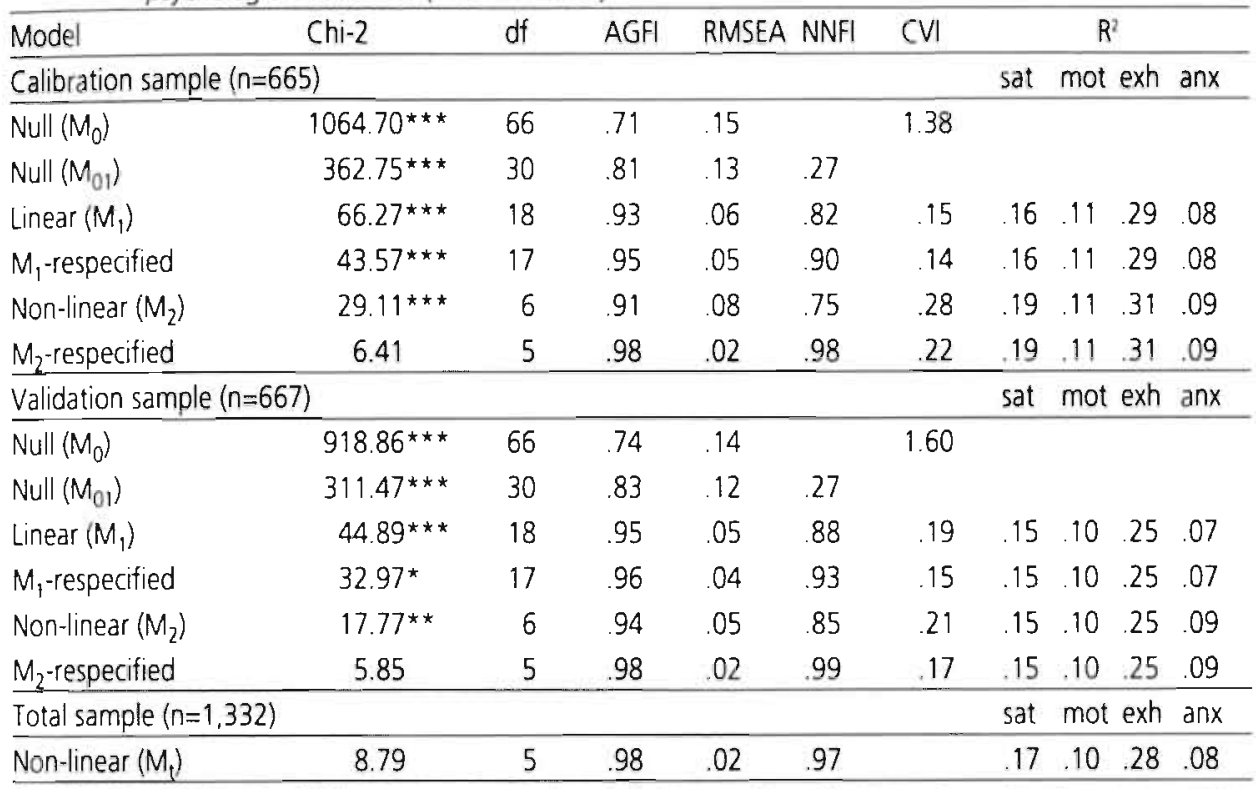

${ }^{*} p \leq .05 * * p \leq .01 * * * p \leq .001$

sat=satisfaction; mot=motivation; exh=exhaustion; anx=anxiety

\section{INTERPRETING STRUCTURAL COEFFICIENTS}

The respecified non-linear models in both subsamples yield the best fit indices. Both models. however, do not appear to be very stable across subsamples. Consequently, to interpret the estimated non-linear structural coefficients as reliably as possible, raw data of both subsamples were merged into a single covariance matrix $(n=1,332)$, that includes the three job characteristics and their corresponding cross-products, the four outcomes variables, and the two covariables. This overall non-linear model $M_{t}$ shows a statistically good fit and acceptable practical fit indices (table 6.7). The magnitude of the squared multiple correlations $\left(R^{2}\right)$ of the outcome variables ranges from .08 for job-related anxiety to 28 for emotional exhaustion (see model $M_{1}$ ).

Figure 6.7 represents the estimated structural coefficients of the modified non-linear model ( $\mathrm{M}_{2}$-respecified), based on the whole sample. In order to interpret the non-linear relationships correctly, significant FIML coefficients between job characteristics and psychological outcomes are shown'2. It should be noted that there is one non-significant FIML coefficient in the model (i.e., the dotted line from job autonomy to exhaustion) because of hierarchical statistical procedures (cf. Bishop, Fienberg \& Holland, 1975; Kleinbaum, Kupper \& Muller, 1988). 


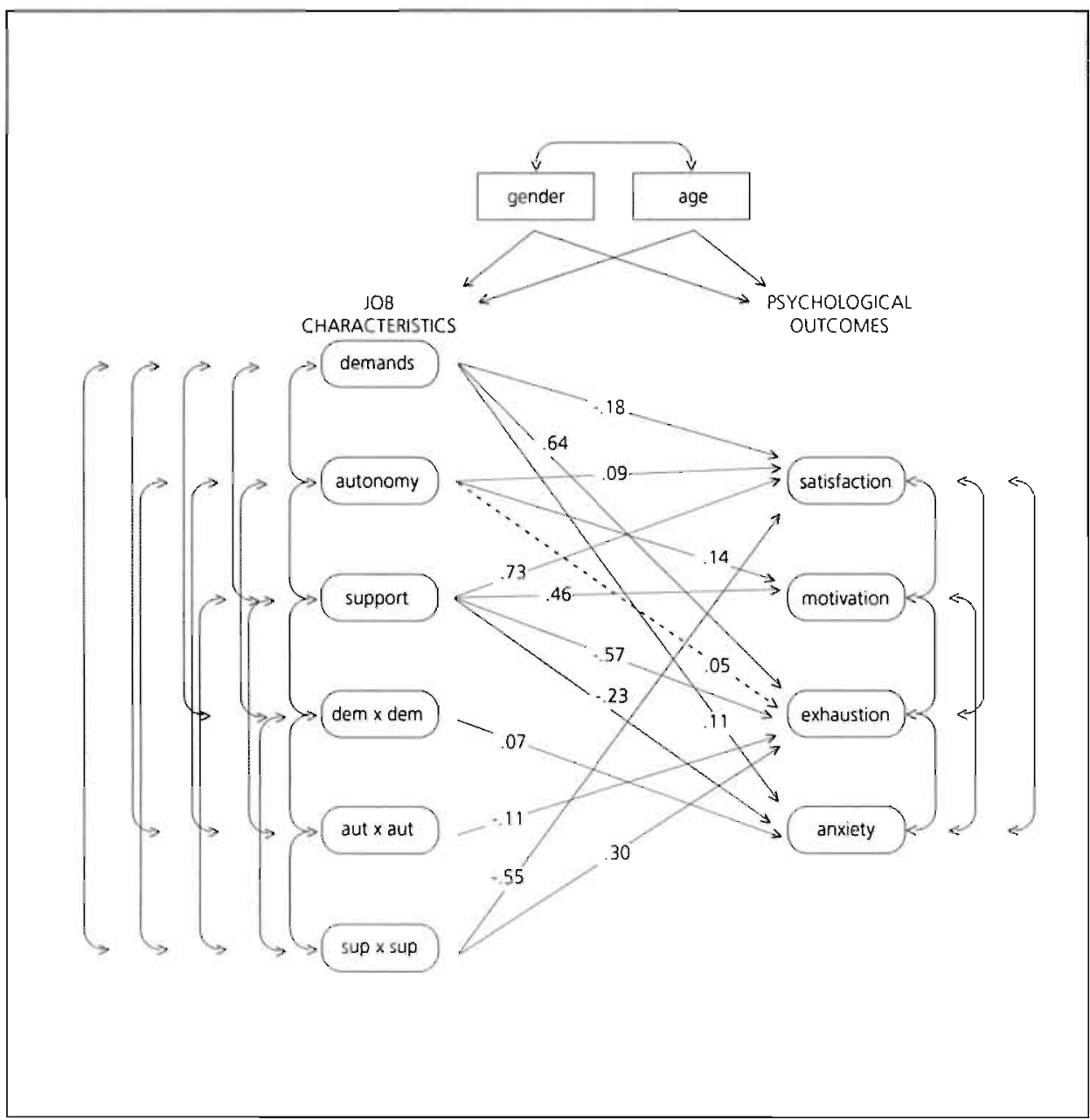

Figure 6.7 Non-linear Vitamin (structural equation) Model with significant FIML coefficients ( $p \leq 05$, two-tailed; total sample: $n=1,332$ )

A closer inspection of the non-linear model in figure 6.7 reveals four significant curvilinear relationships between:

1) job demands and anxiety;

2) job autonomy and emotional exhaustion;

3) social support and job satisfaction;

4) social support and emotional exhaustion.

In figures 6.8 to 6.11 the significant non-linear effects are graphically represented according to the method described by Aiken and West (1991). Following hierarchical statistical principles, the regression equation consists of the squared term as well as the main term of a job characteristic. All other variables were assumed to have average levels and hence were not involved in the equations. Except for figure 6.9, all other figures show the AD pattern as 
postulated by the VM. Since anxiety and emotional exhaustion are negative outcomes, the expected $A D$ pattern is indicated by a U-shape instead of an inverted U-shape (figures 6.8 . 6.9 and 6.11). To be more specific, the results show that: (1) low and particularly high levels of job demands are related with higher levels of job-related anxiety; (2) low and to a lesser extent high levels of social support are associated with lower levels of job satisfaction as well as higher feelings of exhaustion. Contrary to expectations, the curvilinear pattern of job autonomy is somewhat different. Instead of a U-shaped curve, an inverted U-shaped curve is found: low and high levels of job autonomy are associated with relatively low levels of exhaustion.

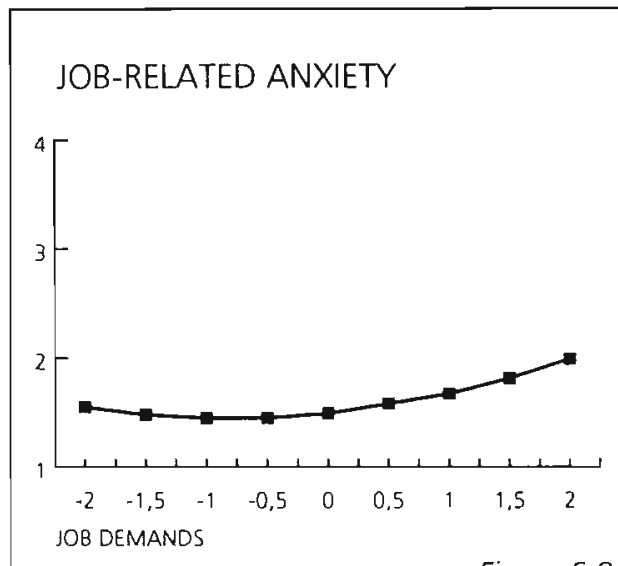

Figure 6.8

\section{JOB SATISFACTION}

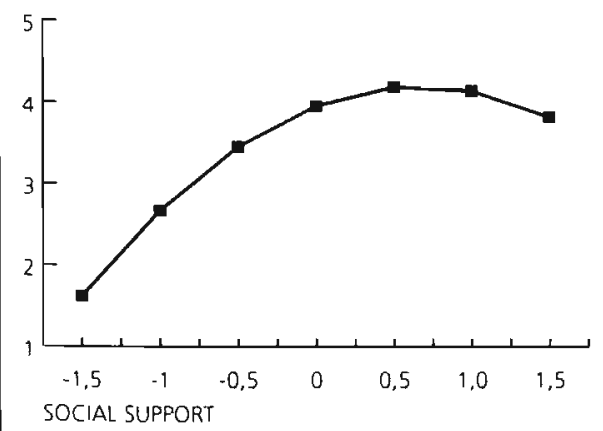

Figure 6.10

\section{EMOTIONAL EXHAUSTION}

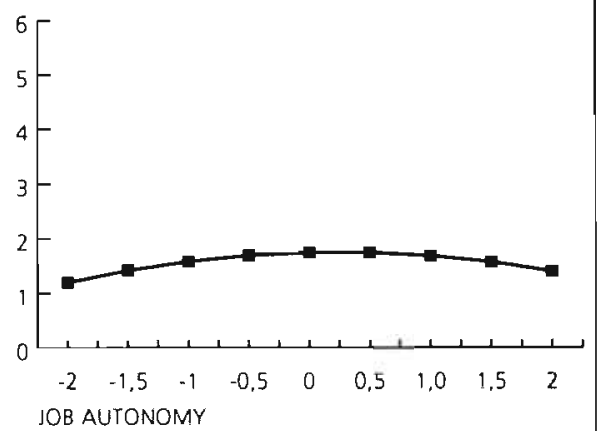

Figure 6.9

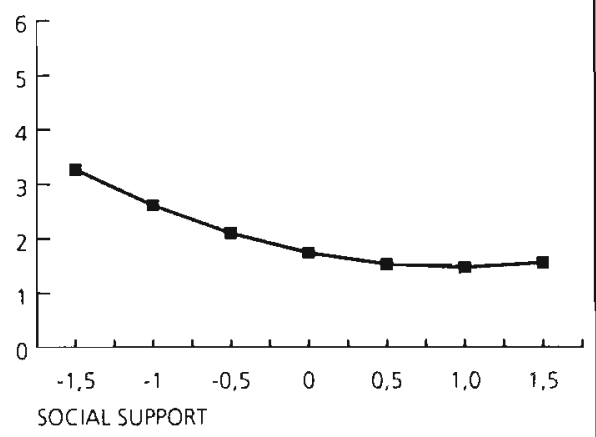

Figure 6.11

Figures 6.8-6.11 Graphical representations of the non-linear relationships (total sample: $n=1,332$ ) 


\subsection{Summary}

This chapter discussed the findings of our cross-sectional analysis. Health care workers from the first measurement point were used as study sample. After some preparatory psychometric analyses, we tested our theoretical models, which were described in chapter 3. The analyses tried to provide an answer on (1) the assessment of job characteristics in the prediction of psychological outcomes, and (2) the form of relationship between job characteristics and psychological outcomes. Regarding the assessment of job characteristics in the prediction of health and well-being, the results showed that emotional exhaustion and jobrelated anxiety were predicted by the main effects of individual job demands as well as aggregated job demands. However, the aggregated variables could not explain the unexplained variance in the individual-level model. Additionally, work motivation and job satisfaction were predicted by the interaction effects of job demands and job autonomy, at individual and aggregated level, respectively. Moreover, the aggregated variables were able to explain some variance that could not be explained by the individual variables. Finally, it seemed that the significant relationships between aggregated variables and psychological outcomes were quite similar to the relationships between individual variables and outcomes. Regarding the particular form of relationship between job characteristics and psychological outcomes, we found little support for interaction effects, and moderate support for curvilinear effects. However, cross-validation showed that the linear structural models were most stable. To be more specific, the results with respect to job autonomy showed evidence for: (1) a positive interactive relationship (in combination with job demands) with respect to work motivation and job satisfaction (MLA only); (2) a positive linear association with work motivation and job satisfaction (MLA \& SEM); and (3) a curvilinear relationship (inverted Ushaped) with emotional exhaustion (SEM).

Altogether, the results indicated that (1) job autonomy is specially related with components of well-being, (2) job demands are in particular associated with aspects of health, and (3) workplace social support is related to both well-being and health.

So far, we have provided evidence for the form of relationships between job characteristics (job autonomy in particular) and psychological outcomes. However, one question still needs to be answered. That is, what is the direction of the relationship between job characteristics and psychological outcomes? In other words, do job characteristics cause outcomes, or do psychological outcomes affect perceptions of job characteristics? We will now turn to a longitudinal panel analysis in the next chapter, which will deal with this particular query.

\section{NOTES}

1. Parts of this chapter are based on several manuscripts ( $f$. De Jonge, Van Breukelen, Landeweerd \& Nijhuis, 1995; De Jonge, Janssen \& Van Breukelen, in press; De Jonge, Janssen \& Landeweerd, 1994; De Jonge, Schaufeli \& Furda, 1995; De Jonge \& Schaufeli, 1995). 
2. Strictly speaking, the analyses which will be performed are not complete model tests of the entire Demand-Control-Support Model or the whole Vitamin Model. in fact, we will test only parts of these models, because not all exogenous and endogenous variables proposed by the founders will be involved. For convenience sake, we call our analyses a 'test' of the Demand-Control-Support Model and a 'test' of the Vitamin Model.

3. For purposes of statistical identification and in order to establish the scale of metric, one of the free parameters being estimated for each factor should be fixed to one (cf. Benson \& Bandalos, 1992; Byrne, 1989).

4. A set of scores is centred by subtracting the overall mean from each 'individual' score. In that case, centred scores have a mean of zero ( $f$. Kleinbaum, Kupper \& Muller, 1988).

5. A halo effect is a tendency for the rating of one job characteristic to influence the ratings of other job characteristics. It seems to be particularly strong in characteristics that are not clearly defined and not easily observable (d. Kerlinger, 1986).

6. The theoretical rationale for aggregating social support measures as well was not totally clear. In addition, the multi-level analysis described is meant to be explorative. Therefore, we tested only Karasek's basic model.

7. Licence number: 90.LNA.01.023. Groningen: iec ProGAMMA.

8. In the literature, covariance structure analysis is also referred to as "structural equation modelling" or "causal modelling" ( $d$. Diamantopoulos, 1994). In order to be consistent, and hence not confusing, we prefer "covariance structure analysis" as the overall multivariate technique, while preserving "structural equation modelling" for the specified second part of the technique.

9. The Greek symbols used are standard LISREL notation. Appendix 3 gives an English translation of the symbols used.

10. The LISREL programme was used to check the identification status of the SEMS (cf. Hayduk, 1987; Jöreskog \& Sörbom, 1989). We first chose a set of reasonable values for all model parameters and obtained the population covariance matrix $\Sigma$ implied by these values. This created $\Sigma$ was then entered as 'data' into LISREL in a run using the same initial estimates. If this results in the same estimated values as those used to generate $\Sigma$, then it is most likely that the model is identified.

11. Generally, the assumption of a multinormal distribution for interaction terms as well as non-linear terms is not tenable (Kenny $\&$ Judd, 1984). So, the presence of these nonnormal higher-order variables may cause invalid FIML-based $\chi^{2}$-tests and, as a consequence, invalid likelihood ratio test statistics. Whether this was the case or not, we performed LISREL analyses with a polychoric correlation matrix and a Weighted Least Squares (WLS) method of estimation (see Jöreskog \& Sörbom, 1989, p. 192). The results showed very small differences between the FIML estimator and the WLS estimator, which means that the outcomes of the likelihood ratio tests were tenable.

12. Not surprisingly, several significant relationships exist between (1) demographic variables and job characteristics, (2) demographic variables and outcomes, (3) job characteristics themselves, (4) outcomes themselves, (5) demographic variables themselves, and (6) error terms. For the sake of brevity, their size and magnitude are not shown in the figures. For a summary of these findings, see appendix 5 , tables A5.1 or A5.2. 


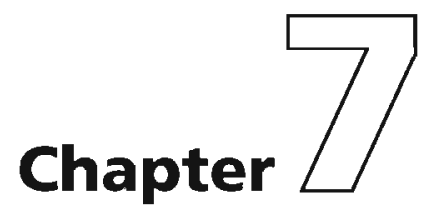




\section{LONGITUDINAL ANALYSIS}

\subsection{Introduction}

This chapter contains the results of the analyses on the data from the panel survey. To be more specific, we will use the health care workers who supplied the data at two measurement points with a one-year interval (see chapter 4 ). The chapter has the following structure:

Section 7.2 deals with two specific preliminary analyses. Firstly, we will perform a test of measurement invariance of the second-order three-factor structure of the job characteristics across time. Secondly, we will check for causal homogeneity in the sample. In the next section (7.3), the outcomes of a longitudinal panel model are presented. Finally, section 7.4 is a summary of this chapter.

\subsection{Preliminary analysis}

In chapter 6 it was concluded that a second-order three-factor solution of job autonomy, job demands, and workplace social support was a more parsimonious representation of five first-order latent factors. We proceeded to test the factorial invariance of this structure over time (cf. Byrne, 1989; see also chapter 5). If this three-factor model holds over time, change scores will reflect changes in the job characteristics rather than changes in the factor structure. Accordingly, several hypotheses were formulated in order to test:

1) the overall inequality of all factorial components (reflected by model A);

2) the equality of first-order factor loadings across time (reflected by model $B$; that is, $\mathrm{H}_{0}$ : $\Lambda_{1}=\Lambda_{2}$, where 1 and 2 are the two measurement points);

3) the equality of second-order factor loadings across time (reflected by model $C$; that is, $\left.H_{0}: \Gamma_{1}=\Gamma_{2}\right)$;

4) the equality of second-order factor correlations across time (reflected by model $D$; that is, $\left.\mathrm{H}_{0}: \Phi_{1}=\Phi_{2}\right)$;

5) the equality of first-order error variances across measurement occasions (reflected by model $\mathrm{E}$; that is, $\left.\mathrm{H}_{0}: \Theta_{1}=\Theta_{2}\right)$;

6) the equality of second-order error variances across time (reflected by model $F$; that is, $H_{0}: \Psi_{1}=\Psi_{2}$ ).

Similar to chapter 5, model $A$ is our basic model, and mirrors a kind of alternative hypothesis $\left(H_{1}\right)$. Covariance matrices which represent items of both measurement points were used in order to analyse the longitudinal CFA models. A model in which certain parameters are constrained to be equal across time was compared with a less restrictive model in which the same parameters are free to take on any value. The difference in fit between the model and the more restrictive model was computed. If the difference in chisquare statistic $\left(\Delta C h i-2\right.$, or $\left.\Delta \chi^{2}\right)$ is not significant, the hypothesis of an invariant pattern is considered tenable 
Again, it might be theoretically reasonable to impose an equality restriction on the secondorder factor loadings with regard to job autonomy and social support (i.e., $\gamma_{11}=\gamma_{21}, \gamma_{43}=\gamma_{53}$, $\gamma_{64}=\gamma_{74}$, and $\gamma_{96}=\gamma_{10,6}$; see also chapter 6). Finally, missing observations were handled by listwise deletion (i.e., a global missing value code for all items was assumed).

Table 7.1 Simultaneous tests of invariance for the second-order factorial model ( $p$ anel group; $n=225$ )

\begin{tabular}{lllrr}
\hline Model & Chi-2 & df & $\Delta$ Chi-2 & $\Delta$ df \\
\hline Model A & $2870.04^{\star \star \star}$ & 1465 & & \\
\hline Model B & $2887.76^{\star \star \star}$ & 1488 & 17.72 & 23 \\
Model C & $2872.35^{\star \star \star}$ & 1468 & 2.31 & 3 \\
Model D & $2879.60^{\star \star \star}$ & 1468 & $9.56^{\star}$ & 3 \\
Model E & $2916.12^{\star \star \star}$ & 1493 & $46.08^{\star}$ & 28 \\
Model F & $2880.67^{\star \star *}$ & 1469 & $10.63^{\star}$ & 4 \\
\hline
\end{tabular}

${ }^{*} p \leq .05^{\star *} p \leq .011^{\star \star *} p \leq .001$

Table 7.1 shows the results of the tests of factorial invariance. First, the overall chi-square statistics are presented, indicating highly significant values. Second, the hypothesis of an invariant pattern of first-order factor loadings was tested by examining the chi-square values of model $A$ and model $B$, respectively. The difference in chi-square was not significant, indicating an invariant pattern of first-order factor loadings. Similarly, table 7.1 reports that invariant patterns of second-order factor loadings are tenable. The difference in chi-square was not significant. However, since the difference in chi-square between model A and model D was (just) significant, the second-order factor correlations are not equal across the two measurement points. Finally, both the first-order error variances and the second-order error variances show significant chi-square differences, which means that these factors are sources of inequality too. These two kinds of error variances are also not invariant over time. Next we shall consider the test-retest reliability of the three measurement scales. These values for job autonomy, job demands and social support are 64,72 and .59 , respectively. This indicates that the scales are relatively stable over time.

In sum, the data support the conclusion that an invariant pattern of the three-factor structure of job autonomy, job demands and workplace social support thus exists. Additionally, the three factors seem to be relatively stable over time.

As we noted in chapter 4 , a serious problem of panel studies is that of panel loss or attrition. In our study, the question is whether disappearance from the sample is not the outcome of a causal dynamic that is different from that of the survivors. To find out whether this is the case or not, it is advisable to check for causal homogeneity in the sample before performing the model tests (cf. Hagenaars, 1990; Kessler \& Greenberg, 1981). In other words, causal relationships should be (nearly) the same for respondents and nonrespondents (i.e., drop-outs). Therefore, cross-sectional multi-sample structural equation analyses were performed to test whether the relationships are equal for both groups (i.e., 261 respondents and 64 drop-outs of the first measurement). More specifically, we tested 
the hypothesis that the pattern of relationships between job characteristics and outcome variables is invariant across groups (i.e., $\mathrm{H}_{0}: \mathrm{B}_{1}=\mathrm{B}_{2}$, where 1 and 2 are the two groups). The results showed that the difference in chi-square was not significant $\left(\Delta \chi^{2}(12)=9.09, p=n\right.$.s. $)$, indicating that an invariant pattern of relationships is tenable. It seems therefore that disappearance from the sample is not likely to be a result of different causal dynamics. Both groups prove to be quite comparable in terms of internal consistency as well as in terms of the pattern of relationships between job characteristics and psychological outcomes. We will use this information in the discussion of this study (chapter 8).

\subsection{Structural equation modelling of longitudinal panel data}

\subsubsection{Introduction}

This section deals with a longitudinal test of our panel data. The previous tests of our theoretical models, based on cross-sectional data, could only provide evidence for associations between job characteristics and psychological outcomes. However, they could not show evidence for causal predominance'. We could, for instance, not assess the effects of earlier levels of job autonomy on the psychological outcomes.

We speak about a causal relationship between two variables $X$ and $Y$ if there is an association of some sort between them, if there is evidence about the direction of causality, and if other explanations can be ruled out (Frese \& Zapf, 1988; Kessler \& Greenberg, 1981). For example, a statistical association between job autonomy and job satisfaction may mean that job autonomy causes job satisfaction, but it may also mean that (1) satisfaction causes autonomy, (2) autonomy and satisfaction are each causes of the other, or (3) there is error in the measurement of job autonomy and job satisfaction.

All these possibilities are not mutually exclusive; some of them may be true at the same time. Generally speaking, the goal will be to estimate the contribution of several mechanisms to the observed correlation.

We will use a first-order model (i.e., a model with only linear additive effects over time) to test causal relationships for several reasons. Firstly, it is theoretically hardly defensible to assume a causal pattern from time 1 psychological outcomes to time 2 interactive or curvilinear terms. Secondly, the results in chapter 6 showed evidence for (1) a linear additive model, and (2) a curvilinear model, but only 4 out of 12 curvilinear terms (i.e., $33 \%$ ) appeared to be significant. The validity of the curvilinear findings is somewhat limited accordingly. Moreover, cross-validation showed that the linear models were most stable. Finally, the main purpose of the present chapter is not to test the form of associations, but the direction of relationships.

The remainder of this section will be concerned with the evaluation of direction of causality. Panel data will be used to detect causal priority between job characteristics and psychological outcomes. According to our theoretical models discussed in chapter 3, one central hypothesis can be formulated: 
H4) "Job characteristics at measurement 1 influence heaith and well-being at measurement 2."

Added to this, two research questions will be posed in order to investigate a few alternative propositions, which were mentioned in chapter 3.

Q4) "Do health and well-being at measurement 1 affect perceptions of job characteristics at measurement 2?"

Q5) "Do job characteristics and health and well-being mutually influencer each other in an asymmetric way?"

In subsection 7.3.2, structural equation modelling applied to longitudinal data will be explained. The final subsection deals with the findings of the hypothesized structural equation models (7.3.3)

\subsubsection{Data-analysis}

We start our discussion of causal predominance in our panel data by describing the most general model in which two variables $X$ and $Y$ are measured at time 1 and time 2 The corresponding path diagram of this two-wave, two-variable model is shown in figure 7.1 According to figure 7.1, six correlations among $X_{1}, X_{2}, Y_{1}$ and $Y_{2}$ can be estimated: two contemporaneous (or synchronous) correlations $\left(X_{1} Y_{1}\right.$ and $\left.X_{2} Y_{2}\right)$; two test-retest correlations $\left(X_{1} X_{2}\right.$ and $\left.Y_{1} Y_{2}\right)$; and two cross-lagged correlations $\left(X_{1} Y_{2}\right.$ and $\left.Y_{1} X_{2}\right)$.

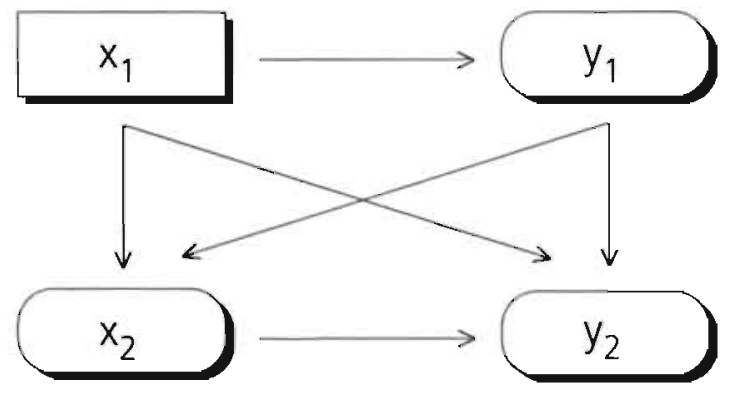

Figure 7.1 A general two-wave, two-variable model 
Several statistical techniques have appeared for analysing panel data, such as cross-lagged panel correlational analysis, path regression analysis, and structural equation modelling (Rogosa, 1980, 1987).

Cross-lagged panel correlational analysis (CLPC) is a technique to assess the relative importance of two variables in a causal analysis by comparing the lagged zero-order correlations (cf. Campbell, 1963). Although this technique has been widely used in the social sciences, it has received considerable criticism (e.g., Dooley, 1984; Hagenaars, 1990; Kessler \& Greenberg, 1981; Rogosa, 1980, 1987). The first critical point is concerned with "synchronicity". The initial approach of comparing two cross-lagged correlations was shown to be unsatisfactory, because misspecified causal lags can create significant crosslagged correlational differences even when they do not exist in reality. Second, potential bias may be caused by a problem called "stationarity"; that is, causal processes are assumed to be the same at both measurement points. If it happens that the relationship between two variables changes through time, the cross-lagged correlations will attenuate in ways unrelated to the causal influences. Third, lagged correlations are determined not only by differences in causal influences, but also by the stabilities of the measurements scales. CLPC will erroneously tend to favour the variable with the lower stability as the cause.

As a result, path regression analysis is preferred (e.g., Dooley, 1984; Kessler \& Greenberg, 1981). This technique allows for a comparison of (cross-lagged) partial regression coefficients in a variety of ways. An additional advantage of this technique is to study a wider variety of panel models (i.e., more than two variables) than the simple cross-lagged model. However, in order to judge the fit of the model as a whole, taking into account all equations simultaneously, we will perform a more comprehensive technique, namely structural equation modelling.

Several assumptions about causal associations have to be made before we can infer causal direction from parameter estimates. The first is that time 1 variables as well as time 2 variables are obtained each at the same time points, also called the synchronicity assumption. This assumption is implicit in our two measurement points (see chapter 4). The time 1 variables were measured in April-May 1993, and the time 2 variables about one year later. The second assumption is stationarity, meaning that the causal structures for the variables do not change over time ( $c$. James, Mulaik \& Brett, 1982). We can check this assumption by testing the equivalence of the synchronous correlations, which are the associations between different variables at the same time points (i.e., $X_{1} Y_{1}=X_{2} Y_{2}$ in figure 7.1). Kenny (1975) introduces a third assumption called homogeneous stability. Equal testretest reliabilities for $X$ and $Y$ (measured without error) are consistent with this assumption. However, differential stability can be controlled for by means of structural equation modelling and, consequently, needs no further discussion.

A final assumption has to do with the self-containment of a structural equation model. Technically, a structural equation model is self-contained if all relevant causes for the outcome variables are included in the equations (James \& James, 1989). This condition is the Achilles heel of structural equation modelling because it is scarcely possible to know whether this has been reasonably satisfied (James, 1980). To deal with the unmeasured 
variables problem statistically, errors in equations predicting the four outcome variables (time 1 and time 2, respectively) are allowed to correlate (see also chapter 6). Moreover, in the case of a not self-contained model, the actual degrees of bias in parameter estimates are also unknown, and may not be severe in well-developed conceptual models (cf. James, 1980). Figure 7.2 shows a variant of the general panel model, as shown in figure 7.1. Structural equation modelling (SEM) with full information maximum likelihood (FIML) estimation was used to assess the fit of this panel (structural equation) model. Note that the panel model consists of regression coefficients linking the job characteristics with the outcomes (numbered 1 and 2 in figure 7.2; B matrix), differential cross-lagged regression coefficients (numbered 3 and 4 in figure $7.2 ; B$ ), test-retest coefficients between the measurement scales $(B)$, covariances between the exogenous variables $(\Phi)$, residual covariances between the job characteristics $(\Psi)$, and errors in equations $(\Psi)$. Moreover, time 1 gender (dummy variable) and time 1 age were introduced into the panel model as potential confounders. Consequently, these demographic characteristics were labelled as exogenous variables (cf. Bollen, 1989, p. 126), and all other variables were labelled as endogenous variables (i.e.. the job characteristics and psychological outcomes). Finally, we assume that gender and age were directly related to the time 1 variables ( $\Gamma$ matrix), and only indirectly to the time 2 variables (i.e., by way of test-retest coefficients (B) from time 1 variables to time 2 variables).

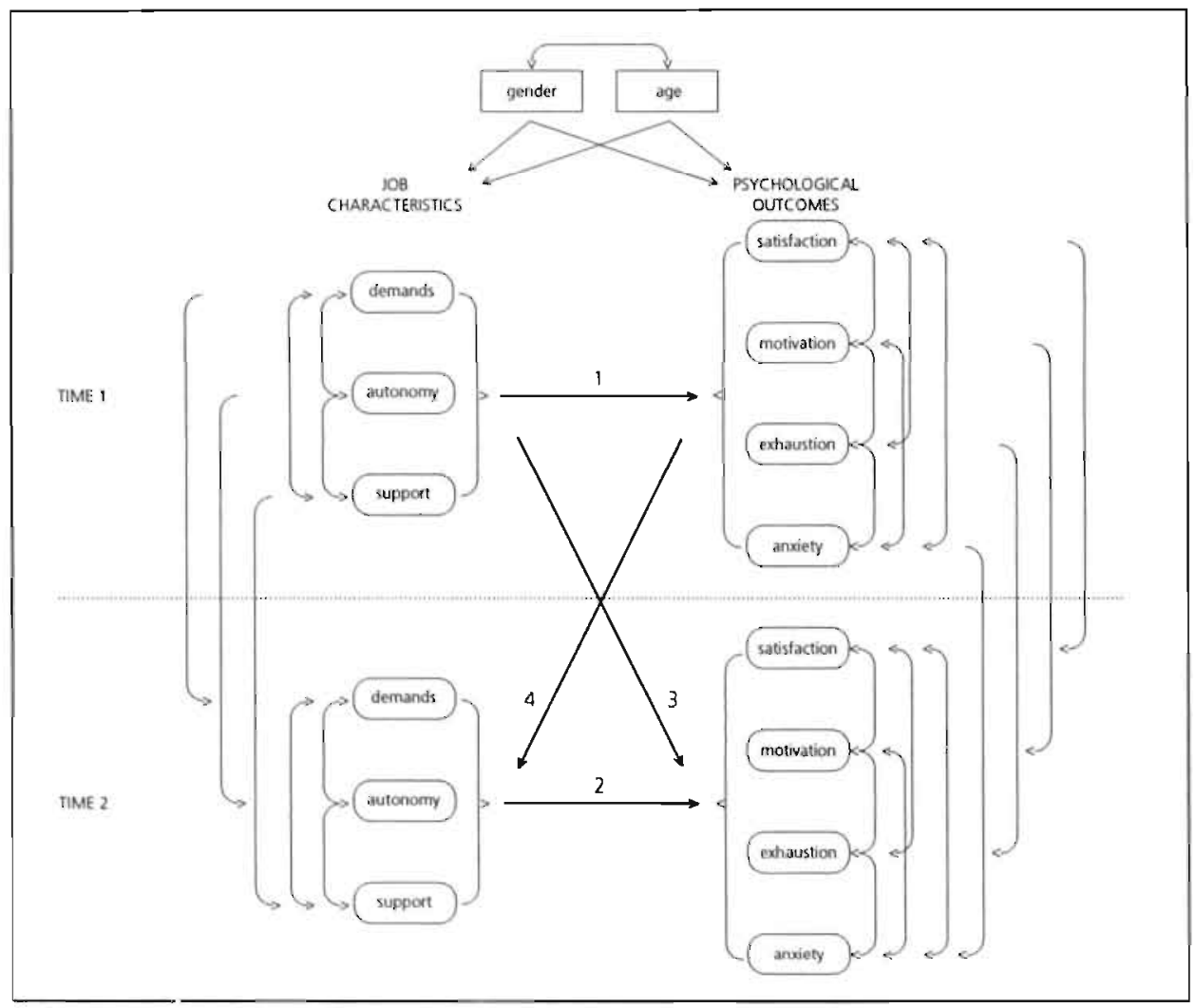

figure 7.2 A longitudinal panel (structural equation) model 
Similar to the two previous chapters, several fit indices have been used to assess the overall fit: the chi-square statistic (Chi-2, or $\chi^{2}$ ); the LISREL adjusted goodness-of-fit index (AGF); the root-mean-square error of approximation (RMSEA); and the non-normed fit index (NNFI). A number of structural models were fitted to the covariance matrix in several steps. Firstly, two models with and without equivalent synchronous correlations were specified in order to test the stationarity assumption (models $M_{1}$ and $M_{01}$, respectively). Secondly, the best fitting model was compared with four more complex models that are next most likely to the hypothesized structural model:

1) a model with cross-lagged correlations from time 1 job characteristics to time 2 psychological outcomes $\left(\mathrm{M}_{2}\right)$;

2) a model with cross-lagged correlations from time 1 psychological outcomes to time 2 job characteristics $\left(\mathrm{M}_{3}\right)$;

3) a model with both cross-lagged correlational patterns $\left(M_{4}\right)$.

Finally, in the case of two significant cross-lagged patterns (i.e., model $M_{4}$ ), we will test the assumption of equal cross-lagged correlational patterns (model $M_{5}$ ) in order to investigate causal predominance of one of the patterns (cf. Rogosa, 1980).

In order to examine the robustness of the ultimate model, a cross-validation procedure was followed (see also chapters 5 and 6). However, the obvious disadvantage of a crossvalidation procedure is that the data has to be split into two (or more) subsamples (Browne \& Cudeck, 1993; Camstra \& Boomsma, 1992; Cudeck \& Browne, 1983). The panel group of the present study consists of 225 subjects (listwise). Cross-validation with such a small sample size $(n<300)$ tends to increase overall error and hence may lead to unstable results (cf. Browne \& Cudeck, 1993; Diamantopoulos, 1994; De Jonge, Janssen \& Van Breukelen. in press; MacCallum, Roznowski \& Necowitz, 1992). To deal with this problem, Browne and Cudeck $(1989,1993)$ suggest using single sample cross-validation indices, like the expected value of the cross-validation index $(E C V I)$. The $E C V I$ is a measure of 'the discrepancy between the fitted covariance matrix in the analysed sample and the expected covariance matrix that would be obtained in another sample of the same size' (Jöreskog, 1993, p. 307). All possible models must be estimated, ranked according the ECVI, and then the model with the smallest value is chosen (Jöreskog, 1993). Possible reference models are the null model (see chapter 6 ) and the saturated model (i.e., a trivial model in which each element of the covariance matrix is regarded as a parameter; cf. Browne \& Cudeck, 1993).

\subsubsection{Results}

Prior to the LISREL analyses, the means, standard deviations, empirical ranges, and zeroorder Pearson intercorrelations of the variables were computed (see appendix 4, tables A4.7 and A4.8). Covariance matrices were used in order to analyse the SEMs. The structural models were identified successfully (see chapter 6 , note 10 ). Therefore, we are able to estimate the fit indices and model parameters.

Let us first consider the two basic models with and without equivalent synchronous correlations (models $M_{1}$ and $M_{01}$, respectively). These different nested models were compared by a likelihood ratio test which was mentioned earlier (see also chapter 6 ). The hypothesis test showed that the difference between the two chi-squares is not significant 
$\left(\Delta \chi^{2}(12)=12.51, p=n . s.\right)$, indicating that $H_{0}$ cannot be rejected. The stationarity model $\left(M_{1}\right)$ has no worse fit than the non-stationarity model $\left(\mathrm{M}_{01}\right)$. meaning that the causal structures for the variables do not change over time.

Consider next the comparison of the stationarity model $\left(M_{1}\right)$ with more complex models. Table 7.2 shows the results of these nested structural models.

Table 7.2 Goodness-of-fit indices of nested structural models of the four psychological outcomes (panel group; $n=225$ )

\begin{tabular}{|c|c|c|c|c|c|}
\hline Model & Chi-2 & $d f$ & comparison ${ }^{3}$ & $\Delta \mathrm{Chi}-2$ & $\Delta \mathrm{df}$ \\
\hline Stationarity $\left(M_{1}\right)$ & $145.55^{\star \star \star}$ & 68 & & & \\
\hline Cross JC, $-\mathrm{PO}_{2}\left(\mathrm{M}_{2}\right)$ & $108.69^{\star \star \star}$ & 56 & $M_{1} \# M_{2}$ & $36.86^{\star \star \star}$ & 12 \\
\hline Cross $P_{1}-J C_{2}\left(M_{3}\right)$ & $121.61^{\star \star \star}$ & 56 & $M_{1} \# M_{3}$ & $23.94^{*}$ & 12 \\
\hline Both cross $\left(M_{4}\right)$ & $81.91^{\star \star \star}$ & 44 & $M_{1} \# M_{4}$ & $58.12^{\star \star \star}$ & 24 \\
\hline Equal $\operatorname{cross}\left(\mathrm{M}_{5}\right)$ & $129.35^{\star \star \star}$ & 56 & $M_{4} \# M_{5}$ & $47.44^{* * *}$ & 12 \\
\hline
\end{tabular}

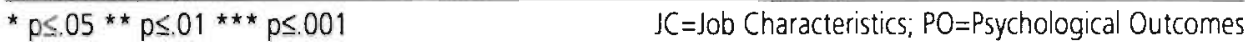

The first likelihood ratio test in table 7.2 shows that the difference between models with and without cross-lagged constraints is significant $\left(M_{1}\right.$ versus $\left.M_{2}: \Delta \chi^{2}(12)=36.86, p \leq .001\right)$. This means that our central hypothesis $(\mathrm{H} 4)$ is confirmed: time 1 job characteristics influence time 2 psychological outcomes. Alternatively, the second test shows that question Q4 is confirmatively answered as well; the likelihood ratio test appears to be significant $\left(M_{1}\right.$ versus $\left.M_{3}: \Delta \chi^{2}(12)=23.94, p \leq .05\right)$. The psychological outcomes in measurement 1 are able to influence the perceptions of job characteristics in measurement 2 .

Furthermore, evidence exists that both types of cross-lagged patterns are valid ${ }^{3}\left(M_{1}\right.$ versus $\left.M_{A}: \Delta \chi^{2}(24)=58.12, p \leq 001\right)$. The question is, however, what kind of pattern has causal predominance: do outcomes tend to occur after the job characteristics, or vice versa? Therefore, we will test equality of cross-lagged patterns conditional on stationarity, as shown in table 7.2 (model $M_{5}$ versus model $M_{4}$ ). The likelihood ratio test shows that the difference between the two models with and without equality constraints is significant $\left(\Delta \chi^{2}(12)=47.44, p \leq .001\right)$. This means that the patterns are not equal; one of the patterns is causally predominant. If we look at which of models $M_{2}$ and $M_{3}$ has the best fit, it appears that model $M_{2}$ does (see also table 7.3). Thus, the psychological outcomes tend to occur after the perceptions of job characteristics, rather than vice versa.

To summarize these findings briefly, it appears that the central hypothesis $(\mathrm{H} 4)$ of this chapter has been confirmed. Time 1 job characteristics influence time 2 outcomes. However, the results also indicate that alternative propositions cannot be ruled out: time 1 psychological outcomes are able to affect time 2 perceptions of job characteristics as well. Moreover, job characteristics and psychological outcomes mutually influence each other in an asymmetric way: there is some evidence of causal predominance of the job characteristics over psychological outcomes. 
Table 7.3 Practical goodness-of-fit indices of nested structural models and squared multiple correlations of the time 2 psychological outcomes (panel model: $n=225$ )

\begin{tabular}{lcccccccc}
\hline Model & AGFI & \multicolumn{1}{l}{ RMSEA NNFI } & ECVI & \multicolumn{5}{l}{$\mathrm{R}^{2}$ (time 2) } \\
\hline & & & & & sat & mot & exh & anx \\
\hline Null model $\left(\mathrm{M}_{0}\right)$ & 33 & .23 & & 7.11 & & & & \\
Stationarity $\left(\mathrm{M}_{1}\right)$ & .86 & .07 & .91 & 1.27 & .43 & .38 & .47 & .37 \\
Cross $\mathrm{C}_{1}-\mathrm{PO}_{2}\left(\mathrm{M}_{2}\right)$ & .87 & .06 & .92 & 1.21 & .43 & .39 & .51 & .38 \\
Cross $\mathrm{PO}_{1}-\mathrm{JC}_{2}\left(\mathrm{M}_{3}\right)$ & .86 & .07 & .90 & 1.27 & .46 & .41 & .51 & .38 \\
Both cross $\left(\mathrm{M}_{4}\right)$ & .87 & .06 & .92 & 1.21 & .46 & .43 & .55 & .40 \\
Equal cross $\left(\mathrm{M}_{5}\right)$ & .85 & .08 & .89 & 1.32 & .46 & .46 & .49 & .38 \\
\hline JC=Job Characteristics & & & & & & \multicolumn{5}{c}{ sat=satisfaction; mot=motivation } \\
PO=Psychological Outcomes & & & & & & & exh=exhaustion; anx=anxiety
\end{tabular}

Table 7.3 presents the practical fit indices of the nested structural models. Model $M_{0}$ is an independent (null) model that assumes zero relationships between the variables. A comparison of all models shows that models $M_{2}$ and $M_{4}$ have the best fit. Absolutely speaking (i.e., in terms of chi-square), model $M_{4}$ shows the best fit (see table 7.2).

Finally, the expected cross-validation index for model $M_{4}\langle E C V I=1.21)$ is equal to or less than the ECVis for the other models fitted $(E C V I \geq 1.21)$ and less than the ECVI for the saturated model (1.23). This rank order of competing models is the same as the rank order according to the expected overall discrepancy. It can be concluded that the model $M_{4}$ has a smaller expected overall discrepancy than all but one of the competing models (i.e., except for $M_{2}$ ). yielding a closer fit. This means that model $\mathrm{M}_{4}$ seems to be the most stable model.

Furthermore, the magnitude of the squared multiple correlations $\left(R^{2}\right)$ in model $M_{4}$ ranges from .40 for time 2 anxiety to .55 for time 2 emotional exhaustion.

Figure 7.3 represents the estimated structural coefficients of model $M_{4}$. It should be noted that the estimates have been standardized and that only (1) significant relationships between job characteristics and psychological outcomes, and (2) test-retest reliability coefficients are shown ${ }^{4}$.

First of all, the contemporaneous associations show in general a pattern similar to the crosssectional results which were described in chapter 6 . In line with our expectations, the pattern and magnitude were nearly the same as the findings in chapter 6 . Only the relationship between job autonomy and work motivation (see the dotted line in figure 7.3) just did not reach the five per cent level of significance.

Regarding the significant cross-lagged parameters, it appears that time 1 job demands influence time 2 emotional exhaustion. It is obvious from figure 7.3 that there are both direct and indirect effects of time 1 job demands on time 2 emotional exhaustion. The sum of the direct effect and all indirect effects is called the total effect (cf. Jöreskog \& Sörbom, 1989, p. 122). The total effect ${ }^{5}$ of time 1 job demands on time 2 emotional exhaustion is .22 accordingly. Higher levels of job demands cause higher levels of emotional exhaustion. In a similar vein, the total effect ${ }^{5}$ of time 1 workplace social support on time 2 work motivation is . 18. Higher levels of social support lead to higher levels of work motivation. 
Conversely, it appears that time 1 work motivation has a direct, total effect of .12 on time 2 job autonomy. A higher level of work motivation causes a perception of more autonomy on the job. Added to this, time 1 emotional exhaustion has a direct, total effect of .17 on time 2 job demands. In other words, higher levels of exhaustion lead to a perception of more job demands.

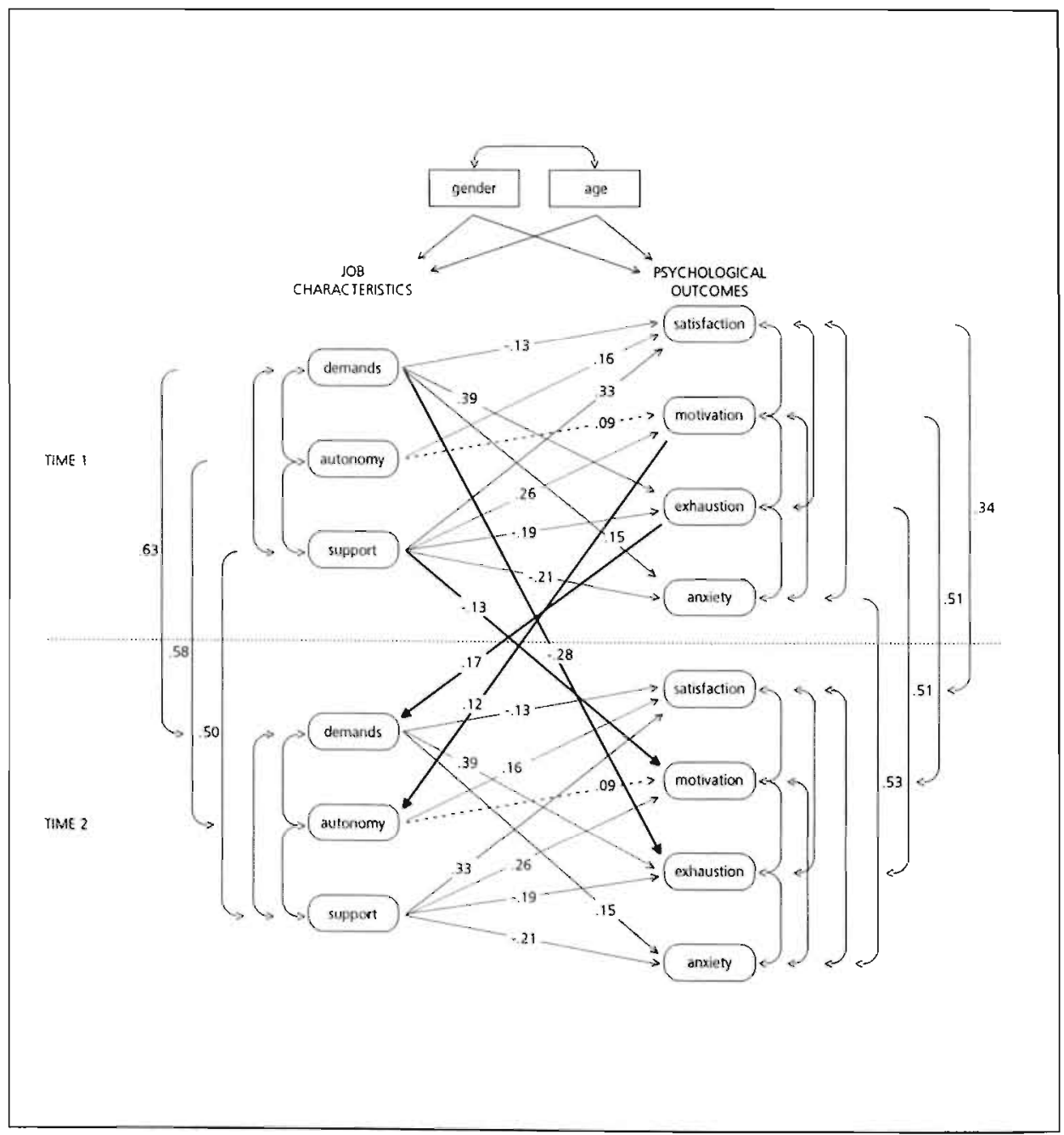

Figure 7.3 The ultimate longitudinal panel (structural equation) model with standardized coefficients (model $M_{4} ; 0 \leq 05$, two-tailed, $n=225$ ) 


\subsection{Summary}

In this chapter the longitudinal analyses have been discussed. Health care employees who responded at the first measurement point as well as the second measurement point were used as study group.

Analogously to chapter 6 , some preliminary analyses and model testing were accomplished. The preliminary analyses were twofold. First, the factorial invariance of the second-order three-factor model from chapter 6 was tested. Second, a causal homogeneity check between respondents and drop-outs was carried out.

Furthermore, the longitudinal structural model tests performed tried to provide an answer on the direction of relationship between job characteristics and psychological outcomes.

The data support the conclusion that an invariant pattern of the three-factor solution of job autonomy, job demands, and social support was tenable. In addition to this, the three latent factors were relatively stable across time. Regarding the homogeneity check, it appeared that both respondents and drop-outs prove to be quite comparable.

We performed SEM in order to provide simultaneous tests of the structural models fitted. Firstly, the hypothesis test showed that the stationarity model was tenable, indicating that the causal patterns for the variables did not change over time. Secondly, evidence existed for a model with both cross-lagged correlational patterns; that is, (1) a pattern from time 1 job characteristics to time 2 psychological outcomes, and (2) a pattern from time 1 psychological outcomes to time 2 job characteristics. Moreover, causal predominance' was detected for the former pattern over and above the latter. In other words, the psychological outcomes tended to occur after the perceptions of job characteristics, rather than vice versa. Finally, cross-validation showed that the best fitted model was also most stable.

To be more specific in regard to the significant relationships, two salient overall results can be mentioned. First, the contemporaneous relationships showed a pattern rather analogously to the cross-sectional results. Second, the findings indicated that: (1) higher levels of time 1 job demands lead to higher levels of time 2 emotional exhaustion: and (2) higher levels of time 1 social support cause higher levels of time 2 work motivation.

In contrast, higher levels of time 1 work motivation lead to higher levels of time 2 job autonomy perceptions, and higher levels of time 1 emotional exhaustion cause a perception of more time 2 job demands.

Taken together, it appears that hypothesis $\mathrm{H} 4$ has been confirmed. That is, time 1 job characteristics influence time 2 psychological outcomes. Conversely, time 1 outcomes are able to affect time 2 perceptions of job characteristics as well. Finally, there is some evidence of causal predominance of the job characteristics over psychological outcomes, which fits in with our theoretical models. 


\section{NOTES}

1. Causal predominance refers to an identification of the source as well as the direction of relationships. Source is the variable that is causally predominant, and direction is whether the causally predominant variable causes an increase or decrease in the other variable ( $f$. Rogosa, 1980).

2. A reciprocal relationship can occur contemporaneously or more gradually over time. Our data only allow a check of lagged reciprocal effects, since we do not have enough information in proportion to the parameters estimated (generally referred to as the identification problem of non-recursive models; see also chapter 8).

3. For the two hypothesis tests concerning the reciprocal models $M_{4}$ and $M_{5}$ (i.e., $M_{1}$ versus $M_{4}$ and $M_{4}$ versus $\mathrm{M}_{5}$ ), we used correlation matrices instead of covariance matrices as input files. The disadvantage of the latter kind of matrix is that it does not have a standardized unit of measurement (e.g., Jöreskog \& Sörbom, 1989, p. 47). In the case of reciprocal relationships, the models have to be scale invariant in order to provide a precise hypothesis test. Although not presented in table 7.2 , the chi-square of model $M_{1}$ using a correlation matrix is 140.03 ( $\left.d f=68, p \leq 001\right)$

4. For a summary of all findings, see appendix 5, table A5.3.

5. The direct effect of time 1 job demands on time 2 emotional exhaustion is -.28 . The indirect effects of time 1 demands on time 2 exhaustion go via three pathways, namely (1) time 2 demands, (2) time 1 exhaustion, and (3) time 1 exhaustion, time 2 demands. The sum of these indirect effects is .50 . So, the total effect of time 1 job demands on time 2 emotional exhaustion is $(-.28+.50=) .22$

Similarly, the direct effect of time 1 social support on time 2 work motivation is -.13 . The indirect effects of time 1 support on time 2 motivation go via two pathways; that is, via (i) time 2 support, and (2) time 1 motivation. The sum of these indirect effects is 31 . Thus, the total effect of time 1 sacial support on time 2 work motivation is $(-.13+.31=) .18$ 
Chapter 0 


$$
\text { - }
$$




\section{GENERAL DISCUSSION}

\subsection{Introduction}

The previous chapters addressed various theoretical as well as empirical issues concerning job autonomy and its role in the relationship between job characteristics and well-being and health. For that reason, three theoretical models were considered to be most relevant for close examination of job characteristics-outcomes relationships. Moreover, a job autonomy study like this derives its significance particularly from being embedded in a theoretical framework. In other words, studying job autonomy can hardly be considered separately from these theoretical models nor separately from related job characteristics.

In this finat chapter, the research findings presented will be discussed and reconsidered. An overview of the essential findings of the study will be given in section 8.2 . The following section gives due consideration to the study's methodological limitations in order to make sense of the various findings and the conclusions drawn. The next two sections discuss successively the theoretical and practical implications of the results. Section 8.6 speculates about avenues for further research. Some final concluding remarks are presented in the last section.

\subsection{Summary of the main findings}

\subsubsection{Introduction}

We will now summarize the principal findings of the study in the sequence as presented in the previous chapters. This section should not be read as a comprehensive summary of specific findings; rather, we will be concerned with some general findings which we shall discuss with special reference to job autonomy: (1) the conceptualization and, in particular, the operationalization of the variables; (2) ways of assessing job characteristics in the prediction of well-being and health; and (3) the relationship between job characteristics on the one hand, and well-being and health on the other.

\subsubsection{The conceptualization and operationalization of the variables}

At the start of this study the literature on job autonomy was reviewed, and a typology of job autonomy was developed. Based upon the relevant literature, it was argued that before we can operationalize job autonomy, we need a clear conceptualization of it. Consequently. job autonomy was explored as a multi-level and multi-facet concept. More specifically, job autonomy was primarily considered as a relative property or characteristic of a job. which impinges upon the employee and causes perceptions. Added to this, people can alter these influences in different ways. In sum, we defined job autonomy as the worker's opportunity or freedom, inherent in the job, to determine a variety of task elements, like the method of working, the pace of work and the work goals. 
Next, a new measurement instrument was developed, namely the Maastricht Autonomy Questionnaire, abbreviated MAQ'. Cross-sectional analysis showed that both a two-dimensional scale (i.e., contextual and content autonomy) and a one-dimensional scale (i.e., overall job autonomy) were tenable. Moreover, the cross-sectional psychometric results were successfully cross-validated as well. Finally, longitudinal analysis provided evidence for equal factorial properties and relatively stable scales over time.

Regarding the other two job characteristics, the overall findings indicated a psychometrically satisfying job demands instrument, but some psychometric problems with the social support instrument, as far as the two subscales are concerned. In addition, this two-factor structure showed a number of correlated error terms, which was greatly diminished after performing a second-order confirmatory factor analysis. The resulting second-order factor "workplace social support" showed acceptable psychometric properties.

Further psychometric findings of interest concern the four outcome variables (i.e., job satisfaction, work motivation, emotional exhaustion and job-related anxiety). Except for the factorial variance across time of work motivation, all outcome instruments showed good and invariant factor solutions, acceptable internal consistencies and reasonable test-retest reliabilities.

In sum, based upon a profound and clear conceptualization, the MAQ indicated a sound operationalization of job autonomy. In addition to this, all but one of the other measurement instruments showed acceptable factorial validities and reliabilities.

\subsubsection{Individual and group assessment of job characteristics}

With respect to the assessment of job characteristics, the question was whether individual assessment and an alternative (i.e., group) assessment of job characteristics are both able to explain well-being and health. More specifically, this group assessment consisted of aggregated individual data.

The results of the parsimonious multi-level models with regard to the adverse health outcomes showed that high levels of 'individual' job demands were positively associated with high levels of exhaustion and anxiety. Furthermore, the interaction term at individual level with regard to work motivation indicated that job demands and work motivation were slightly positively related at high levels of autonomy. At the same time, however, job demands and work motivation were slightly negatively associated in the case of low levels of autonomy. In addition, an interaction effect at aggregated level in regard to job satisfaction was found. It appeared that aggregated job demands and job satisfaction were positively related in the case of high levels of aggregated job autonomy. At low levels of job autonomy, however, job demands and job satisfaction were negatively associated. Finally, high levels of aggregated job demands were related with low levels of work motivation, while high levels of 'individual' job autonomy were associated with high levels of job satisfaction.

All in all, it may be concluded that individual job characteristics data as well as aggregated individual job characteristics data were related to well-being. On the other hand, only individual job characteristics data were associated with adverse health outcomes, as far as the parsimonious models were concerned. 


\subsubsection{The relationship between job characteristics and psychological outcomes}

Regarding the typical form of relationships between job characteristics on the one hand, and well-being and health on the other, the current findings showed evidence for: (1) linear interactive relationships in multi-level analysis (see above); (2) curvilinear relationships in structural equation analysis; and (3) linear additive associations in both types of analysis. The two interaction terms and several linear additive relationships detected in multi-level analysis have been described in the former subsection. To be more specific with respect to the curvilinear and linear additive relationships in structural equation analysis, it appeared that low and high levels of job autonomy were related with relatively low levels of emotional exhaustion; that is, an inverted U-shaped curve was found. Additionally, high levels of job autonomy were - linearly - associated with (1) high levels of work motivation, and (2) high levels of job satisfaction.

With respect to job demands, the results showed a curvilinear - U-shaped - relationship between job demands and job-related anxiety. In other words, low and high levels of job demands were associated with higher levels of anxiety. Furthermore, linear additive effects were detected as well: high levels of job demands were related with low levels of job satisfaction, and with high levels of exhaustion as well as high levels of anxiety.

The findings concerning workplace social support indicated two curvilinear relationships and four linear additive associations. The former kind of relationships showed that low and to a lesser extent high levels of social support were associated with lower levels of job satisfaction (inverted $U$-shaped) as well as higher levels of emotional exhaustion (U-shaped). The latter kind of relationships demonstrated that high levels of workplace social support were linearly related with: (1) high levels of job satisfaction; (2) high levels of work motivation; (3) low levels of emotional exhaustion; and (4) low levels of job-related anxiety. Finally, cross-sectional cross-validation analysis showed the robustness of all structural models analysed, and demonstrated that the linear additive models were most stable.

With regard to the direction of the relationships between job characteristics and psychological outcomes, it appeared that time 1 work motivation has a positive effect on time 2 job autonomy. In other words, higher levels of time 1 work motivation caused a perception of more job autonomy.

Regarding job demands, the findings showed evidence for a significant lagged relationship between time 1 job demands and time 2 exhaustion. That is, higher levels of time 1 demands led to higher levels of time 2 emotional exhaustion. Added to this, evidence was also found for a significant lagged relationship between time 1 exhaustion and time 2 demands: higher levels of time 1 emotional exhaustion caused a perception of higher levels of time 2 job demands.

Finally, the results with respect to social support showed one significant lagged relationship higher levels of time 1 social support led to higher levels of time 2 motivation

Furthermore, the two cross-sectional models at both measurement points indicated that the causal structures for the job characteristics and psychological outcomes did not change over 
time. At both measurement points, job autonomy appeared to be positively associated with job satisfaction: high levels of job autonomy were related with high levels of job satisfaction.

Sirnilar to the findings of chapter 6 , high levels of job demands were associated with low levels of job satisfaction, and related with high levels of exhaustion and anxiety, respectively. In addition to this, high levels of social support were related with high levels of satisfaction as well as high levels of motivation. Regarding the adverse health outcomes, the results showed negative relationships between social support on the one hand, and exhaustion and anxiety on the other. Low levels of social support were associated with high levels of exhaustion as well as high levels of anxiety.

Summarizing these primary outcomes, we may tentatively conclude that:

1) Job autonomy, considered as a multi-level and multi-facet job characteristic, can be defined as the employee's opportunities or freedom, inherent in the job, to determine a variety of task elements.

2) The Maastricht Autonomy Questionnaire indicated a sound operationalization of job autonomy. Additionally, all but one of the other measurement instruments used (i.e., work motivation) showed acceptable psychometric properties in terms of factorial validity as well as reliability.

3) Multi-level analysis suggested that both individual assessment and group assessment of job characteristics were associated with well-being. Individual assessment of job characteristics was related with adverse health.

4) Multi-level analysis revealed linear interactive relationships of job autonomy and job demands in regard to well-being, and linear additive associations of both job characteristics with respect to well-being and health.

5) Cross-sectional structural equation modelling showed curvilinear relationships as well as linear additive relationships of job autonomy, job demands and social support in regard to well-being and health. What is more, cross-validation showed that the linear additive relationships were most stable.

6) Longitudinal structural equation analysis indicated lagged reciprocal relationships between the three job characteristics and psychological outcomes. Furthermore, causal structures for job characteristics and psychological outcomes did not appear to be variant across time.

\subsection{Methodological considerations}

So far, we have summarized the essential findings of this thesis with respect to the three job characteristics examined. However, the present study shares several methodological limitations with other comparable studies. In order to examine the validity of the results, it seems worthwhile discussing the methodological issues inherent in the study. The considerations presented will concentrate on: (1) the research method; (2) the measurement instruments; and (3) the statistical analysis. 


\section{RESEARCH METHOD}

In chapter 4 we already discussed some panel design problems. One of these problems merits further attention: panel mortality, or attrition. If non-response does not occur completely at random, attrition may threaten the statistical conclusion validity (Cook \& Campbell, 1979; Hagenaars, 1990). Our two comparisons of panel members and drop-outs (i.e., demographic differences (chapter 4) and causal relationships (chapter 7), respectively) suggest that the non-response seemed not to bias systematically the main findings. More specifically, this non-response reduced only the sample size and led probably to less precise parameter estimates and less powerful statistical tests.

Another remaining problem concerns the time interval over which to space data collection. A critical consideration in the selection of time intervals between waves concerns the causal lag between the exogenous and endogenous variables (cf. Frese \& Zapf, 1988; Kessler \& Greenberg, 1981). A causal lag can be based theoretically or empirically. However, it is hardly possible to decide on an appropriate causal lag on a theoretical basis, since many variants of theoretical time models exist (for a review, see Frese \& Zapf, 1988).

Ordinarily, the most we had were common sense notions about the rough magnitude of time. Based upon a longitudinal pilot study (De Jonge, Landeweerd \& Van Breukelen, 1994; Vermaat, 1994), we knew for instance that a minimum lag of at least eight months would be required to obtain a meaningful amount of change in several criteria of interest. Nevertheless, time misspecifications may lead to serious problems if the time lag is either too short or too long (Kessler \& Greenberg, 1981). We cannot study dynamic processes when the panel lag does not fit in with the assumed causal lag. Although we have tried to approximate an 'ideal' two-wave design (i.e., a one-year time interval and no season fluctuations), we could not cope with all the time problems.

A third problem involves the study population. Studying people in just one occupation has advantages as well as disadvantages. As we mentioned in chapter 4 , an advantage of a single-occupation group like health care workers is that we had virtually no variance in socio-economic status, which precludes confounding effects. The challenge is, however, to obtain enough variance on the (exogenous) variables to allow hypothesis tests. Compared to large multi-occupation studies, we might have some restriction in range in our variables. But health care workers as an occupational group have the advantage of providing much natural variance because of different types of health care areas, and because different specialties exist within the same general hospital or nursing home (cf. Fox, Dwyer \& Ganster, 1993; Ganster \& Fusilier, 1989).

Another possible limitation is that employees may bias their (self-report) responses depending upon a dispositional factor like "negative affectivity" (e.g., Burke, Brief \& George, 1993; Schnall, Landsbergis \& Baker, 1994). Such an explanation might be plausible if most of the workers who report high demands also report low autonomy, and if the combination "high demands-high autonomy" hardly occurs. This would imply a strongly negative association between job demands and job autonomy. However, the actual correlation between these variables was -.29 in the calibration sample, -.23 in the validation sample and -.30 in the panel group (see appendix 4, tables A4.4 and A4.8). A median-split procedure (i.e., dichotomizing both variables at their median) indicated that all four cells 
were equally filled, particularly the high strain cell (i.e., high demands-low autonomy) and the active cell (i.e., high demands-high autonomy; cf. De Jonge, Landeweerd, Nijhuis \& Boumans, 1994). It seems therefore hardly credible that people who are ranged under negative affectivity would falsely overestimate their level of job autonomy, thus classifying themselves in active jobs. The reason for this is that affective experience is characterized by two relatively independent dimensions (i.e., negative and positive affect) rather than a single dimension (Burke, Brief \& George, 1993; Watson \& Tellegen, 1985). Additionally, our multilevel analysis suggested quite similar strengths of associations for both aggregated data and individual data with regard to cross-sectional outcomes, indicating hardly any problems with respect to this kind of information bias.

Finally, any research that samples people from a working population may be influenced by a so-called "healthy worker effect" (Frese, 1985; De Jonge \& Landeweerd, 1993). Employees with adverse health reactions might be absent more frequently and thus be underrepresented in our samples. So, the relationship between job characteristics and psychological outcomes may be underestimated because of restriction of variance in the outcome variable(s).

\section{Measurement instruments}

The present study relied exclusively on self-report measures of both exogenous and endogenous variables. The problems associated with this practice are, for instance, a pussible inflation of true correlations and spurious higher-order effects (e.g., Boumans \& Landeweerd, 1993; Evans, 1985; Roberts \& Glick, 1981; Spector, 1987, 1992; Williams, Cote \& Buckley, 1989). While Spector (1987) concluded that there is lack of common method variance in these kinds of studies, Williams, Cote and Buckley (1989) challenged his statement suggesting that Spector's conclusions were an artifact of his method. One year later, Bagozzi and Yi (1990) criticized Williams, Cote and Buckley's procedures, and showed very little method variance in their study. So, the jury is still out on this issue.

We did try to reduce the problem of method variance by (1) classifying job characteristics in terms quite different from those for the outcome variables, (2) measuring the indicators with differing response formats, and (3) positioning measures of the indicators in different locations throughout a larger survey questionnaire. Unfortunately, we cannot test the strength of method variance, but several findings recently reported in the literature (e.g. Boumans \& Landeweerd, 1993; Semmer, Zapf \& Greif, in press; Spector, 1992) indicate that common method variance is not very troublesome. Although potential threats cannot totally be ruled out, the data do not seem to be extremely limited by problems due to method variance

\section{Statistical analysis}

Some considerations concerning the multi-level modelling can be mentioned. First, group assessments are sensitive to spurious group consensus, social cues or not quite identical workplaces (e.g., Griffin, Bateman, Wayne \& Head, 1987). However, although group data have their limitations, they are probably more valid than observers' ratings and less vulnerable to some of the disadvantages of both observers' and subjects' ratings that were mentioned above. Group culture and group norms may be present, but these aspects 
contribute to the homogeneity in the unit and do not have a direct relationship with the individual outcome variables. Furthermore, the health care workers who work in the same unit did not belong to a single identity or organizational group at work (cf. Alderfer, 1987). In some cases the health care workers studied were working in different shifts.

Second, group indicators are more reliable than individual data and thus less affected by attenuation. For this reason, the relationships may be less underestimated.

Finally, we used an exploratory procedure to derive a parsimonious model. So, there is a possibility that some decisions we have made are based on chance.

Structural equation modelling faces the same restrictions as other statistical methodologies. As Bollen (1989) noted, we can only reject a structural model - we can never prove a model to be valid. If the data were consistent with the model in terms of statistical or practical fit, this does not imply that the model corresponds to reality.

Kenny and Judd (1984) indicated that higher-order constructs (like interaction and nonlinear terms) derived from multinormally distributed variables cannot be multinormally distributed themselves. So, the assumption of multinormality can be violated, and the use of Full Information Maximum Likelihood (FIML) estimation is formally unjustified. As we noted in chapters 5 and 6 , however, the FIML estimator is relatively robust against departures from the skewness and kurtosis of the normal distribution for parameter estimates. Added to this, in the case of normality violation FIML estimation provides parameter estimates that are as good as those provided by other kinds of estimates such as Weighted Least Squares (WLS) or Ordinary Least Squares (OLS; ff. Bollen, 1989; Boomsma, 1987; Hayduk, 1987; Muthén \& Kaplan, 1985).

The (cross-sectional) cross-validation procedure used seemed valuable for assessing the model stability. Although the use of a test of model fit often leads to the model with the largest number of parameters, this will frequently not be the case for the cross-validation criteria (Camstra \& Boomsma, 1992; Cudeck \& Browne, 1983). With small sample sizes cross-validation tends to favour models with relatively small numbers of parameters, whereas with large sample sizes models with large numbers of parameters tend to crossvalidate best. In the present study, it appeared that the linear models were slightly more stable, but the non-linear models were slightly superior in terms of fit indices in both subsamples. Therefore, it would also be of interest to compare the utility of CVIs in choosing among competing models to that of other goodness-of-fit indices such as the $\chi^{2}$, AGFI, NNFI and RMSEA.

The choice of our longitudinal structural equation model was made on theoretical grounds. However, although the plausibility of a particular causal ordering is not always strong, one cannot include all possible causal effects in one model (cf. Saris \& Stronkhorst, 1984). The reason for this is that a two-wave panel model with reciprocal effects between all variables is not identified. Choosing a causal order between job characteristics and psychological outcomes is a requirement in order to obtain an identified structural equation model. Causal ordering of a few variables is feasible, but the possibilities are limited. Although competing models were compared in the present study, it was not possible to test a causal model with all conceivable reciprocal effects. 
Despite these methodological issues, we believe that the theoretical and practical implications of this study are not seriously affected. In the next two sections, these implications will be discussed in the light of the considerations of the present section.

\subsection{Theoretical implications}

\subsubsection{Introduction}

While growing empirical research has supported the importance of job autonomy in regard to well-being and health, the present status of job autonomy research is still in dispute. Therefore, the main purpose of the present study was to gain a better understanding of the concept of job autonomy, which may result in a clear (or clearer) conceptualization and operationalization. In addition, we wanted to make a comprehensive and profound study of the role of job autonomy in the relationship between job characteristics and psychological outcomes by means of sophisticated statistical techniques.

In this section, we will discuss the theoretical implications of the study. The second subsection (8.4.2) discusses the conceptualization, measurement and assessment of job autonomy. Subsection 8.4 .3 considers the results with regard to the theoretical models used, while subsection 8.4 .4 deals with the particular role of the demographic characteristics. The final subsection ( 8.4 .5 ) presents a heuristic model that attempts to integrate the various separate research findings.

\subsubsection{Job autonomy: conceptualization, measurement, and assessment}

What does the present study teach us about the concept of job autonomy? The study considered job autonomy in a more differentiated way than has often been the case. It is the failure to make a distinction between different facets and levels of job autonomy that may create many of the dilemmas.

A review of the literature highlighted that there is value in distinguishing facets of job autonomy. The discussion about a multi-facet job autonomy construct has led to an important turning-point in the traditional treatment of job autonomy as a global construct. Job autonomy appeared to be a relative term as well and, consequently, different task facets, or task elements, could be recognized (e.g., method of working, pace of work, work goals, amount of work, working-hours and work evaluation).

The different facets of job autonomy were further complicated by adding a set of levels, or dimensions, to job autonomy. Two levels of job autonomy have been revealed: (1) contextual autonomy; and (2) content autonomy. The former level refers to opportunities in regard to the norms of a worker's job, while the latter bears upon the opportunities within given job standards. These two levels represent the whole spectrum of job autonomy, which in turn is related to an organizational subsystem (i.e., a unit or an individual worker). 


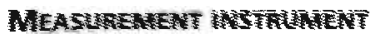

Consequenty, we nowed away from an exclusive relance on an absolute and giobat measmement instrument of job autonomy. We therefore developed a new lohtem measurement instrument for job autonomy. Which seems to respond to all the riticisms which were mentioned in chapter 2. However, the notion that some wokers have autonomy over some aspects of theit wok and not over others is one that desenes considerable atention. ft shoub be mentioned that the ten task dements of job sutonomy examined in this study are not necessarily the only ones which exist Rather, they were chosen because ou extensive rewew of the hterature as well as several experts hohluhted theit significance. Future research in job autonomy will, we hope, discover addiwnal elements which mert attention. Moreover, we tried to avoid some of the problems hat have plagued other job autonomy instruments. That is, we did not utilize negatwely worded and cognitwely-loaded items, nor did we use different response scale formats.

Strong empitical attempts have been made to add further to the evolution of this job autonomy instument, named the Maastricht Autonomy Questionnaire (MAQ). A number of statustical fests were applied, and both (longitudinal) factor and reliability analyses showed reasonaby good psychometric properties of the instrument. The specificity of the MAQ in terms of dmensionality was good enough. Conceming this specificity, it appears to be simplistic to argue that one approach (e.g., measuring autonomy generally or measuring two dimensions) is correct. Rather, it seems best to have a choice among measuring devices so that one can match one's measurement strategy to one's particular research question. In some cases a general autonomy index is appropriate, like theoretical model testing (as was the case in chapter 6 ). On the other hand, there is considerable value in differentiating levels of job autonomy for making precise organizational diagnoses.

Another point of attention is the conceptual and statistical independency of the scale. The two dimensions of job autonomy (i.e., contextual and content autonomy) were reasonably strongly correlated, as was the case in previous studies (e.g., De Jonge, Landeweerd \& Van Breukelen, 1994). As noted by Bailyn (1985), variables can be independent conceptually, even though in reality they may be associated (like weight and height). In other words, the fact that the two dimensions were correlated does not suggest that making conceptual distinctions is not important. In contrast, these dimensions allow for another turning-point in thinking about - and the measurement of - job autonomy.

\section{THE ASSESSMENT OF JOB AUTONOMY}

A final point concerns the assessment of job autonomy in the prediction of well-being and health: either objectively or subjectively. At the end of chapter 2 it was argued that these two kinds of assessment have to be reconsidered in regard to the primary focus of job redesign. Because many problems were detected in the use of 'objective' and subjective assessments, we utilized an alternative source to reflect the work conditions. That is, we used group assessments (i.e., aggregated individual data) in measuring job characteristics. An important - exploratory - question was whether aggregated job characteristics data 
significantly add explained variance to 'individual' job characteristics data with respect to the psychological outcomes. This could mean that some of the explained variance of the outcome variables is grounded in - environmental - conditions outside the individual worker. The findings indicated that both aggregated and individual data are important in explaining well-being and health. A comparison of magnitudes in explained variance across levels seems to be premature, because group assessments are not viewed as more important or more meaningful (cf. Alderfer, 1987; George, 1990). Additionally, group-level relations are not hypothesized to be stronger or weaker than individual-level relations. An interesting explanation for the current findings may be that group and individual assessments reflect more or less the same features of the work situation, which are sometimes referred to as 'affordances' (Gibson, 1979; Krahé, 1992; Warr, 1987). An affordance is a term derived from ecology, and is a construct that refers to the work environment as well as the individual worker. It implies the complementarity of both in terms of positive or negative potentials for action. Affordances are identified as important for an individual worker or a group of workers. Consequently, they have to be measured relative to the employee(s), because they are unique for a particular work setting. In Gibson's approach, they are neither objective nor subjective (or perhaps they are both), because affordances are connected with both the environment and the person. Additionally, Baron and Boudreau (1987) argued that the physical properties of affordances can exert an influence on the worker only if he or she possesses the complementary characteristic to make use of or 'tune into' a certain affordance.

Furthermore, it appeared that some of the variance in well-being is attributable to some properties outside the individual worker. These findings are in accordance with several other studies (for a review, see Spector, 1992). A theoretical rationale for these findings has been provided by an intergroup theory (cf. Alderfer, 1987; Schneider, 1985). The logic of this theory is that interactions of employees at any level of analysis - partly - represent the effects of group memberships. In its most expanded form, this perspective emphasizes the embedded nature of subsystems. In other words, every person can be embedded in a group (an employee in a unit), every group can be embedded in other groups (a unit in an organization), and so on. Applied to our study, employee well-being might be a product of multilevel embeddedness of job characteristics. That is, the individual level of analysis is embedded in, and affected by, at least the next level of analysis. So, it seems that the next larger unit(s) in which 'individual' job characteristics are embedded will also have an impact, at least on well-being.

Aggregated data, however, did not appear to be important regarding adverse health outcomes, as far as the parsimonious models were concerned. This finding is somewhat puzzling. However, there are many ways to state the finding. For instance, an explanation may be that other factors (e.g., social cues, method variance) must be acknowledged as potential sources of variation (cf. Fried \& Ferris, 1987; O'Brien, 1986). Another explanation may be that general disagreement exists about the amount of job demands within a unit. If this is the case, more variance is present in the individual data, which in turn may probably lead to non-significant unit-level effects (Vancouver, Millsap \& Peters, 1994). 
Finally, a closer inspection of our multi-level analyses showed that the aggregated job characteristics data affect directly the adverse health outcomes (see chapter 6 , tables 6.2 and 6.3, model 4). Because (1) both aggregated and individual job characteristics data have a direct effect on adverse health, (2) the aggregated data are related to the individual data (see appendix 4, table A4.2), (3) the individual job characteristics data are associated with the outcomes in the presence of the aggregated variables, and (4) the influence of the aggregated data in the parsimonious model is (nearly) zero, these findings suggest a mediating role of the individual job characteristics data in regard to the adverse health outcomes (cf. Fox, 1984; Van de Geer, 1986). in other words, it can be speculated that the aggregated job characteristics data are 'appraised' (i.e., linked to individual data) and these are, in turn, related with the adverse health outcomes.

All in all, the present study has shown that it is possible to think of job autonomy in a more profound and refined way than has been done in previous research. The corresponding operationalization, reflected by the Maastricht Autonomy Questionnaire, has proven to be factorially valid and reliable. The results of the statistical analyses were consistent and quite impressive. Moreover, our conceptualization and operationalization of job autonomy not only may lead to improved theory development, but also will support organization intervention efforts. That is, more specific information about how a job (or tasks) might be modified will be available.

Finally, it was found that individual job characteristics data are powerful in explaining both health and well-being, whereas aggregated job characteristics data are powerful in explaining well-being in the presence of individual job characteristics. So, perceptions of job characteristics (including job autonomy) do not merely reflect subjective feelings but also are grounded in some kind of - environmental - reality, particularly as far as well-being is concerned.

\subsubsection{Job characteristics, well-being, and health: tests of theories}

The main purpose of this part of the study was to investigate the particular form and direction of the relationship between job characteristics on the one hand, and well-being and health on the other. We therefore used three representative and rather impressive theoretical models in order to test several forms of relationships. It was primarily hypothesized that job characteristics were linearly interactively or curvilinearly related with aspects of well-being and health. These hypotheses were set against the null hypotheses that no interactive or curvilinear relationships exist. In this case, several linear additive relationships as predicted by Hackman and Oldham (1980) could be investigated.

\section{Cross-sectional models}

First of all, we tested the basic Job Demand-Control (JD-C) Model in multi-level analysis (MLA). The corresponding results partly support hypothesis $\mathrm{H} 1$ (i.e., the existence of an interactive relationship of job demands and job autonomy) by finding two significant interaction effects in the hypothesized direction. These interaction terms represent 25 per cent of the interactions tested, which means no strong support for the JD-C Model. 
The support for the model is quite meaningful, however, because one significant interaction was found at the aggregated level. As noted earlier, most empirical support for the JD-C Model comes from the multi-occupation studies, but they cannot rule out possible confounding effects of socio-economic status. In our study these confounding effects cannot provide a strong alternative explanation for this significant interaction effect. Second, the modelled variance for the best fitting models ranged from nearly .09 for jobrelated anxiety to almost 25 for emotional exhaustion. Added to this, the job characteristics account for a higher proportion of modelled variance in health outcomes (see above) than in the two well-being variables (i.e., almost .13 for both well-being outcomes). Although these values are not very high, they are rather consistent with those obtained by other occupational stress studies (e.g., Karasek, 1989; Semmer, Zapf \& Greif, in press; Warr, 1990b). Finally, there is hardly any residual variance left in the parsimonious models at higher levels of analysis. This means that almost all higher-level unexplained variance in well-being and particularly in adverse health can be explained by the control and predictor variables. For that and other reasons (see chapter 6), we could proceed with mono-level structural equation modelling (SEM).

Regarding the Demand-Control-Support (DCS) Model, the fit indices of the structural equation models showed that the fit of the linear additive model is better than that of the linear interactive model. The fit of the former was also better than a model without linear additive relations. Moreover, the stability of the linear additive model was successfully demonstrated in two independent subsamples: a calibration sample and a validation sample. As a result, the plausibility of linear additive associations is confirmed, as far as the comparison with an interactive model is concerned. However, hypothesis $\mathrm{H} 2$ (i.e., the existence of an interactive relationship between job demands, job autonomy and workplace social support) is not confirmed; there is no empirical evidence for the interactive DCS Model in our study.

A first question that suggests itself is the inconsistency in interactive findings in MLA and SEM. As already mentioned, we used an exploratory procedure in MLA to derive our models. So, there is a possibility of chance capitalization in MLA, whereas in SEM alt relationships were tested simultaneously (see also the significant intercorrelations between interaction terms and outcomes in appendix 4, table A4.4). Another explanation might be that the moderating effect of job autonomy on the job demands-outcomes relationship tends to be specific to the hierarchical level of positioning (cf. Beehr \& Drexler, 1986; Westman, 1992). Recall that in MLA we used only one hierarchical level, namely registered nurses. Their level can be typified as a mid-level occupational position. Higher-level as well as lower-level positions were excluded from this analysis. The exact reason why hierarchical level might act as a moderator remains unclear, but includes the ideas that (1) job autonomy is inherent in higher-level positions, (2) the employees in these positions tend to be more capable, lessening what might in other cases be demanding aspects of their jobs, and (3) there is less variation in job autonomy at higher-level positions. Regarding lowerlevel positions, the work of Siegrist and his team is rather impressive and gives several 
interesting points of view (e.g., Siegrist, 1991, in press; Siegrist \& Matschinger, 1989; Siegrist, Peter, Junge, Cremer \& Seidel, 1990). Blue-collar and lower-level white-collar positions are often characterized by, for instance, low job autonomy, high job demands, job instability, few promotion prospects and, consequently, fragmented job careers. For many of these instances, control over objective job conditions is restricted, and adjustment to potential threats caused by these conditions is very difficult. For similar lower-level positions, Siegrist and colleagues introduced the term "low occupational status control", or low control over long-term rewards. In sum, people in lower-level occupational positions are hardly able to adapt to the conditions of low status control, which could put the moderating role of job autonomy out of the picture.

5o, it can be speculated that the moderating role of job autonomy in the job demandsoutcomes relationship is more important in mid-level occupational positions than in higherlevel or lower-level positions.

As postulated by the Vitamin Model (VM), the fit of the structural equation model that includes non-linear relations between job characteristics and well-being is superior to the model that only includes linear additive relationships. Moreover, with one notable exception (i.e., the curvilinear relationship between job autonomy and emotional exhaustion) these non-linear relationships follow the expected inverted U-shaped AD pattern. Finally, although the linear model was slightly more stable, the robustness of fit of the non-linear model is demonstrated because it was equally successfully fitted in the calibration sample and the validation sample. Consequently, the plausibility of the VM, reflected by hypothesis $\mathrm{H} 3$ (i.e., the existence of curvilinear relationships of the job characteristics), is confirmed by our results. It should be emphasized, however, that the relative magnitude of the squared multiple correlations $\left(R^{2}\right)$ ranges from .08 for job-related anxiety to .28 for emotional exhaustion. Furthermore, the job characteristics account for a higher proportion of $\mathrm{R}^{2}$ in adverse health outcomes (.28 for emotional exhaustion and .08 for anxiety) than in well-being outcomes (.17 for job satisfaction and .10 for work motivation). Again, these values are not very high, but are similar to those gained in other - comparable - studies (e.g., Karasek, 1989; Semmer, Zapf \& Greif, in press; Warr, 1990b).

Unfortunately, 4 out of 12 quadratic terms (i.e., 33\%) appeared to be significant. The validity of these findings is somewhat limited accordingly. Beside the possible problems with respect to higher-order terms which were mentioned before, the results might be caused by a heaithy worker effect. In that case, moderate rather than extreme levels of the job characteristics under examination were exhibited ( $d$. Warr, 1994). Finally, we measured only three key job characteristics instead of all nine features of the VM. Although these nine features are expected to be interrelated, we cannot expect them all to make contributions to our psychological outcomes that take on equal weight (cf. Feather, 1990). In other words, the question as to which are the more important 'work vitamins' has still to be answered.

Taken together, it appears that the Demand-Control-Support Model is inferior to a linear additive model, and that the Vitamin Model is superior to a linear additive model. 


\section{NON-LINEAR AND LINEAR REPRESENTATIONS}

The first-order coefficients from centred equations always represent the effects of the predictors at the mean of the other predictors (cf. Aiken \& West, 1991; Jaccard, Turrisi \& Wan, 1990). Therefore, they may also be considered as the weighted average effect of each predictor across all observed values of the other predictor. This average effect of an exogenous variable on an endogenous variable usually will be a meaningful piece of information (Jaccard, Turrisi \& Wan, 1990). From this point of view, we will discuss the higher-order (non-linear) as well as the first-order (linear) relations within the Vitamin Model. As far as the non-linear relationships are concerned, our findings agree with other similar studies. For instance, Warr (1990b) found a similar significant non-linear 'AD' relationship between job demands and job-related anxiety.

\section{JOB AUTONOMY}

The finding that job autonomy is non-linearly related with emotional exhaustion (De Jonge, Schaufeli \& Furda, 1995) is replicated in the present study. However, compared to the earlier study, the shape of the curve is inverted: instead of moderate levels of exhaustion being related to low levels of exhaustion, the present study reveals that moderate autonomy is related to higher levels of exhaustion. This particular result might be caused by the neglect of some important individual characteristics in this study, like "need for autonomy". It can be speculated that employees with a high need for autonomy, for instance, are likely to be less negatively affected by high levels of job autonomy than those lacking this need (cf. Landeweerd \& Boumans, 1994; Warr, 1994). Moreover, there is empirical as well as statistical evidence that the shape of a curve might change as a function of a moderator variable (Champoux, 1992; Jaccard, Turrisi \& Wan, 1990). For example, in the case of low need for autonomy, job autonomy could be positively related to emotional exhaustion (cf. De Jonge, Landeweerd \& Van Breukelen, 1994), whereas for high need for autonomy the resulting relationship between job autonomy and exhaustion could be curvitinear (representing an inverted $U$-shape)

In addition, job autonomy has small but significant linear relationships with job satisfaction and work motivation. These relationships are consistent with those in prior job redesign research (e.g., Fried \& Ferris, 1987; Loher, Noe, Moeller \& Fitzgerald, 1985) and job stress research (e.g., Landsbergis, 1988; Melamed, Kushnir \& Meir, 1992; Parkes \& Von Rabenau, 1993).

\section{JoB DEMANDS}

As in our study, several authors did not find non-linear relationships between job demands and the "depressed-actively pleased" axis of Warr's affective well-being (e.g., Fletcher \& Jones, 1993; De Jonge, Schaufeli \& Furda, 1995; Parkes, 1991). Thus, it seems that job demands are only linearly associated with indicators of job-related depression such as occupational burnout (e.g., emotional exhaustion). An explanation for this unexpected result may be some restriction of range in experienced workload. Generally, the experienced workload in health care is quite high; then because of financial cut-backs and higher care 
standars, more (complex) wotk has to be pertomed with fewer professionals (ct, De Jonge, schatel furda, 1995). As a consequence, whtulu ho protessionals are heluted who experience low levels of job demands. In cther words, in tems of lgure 3 , ony employees at the right-hand side (segment $C$ ) are induded. Another explanation may be the reciprocalty of this relationship (see below). The present longitudinal hindings indicated lagged reciprocal relationshos between job demands and emotional exhaustion. it could be that emotionaly cxhausted people tend to perceive their wokload 3 shigher, which in wh may lead to more feelings of exhaustion. Accordingly. a linear patten of association between job demands and occupational bumout is to be expected.

Finaly, job demands are negatively, but only inearly, related with job satisfaction. Several other inestigators have reported this significant association in health care workers. For example, Mclaney and Hurrell (1988) reported in their study among 765 health care workers a sigrificant zero-order correlation of -20 between job demands and job satisfaction. a simiar vein, a study among 289 nurses and nurses aides revealed that job demands were posinively associated with job dissatisfaction (Landsbergis, 1988),

\section{WORKPLACE SOCIAL SUPPORT}

Social support showed significant non-linear relationships with job satisfaction and emotional exhaustion. Both relationships followed the postulated $A D$ pattern, while the latter also corroborates a similar finding of De Jonge, Schaufeli and Furda (1995). A tentative explanation for these relatively strong non-linear relationships of social support is the nature of the work of nurses and nurses' aides. A first characteristic feature of their jobs is that workplace social support plays an important role in daily work, because for the most part nurses and nurses' aides work closely together in teams (e.g., De Jonge \& Landeweerd, 1993; Shinn, Rosario, Morch \& Chestnut, 1984). A second characteristic feature is the relatively low level of job autonomy compared to other occupations (cf. Mulder, De Jonge \& Nijhuis, 1995). When the level of autonomy is rather poor, social and collective forms of job autonomy may become more important (Boone \& De Jonge, in press; Johnson \& Hall, 1994). So, it can be speculated that workplace social support plays a more significant role in these workers' well-being and health than job autonomy does.

Another finding of interest is the decreasing level of job satisfaction and the increasing level of emotional exhaustion at high levels of social support. This result provides some evidence for the 'stress-transfer' buffering theory of Karasek, Triantis and Chaudhry (1982). In the case of high social cohesion, the work group serves as a reservoir for moderating strain of any of its members. In other words, less strained workers absorb part of the problems of their more strained colleagues, equilibrating individual strain differences.

Finally, social support appeared to be positively related with job satisfaction and work motivation, and negatively related with anxiety and emotional exhaustion. Similar plausible significant associations have frequently been observed in occupational research. A longitudinal study by Parkes (1982), for instance, revealed that changes in social support were positively associated with changes in job satisfaction and negatively associated with changes in anxiety and depression. 


\section{Differential associations}

The validity of the VM has been supported in this study. A closer inspection of the findings indicates, however, that different aspects of health and well-being - reflected in Warr's three-axial framework - are differentially associated with various job characteristics. For instance, variations in job autonomy are related with axis one (i.e., "discontentedcontented") and axis three (i.e., "depressed-actively pleased") rather than with axis two (i.e., "anxious-comfortable"). In line with more general notions of depression, Warr (1990b) argued that job-related depression is thought more likely to be related to loss or deprivation. In occupational research, job characteristics such as job autonomy are considered important at levels representing deprivation, because they often exist in low quantities. This line of reasoning is also consistent with Karasek's (1979) study. His two survey studies showed that the highest levels of depression were particularly observed in employees who experienced low levels of job control.

Additionally, variations in job demands are more likely to bear upon axis three of the axial framework (i.e., depressed-actively pleased) than on both other axes. This result confirms the role of job demands as 'stressors' that have an impact on the individual's mood rather than on his or her level of anxiety or satisfaction. More particularly, our results agree with the burnout literature that shows consistent and rather substantive relationships, especially between emotional exhaustion and measures of job demands such as perceived stress, workload, and time pressure (Schaufeli \& Buunk, in press).

Finally, variations in workplace social support are somewhat more strongly associated with axis one (i.e., discontented-contented) than with both other axes. Nonetheless, all three axes showed meaningful relationships with social support. In the literature, several theories can be found which distinguish the different roles of workplace support ( $f$. Johnson, 1989). On the most basic level, social support satisfies a human need for companionship and group affiliation, thereby promoting feelings of satisfaction. Moreover, workplace support may also serve as a resource to reduce the impact of job demands, and may lead to lower levels of anxiety and emotional exhaustion.

In brief, different job characteristics are more or less important in relation to different aspects of employees health and well-being. More specifically, it seems important to consider both positive and negative outcomes in studies of job characteristics.

\section{LONGITUDINAL MODEL}

While the previous findings preclude causal interpretation of the relationships between job characteristics and psychological outcomes, the longitudinal panel data allow more rigorous interpretation. Because the direction of the relationships between job characteristics and outcomes was a primary aim, only a first-order model (i.e., a model without interaction and non-linear terms) was tested.

As postulated, hypothesis $\mathrm{H} 4$ (i.e., time 1 job characteristics influence time 2 outcomes) was confirmed by the empirical finding that time 1 job characteristics influence time 2 psychological outcomes. Alternatively, the results showed that the psychological outcomes of measurement 1 are able to influence the perceptions of job characteristics in measurement 
2 - a confirmative answer to question Q4 as well. However, the former causal pattern was causally predominant: the psychological outcomes tend to occur after the perceptions of job characteristics, rather than the process being initiated in the reverse sequence. In other words, question Q5 was affirmatively answered. Finally, the size of the squared multiple correlations of the time 2 outcome variables is moderate (i.e., ranging from .40 for time 2 job-related anxiety to .55 for time 2 emotional exhaustion).

The present findings are consistent with the scarce longitudinal studies in this research area (for a short overview, see Vogelaar \& Van der Vlist, 1995). For example, James and Tetrick (1986) performed a two-stage least squares (2SLS) analysis of job characteristics and job satisfaction. Through comparisons between three alternative causal models, they concluded that job characteristics and job satisfaction influenced each other reciprocally. Another point of interest was that job characteristics appeared to be a stronger cause of job satisfaction than vice versa

An inspection of the lagged relationships indicates additional support for job characteristicsoutcomes relationships, as far as job demands and social support are concerned. Both variables showed a lagged pattern of relation similar to the cross-sectional findings. These results provide additional empirical evidence for these two job characteristics in the prediction of well-being and health. Conversely, and not completely expected, two lagged relationships with outcomes as predictors were found for job autonomy and job demands. A theoretical rationale for these findings is that (1) employees respond affectively to characteristics of their jobs, and (2) existing or desired levels of affect may cause employees to be selectively attentive to - or to redefine - situational job characteristics in cognitive information processing ( $f$. James \& Jones, 1980; James \& Tetrick, 1986; Kohn \& Schooler, 1983; Lord \& Maher, 1989). This implies that job perceptions are not only reflections of situational job characteristics, but also products of higher-order cognitive information processing. Perceptions of job characteristics are at least partially descriptive in the sense that they are - partly - caused by situational job characteristics. On the other hand, psychological outcomes may be regarded as a result of additional cognitive information processing and seem to be important factors in the formulation of (future) job perceptions.

Another theoretical explanation is employees' behavioural impact upon their work environment (cf. Krahé, 1992; Lorence \& Mortimer, 1985; Warr, 1987). This impact may take two forms: (1) choices about which work environments to enter or to avoid (i.e., occupational self-selection); and (2) behaviours which shape present situational job characteristics and the process of future interaction. Although such a behavioural impact is ubiquitous, there is still a lack of general theorizing which can account for it.

In general, however, empirical support for the causal predominance of job characteristics over outcomes affirms what our theoretical models have postulated to be the causal ordering among job characteristics and affective responses to jobs (cf. Hackman \& Oldham. 1980; Karasek \& Theorell, 1990; Warr, 1987, 1994). 
A final point concerns the contemporaneous findings. Generally speaking, the longitudinal data available from four institutions indicate invariant (causal) relationships across time. They also support the main inferences drawn from the cross-sectional findings. More specifically, all but one of the corresponding relationships were to be found significant, and all relationships were (quite) similar in magnitude and direction. A possible reason for the single non-significant relationship may be the lack of power in the panel group, because of the lower number of people included. Although the relationship was equal in magnitude and direction, the level of five per cent significance could not be reached.To summarize these findings briefly, the effects were in general contemporaneous rather than lagged.

\subsubsection{The particular role of demographic characteristics}

We will briefly comment upon the demographic characteristics of the people involved in the analyses. Although these characteristics were not a major focus of the present study, the review in chapter 3 highlighted the need to include gender and age as demographic control variables.

As might be expected, the role of gender was prominent with respect to the three job characteristics and job satisfaction. Moreover, the size and magnitude of the relationships were in accordance with the results of other comparable studies (see chapter 3). For example, the findings indicated that women tended to report greater job satisfaction, and men's average levels of job autonomy were higher than women's levels. Contrarily, age did not play an important role. Although several relationships with job characteristics as well as outcomes were significant, their magnitude was extremely low (i.e., nearly zero). In sum. based on our results, only gender occupies a legitimate place in the models.

\subsubsection{Towards a heuristic model of job characteristics and psychological outcomes}

Based upon the insights we gained from the separate cross-sectional and longitudinal analysis, we will now make an effort to formulate the outline of a more representative and general model, as shown in figure 8.1. We will take the position that this model indicates a heuristic framework of job characteristics and psychological outcomes, and we will suggest that job characteristics research should be extended in the direction of the further development of this model. It should be noted that a few suggestions for further research will be discussed later in this chapter.

The present model has been created as explicitly "situation-centred and enabling" (cf. Gergen \& Gergen, 1982; Warr, 1987; see also chapters 2 and 3). Such a model focuses mainly on environmental influences, but postulates that people can alter these influences. As a consequence, a core assumption of this model is that perceived job characteristics grounded in situational job characteristics - affect psychological outcomes (e.g., linearly or non-linearly). As a result of, for instance, cognitive and/or behavioural influences, psychological outcomes in their turn affect perceptions of job characteristics. The postulated asymmetric - reciprocal pattern may be influenced by several individual variables, such as gender or need for autonomy. Finally, situational job characteristics themselves affect psychological outcomes, quite independently of job perceptions. 


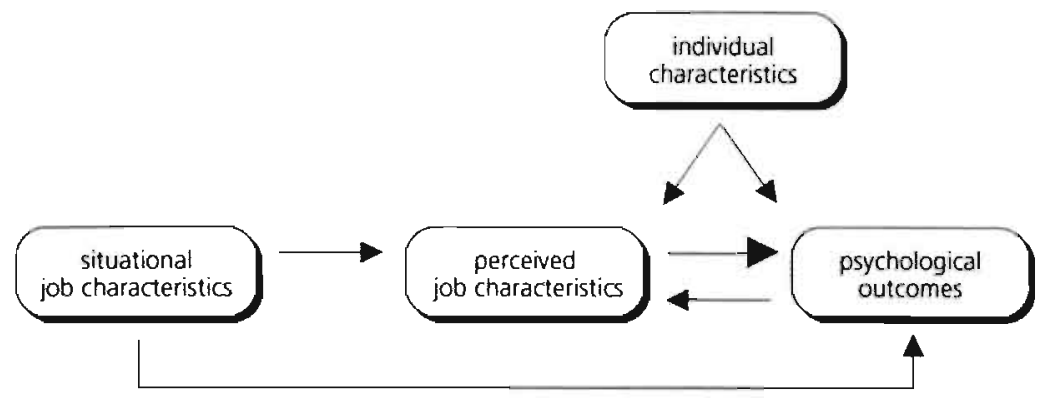

Figure 8.1 A heuristic model for the study of job characteristics and psychological outcomes

We feel that a further development of the model along these lines may prove to be a fruitful approach toward the specification of an improved job characteristics model. Almost needless to say, Warr's Vitamin Model can be used as a theoretical framework in order to make a more profound, accurate and comprehensive study of particular job characteristics, individual variables, outcomes, and their linear or non-linear relationships. This model brings together much of what has been established so far, and goes beyond other views in the ways mentioned in chapter 3 .

\subsection{Practical implications}

Although the primary aim of this study was to contribute to theoretical insights about job autonomy, the current findings also seem to have some implications for organizational practice. Recall that modern working life within bureaucratic and professional health care organizations appeared to be an important source of work stress. In addition, with increasing pressure for cost containment and quality guarantees, and the development of new care delivery systems, the trend appears to be in the direction of increasing job demands and a growing interest in job-related resources like job autonomy and workplace social support.

The present study indicated that job characteristics themselves were relatively important and causally predominant - predictors of well-being and health. Consequently, there is reason to believe that some of the observed problems may have their roots in the properties of the job, or task, itself. Therefore, job redesign is probably a useful category of worksite interventions which could improve the psychosocial, stress-inducing characteristics of the job. 
However, a common problem of worksite methods like job redesign is the difficulty in changing the task structure when the embedding organizational structure remains unimpaired (cf. Algera, 1991; Karasek, 1992; Landsbergis, 1988). Moreover, the use of multi-level analysis has shown that when changing anything to promote health and wellbeing, the context of the change also needs to be considered and probably also needs to be changed. So, a more integrated approach to change focuses not on one aspect within the organization, but on long-term change and development throughout the organization. Therefore, we will first venture into an action research approach before discussing job redesign strategies.

\section{Participatory Action Research}

Job characteristics research requires a process by which job redesign can actually be achieved. Such a process is provided by the tradition of Organization Development, or OD (Bartol \& Martin, 1991; Landsbergis \& Vivona-Vaughan, 1995). OD can be defined as a planned change effort aimed at enhancing organizational health and effectiveness. A central aspect of many OD efforts is Action Research (AR). An AR approach in the work setting involves outside experts (usually researchers) and organization members in a joint process aimed at meeting both research and intervention objectives (Israel, Schurman \& House, 1989). One particular version of AR is Participatory Action Research, abbreviated PAR (cf. Landsbergis, Schurman, Israel, Schnall, Hugentobler, Cahill \& Baker, 1993). PAR is a flexible set of intervention processes and methods as well as an innovative research method. PAR assumes relative equality among researchers and organization members in all aspects of the research and intervention process. It is beyond the scope of this study to present all key characteristics of PAR. In short, this strategy emphasizes participation and collaboration, in which researchers and employees are co-learners in an empowering process. Furthermore, PAR is a cyclical process that involves three basic sequences of activities: (1) group development; (2) research; and (3) action. Not surprisingly, evaluation is a crucial ongoing component in each of the three sequences.

Although PAR can make a substantial contribution to job redesign efforts, it has not been extensively applied to this kind of strategies (cf. Karasek, 1992; Landsbergis \& VivonaVaughan, 1995). It requires a rather subtle reorientation in thinking, which will be briefly described below

According to the first sequence of PAR, representative problem-solving committees have to be installed by which workers could locate and identify important job stressors (i.e., job characteristics) in order to plan action to alter them. Thus, improved group processes, communication, and mutual influence and trust would be the first step. After successful group processing, joint problem definition should take place as well as progress through all steps of the action research process (i.e., data gathering, data analysis, planning and implementing feedback, formulation of action hypotheses). Finally, the action research group makes a few recommendations about problems and potential solutions based upon the data obtained. Depending on the nature of the problem, the group will be involved in job redesign - interventions. 


\section{Job Redesign}

After PAR has avoided the pitfalls and limitations of traditional organizational change efforts, several job redesign methods can be formulated and recommended. Regarding the present study, the findings showed several curvilinear, linear interactive and linear additive relationships between the three job characteristics and psychological outcomes

Starting with the curvilinear relationships, the AD patterns of job autonomy, job demands and workplace social support suggest an optimum dose of these psychological work vitamins in the work situation (De Jonge, Schaufeli \& Furda, 1995). For example, increasing job autonomy in a particular workplace should be tailor-made in order to prevent occupational burnout.

The presence of interactive effects implies that job strains can be ameliorated by increasing job autonomy, more or less independently of changes in job demands (cf. Karasek, 1979). In other words, an increase in job autonomy - even without meaningful changes in job demands - could improve employee well-being.

Finaliy, linear additive relationships suggest (1) increasing job autonomy and social support as such, and (2) reducing or regulating the job demands as such might have beneficial effects too. Employee well-being can be particularly promoted by increasing both job autonomy and social support. In addition, adverse health can be reduced by decreasing job demands and increasing social support.

There are a variety of job redesign methods that focus on an increase in job autonomy and workplace social support. Of all these methods, job enrichment has been the most crucial for a long time. Job enrichment involves changing a job both horizontally (i.e., adding tasks) and vertically (i.e., adding responsibility and authority). There are several ways to enrich the job in order to provide employees more job autonomy. Employees can be given content opportunities in setting work goals, determining the work method and work order, and evaluating the work themselves. Furthermore, employees can be given contextual opportunities in determining, for instance, their own working-hours, the amount of work and the kind of work to be done. Contextual opportunities may be consulted with other employees if necessary.

As mentioned before, characteristic features of the health care jobs studied are the relatively low importance of job autonomy and the relatively important role of workplace social support (see also De Jonge, Boumans, Landeweerd \& Nijhuis, 1995a). In today's bureaucratic health care institutions, employees' job autonomy is relatively limited; instead, social and collective forms of job autonomy may become even more important (cf. Boone \& De Jonge, in press; Johnson \& Hall, 1994). One such collective job redesign method involves the reconstruction of fragmented and isolated work through the development of small-scale, decentralized semi-autonomous work groups (d. Gardelł, 1982; Trist, 1981). According to Gardell (1982), (1) work should be based on groups rather than individuals; (2) the group should be given responsibility for planning and performing tasks; and (3) supervisors should serve primarily as resources rather than exerting authority. Added to this, semi-autonomous work groups should be integrated in an overall organizational structure by means of PAR methods and union policies (cf. Karasek \& Theorell, 1990). 
Applied to health care work, semi-autonomous work groups may be reflected by patientoriented as well as team-centred care delivery systems (cf. Boone \& De Jonge, in press). This job redesign method enables health care workers to counteract the problems of work fragmentation, social isolation and job complexity that are so common. Self-regulating groups perform many roles traditionally assigned to management, such as allocation of tasks, determining work processes and provision of all kinds of support. Within the context of the work group, the opportunities and personal contacts are more widespread. The result may be more nearly equal roles and more (supportive) social relationships. In other words, the semi-autonomous work group seems to be a basic condition for (1) enhancing job autonomy, and (2) creating social networks and social resources.

Finally, regulating job demands in health care requires firstly a well-documented, 24-hour job demands-profile (e.g., Blok, De Vries-Griever, Bloemendaal \& De Jong, 1995). This method can optimize the balance between job demands and recovery, probably resulting in a reduction of peaks in the work. Secondly, shift schedules need to be changed in the way of regularity, long-term planning and forward rotation. Finally, the admission policy has to be well controlled; that is, regularity, prevention of patient overspill and creation of emergency space is required.

In sum, Participatory Action Research can be a valuable and effective tool to achieve the ultimate goals of job redesign. With the help of this multi-focus comprehensive approach, the work environment can be redesigned in two ways: (1) increasing job autonomy and workplace social support mainly through the development of semi-autonomous work groups; and (2) regulation of job demands by means of a job demands-profile, healthy shift schedules, and a sound admission policy.

\subsection{Directions for future research}

Although this thesis has yielded some interesting findings, several unanswered questions and imperfections need to be addressed. The study offers some avenues for further research in the context of job redesign, which will be discussed in this section.

A first issue concerns the measurement instrument of job autonomy: the Maastricht Autonomy Questionnaire. Although the psychometric qualities of the MAQ are promising, efforts to validate the instrument should continue. For example, the ecological validity of the MAQ can be examined in other occupations and in other job settings. In addition, supplementary sources of data like independent measures or observers' ratings might be useful to cross-validate with the MAQ. Therefore, a standardized observation scheme with clear and precise anchored rating scales has to be developed. Finally, there seems to be considerable value in differentiating two levels of job autonomy for making precise (organizational) diagnoses. Thus, further research is needed to explore the dynamic of the two dimensions of the MAQ with regard to organizational issues as well as psychological outcomes. 
A second point of attention is to be concerned with the possible hierarchical-level specific effects of job autonomy. As we have emphasized, the controversy is whether or not job autonomy is inherent in a particular organizational position. Future research may profitably compare level-specific effects of job autonomy at different hierarchical levels within an organization.

A third issue involves the theoretical models used. A problem is that middle grounded theoretical models like the Vitamin Model may not be sufficiently well articulated to meet the complex conditions of real-life situations and events. Using the proposed heuristic model, the theoretical models can be improved, refined, combined and even reciprocally revised by testing them against a range of applied contexts instead of one particular job setting in a single Western country. So, generalization of the current findings to other occupations, other job settings and even to other countries awaits further empirical examination. One Dutch study is now in progress including several occupational groups such as bank and insurance employees, cleaners, truck drivers and construction workers (Mulder, De Jonge \& Nijhuis, 1995). A series of preliminary findings indicate that, in general, parts of the theoretical models hold under these conditions too.

Another important avenue for further research involves investigating whether the results revealed here can be applied to other outcome variables. We expect these effects to generalize since our psychological outcomes were found to correlate with several outcomes like psychosomatic complaints and job involvement (cf. De Jonge, Boumans, Landeweerd \& Nijhuis, 1995b; De Jonge, Janssen \& Van Breukelen, in press). Further research should be devoted to other outcome variables, like behavioural and physiological outcomes.

A particular important area for future research is the role of individual characteristics in job characteristics research. While the general Task Characteristics Approach assumes that almost every employee will respond to job characteristics in the same fashion, growing empirical evidence supports the idea that matching individual characteristics modify the linear additive, interactive, or non-linear - job characteristics-outcomes relationships (e.g., Furda, 1995; De Jonge, Landeweerd \& Van Breukelen, 1994; Landeweerd \& Boumans, 1994; De Rijk, Le Blanc, Schaufeli \& De Jonge, 1995; Parkes, 1991, 1994). For example, De Rijk and her team showed that coping and need for autonomy were important moderators of interactive job characteristics-burnout relationships. Future research, incorporating these and other individual characteristics, would be valuable in extending the present findings

Several methodological suggestions for further research can be formulated as well. We still need to concentrate on longitudinal studies of the work setting, preferably those designed around 'natural experiments' (Kasl, 1978, 1989; Parkes, 1982). That is, data should be collected before and after significant events and transitions, which may better reveal the way (situational) job characteristics affects well-being and health than cross-sectional studies of stable work environments will. Although it is not easy to find a natural starting point, it seems useful to start studies at a point where significant events appear for the first time (e.g., the start of a new job or a significant redesign of a job; see also Karasek, 1990). Furthermore, data should be collected for more than a single follow-up wave, providing three or more waves in total. Besides the advantage of following job characteristics over a 
lifetime ( $c$. Johnson \& Stewart, 1993), these additional waves of data are extremely useful for identifying non-recursive models that remain unidentified in one or two waves (Kessler \& Greenberg, 1981). Moreover, Frese and Zapf (1988) have proposed different models of the time course of cause and effect in research on work stress. These time models could be tested with such multi-wave longitudinal data, incorporating the time component as a variable into the research design

A final point of attention is the application of covariance structure modelling, while at the same time taking the hierarchy in data into account. Although multi-level analysis is very flexible and can be used in many different applications, there are models which cannot be analysed, notably factor models and structural equation models (Hox, 1994). Recently, multi-level extensions of covariance structure modelling have been elaborated, such as multi-level factor analysis and multi-level structural equation modelling (e.g., Muthén, 1994). These statistical techniques provide a large set of new analytic possibilities for future model testing.

\subsection{Final remarks}

In this thesis we have tried to elucidate the concept of job autonomy and its role in the relationship between job characteristics on the one hand, and well-being and health on the other. Besides introducing and testing a new measurement instrument, we introduced three theoretical models which could serve as a platform for a joint test of three important job characteristics and their particular relationship with regard to well-being and health. In this section we will make some final remarks with respect to the various issues that have been addressed in this study.

The present study has shown that it was possible to capture theoretically as well as empirically the construct of job autonomy. However, it is doubtful that we have derived the final solution in terms of conceptualization, operationalization and assessment. The issues concerning job autonomy should be viewed as an evolutionary process. As Siegrist (in press) has emphasized, the question remains whether it is useful for a construct like job autonomy to extend its scope to a wide range of phenomena, or whether it is more valuable to study profoundly its merits by restricting the potential range of phenomena.

A second remark concerns the three theoretical models. The Job Characteristics Model as well as the Demand-Control-Support Model have inspired an increased research effort in the job redesign area by stressing linear (interactive) relationships between job characteristics and psychological outcomes. Warr's non-linear Vitamin Model, however, has successfully challenged this popular belief of the existence of linear relationships.

Another remark pertains to the occupational group studied. In this thesis, the group of health care workers was included primarily for methodological purposes, rather than as a topic of investigation per se. Substantive issues relating to the particular work of this occupational group have been extensively considered in other publications (e.g., De Jonge, Boumans, Landeweerd \& Nijhuis, 1995a, 1995b; De Jonge, Janssen \& Landeweerd, 1994). 
Taken together, we believe it is possible to conceive of job autonomy not only as a perception of a job, but also as a situation-centred characteristic which provides the opportunities to determine diverse task elements. It is this positive effect of job redesign. which holds the promise of significant gains in health and particularly in well-being.

Questions about the future of work and about how specific job characteristics affect wellbeing and health (or vice versa) merit further study at a multidisciplinary level. In seeking remedies to the current pitfalls and deficiencies, we should work together with other disciplines (like organizational sociologists and statisticians) in order to obtain the conceptual and methodological tools that are necessary (cf. Brief \& George, 1995). For example, multi-level models, developed in educational psychology, can throw a new light upon the area of job redesign research by applying efficient algorithms for estimation. In this way, we are more able to understand the richness of the work environment, and consequently more able to understand the employees' reactions to that enviromment. In other words, we must not lose sight of our focus on the work context and, at the same time, our responsibility to the employees who work in that context.

The challenge to researchers in this area is the development of not only practical tools, but also theoretical models to guide one to identify those psychological 'work vitamins' likely to affect the well-being and health of most people exposed to them (cf. Brief \& George, 1995; Warr, 1994). We hope that the serious - human - costs of work stress will be considered to be an important factor in future decisions over employees' job autonomy, well-being and health in terms of long-term organizational planning.

\section{NOTES}

1. Appendix 1 gives a list of abbreviations used in this chapter.

2. Negative affectivity can be defined as a mood-dispositional dimension that reflects pervasive individual differences in negative emotionality and self-concept (Watson \& Clark, 1984). 
Summaries 


\section{SUMMARY}

The present thesis addresses the role of job autonomy in the relationship between job characteristics on the one hand, and well-being and health on the other. The study focuses on job autonomy primarly in the context of job redesign, and elaborates two issues. The first concerns the conceptualization, measurement and assessment of job autonomy, Whereas the second issue deals with the particular role of job autonomy in the associations between job characteristics and psychological outcomes. Accordingly, the aim of the study was wofold: (1) to gain more insight into, and understanding of the term job autonomy: and (2) to gain a better understanding of the specific nature and magnitude of the effects of job autonomy (whether or not in combination with other job characteristics) on well-being and health.

The research design of the study includes a cross-sectional design as well as a longitudinal design (i.e., two measurement points; one-year time interval). A disproportional random sample was drawn from all general hospitals that included a psychiatric unit and all combined nursing homes in the Netherlands ( $N=218$ ). Eight hospitals and eight nursing homes participated in the study. Self-report questionnaires were fllled in and returned by 1,489 health care workers from 64 units $(82 \%$ response rate). in addition to this, 363 health care workers from four institutions participated in a second measurement sample (80\% response rate).

At the start of the study the literature on job autonomy was reviewed, and a typology of job autonomy was generated. As a consequence, job autonomy was defined as the worker's opportunity or freedom, inherent in the job, to determine a variety of task elements. In addition, a new measurement instrument was developed, named the Maastricht Autonomy Questionnaire (MAQ). After a thorough test, the 10-item MAQ showed reasonably good psychometric properties. Both a two-dimensional scale (i.e., contextual and content autonomy) and a one-dimensional scale (i.e., overall job autonomy) were tenable. In order to assess job characteristics, the question was whether aggregated job characteristics data significantly add explained variance to individual-level job characteristics data in the prediction of well-being and health. Multi-level analysis (VARCL) indicated that aggregated job characteristics data are only powerful in explaining well-being in the presence of individual-level job characteristics, which means that some of the variance in well-being reflects some properties outside the individual worker.

This job autonomy study derives its significance particularly from being embedded in a theoretical classification system of job characteristics and psychological outcomes: the Task Characteristics Approach. Within this approach, three rather impressive theoretical models were presented in order to test several forms as well as the direction of relationships mentioned (i.e., the Job Characteristics Model, the Demand-Control-Support Model, and the Vitamin Model). According to the last two models, it was hypothesized that three job characteristics (i.e., job autonomy, job demands, and workplace social support) are linearly interactively or curvilinearly related with four indicators of well-being and health (i.e., job satisfaction, work motivation, emotional exhaustion, and job-related anxiety). These hypotheses were set against a null hypothesis that no such relationships exist. In this case, 
some evidence for a linear additive model (e.g., the Job Characteristics Model) could be investigated. Finally, it was hypothesized that time 1 job characteristics influence time 2 psychological outcomes.

Structural equation modelling (LISREL) was employed to test the hypotheses. Broadly speaking, the results showed: (1) no empirical evidence for the interactive DCS Model; (2) a superior non-linear Vitamin Model with regard to a linear model; and (3) the influence of time 1 job characteristics on time 2 psychological outcomes. Furthermore, the results revealed that time 1 outcomes are able to influence perceptions of time 2 job characteristics. However, the former causal pattern was stronger; that is, causally predominant. In the last part of the thesis, the research findings presented are discussed and reconsidered. The present study has shown that it was possible to capture job autonomy theoretically as well as empirically. In addition to this, perceptions of job characteristics do not merely reflect subjective feelings but also are grounded in an environmental reality, as far as well-being is concerned. Finally, although the linear models were slightly more stable, the findings supported the non-linear Vitamin Model. Moreover, empirical support for the causal predominance of job characteristics over outcomes affirmed what our theoretical models have postulated to be the causal ordering among these variables. The thesis concludes with several practical implications as well as some avenues for future research.

\section{SUMMARY IN GERMAN}

Die vorliegende Dissertation thematisiert die Rolle von Handlungsspielraum ('job autonomy') für den Zusammenhang von Merkmalen der Arbeit mit Wohlbefinden und Gesundheit. In der Studie wird Handlungsspielraum in erster Linie im Kontext von Arbeits(neu)gestaltung betrachtet, wobei auf zwei Themen näher eingegangen wird: Das erste Thema betrifft die Konzeptualisierung, Messung und Bewertung von Handlungsspielraum, während es sich beim zweiten Thema um die besondere Rolle von Handlungsspielraum für die Wirkungszusammenhänge zwischen Arbeitsmerkmalen und psychologischen Reaktionen handelt. Dementsprechend hat die Studie zwei Ziele: (1) Sie soll zu einem klareren Verständnis des Begriffs "Handlungsspielraum" ('job autonomy') beitragen; und (2) sollen die besondere Natur von Handlungsspielraum und das Ausmaß seines Einflusses (mit oder ohne Berücksichtigung anderer Merkmale der Arbeit) auf Wohlbefinden und Gesundheit geklärt werden.

Das Forschungdesign der Studie ist sowohl quer- als auch längsschnittlich (das heißt: zwei Meßzeitpunkten und einem Intervall von einem Jahr). Aus allen niederländischen Allgemeinkrankenhäusern mit Psychiatrischen Abteilungen und allen kombinierten Pflegeheimen ( $N=218$ ) wurde eine disproportionale Zufallsstichprobe gezogen. Acht Krankenhäuser und acht Pflegeheime beteiligten sich an der Studie (d.h. insgesamt 16 Einrichtungen). Von 1489 Krankenpflegern und Pflegekräften aus insgesamt 64 Abteilungen wurden Fragebögen ausgefüllt und zurückgesandt (Rücklaufquote $82 \%$ ). Zusätzlich nahmen 363 Mitarbeiter aus vier Einrichtungen an einer zweiten Befragung teil (Rücklaufquote $80 \%$ ). 
Zum Anfang der Studie wurde die Literatur zu Handlungsspielraum ('job autonomy') ausgewertet und eine Typologie von Handlungsspielraum erstellt. Daraus abgeleitet wurde Handlungsspielraum als die Möglichkeit oder Freiheit des Arbeiters definiert, die Vielfalt der Aufgabenelemente innerhalb der Arbeit zu bestimmen. Des weiteren wurde ein Meßinstrument, der 'Maastricht Autonomy Questionnaire (MAQ)', entwickelt. Nach ausführlicher Analyse erwies sich der 10 Items umfassende MAQ als ein Instrument mit guten psychometrischen Eigenschaften. Der MAQ kann sowohl als ein zweidimensionales (d.h. die Kontext- und Inhaltsautonomie) als auch als eindimensionales (d.h. allgemeiner Handlungsspielraum) Instrument betrachtet und benutzt werden.

Bezüglich der Bewertung von Merkmalen der Arbeit ergab sich das Problem, ob aggregierte Daten von Arbeitsmerkmalen über die individuell bewerteten Daten von Arbeitsmerkmalen hinaus signifikant zur Vorhersage von Wohlbefinden und Gesundheit beitragen. MultiLevel-Analysen (VARCL) ergaben, daß aggregierte Daten von Arbeitsmerkmalen bei Berücksichtigung 'individueller' Merkmale nur einen deutliche Beitrag zur Erklärung von Wohlbefinden leisten. Dies bedeutet, daß ein Teil der Varianz von Wohlbefinden die Wirkung von Merkmalen außerhalb des Individuums wiederspiegelt.

Die Besonderheit dieser Studie zu Handlungsspielraum ergibt sich daraus, daß sie in ein theoretisch fundiertes Klassifikationssystem von Arbeitsmerkmalen und psychologischen Reaktionen eingebettet ist, das heißt in den "Task Characteristics Approach". Innerhalb dieses Ansatzes wurden drei eindrucksvolle theoretische Modelle dargestellt, um dann daraus abgleitete verschiedene Varianten und die in ihnen postulierten Wirkungszusammenhänge zu testen (das 'Job Characteristics Model', das 'Demand-Control-Support Model' und das 'Vitamin Model'). Entsprechend der beiden letzten Modelle wurde angenommen, daß drei Merkmale der Arbeit (Handlungsspielraum, Arbeitsanforderungen. soziale Unterstützung in der Arbeit) linear oder kurvilinear mit vier Indikatoren des Wohlbefindens und der Gesundheit (Arbeitszufriedenheit, Arbeitsmotivation, emotionale Erschöpfung, arbeitsbezogene Angst) verknüpft sind. Dieser Annahme wurde die Nullhypothese, daß keine derartigen Zusammenhänge existieren, entgegengesetzt. Für diesen Fall könnten Belege für ein lineares additives Modell (d.h. das 'Job Characteristics Model') genauer untersucht werden. Schließlich wurde angenommen, daß Arbeitsmerkmale des ersten Meßzeitpunkts psychologischen Reaktionen zum zweiten Meßzeitpunkt beeinflussen. Die Hypothesen wurden mittels linearer Strukturgleichungsmodelle (LISREL) getestet. Grob zusammengefaßt ergaben sich folgende Ergebnisse: (1) es gibt keine empirischen Belege für ein interaktives 'Demand-Control-Support Model'; (2) ein nicht-lineares 'Vitamin Model' ist einem linearen Modell überlegen; und (3) Arbeitsmerkmale zum ersten Meßzeitpunkt beeinflussen psychologische Reaktionen zum zweiten Meßzeitpunkt. Des weiteren stellte sich heraus, daß psychologische Reaktionen zum ersten Meßzeitpunkt die Wahrnehmung der Arbeitsmerkmale zum zweiten Meßzeitpunkt beeinflussen können, wobei allerdings der erstgenannte Wirkungszusammenhang stärker, das heißt kausal dominant, ist.

Im letzten Teil der Dissertation werden die Forschungsergebnisse zusammenfassend diskutiert. Die vorliegende Studie hat gezeigt, daß es möglich ist, Handlungsspielraum ('job autonomy') sowohl theoretisch als auch empirisch abzugrenzen und zu erfassen. Des weiteren zeigte sich, daß die Bewertung von Merkmalen der Arbeit nicht nur einen 
subjektive Zustand wiederspiegelt, sondern auch daß ihr - zumindest was Wohlbefinden betrifft - objektive Umweltgegebenheiten zugrunde liegen. Schließlich unterstützen die Ergebnisse das nicht-lineare 'Vitamin Model', obwohl sich lineare Modelle als etwas stabiler erwiesen haben. Darüber hinaus bestätigten die empirischen Daten die theoretisch postulierten Wirkungszusammenhänge bezüglich der kausalen Dominanz von Arbeitsmerkmalen über psychologischen Reaktionen. Die Doktorarbeit schließt mit der Thematisierung praktischer Implikationen sowie von Konsequenzen für weiterführende, zukünftige Forschung.

\section{GENERAL OUTLINE IN DUTCH}

Dit proefschrift handelt over "autonomie in het werk". Het doel van deze studie is tweeledig. In de eerste plaats dient inzicht verkregen te worden in de term "autonomie in het werk" binnen de context van de taakherontwerptraditie. In de tweede plaats wordt beoogd inzicht te verkrijgen in de specifieke aard en grootte van de effecten van werkgerelateerde autonomie - al dan niet in combinatie met andere werkkenmerken - op het welbevinden en de gezondheid.

In hoofdstuk 1 wordt het onderwerp geintroduceerd en wordt de achtergrond van het onderzoek geschetst. Autonomie in het werk lijkt een belangrijke voorspeller van welbevinden en gezondheid te zijn. Het blijkt echter riskant en prematuur om het effect van autonomie op deze variabelen te generaliseren vanwege theoretische, conceptuele en methodologische problemen.

Hoofdstuk 2 bevat een theoretische verhandeling over autonomie in het werk. Achtereenvolgens komen de conceptualisering, de operationalisering en de inschatting van werk-gerelateerde autonomie aan bod. Uit de verrichte literatuurstudie blijkt dat veel conceptualiseringen en operationaliseringen van autonomie in het werk niet voldoen aan gangbare criteria. Zo blijkt bijvoorbeeld dat werk-gerelateerde autonomie meestal beschouwd wordt als een absoluut, globaal en algemeen begrip. Vervolgens laten de operationaliseringen van autonomie te wensen over ten gevolge van onder meer (1) onnauwkeurige, deels met andere begrippen overlappende items, (2) diversiteit in dimensionaliteit van items, en (3) verschillende typen schaalankers. Tenslotte komt uit deze studie naar voren dat nog steeds onenigheid bestaat over de inschatting van autonomie. Gezien het feit dat taakherontwerp de nadruk legt op objectieve werkkenmerken, resteert de vraag hoe werkkenmerken ingeschat dienen te worden: objectief (in de betekenis van onafhankelijk van een menselijk oordeel) of subjectief?

Aan het eind van dit hoofdstuk wordt geconcludeerd dat genuanceerder over autonomie in het werk gedacht moet worden. Werk-gerelateerde autonomie kan namelijk beschouwd worden als een relatief kenmerk van het werk, dat gerelateerd is aan verschillende elementen van de taak van de werknemer. Verder lijkt autonomie primair een unidimensioneel construct, hoewel ter exploratie ook twee dimensies mogelijk zijn. Het gehele 
spectrum van werk-gerelateerde autonomie omvat: namelijk externe (contextuele) mogelykheden en interne (inhoudeijke) mogelikheden. Externe mogeliikheden hebben bijvoorbeeld te maken met de werkplek verlaten indien men dat wil en met het zelfstandig bepalen van werktijden. Interne mogelikheden betreffen het bepalen van bijvoorbeeld de volgorde en methode van het werk. De breedte van dit spectrum blijkt athankelijk te zijn van het gekozen subsysteem in de arganisatie bivoorbeeld de afdeling of de individuele werknemer). Tot slot wordt de conclusie getrokken dat de inschatting van werkkenmerken opnieuw beschouwd dient te worden in de context van de takkheroritwerpladitie. Er zal gezocht moeten worden naar alternatieve inschattingen on de werkenmerken te reflecteren.

Hoofdstuk 3 weerspiegelt een theoretisch classificatie-systeem waarbinnen werksenmerken en hun effecten op welbevinden en gezondheid onderzocht kunnen worden, Bamelijk de Taakkenmerken-benadering. Aangezien het moeilik is om autonomie en zịn mogelipke effecten te bestuderen zonder een theoretisch raamwerk, worden die theoretische modellen gebruikt die gerangschikt kunnen worden onder de Taakkenmerken-benadering: (1) het "Job Characteristics Model' van Hackman en Oldham; (2) het 'Demand-ControlSupport Model van Karasek en zijn collega's; en (3) het 'Vitamin Model' van Warr. Analoog aan deze modellen worden drie typen relaties tussen werk-gerelateerde autonomie en diverse reactie-variabelen (werkmotivatie, arbeidstevredenheid, emotionele uitputting en angst) verondersteld. Het eerste type is dat autonomie een rechtlijnige relatie met deze variabelen heeft. De tweede veronderstelt een rechtlijnige interactieve relatie van autonomic (in combinatie met andere werkkenmerken) met reactie-variabelen. Het laatste type postuleert een kromlijnig verband tussen autonomie en welbevinden en gezondheid. Uit een empirisch overzicht blijkt dat de empirische ondersteuning voor deze modellen nog niet optimaal is. Theoretische, conceptuele en methodologische problemen liggen hier mogelijkerwijs aan ten grondslag. In dit onderzoek wordt derhalve getracht aan enkele van deze problemen het hoofd te bieden.

Aan het eind van hoofdstuk 3 wordt de algemene probleemstelling uitgewerkt in drie centrale onderzoeksvraagstellingen, te weten:

1) "Hoe kan autonomie in het werk duidelijk en precies geoperationaliseerd worden, en wat zijn de psychometrische eigenschappen van het meetinstrument?"

2) "Kunnen welbevinden en gezondheid beter voorspeld worden door individuele inschattingen van autonomie, of door een alternatieve (groeps) inschatting?"

3) "Wat is de specifieke vorm en richting van de relatie tussen werk-gerelatevide autonomie (al dan niet in combinatie met andere werkkenmerken) en welbevinden en gezondheid?"

$\mathrm{Na}$ de introductie van een conceptueel raamwerk worden een viertal hypothesen en een vijftal specifieke onderzoeksvragen geponeerd. 
In hoofdstuk 4 wordt de methode van onderzoek beschreven. Het onderzoeksontwerp kent een tweeledige karakterisering. Enerzijds zijn bij een groot aantal werknemers op éen tijdstip gegevens verzameld, waardoor het onderzoek als cross-sectioneel survey-onderzoek bestempeld kan worden. Anderzijds zijn bij een deel van diezelfde werknemers op twee tijdstippen onderzoeksgegevens verzameld, waardoor gesproken kan worden van longitudinaal survey-onderzoek, ook wel panelonderzoek genoemd. De onderzoekspopulatie bestaat uit verplegenden en verzorgenden uit twee sectoren van de Nederlandse gezondheidszorg, namelijk (1) algemene ziekenhuizen en (2) gecombineerde verpleeghuizen. Zestien willekeurige instellingen zijn benaderd om deel te nemen aan het onderzoek. Gevraagd werd vier afdelingen uit elke instelling aan het onderzoek te laten deelnemen. Voor het algemeen ziekenhuis betrof dit een intensieve, psychiatrische, interne en chirurgische afdeling, terwijl het in de verpleeghuizen ging om twee somatische en twee psychogeriatrische afdelingen. In totaal zijn 64 afdelingen met een personeelsbezetting van 1806 personen gevraagd om hun medewerking.

De onderzoeksgegevens zijn verzameld met behulp van een schriftelijke vragenlijst. Van de totale groep hebben uiteindelijk 1489 personen de vragenlijst teruggestuurd, wat een respons van 82 procent betekent. De vragenlijsten voor de tweede meting werden ongeveer een jaar later uitgedeeld aan 454 verplegenden en verzorgenden van vier van de zestien instellingen. Eén algemeen ziekenhuis en drie gecombineerde verpleeghuizen waren namelijk bereid mee te werken aan deze tweede meting. Van de totale groep van 454 verplegenden en verzorgenden hebben 363 personen de vragenlijst geretourneerd, hetgeen een respons van 80 procent oplevert.

Hoofdstuk 5 handelt over de resultaten met betrekking tot de eerste centrale onderzoeksvraag. Na een bespreking van het meetinstrumentarium worden de psychometrische eigenschappen van de instrumenten besproken. Dit is onderzocht aan de hand van confirmatieve factoranalyses en betrouwbaarheidsanalyses. Daarnaast is gebruik gemaakt van kruisvalidering om te bezien in hoeverre de verkregen resultaten met succes gebruikt kunnen worden bij het voorspellen van scores in andere, vergelijkbare groepen. Hiervoor is de cross-sectionele onderzoeksgroep verdeeld in twee - willekeurige subgroepen. Uit de resultaten van de analyses blijkt dat het instrument om autonomie in het werk te meten, de zogeheten Maastrichtse Autonomielijst, goede psychometrische eigenschappen kent. Ook de meetinstrumenten voor de overige werkkenmerken (zoals werkdruk) en reactie-variabelen (bijvoorbeeld emotionele uitputting) blijken redelijke tot goede eigenschappen te bezitten. De gepostuleerde factormodellen blijken robuust en stabiel te zijn, zowel in de kruisvalidering als in de tijdspanne.

In hoofdstuk 6 wordt getracht een antwoord te vinden op de tweede centrale onderzoeksvraag en het eerste deel van de derde onderzoeksvraag. Met betrekking tot de inschatting van werkkenmerken zijn multi-niveau analyses uitgevoerd bij een deel van het databestand van de eerste meting, namelijk 895 gediplomeerde verplegenden. Gelet op de hiërarchische data-structuur is een drie-niveau model toegepast: zestien instellingen op 
macro-niveau, 64 afdelingen op meso-niveau en 895 zorgverleners op micro-niveau. Uit de resultaten blijkt dat de gezondheidsvariabelen "emotionele uitputting " en "angst" gerelateerd zijn aan zowel de individueel ingeschatte werkdruk als de groepsvariabele werkdruk. Oftewel, een hoge werkdruk hangt samen met relatief veel gezondheidsklachten. Echter, de groepsvariabele blijkt niet in staat verklaarde variantie toe te voegen aan de 'individuele' werkdruk. Vervolgens komt naar voren dat werkmotivatie en arbeidstevredenheid samenhangen met de interactie-term van werkdruk en autonomie; werkmotivatie met de 'individuele' interactie-term en arbeidstevredenheid met de groepsterm. Anders gezegd, bij veel autonomie gaat een hoge werkdruk gepaard met een hoge werkmotivatie en arbeidstevredenheid, terwijl bij weinig autonomie cen hoge werkdruk gepaard gaat met een lage werkmotivatie en arbeidsteviedenheid. Tevens bliken de groepsvariabelen verklaarde variantie toe te kunnen voegen aan de 'individuele' variabelen. wat kan duiden op het feit dat een deel van de variantie in welbevinden gereflecteerd wordt door taakeigenschappen buiten de directe waarneming van de individuele werknemer. Met betrekking tot de specifieke vorm van de relaties tussen enerzijds werkkenmerken en anderzijds welbevinden en gezondheid hebben structurele modeltoetsingen plaatsgevonden. Deze toetsingen zijn in stat meerdere typen variabelen (zoals werkkenmerken en reactie-variabelen) modelmatig en bovendien gelijktijdig te onderzoeken (Uit de bevindingen blijkt dat enige ondersteuning gevonden wordt voor kromlijnige relaties. Daarentegen blijken de rechtlijnige modellen het meest stabiel te zijn. Ten aanzien van autonomie blijkt: (1) een kromlijnige relatie met emotionele uitputting (omgekeerdc U-vorm); en (2) een rechtlijnige relatie met werkmotivatie en arbeidstevredenheid. Met andere woorden: (1) zowel weinig als veel autonomie gaat gepaard met weinig emotionele uitputting; en (2) veel autonomie gaat gepaard met relatief veel werkmotivatie en relatief veel arbeidstevredenheid.

Het laatste gedeelte van de derde centrale onderzoeksvraag wordt behandeld in hoofdstuk 7 , te weten de richting van het verband tussen werkkenmerken enerzijds en welbevinden en gezondheid anderzijds. Overeenkomstig de theoretische modellen wordt verondersteld dat werkkenmerken het welbevinden en de gezondheid van de werknemer beïnvloeden (in plaats van andersom). Uit enkele longitudinale structurele modeltoetsingen blikt dat deze veronderstelling inderdaad bevestigd wordt. Bijvoorbeeld, de werkdruk op tijdstip 1 leidt tot meer emotionele vitputting op tijdstip 2. Echter, ook de invloed van het welbevinden en de gezondheid op percepties van werkkenmerken wordt bevestigd. Zo blijkt bijvoorbeeld dat de werkmotivatie op tijdstip 1 invloed heeft op de perceptie van autonomie op tijdstip 2. Hoe meer werkmotivatie, hoe meer autonomie in een later stadium ervaren wordt. Wèl blijkt het eerste type relatie (werkkenmerken $\rightarrow$ welbevinden en gezondheid) sterker te zijn dan het tweede type relatie (welbevinden en gezondheid $\rightarrow$ werkkenmerken).

In het laatste hoofdstuk van dit proefschrift, hoofdstuk 8 , worden de resultaten van deze studie in onderlinge samenhang besproken. Begonnen wordt met een overzicht van alle onderzoeksbevindingen, met speciale aandacht voor autonomie in het werk. Vervolgens 
worden enkele methodologische kanttekeningen geplaatst bij successievelijk de onderzoeksmethode, de meetinstrumenten en de statistische analysetechnieken. De theoretische gevolgtrekkingen van de studie gaan over (1) de conceptualisering, operationalisering en inschatting van werk-gerelateerde autonomie, en (2) het empirische bewijs voor de theoretische modellen. Ten eerste blijkt het mogelijk autonomie in het werk grondiger en verfijnder te bestuderen dan tot op heden gebeurd is, Ook komt naar voren dat percepties van werkkenmerken niet alleen subjectieve gevoelens reflecteren, maar ook gegrond zijn in een omgevingsgebonden werkelijkheid. Daamaast blijkt de Maastrichtse Autonomielijst een goede operationalisering van het autonomie-begrip te zijn.

Ten tweede komt naar voren dat, ondanks de iets stabielere rechtlijnige modeilen, Warr's kromlijnige Vitaminemodel wordt ondersteund door de onderzoeksgegevens. Verder blijkt dat, ondanks twee interacties in multi-niveau analyse, geen bevestiging gevonden wordt voor de interactieve veronderstellingen van het Demand-Control-Support Model van Karasek en zijn collega's. Warr's model heeft aldus aangetoond dat kromlijnige verbanden belangrijk zijn voor studie naar werkkenmerken, welbevinden en gezondheid. Tenslotte bevestigen de longitudinale resultaten de veronderstellingen van de theoretische modellen aangaande het dominante oorzaak-gevolg patroon tussen werkkenmerken en welbevinden en gezondheid. Aan het eind van de paragraaf wordt een heuristisch model gepresenteerd dat richting kan geven aan verder onderzoek op het gebied van werkkenmerken, welbevinden en gezondheid.

$\mathrm{Na}$ de bespreking van de theoretische betekenis van deze studie worden enkele aanbevelingen gedaan om de autonomie en sociale ondersteuning in het werk te vergroten en de werkdruk te verminderen dan wel te reguleren. Eén van de aanbevolen taakherontwerpmethoden omvat de reconstructie van gefragmenteerd en geïsoleerd werk in kleinschalige, gedecentraliseerde semi-autonome taakgroepen. Het hoofdstuk wordt tenslotte afgesloten met enkele suggesties voor verder onderzoek op het gebied van werkkenmerken (in het bijzonder autonomie), welbevinden en gezondheid. 
References 
Abramson, L.Y., Seligman, M.E.P. \& Teasdale, J.D. (1978). Learned helplessness in humans: Critique and reformulation. Journal of Abnormal Psychology. 87, 49-74

Aiken, L.S. \& West, S.G. (1991). Multiple Regression: Testing and interpreting Interactions. Newbury Park, California: Sage Publications.

Aitkin, M. \& Longford, N. (1986). Statistical modeling issues in school effectiveness studies, Journal of the Royal Statistical Society, Series A, 149, 1, 1-43.

Aldag, R.J., Barr, S.H. \& Brief, A.P. (1981). Measurement of Perceived Task Characteristics. Psychological Bulletin, 90, 3, 415-431.

Alderfer, C.P. (1987). An intergroup perspective on group dynamics. In: J. Lorsch (Ed), Handbook of Organizational Behavior (pp. 190-222). New Jersey: Englewood Cliffs/Prentice-Hall.

Algera, J.A. (1983). 'Objective' and perceived task characteristics as a determinant of reactions by task performers. Journal of Occupational Psychology, 56, 95-107

Algera, J.A. (1989). Taakkenmerken [Task Characteristics]. In: P.J.D. Drenth, H. Thierry \& Ch J. de Wolff (Eds.), Nieuw Handboek Arbeids- en Organisatiepsychologie (2.2, pp. 1-30). Deventer: Van Loghum Slaterus.

Algera, J.A. (1991). Arbeidsanalyse ten behoeve van motivatie en satisfactie [Analysis of work with regard to motivation and satisfaction]. In: J.A. Algera (Ed.), Analyse van arbeid vanuit verschillende. perspectieven (pp. 143-177). Amsterdam: Swets \& Zeitlinger.

Algera, J.A., Van der Flier, H. \& Van der Kamp, L.J.Th. (1986). Causal modeling of quality of work In: G. Debus \& H.-W. Schroiff (Ed5.), The psychology of work and organization (pp. 175-182) Amsterdam: Elsevier Science Publishers.

Anderson, J.C. \& Gerbing, D.W. (1984). The effect of sampling error on convergence, improper solutions and goodness-of-fit indices for maximum likelihood confirmatory factor analysis. Psychometrika, 49, 155-173.

Aronsson, G. (1989a). Dimensions of control as related to work organization, stress and health. International Journal of Health Services, 19, 3, 459-468

Aronsson, G. (1989b). Swedish Research on Job Control, Stress and Health. In: S.L. Sauter, J.J. Hurrell Jr. \& C.L. Cooper (Eds.), Job Control and Worker Health (pp. 75-88). Chichester: Wiley \& Sons.

Aronsson, G. (1991). Dimensions of Control as Related to Work Organization, Stress, and Health. In: J.V. Johnson \& G. Johansson (Eds.), The Psychosocia/ Work Environment: Work Organization, Democratization and Health (pp. 111-120). Amityville, NY: Baywood Publishing Company.

Bacharach, S.8. \& Aiken, M. (1976). Structural and process constraints on influence in organizations: A level-specific analysis. Administrative Science Quarterly, 21, 623-642.

Babcock Gove, P. (Ed.) (1971). Webster's Third New International Dictionary of the English Language Unabridged. Springfield: G. \& C. Merriam Company.

Bagozzi, R.P. \& Yi, Y. (1990). Assessing method variance in multitrait-multimethod matrices: The case of self-reported affect and perceptions at work. Journal of Applied Psychology, 75, 547-560.

Bailyn, L. (1985). Autonomy in the industrial R\&D lab. Human Resource Management, 24, 129-146

Baker, D. (1985). The study of stress at work. Annual Review of Public Health, 6, 367-381.

Baker, F. \& Green, G.M. (1991). Work, Health, and Productivity: Overview. In. G.M. Green \& F. Baker (Eds.), Work, Hea/th, and Productivity (pp. 3-18). Oxford: Oxford University Press.

Bannister, D. \& Fransella, F. (1980). Inquiring Man. London: Penguin.

Baron, R.M. \& Boudreau, L.A. (1987). An ecological perspective on integrating personality and social psychology. Journal of Personality and Social Psychology, 53, 1222-1228.

Bartels, L.P. (1992). Instellingen van intramurale gezondheidszorg: basisgegevens per 1-1-92 naar provincie en naar gezondheidsregio [Health care institutions: basic information from 1/1/92 according to province and health region]. Utrecht: Nationaal Ziekenhuis Instituut.

Bartol, K.M. \& Martin, D.C. (1991), Management. New York: McGraw-Hill.

Bazerman, M.H. (1982). Impact of Personal Control on Performance: Is Added Control Always Beneficial? Journal of Applied Psychology, 67, 4, 472-479.

Beehr, T.A. (1976). Perceived situational moderators of the relationship between subjective role ambiguity and role strain. Journal of Applied Psychology, 61, 35-40.

Beehr, T.A. \& Drexler. J.A. Jr. (1986). Social support, autonomy, and hierarchical level as moderators of the role characteristics-outcome relationship. Journal of Occupational Behaviour, 7, 207-214.

Benson, J. \& Bandalos, D.L. (1992). Second-Order Confirmatory Factor Analysis of the Reactions to Tests Scale with Cross-Validation. Multivariate Behavioral Research, 27, 3, 459-487. 
Bentler, P.M. (1990). Comparative fit indices in structural models. Psychological Bulletin, 107, 238-246.

Bentler, P.M. \& Bonett, D.G. (1980). Significance Tests and Goodness of Fit in the Analysis of Covariance Structures. Psychological Bulletin, 88, 3, 588-606.

Bentler, P.M. \& Chou, C.P. (1987). Practical Issues in Structural Modelling. Sociological Methods \& Research, 16, 1, 78-117.

Bergers, G.P.A., Marcelissen, F.H.G. \& Wolff, Ch.J. de (1986). VOS-D. Vragenlijst Organisatiestress-D: handleiding [VOS-D. Work stress questionnaire Doetinchem]. Nijmegen: University of Nijmegen.

Bernstein, I.H., Garbin, C.P. \& Teng, G.K (1988). Applied Multivariate Analysis. New York: SpringerVerlag.

Bernstein, I.H. \& Teng, G. (1989). Factoring Items and Factoring Scales Are Different: Spurious Evidence for Multidimensionality Due to Item Categorization. Psychological Bulletin, 105, 3, 467-477.

Bishop, Y.M.M., Fienberg, S.E. \& Holland, P.W. (1975). Discrete multivariate analysis: theory and practice. Cambridge: MIT Press.

Blanc, P.M. Le (1994). De steun van de leiding: een onderzoek naar het Leader Member Exchange model in de verpleging [Leader's support: a study of the Leader Member Exchange model among nurses]. Amsterdam: Thesis Publishers.

Blok, A.J., Vries-Griever, A.H.G. de, Bloemendaal, A. \& Jong, M. de (1995). The balance between workload and recovery during working hours. In: ISMA-5 Book of Abstracts, Stress at the Workplace: health and productivity (p. 95). Soest: ISMA-Netherlands.

Bollen, K.A. (1989). Structural equations with latent variables. New York: Wiley

Bollen, K.A \& Scott Long, J. (1993). Introduction. In: K.A. Bollen \& J. Scott Long (Eds.), Testing structural equation models (pp. 1-9). Newbury Park. California: Sage Publications.

Boomsma, A. (1987). The robustness of maximum likelihood estimation in structural equation models. In: P. Cuttance \& R. Ecob (Eds.), Structural modeling by example: applications in educational, sociological, and behavioral research (pp. 160-188). Cambridge: Cambridge University Press.

Boone, H. \& Jonge, J. de (in press). De relatie tussen verpleegsystemen en werkkenmerken: een exploratieve studie [The relationship between nursing systems and job character:stics: an exploratory study]. Verpleegkunde: Nederlands-Vlaams wetenschappelijk tijdschrift voor verpleegkundigen.

Bosker, R.J. \& Snijders, T.A.B. (1990). Statistische aspecten van multi-niveau onderzoek [Statistical aspects of multi-level research]. Tijdschrift voor Onderwijsresearch, 15, 5, 317-329.

Bosker, R.J. \& Snijders, T.A.B. (1991). Center forward. Unpublished manuscript.

Boumans, N.P.G. (1990). Het werk van verpleegkundigen in algemene ziekenhuizen: een onderzoek naar werkaspecten en hun invloed op verpleegkundigen [Nurses' work in general hospitals: a study of work aspects and their influence on nurses]. Maastricht: Datawyse

Boumans, N.P.G. \& Landeweerd, J.A. (1993). Some problems concerning the measurement of job characteristics in nursing work. The European Work and Organizational Psychologist, 2, 4, 303-317.

Brady, G.F., Judd, B.B. \& Javian, S. (1990). The Dimensionality of Work Autonomy Revisited. Human Relations, 43, 12, 1219-1228.

Breaugh, J.A. (1985). The measurement of work autonomy. Human Relations, 38, 551-570.

Breaugh, J.A. (1989). The Work Autonomy Scales: Additional Validity Evidence. Human Relations, 42, $11,1033-1056$

Breaugh, J.A. \& Becker, A.5. (1987). Further examination of the work autonomy scales: Three studies. Human Relations, 40, 381-400.

Brief, A.P. \& Aldag, R.J. (1978). The Job Characteristics Inventory: An examination. Academy of Management Journal, 21, 659-670.

Brief, A.P. \& George, J.M. (1995). Psychological Stress and the Workplace: A Brief Comment on Lazarus' Outlook. In: R. Crandall \& P.L. Perrewé (Eds.), Occupational Stress: A Handbook (pp. 15. 19). Washington: Taylor \& Francis.

Broadbent, D.E. (1985). The clinical impact of job design. British Journal of Clinical Psychology, 24, 33-44.

Biowne, M.W. \& Cudeck, R. (1989). Single sample cross-validation indices for covariance structures Multivariate Behavioral Research, 24, 445-455.

Browne, M.W. \& Cudeck, R. (1993). Alternative Ways of Assessing Model Fit. In: K.A. Bollen \& J. Scott Long (Eds.), Testing structural equation models (pp. 136-162). Newbury Park, California: Sage Publications. 
Bryk, A.S. \& Raudenbush, S.W. (1992). Hierarchical linear models: applications and data analysis methods. Newbury Park, California: Sage Publications

Bullock, R.P. (1952). Social factors related to job satisfaction: A technique for the measurement of job satisfaction. Columbus, Ohio: Ohio State University.

Burke, M.J., Brief, A.P. \& George, J.M. (1993). The Role of Negative Affectivity in Understanding Relations Between Self-Reports of Stressors and Strains: A Comment on the Applied Psychology Literature. Journal of Applied Psychology, 78, 3, 402-412.

Byrne, B.M. (1989). A Primer of LISREL: Basic Applications and Programming for Confirmatory Factor Analytic Models. Berlin: Springer-Verlag.

Byrne, B.M. (1991). The Maslach Burnout Inventory: Validating Factorial Structure and Invariance Across Intermediate, Secondary, and University Educators. Multivariate Behavioral Research, 26, 4, 583-605.

Byrne, B.M., Shavelson, R.J. \& Muthén, B. (1989). Testing for the equivalence of factor covariance and mean structures: The issue of partial measurement invariance. Psychological Bulletin, 105, 456-466.

Cammann, C., Fichman, M., Jenkins, D. \& Klesh, J. (1979). The Michigan Organizational Assessment Questionnaire. Ann Arbor, Michigan: University of Michigan.

Campbell, D.T. (1963). From Description to Experimentation: Interpreting Trends as Quasi-experiments. In: C.W. Harris (Ed.), Problems in the Measurement of Change (pp. 212-254). Madison: University of Wisconsin Press.

Camstra, A. \& Boomsma, A. (1992). Cross-Validation in Regression and Covariance Structure Analysis. Sociological Methods \& Research, 21, 1, 89-115

Caplan, R.D., Cobb, S., French, J.R.P. Jr., Harrison, R.V. \& Pinneau, S.R. Jr. (1975). Job Demands and Worker Health: Main Effects and Occupational Differences. Washington D.C.: U.S. Government Printing Office.

Carayon, P. (1993). Job design and job stress in office workers. Ergonomics, 36, 5, 463-477.

Champoux, J.E. (1992). A Multivariate Analysis of Curvilinear Relationships Among Job Scope, Work Context Satisfactions, and Affective Outcomes. Human Relations, 45, 1.87-111.

Child, J. (1984). Organization: a guide to problems and practice (2nd Edition). London: Harper and Row.

Chung, K.H. (1977). Motivational theories and practices. Columbus, Ohio: Grid Publishing.

Cohen, J. (1988). Statistical Power Analysis for the Behavioral Sciences (2nd Edition). Hillsdale. New Jersey: Lawrence Erlbaum Associates.

Cohen, I. \& Cohen, P. (1983). Applied Multiple Regression/Correlation Analysis for the Behavioral Sciences (2nd edition). Hillsdale: Lawrence Erlbaum Associates.

Cohen, S. \& Wills, T.A. (1985). Stress, Social Support, and the Buffering Hypothesis. Psychological Bulletin, 98, 2, 310-357

Cook, T.D. \& Campbell, D.T. (1979). Quasi-experimentation: Design and Analysis: Issues for Field Settings. Chicago: Rand McNally.

Cook, J.D., Hepworth, S.J., Wall, T.D. \& Warr, P.B. (1981). The experience of work. A Compendium and Review of 249 Measures and their Use. New York: Academic Press.

Cordes, C.L. \& Dougherty, T.W. (1993). A review and an integration of research on job burnout. Academy of Management Review, 18, 4, 621-656.

Cortina, J.M. (1993). What is Coefficient Alpha? An Examination of Theory and Applications. Journal of Applied Psychology, 78, 1, 98-104.

Cronbach, L.J. (1951). Coefficient alpha and the internal structure of tests. Psychometrika, 16, 297-73.34

Cronbach, L.J., Gleser, G.C., Nanda, H. \& Rajaratnam, N. (1972). The dependability of behavioral measurements: Theory for generalizeability of scores and profiles. New York: Wiley

Cudeck, R. \& Browne, M.W. (1983). Cross-validation of covariance structures. Multivariate Behavioral Research, 18, 147-167.

Cuttance, P. (1987). Issues and problems in the application of structural equation models. In: P. Cuttance \& R. Ecob (Eds.), Structural modeling by example: applications in educational, sociological, and behavioral research (pp. 241-279). Cambridge: Cambridge University Press.

DeCotiis, T.A \& Koys, D.J. (1980). The Identification and Measurement of the Dimensions of Organizational Climate. Academy of Management Proceedings, 171-175.

Devlin, T.M. (1992). Textbook of biochemistry: with clinical correlations. Chichester: Wiley \& Sons.

Diamantopoulos, A. (1994). Modelling with LISREL, A Guide for the Uninitiated. Journal of Marketing Management, 10, 105-136. 
Dijck, J.J.J. van (1987). Autonomie en arbeid: een fundamentele polariteit [Autonomy and work: a fundamental polarity]. In: M.J.W.M. Akkermans (Ed.), Autonomie als arbeidssociologisch vraagstuk (pp. 19-27). Zeist: Kerckebosch.

Dooley, D. (1984). Social Research Methods. New Jersey: Prentice Hall/Englewood Cliffs

Dunham, R.B. (1976). The Measurement and Dimensionality of Job Characteristics. Journal of Applied Psychology, 61, 404-409.

Dunham, R.B., Aldag, R.J. \& Brief, A.P. (1977). Dimensionality of task design as measured by the lob Diagnostic Survey. Academy of Management Journal, 20, 209-223.

Dworkin, G. (1988). The Theory and Practice of Autonomy. Cambridge: Cambridge University Press.

Dwyer, D.J. \& Ganster, D.C. (1991). The effects of job demands and control on employee attendance and satisfaction. Journal of Organizational Behavior, 12, 595-608

Ecob, R. \& Cuttance, P. (1987). An overview of structural equation modeling. In: P. Cuttance \& R. Ecob (Eds.), Structural modeling by example: applications in educational, sociological, and behavioral research (pp. 9-23). Cambridge: Cambridge University Press.

Evans, M.G. (1985). A Monte Carlo study of the effects of correlated method variance in moderated multiple regression analysis. Organizational Behavior and Human Decision Processes, 36, 305-323.

Evans, B.K. \& Fischer, D.G. (1992). A Hierarchical Model of Participatory Decision-Making, Job Autonomy, and Perceived Control. Human Relations, 45, 11, 1169-1189.

Farh, J.L. \& Scott, W.E. Jr. (1983). The Experimental Effects of "Autonomy" on Performance and Self-Reports of Satisfaction. Organizational Behavior and Human Performance, 31, 203-222.

Farina, A.J. Jr. \& Wheaton, G.R. (1973). Development of a taxonomy of human performance: The task characteristic approach to performance prediction. JSAS Catalog of Selected Documents in Psychology, 3, 26-27.

Feather, N.T. (1990). The Psychological Impact of Unemployment. New York: Springer-Verlag.

Fleishman, E.A. (1975). Development of ability requirements scales for the analysis of Bell System jobs Bethesda: Management Research Institute

Fleishman, E.A. \& Quaintance, M.K. (1984). Taxonomies of Human Performance: The Description of Human Tasks. Orlando: Academic Press.

Fletcher, B.C. \& Jones, F. (1991). The role of occupational factors in casual blood pressure: some unexpected findings. In: M. Johnston, M. Herbert \& T. Marteau (Eds.), Proceedings of the 4th Annual Conference of the European Health Psychology Society (pp. 40-41). Leicester: The British Psychological Society

Fletcher, B.(C.) \& Jones, F. (1993). A refutation of Karasek's demand-discretion model of occupational stress with a range of dependent measures. Journal of Organizational Behavior, 14, 319-330.

Fox, J. (1984). Linear Statistical Models and Related Methods. New York: Wiley \& Sons.

Fox, M.L., Dwyer, D.J. \& Ganster, D.C. (1993). Effects of stressful job demands and control on psychological and attitudinal outcomes in a hospital setting. Academy of Management Journal, 36, 2 , 289-318

Fiese, M. (1985). Stress at Work and Psychosomatic Complaints: A Causal Interpretation. Journal of Applied Psychology, 70, 2, 314-328.

Frese, M. (1989). Theoretical Models of Control and Health. In: S.L. Sauter, J.J. Hurrell Jr. \& C.L. Cooper (Eds.). Job Control and Worker Health (pp. 107-128). Chichester: Wiley \& Sons.

Frese, M. \& Zapf, D. (1988). Methodological issues in the study of work stress: Objective vs subjective measurement of work stress and the question of longitudinal studies. In: C.L. Cooper \& R. Payne (Eds.). Causes, Coping and Consequences of Stress at Work (pp. 375-411). Chichester: Wiley \& Sons.

Freudenberger, H.J. (1974). Staff burnout. Journal of Social issues, 30, 159-165.

Fried, Y. (1991). Meta-Analytic Comparison of the Job Diagnostic Survey and Job Characteristics Inventory as Correlates of Work Satisfaction and Performance. Joumal of Applied Psychology, 76, 5, 690-697

Fried, Y. \& Ferris, G.R. (1986). The Dimensionality of Job Characteristics: Some Neglected Issues. Journal of Applied Psychology, 71, 3, 419-426.

Fried, Y. \& Ferris, G.R. (1987). The validity of the Job Characteristics Model: A review and meta-analysis. Personnel Psychology: 40, 287-322.

Furda, J. (1995). Werk, persoon en welzijn: een toetsing van het Job Demand-Control Model [Work, person and well-being: a test of the Job Demand-Control Model]. Enschede: CopyPrint 2000. 
Furda, J., Jonge, J. de, Blanc, P. Le, Meijman, T., Schreurs, P. \& Scheenen, J. (1994). Het Demandcontrol-support model in relatie tot gezondheidsklachten en herstelklachten: een longitudinale studie [The Demand-Control-Support Model in relation to health complaints and recovery complaints: a longitudinal study]. Gedrag en Organisatie, 7, 4, 225-238.

Furnham, A. (1992). Personality at Work: The role of individual differences in the workplace. London: Routledge.

Ganster, D.C. (1988). Improving Measures of Worker Control in Occupational Stress Research. In: J.J. Hurrell Jr., L.R. Murphy, S.L. Sauter \& C.L. Cooper (Eds.), Occupational Stress: Issues and Developments in Research (pp. 88-99). New York: Taylor \& Francis.

Ganster, D.C. (1989). Worker Control and Well-being: A Review of Research in the Workplace. In: S.L. Sauter, J.J. Hurrell Jr. \& C.L. Cooper (Eds.), Job Control and Worker Health (pp. 3-23). Chichester: Wiley \& Sons.

Ganster, D.C. \& Fusilier, M.R. (1989). Control in the workplace. In: C.L. Cooper \& I.T. Robertson (Eds.). International Review of Industrial and Organizational Psychology (pp. 235-280). Chichester: Wiley \& Sons.

Ganster, D.C. \& Schaubroeck, J. (1991). Work Stress and Employee Health. Journal of Management, $17,2,235-271$.

Gardell, B. (1977). Autonomy and Participation at Work. Human Relations, 30, 6, 515-533.

Gardell, B. (1982). Worker participation and autonomy: a multilevel approach to democracy at the workplace. International Journal of Health Senices, 12, 4, 527-558

Geer, J.P. van de (1986). Introduction to linear multivariate data analysis. Leiden: DSWO Press

George, J.M. (1990). Personality, Affect, and Behavior in Groups. Journal of Applied Psychology, 75, 2. 107-116

Gerbing, D.W. \& Anderson, J.C. (1984). On the meaning of within-factor correlated measurement errors. Journal of Consumer Research, 11, 572-580.

Gergen, K.J. \& Gergen, M.M. (1982). Explaining Human Conduct: Form and Function. In: P.F. Secord (Ed.), Explaining human behavior: Consciousness, Human Action, and Social Structure (pp. 127. 154). Beverly Hills: Sage Publications

Gibson, J.J. (1979). The Ecological Approach to Visual Perception. Boston: Houghton Mifflin.

Grandison, A., McGinley, D., Shearer, T., Knight, L., Summers, E., Lyons, C. \& Forde, C. (Eds.) (1991). Collins English Dictionary (Third edition). Glasgow: HarperCollins Publishers.

Griffin, R.W. (1987). Towards an integrated theory of task design. In: L.L. Cummings \& B.M. Staw (Eds.), Research in Organizational Behavior (pp. 79-120). London: JAl Press.

Griffin, R.W., Bateman, T.S., Wayne, S.J. \& Head, T.C. (1987). Objective and social factors as determinants of task perceptions and responses: An integrated perspective and empirical investigation. Academy of Management Journal, 30, 501-523.

Hackman, J.R. (1968). Tasks and task performance in research on stress. In: J.E. McGrath (Ed.), Social and psychological factors on stress (pp. 11-18). New York: Holt, Rinehart \& Winston.

Hackman, J.R. (1969). Toward understanding the role of tasks in behavioral research. Acta Psychologica, 31, 97-128.

Hackman, J.R. \& Lawier Iil, E.E. (1971). Employee Reactions to Job Characteristics. Journal of Applied Psychology Monograph, 55, 3, 259-286.

Hackman, J.R. \& Oldham, G.R. (1975). Development of the Job Diagnostic Survey. Journal of Applied Psychology, 60, 2, 159-170.

Hackman, J.R. \& Oldham, G.R. (1976). Motivation through the design of work: Test of a theory. Organizational Behavior and Human Performance, 16, 250-279.

Hackman, J.R. \& Oldham, G.R. (1980). Work Redesign. Reading. Massachusetts: Addison-Wesley Publishing Company

Hagenaars, J.A. (1990). Categorical Longitudinal Data: Log-Linear Panel, Trend, and Cohort Analysis. Newbury Park, California: Sage Publications

Harvey, R.J., Billings, R.S. \& Nilan, K.J. (1985). Confirmatory Factor Analysis of the Job Diagnostic Survey: Good News and Bad News. Journal of Applied Psychology, 70, 3, 461-468.

Hayduk, L.A. (1987). Structural Equation Modelling with LISREL: Essentials and Advances. Baltimore: The John Hopkins University Press.

Herzberg, F., Mausner, B. \& Snyderman, B. (1959). The Motivation to Work. New York: Wiley. Hingley, P. \& Cooper, C.L. (1986). Stress and the nurse manager. Chichester: Wiley \& Sons. 
Hodson, R., Creighton, S., Sorenson Jamison, C., Rieble, S. \& Welsh, S. (1994). Loyalty to Whom? Workplace Participation and the Development of Consent. Human Relations, 47, 8, 895-909.

Hogan, E.A. \& Martell, D.A. (1987). A confirmatory structural equations analysis of the Job Characteristics Model. Organizational Behavior and Human Decision Processes, 39, 242-263.

Hoof, J.A.P. van (1963). Autonomie en motivatie van arbeiders in industriële bedrijven [Autonomy and motivation of industrial workers]. Nijmegen: Dekker \& Van de Vegt.

Houtman, I.L.D. \& Kompier, M.A.J. (1995). Risk factors and occupational risk groups for work stress in the Netherlands. Washington: NIOSH/APA.

Hox, J.J. (1994). Applied Multılevel Analysis. Amsterdam: TT-Publikaties

Hox, J.J. \& Kreft, I.G.G. (1994). Multilevel Analysis Methods. Sociological Methods \& Research, 22, 3, 283-299.

Hsiao, C. (1986). Analysis of panel data. Cambridge: Cambridge University Press.

Hulin, C.L. \& Blood, M.R. (1968), Job enlargement, individual differences, and worker responses. Psychological Bulletin, 69, 41-55.

Idaszak, J.R. \& Drasgow, F. (1987). A revision of the Job Diagnostic Survey: Elimination of a measurement artifact. Journal of Applied Psychology, 72, 69-74.

Israel, B.A., Schurman, S.J. \& House, J.S. (1989). Action research on occupational stress: involving workers as researchers. International Journal of Health Services, 19, 1, 135-155

Jaccard, J., Turrisi, R. \& Wan, C.K. (1990). Interaction effects in multiple regression. Newbury Park, California: Sage Publications.

Jackson, S.E. (1989). Does Job Control Control Job Stress? In: S.L. Sauter, J.J. Hurrell Jr. \& C.L. Cooper (Eds.), Job Control and Worker Health (pp. 25-53). Chichester: Wiley \& Sons.

James, L.R. (1980). The unmeasured variable problem in path analysis. Journal of Applied Psychology, $65,415-421$

James, L.R. \& James, L.A. (1989). Causal modelling in organizational research. In: C.L. Cooper \& I.T. Robertson (Eds.). International Review of Industrial and Organizational Psychology ( $\mathrm{pp}$. 371-404). Chichester: Wiley \& Sons.

James, L.R. \& Jones, A.P. (1980). Perceived job characteristics and job satisfaction: An examination of reciprocal causation. Personnel Psychology, 33, 97-135.

James, L.R., Mulaik, S.A \& Brett, J.M. (1982). Causal analysis: Assumptions, models, and data. Beverly Hills, California: Sage Publications.

James, L.R. \& Tetrick, L.E. (1986). Confirmatory Analytic Tests of Three Causal Models Relating Job Perceptions to Job Satisfaction. Journal of Applied Psychology, 71, 1, 77-82

Johansson, G. \& Aronsson, G. (1991). Psychosocial Factors in the Workplace. In: G.M. Green \& F. Baker (Eds.), Work, Health, and Productivity (pp. 179-197). Oxford: Oxford University Press.

Johnson, J.V. (1986). The impact of workplace social support and work control upon cardiovascular disease in Sweden. Stockholm: Division of Environmental and Organizational Psychology.

Johisson, J.V. (1989). Control, Collectivity and the Psychosocial Work Environment. In: S.L. Sauter, J.J. Hurrell Ir. \& C.L. Cooper (Eds.), Job Control and Worker Health (pp. 56-74) Chichester: Wiley \& Sons.

Johnson, J.V. \& Hall, E.M. (1988). Job Strain, Work Place Social Support, and Cardiovascular Disease: A Cross-Sectional Study of a Random Sample of the Swedish Working Population. American Journal of Public Health, 78, 10, 1336-1342

Johnson, J.V. \& Hall, E.M. (1994). Social Support in the Work Environment and Cardiovascular Disease. In: S.A. Shumaker \& S.M. Czajkowski (Eds.), Social Support and Cardiovascular Disease (pp. 145167). New York: Plenum Press.

Johnson, J.V., Hall, E.M. \& Theorell, T. (1989). Combined effects of job strain and social isolation on cardiovascular disease morbidity and mortality in a random sample of the Swedish male working population. Scandinavian Journal of Work, Environment, \& Health, 15, 271-279.

Johnson, J.V., Hall, E.M., Stewart, W., Fredlund, P. \& Theorell, T. (1991). Combined exposure to adverse work organization factors and cardiovascular disease: towards a life-course perspective. In: L.D. Fechter (Ed.), Proceedings of the $\mathrm{V}$-th International Conference on the combined effects of environmental factors (pp. 117-122). Baltimore: John Hopkins University School of Hygiene and Public Health.

Johnson, J.V. \& Stewart, W.F. (1993). Measuring work organization exposure over the life course with a job-exposure matrix. Scandinavian Journal of Work, Environment, \& Health, 19, 21-28. 
Jonas, S. (1990). Health manpower: With an emphasis on physicians. in: A.R. Kovner (Ed.), Health care delivery in the United States (4th edition) (pp. 50-86). New York: Springer.

longe. 1. de (1992). Autonomie in het werk: een literatuuroverzicht (job autonorry: a review: of the Giterature]. Studies bedrijtsgezondheidszorg nummer 8. Maastricht: University of Limburg.

Jonge, f. de, Boumans, N., Landeweerd, A. \& Nijhuis, F. (1995a). Werkkenmerken en werkbeleving liob characteristics and psychological outcomes]. Tijdschrift voor Ziekenverpleging, $105,6,186-189$.

Jonge, J. de, Boumans, N. Landeweerd, A. \& Nijhuis, F. (1995b). De relatie tussen werk en werkbeleving the relationship between job characteristics and psychological outcomes!. Tijdschrift woor Ziekenverpleging, 105, 7, 212-216.

Jonge, I. de, Breukelen, G.J.P. van, Landeweerd, J.A. \& Nijhuis, F.J.N. (1995). Group and indisiduat assessment of job characteristics: a multi-level approach. Manuscript submitted for publication.

Jonge, 1. de \& Furda, J. (in press). Taakgebonden aspecten van gezondheid en welzin [Task-related aspects of health and well-being]. In: M.J. Schabracq \& J.A.M. Winnubst (tds.), Mentale belasting in het werk. Heerlen: Open University.

Jonge, 1. de \& Furda, 1. (1995). Het lob Demand-Control Model (The lob Demand-Control Model?. De Psycholoog, 30, 12, 496-501.

lange, J. de, Janssen, P.P.M. \& Breukelen, G.J.P. van (in press). Testing the Demand-Contro-Support Model among health care professionals: a structural equation model. Work and Stress.

Jonge, J. de, Janssen, P. \& Landeweerd, A. (1994). Effecten van werkdruk, autonomie en sociale ondersteuning op de werkbeleving van verplegenden en verzorgenden [Effects of workload, autonomy, and social support on psychological outcomes of nurses and nurses' aides]. Verpleegkunde: Nederlands-Viaams wetenschappelijk tijdschrift voor verpleegkundigen, 9, 1, 17-27.

Jonge, I. de \& Landeweerd, I.A. (1992a). Beroepsontwikkeling van verpleegkundigen: een verkennende studie [Nurses' professionalism: an exploratory study]. Verpleegkunde: Nederlands-Vlaams wetenschappelijk tijdschrift voor verpleegkundigen, 7, 1, 12-22

Jonge, J. de \& Landeweerd, J.A. (1992b). Werkdruk en autonomie [Workload and autonomy]. Tijdschrift voor Ziekenverpleging, 102, 13, 465-468.

Jonge, J. de \& Landeweerd, J.A. (1993). Toetsing van de Job Demand-Control benadering bij werknemers in de gezondheidszorg: een secundaire data-analyse [Testing of the Job Demand-Control approach among health care workers: a secondary analysis]. Gedrag en Organisatie, 6, 2, 79-92.

Jonge, J. de, Landeweerd, J.A. \& Breukelen, G.J.P. van (1994). De Maastrichtse Autonomielijst: achtergrond, constructie en validering [The Maastricht Autonomy Questionnaire: background, construction and validation]. Gedrag en Organisatie, 7, 1, 27-41

Jonge, J. de, Landeweerd, J.A. \& Nijhuis, F.J.N. (1993). Constructie en validering van de vragenlijst ten behoeve van het project 'autonomie in het werk' 'Construction and validation of the questionnaire for the 'job autonomy project']. Studies bedrijfsgezondheidszorg nummer 9 . Maastricht: University of Limburg.

Jonge, J. de, Landeweerd, J.A. \& Nijhuis, F.J.N. (1994). Het werk van verplegenden en verzorgenden: terugrapportage tweede meting [Work of nurses and nurses' aides: second measurement research report]. Maastricht: University of Limburg.

Jonge, J. de, Landeweerd, J.A., Nijhuis, F.J.N. \& Boumans, N.P.G. (1994). Het werk van verplegenden en verzorgenden: een onderzoek naar het werk en de werkbeleving in gecombineerde verpleeghuizen en algemene ziekenhuizen, deel 1, 2 en 3 [Work of nurses and nurses' aides: an investigation of work and psychological outcomes in combined nursing homes and general hospitals, Volume $1,2$. and 3]. Maastricht: University of Limburg

Jonge, J. de, Schaufeli, W.B. \& Furda, J. (1995). Werkkenmerken: psychologische arbeidsvitamines? [Job characteristics: psychological work vitamins?]. Gedrag en Organisatie, 8, 4, 231-248.

Jonge, J. de \& Schaufeli, W.B. (1995). Job characteristics and employee well-being: a test of Warr's Vitamin Model in health care workers using structural equation modelling. Manuscript submitted for publication.

Jöreskog, K.G. (1993). Testing Structural Equation Models. In: K.A. Bollen \& J. Scott Long (Eds.), Testing structural equation models (pp. 294-316). Newbury Park, California: Sage Publications.

Jöreskog, K.G. \& Sörbom, D. (1989). LISREL 7: A Guide to the Program and Applications (2nd Edition). Chicago: SPSS.

Jöreskog, K.G. \& Sörbom, D. (1993a). LISREL 8: User's Reference Guide. Chicago: Scientific Software International 
Joreskog, K.G. \& Sörbom, D. (1993b). LISREL 8: Structural Equation Modelling with the SIMPLIS Command Language. Chicago: Scientific Software International.

Jöreskog, K.G. \& Sörbom, D. (1993c). PRELIS 2: User's Reference Guide. Chicago: Scientific Software International.

Kahn, R. (1981). Work and health: Some psychological effects and advanced technology. In: B. Gardell \& G. Johansson (Eds.), Man and Working Life (pp. 17-37). Chichester: Wiley \& Sons.

Kahn, R.L. \& Antonucci, T.C. (1980). Convoys over the lifecourse: Attachment, roles, and social support. In: P.B. Baltes \& O. Brim (Eds.), Life-span development and behavior, Volume 3 (pp. 253-286). New York: Academic Press.

Kahn, R.L. \& Byosiere, P. (1994). Stress in organizations. In: M.D. Dunette, J.M. Hough \& H.C. Triandis (Eds.), Handbook of Industrial and Organizational Psychology Nolume 4) (pp. 573-650). Palo Alto, California: Consulting Psychologists Press.

Kanfer, R. (1992). Work motivation: New Directions in Theory and Research. In: C.L. Cooper \& I.T. Robertson (Eds.), International Review of Industrial and Organizational Psychology (pp. 1-53). New York: Wiley.

Karasek, R.A. Jr. (1979). Job Demands, Job Decision Latitude, and Mental Strain: Implications for Job Redesign. Administrative Science Quarterly, 24, 2, 285-308.

Karasek, R. (1989). Control in the Workplace and its Health-related Aspects. In: S.L. Sauter, J.J. Hurrell Jr. \& C.L. Cooper (Eds.), Job Control and Worker Health (pp. 129-159). Chichester: Wiley \& Sons.

Karasek, R. (1990). Lower health risk with increased control among white collar workers. Journal of Organizational Behaviour, 11, 171-185

Karasek, R. (1992). Stress prevention through work reorganization: A summary of 19 international case studies. In: ILO, Conditions of work digest on Preventing stress at work, 11, 2, 23-41.

Karasek, R.A. \& Theorell, T. (1990). Healthy work: stress, productivity and the reconstruction of working life. New York: Basic Books.

Karasek, R.A., Triantis, K.P. \& Chaudhry, S.S. (1982). Coworker and supervisor support as moderators of associations between task characteristics and mental strain. Journal of Occupational Behaviour, 3 , $181-200$

Kasl, S.V. (1978). Epidemiological Contributions to the Study of Work Stress. In: C.L. Cooper \& R. Payne (Eds.), Stress at Work (pp. 3-48). Chichester: Wiley \& Sons

Kasl, S.V. (1987). Methodologies in Stress and Health: Past, Difficulties, Present Dilemmas, Future Directions. In: S.V. Kasl \& C.L. Cooper (Eds.), Stress and Health: Issues in Research Methodology (pp. 307-318). Chichester: Wiley \& Sons.

Kasl, S.V. (1989). An Epidemiological Perspective on the Role of Control in Health. In: S.L. Sauter, J.J. Hurrell Ir. \& C. L. Cooper (Eds.), Job Control and Worker Health (pp. 161-189). Chichester: Wiley \& Sons.

Katz, R. (1978a). Job longevity as a situational factor in job satisfaction. Administrative Science Quarterly, 23, 204-223.

Katz, R. (1978b). The influence of job longevity on employee reactions to task characteristics. Human Relations, 31, 703-725.

Kawakami, N., Haratani, T. \& Araki, S. (1992). Effects of perceived job stress on depressive symptoms in blue-collar workers of an electrical factory in Japan. Scandinavian Journal of Work, Environment, \& Health, 18, 195-200.

Kenny, D.A. (1975). Cross-lagged Panel Correlation: A Test for Spuriousness. Psychological Bulletin, 82, 887-903.

Kenny, D.A. \& Judd, C.M. (1984). Estimating the Nonlinear and Interactive Effects of Latent Variables. Psychological Bulletin, 96, 1, 201-210.

Kerlinger, F.N. (1986). Foundations of behavioral research (3rd edition). New York: CBS College Publishing.

Kessler, R.C. \& Greenberg, D.F. (1981). Linear Panel Analysis. New York: Academic Press.

Kiggundu, M.N. (1983). Task Interdependence and Job Design: Test of a Theory. Organizational Behavior and Human Performance, 31, 145-172

Kleinbaum, D.G., Kupper, L.L. \& Muller, K.E. (1988). Applied Regression Analysis and Other Multivariable Methods (2nd edition). Boston: PWS-KENT Publishing Company

Knox, S.S., Theorell, T., Svensson, J.Ch. \& Waller, D. (1985). The relation of social support and working environment to medical variables associated with elevated blood pressure in young males: a structural model. Social Science and Medicine, 21, 5, 525-531. 
Koeske, G.F. \& Koeske, R.D. (1989). Construct validity of the Maslach Burnout Inventory: A critical review and reconceptualization. The loumal of Applied Behavioral Science, 25, 131-144.

Kohn, M.L. S Schooler, C. (1983), Work and Personality. An inquily into the impact of Sociai Stratifcation. Nomood. NI: Ablex Publishing.

Kompier, M, Gier, E. de. Smulders, P. \& Draaisma, D. (1994). Regulations, policies and practices conceming work stress in five European countries. Work and Stress, 8, 4, 296-318.

Krahe, B. (1992). Personality and Social Psychology: Towards a Synthesis. Newbury Park, Cabifornia: Sage Publications.

Kristensen, T.S. (1995). The Demand-Control-Support Model: Methodological Challenges for Future Research. Stress Medicine, 11, 17-26.

Landeweerd. 1.A. \& Boumans, N.P.G. (1994). The effect of work dimensions and need for autonomy on nurses work satistaction and health. Journal of Occupational and Organizational Psychology. $67.207-217$.

Landsbergis, P.A. (1988). Occupational stress among health care workers: A test of the job demandscontrol model. Journal of Organizational Behavior, 9, 217-239.

Landsbergis, P.A., Schnali, P.L., Deitz, D., Friedman, R. \& Pickering. T. (1992). The Patterning of Psychological Atributes and Distress by "Job Strain" and Social Support in a Sample of Working Men. Journal of Behavioral Medicine, 15, 4, 379-405.

Landsbergis, P.A., Schnall, P.L., Warren, K., Pickering, T.G. \& Schwartz, J.E. (1994). Association between ambulatory blood pressure and alternative formulations of job strain. Scandinavian lownal of Work, Environment, \& Health, 20,349-363.

Landsbergis, P.A., Schurman, 5.J., Israel, B.A., Schnalt, P.L., Hugentobler, M.K., Cahill, J. \& Baker, D. (1993). Job Stress and Heart Disease: Evidence and Strategies for Prevention. New Solutions, Summer, 42-58.

Landsbergis, P.A. \& Vivona-Vaughan, E. (1995). Evaluation of an occupational intervention in a public agency. Journal of Organizational Behavior, 16, 29-48

Lawler, E.E. (1980). Motivation: Closing the Gap Between Theory and Practice. In: K.D. Duncan, M.M. Gruneberg \& D. Wallis (Eds.), Changes in Working Life (pp. 539-550). Chichester: Wiley \& Sons.

Lee, R.T. \& Ashfort, B.E. (1993). A Longitudinal Study of Burnout among Supervisors and Managers: Comparisons between the Leiter and Maslach (1988) and Golembiewski et al. (1986) Models. Organizational Behavior and Human Decision Processes, 54, 369-398.

Lennerlöf, L. (1988), Learned helplessness at work. International Journal of Health Services, 18, 2 , 207-222.

Linden, G. van der (1992). Toetsing van het Job Characteristics Model en de Job Diagnostic Survey als meetinstrument van de taakstructuur [Testing of the Job Characteristics Model and the Job Diagnostic Survey as Measuring Instrument of Taskstructure]. Gedrag en Organisatie, 5, 3, 184-202.

Lindström, K. (1992). Work organization and well-being of Finnish health care personnel. Scandinavian Journal of Work, Environment, \& Health, 18, Suppl. 2, 90-93

Locke, E.A. (1969). What is job satisfaction? Organizational Behavior and Human Performance, 4, 309 336.

Locke, E.A. \& Schweiger, D.M. (1979). Participation in Decision-Making: One More Look. In: B.M. Staw (Ed.), Research in Organizational Behavior (pp. 265-339). Greenwich, Connecticut: JAl Press.

Loher, B.T., Noe, R.A., Moeller, N.L. \& Fitzgerald, M.P. (1985). A Meta-Analysis of the Relation of Job Characteristics to Job Satisfaction. Journal of Applied Psychology, 70, 280-289.

Longford, N.T. (1993). VARCL. Software for variance component analysis of data with nested random effects (maximum likelihood). Groningen: iec ProGAMMA.

Lord, R.G. \& Maher, K.J. (1989). Cognitive processes in industrial and organizational psychology In: C.L. Cooper \& I.T. Robertson (Eds.), International Review of Industrial and Organizational Psychology (pp. 49-91). Chichester: Wiley \& Sons.

Lorence, J. \& Mortimer, J.T. (1985). Job involvement through the life course: A panel study of three age groups. American Sociological Review, 50, October, 618-638.

Lubinski, D. \& Humphreys, L.G. (1990). Assessing Spurious "Moderator Effects": Hllustrated Substantively With the Hypothesized ("Synergistic") Relation Between Spatial and Mathematical Ability. Psychological Bulletin, 107, 3, 385-393.

MacCallum, R.C., Roznowski, M., Mar, C.M. \& Reith, J.V. (1994). Alternative Strategies for Cross-Validation of Covariance Structure Models. Multivariate Behavioral Research, 29, 1, 1-32. 
MacCallum, R.C., Roznowski, M. \& Necowitz, L.B. (1992). Model Modifications in Covariance Structure Analysis: The Problem of Capitalization on Chance. Psychological Bulletin, 111, 3, 490-504.

MacCallum, R.C. \& Tucker, L.R. (1991). Representing sources of error in the common-factor model: Implications for theory and practice. Psychological Bulletin, 109, 502-511.

MacCallum, R.C., Wegener, D.T., Uchino, B.N. \& Fabrigar, L.R. (1993). The Problem of Equivalent Models in Applications of Covariance Structure Analysis. Psychological Bulletin, 114, 1, 185-199.

Mackay, C.J. \& Cooper, C.L. (1987). Occupational Stress and Health: Some Current Issues. In: C.L. Cooper \& I.T. Robertson (Eds.), International Review of Industrial and Organizational Psychology (pp. 167-199). Chichester: Wiley \& Sons.

Mardia, K.V. (1985). Mardia's test of multinormality. In: S. Kotz \& N.L. Johnson (Eds.), Encyclopedia of Statistical Sciences Nolume 5) (pp. 217-221). New York: Wiley \& Sons.

Marsh, H.W., Balla, J.R. \& MCDonald, R.P. (1988). Goodness-of-Fit Indexes in Confirmatory Factor Analysis: The Effect of Sample Size. Psychological Bulletin, 103, 3, 391-410.

Marsh, H.W. \& Hocevar, D. (1985). Application of Confirmatory Factor Analysis to the Study of SelfConcept: First-and Higher Order Factor Models and Their Invariance Across Groups. Psychological Bulletin, 97, 3, 562-582.

Maslach, C. (1993). Burnout: a multidimensional perspective. In: W. B. Schaufeli, C. Maslach \& T. Marek (Eds.), Professional Burnout: recent developments in theory and research (pp. 19-32). New York: Taylor \& Francis.

Maslach, C. \& Jackson, S. (1986). MBl: Maslach Burnout Inventory, manual research edition. Palo Alto: University of California.

Maslach, C. \& Schaufeli, W.B. (1993). Historical and conceptual development of burnout. In: W.B. Schaufeli, C. Maslach \& T. Marek (Eds.), Professional Burnout: recent developments in theory and research (pp. 1-18). New York: Taylor \& Francis.

Mclaney, M.A. \& Hurrell, J.J. Jr. (1988). Control, stress, and job satisfaction in Canadian nurses. Work and Stress, 2, 3, 217-224.

Melamed, S., Kushnir, T. \& Meir, E.I. (1991). Attenuating the Impact of Job Demands: Additive and Interactive Effects of Perceived Control and Social Support. Journal of Vocational Behavior, 39, 40-53.

Mok, A.L. (1980). Arbeidstaakbeheersing, kwalificatie en beroep [Job control, qualification, and profession]. In: J.J.J. van Dijck, J.A.P. van Hoof, A.L. Mok \& W.F. de Nijs (Eds.), Kwaliteit van de arbeid: een sociologische verkenning (pp. 21-42). Leiden: Stenfert Kroese.

Monge, P.R. \& Miller, K.I. (1988). Participative Processes in Organizations. In: G.M. Goldhaber \& G.A. Barnett (Eds.), Handbook of Organizational Communication (pp. 213-229). Norwood, NJ: Ablex Publishing.

Mulder, M.J.G.P., Jonge, J. de \& Nijhuis, F.J.N. (1995). Effecten van werkkenmerken op de gezondheid: lineair additief, lineair interactief of curvelineair? [Effects of job characteristics on health: linear additive, linear interactive, or curvilinear?]. Manuscript submitted for publication.

Muntaner, C., Eaton, W.W. \& Garrison, R. (1993). Dimensions of the psychosocial work environment in a sample of the US metropolitan population. Work and Stress, 7, 4, 351-363.

Muntaner, C. \& O'Campo, P.J. (1993). A critical appraisal of the demand/control model of the psychosocial work environment: epistemological, social, behavioral and class considerations. Social Science and Medicine, 36, 11, 1509-1517.

Murray, J.A.H., Bradley, H., Craigie, W.A. \& Onions, C.T. (Eds.) (1961). The Oxford English Dictionary Volume I. Oxford: Clarendon Press.

Muthen, B.O. (1994). Multilevel Covariance Structure Analysis. Sociological Methods \& Research, 22, 3, 376-398.

Muthén, B. \& Kaplan, D. (1985). A comparison of some methodologies for the factor analysis of non-normal Likert variables. British Journal of Mathematical and Statistical Psychology, 38, 171-189.

Nunnally, J.C. (1978). Psychometric theory (2nd edition). New York: McGraw-Hill.

O'Brien, G.E. (1986). Psychology of Work and Unemployment. Chichester: Wiley \& Sons.

Offermann, L.R. \& Gowing, M.K. (1990). Organizations of the Future: Changes and Challenges. American Psychologist, 45, 2, 95-108.

Orpen, C. (1979). The Effects of Job Enrichment on Employee Satisfaction, Motivation, Involvement, and Performance: A Field Experiment. Human Relations, 32, 3. 189-217.

Parkes, K.R. (1982). Occupational stress among student nurses: A natural experiment. Journal of Applied Psychology, 67, 784-796. 
Parkes, K.R. (1989). Personal control in an occupational context. In: A. Steptoe \& A. Appels (Eds.), Stress, Personal Control and Health (pp. 21-47). Chichester: Wiley \& Sons.

Parkes, K. (1991). Locus of control as moderator: An explanation for additive versus interactive findings in the demand-discretion model of work stress? British Journal of Psychology, 82, 291-312.

Parkes, K.R. (1994). Personality and coping as moderators of work stress; processes: models, methods and measures. Work and Stress, 8, 2, 110-129.

Parkes, K.R., Mendham, C.A. \& Rabenau, C. von (1994). Social Support and the Demand-Discretion Model of Job Stress: Tests of Additive and Interactive Effects in Two Samples. Joumal of Vocational Behavior, 44, 91-113.

Parkes, K.R. \& Rabenau, C. von (1993). Work Characteristics and Well-beingl Among Psychiatric HealthCare Staff. Journal of Community \& Applied Social Psycholagy, 3, 243-259.

Payne, R. \& Firth-Cozens, J. (1987). Stress in Health Professionals. Chichester: Wiley \& Sons.

Payne, R. \& Fletcher, B.(C). (1983). Job Demands, Supports, and Constraints as Predictors of Psychologicał Strain among Schoolteachers. Journal of Vocational Behavior, 22, 136-147.

Perrewé. P.L. \& Ganster, D.C. (1989). The impact of job demands and behavival control on experienced job stress. Journal of Organizational Behavior, 10, 213-229.

Philipsen, H. (1969). Afwezigheid wegens ziekte: Een onderzoek naar oorakes wan verschillen in ziekteverzuim tussen 83 middelgrote bedrijven [Absence due to sickness]. Groningen: WoltersNoordhoff.

Pierce, J.L. \& Dunham, R.B. (1978). The measurement of perceived job characteristics: The Job Diagnostic Survey versus the Job Characteristics Inventory. Academy of Management Journal $2 *$ 123-128.

Polit, D.F. \& Hungler, B.P. (1987). Nursing research: principles and methods (Bro edition. Philadelphia: Lippincott Company.

Quinn, R.P. \& Shepard, L.J. (1974). The 1972-73 Quality of Employment Survey. Ann Arbor, Michigan: Institute for Social Research. University of Michigan.

Raudenbush, S. (1989). "Centering" predictors in multilevel analysis: choices and consequences. Multilevel modelling newsletter, 1.2, 10-12.

Reiche, H.M.J.K.I. \& Dijkhuizen, N. van (1979). Vragenlijst Organisatie Stress: test-handleiding [Organizational Stress Questionnaire: test-manual]. Nijmegen: University of Nijmegen.

Rijk, A.E. de, Blanc, P.M. Le, Schaufeli, W.B. \& Jonge, J. de (1995). Coping and need for control as moderators of the Job Demand-Control Model: Effects on Burnout. Manuscript submitted for publication.

Roberts, K.H. \& Glick, W. (1981). The Job Characteristics Approach to Task Design: A Critical Review. Journal of Applied Psychology, 66, 2, 193-217.

Roe, R.A. (1984). Individual characteristics. In: P.J.D. Drenth, H. Thierry, P.J. Willems \& Ch.1. de Wolff (Eds.), Handbook of Work and Organizational Psychology Volume 1 (pp. 103-130). Chichester: Wiley \& Sons.

Rogosa, D. (1980). A Critique of Cross-Lagged Correlation. Psychological Bulletin, 88, 2, 245-258.

Rogosa, D. (1987). Casual Models Do Not Support Scientific Conclusions: A Comment in Support of Freedman. Journal of Educational Statistics, 12, 2, 185-195

Rosenfield, S. (1989). The effects of women's employment: Personal control and sex differences in mental health. Journal of Health and Social Behavior, 30, 77-91.

Russell, J.A. (1980). A circumplex model of affect. Journal of Personality and Social Psychology, 39, 1161-1178

Sarason, B.R. \& Sarason, I.G. (1994). Assessment of Social Support. In: S.A. Shumaker \& S.M. Czajk.owski (Eds.), Social Support and Cardiovascular Disease (pp. 41-63). New York: Plenum Press.

Saris, W.E. \& Stronkhorst, L.H. (1984). Causal Modelling in Nonexperimental Research: An Introduction to the LSREL Approach. Amsterdam: Sociometric Research Foundation.

Sauter, S.L. (1989). Moderating Effects of Job Control on Health Complaints in Office Work. In: S.L. Sauter, J.J. Hurrell Jr. \& C.L. Cooper (Eds.), Job Control and Worker Health (pp. 91-103). Chichester: Wiley \& Sons

Sauter, S.L. \& Hurrell Jr., J.J. (1989). Introduction. In: S.L. Sauter, J.J. Hurrell Jr. \& C.L. Cooper (Eds.). Job Control and Worker Health (pp. xiii-xx). Chichester: Wiley \& Sons.

Scarpello, V. \& Campbell, J.P. (1983). Job satisfaction: are all the parts there? Personnel Psychology, 36, $577-600$ 
Schaefer, J.A. \& Moos, R.H. (1993). Work Stressors in Health Care: Context and Outcomes. Journal of Community \& Applied Social Psychology, 3, 235-242.

Schalk, R., Keunen, A. \& Meijer, T. (1995). Warr's schalen voor welzijn en mentale gezondheid: factorstructuur en betrouwbaarheid [Warr's scales of well-being and mental health: factor structure and reliability]. Gedrag en Organisatie, 8, 2, 116-127.

Schaufeli, W.B. \& Buunk, A.P. (in press). Burnout. in: M.J. Schabracq, J.A.M. Winnubst \& C.L. Cooper (Eds.), Handbook of Work and Health Psychology. Chichester: Wiley \& Sons

Schaufeli, W.B. \& Dierendonck, D. van (1993). The Construct Validity of Two Burnout Measures. Journal of Organizational Behavior, 14, 631-647.

Schaufeli, W.B. \& Dierendonck, D. van (1994). Burnout, een begrip gemeten: de Nederlandse versie van de Maslach Burnout Inventory [Burnout, the measurement of a construct: the Dutch version of the Maslach Burnout Inventory]. Gedrag en Gezondheid, 22, 4, 153-172.

Schaufeli, W.B., Enzmann, D. \& Girault, N. (1993). Measurement of burnout: A review. In: W. B. Schaufeli, C. Maslach \& T. Marek (Eds.), Professional burnout: Recent developments in theory and research (pp. 199-215). New York: Taylor \& Francis.

Schaufeli, W.B. \& Janczur, B. (1994). Burnout among nurses: A Polish-Dutch comparison. Journal of Cross-Cultural Psychology, 25, 95-113.

Schnall, P.L., Landsbergis, P.A. \& Baker, D. (1994). Job Strain and Cardiovascular Disease. Annual Review of Public Health, 15, 381-411

Schneider, B. (1985). Organizational Behavior. Annual Review of Psychology, 36, 573-611.

Schwab, D.P. (1980). Construct validity in organizational behavior. In: B.M. Staw \& L.L. Cummings (Eds.). Research in Organizational Behavior (pp. 3-43). London: JAl Press.

Schwartz, J.E., Pieper, C.F. \& Karasek, R.A. (1988). A Procedure for Linking Psychosocial Job Characteristics Data to Health Surveys. American Journal of Public Health, 78, 8, 904-909.

Scott Long, J. (1983a). Confirmatory factor analysis: a preface to LISREL. Newbury Park, California: Sage Publications

Scott Long, J. (1983b). Covariance structure models: an introduction to LISREL. Newbury Park, California: Sage Publications

Semmer, N., Zapf, D. \& Greif, S. (in press). "Shared well-being" on the job: A new approach for assessing the validity of job stress measurements. Journal of Occupational and Organizational Psychology.

Sevastos, P., Smith, L. \& Cordery, J.L. (1992). Evidence on the reliability and construct validity of Warr's (1990) well-being and mental health measures. Journal of Occupational and Organizational Psychology, 65, 33-49.

Shinn, M., Rosario, M., Morch, H. \& Chestnut, D.E. (1984). Coping with job stress and burnout in human services. Journal of Personality and Social Psychology, 46, 864-876.

Shirom, A. (1989). Burnout in work organizations. In: C.L. Cooper \& I. Robertson (Eds.), International Review of Industrial and Organizational Psychology (pp. 25-48). Chichester: Wiley \& Sons.

Siegrist, J. (1991). Contributions of Sociology to the Prediction of Heart Disease and Their Implications for Public Health. European Journal of Public Health, 1, 10-21.

Siegrist, J. (in press). Adverse health effects of high effort-low reward conditions. Journal of Occupational Health Psychology.

Siegrist, J. \& Matschinger, H. (1989). Restricted status control and cardiovascular risk. In: A. Steptoe \& A. Appels (Eds.). Stress, Personal Control and Health (pp. 65-82). Chichester: Wiley \& Sons.

Siegrist, J., Peter, R., Junge, A., Cremer, P. \& Seidel, D. (1990). Low status control, high effort at work and ischemic heart disease: prospective evidence from blue-collar men. Social Science and Medicine, 31, 10, 1127-1134.

Sims, H.P. (1977). A longitudinal study of job characteristics relationships. Proceedings of the Midwest Division of the Academy of Management, 20, 163-172.

Sims, H.P., Szilagyi, A.D. \& Keller, R.T. (1976). The measurement of job characteristics. Academy of Management Journal, 19, 195-212.

Smith, A. (1776). The Wealth of Nations. (Republished in 1974). Harmondsworth: Penguin.

Snijders, T.A.B. \& Bosker, R.J. (1994). Modeled Variance in Two-Level Models. Sociological Methods \& Research, 22, 3, 342-363

Soeters, J. \& Nijhuis, F. (1988). Measuring the quality of working life, using institutional and questionnaire approaches. In: S. Tyson, K.F. Ackermann, M. Domsch \& P. Joynt (Eds.), Appraising and Exploring Organizations (pp. 118-143). London: Croom Helm. 
Southwood, K.E. (1978). Substantive theory and statistical interaction: Five models. American Joumal of Sociolog, 83, 1154-1203.

Spector, P.E. (1985). Higher-order need strength as a moderator of the job scope-employee outcome relationship: A meta-analysis Joumal of Occupational Psychology, 58, 119.127.

Spector, P.E. (1986). Perceived Control by Employees: A Meta-Analysis of Studies Concerning Autonomy and Participation at Work. Human Relations, 11, $1005-1016$.

Spector, P.E. (1987). Method Variance as an Artifact in Self-Reported Affect and Perceptions at Work: Myth or Significant Problem? Journal of Applied Psychology, 72, 438-443.

Spector, P.E. (1992). A consideration of the validity and meaning of self-report measures of job conditions. In: C.L. Cooper \& I.T. Robertson (Eds.), international Review of Industrial and Organizational Psychology (pp. 123-151). New York: Wiley \& Sons.

Spector, P.E., Brannick, M.T. \& Coovert, M.D. (1989). Job Analysis. In: C.L. Cooper \& I.T. Robertson (Eds.), International Review of industrial and Organizational Psychology (pp. 281-328). Chichester: Wiley \& Sons.

Spector, P.E., Dwyer, D.J. \& Jex, S.M. (1988). Relation of Job Stressors to Affective, Health, and Performance Outcomes: A Comparison of Multiple Data Sources. Journal of Applied Psychology, 73, 1,11-19.

Spector, P.E. \& Jex, S.M. (1991). Relations of Job Characteristics From Multiple Data Sources With Employee Affect, Absence. Turnover Intentions, and Health. Journal of Applied Psychology, 76 , 1. 46-53

Spielberger, C.D. \& Reheiser, E.C. (1995). Measuring Occupational Stress: The Job Stress Survey. In: R. Crandall \& P.L. Perrewé (Eds.), Occupational Stress: A Handbook (pp. 51-69). Washington: Taylor \& Francis.

Steers, R.M. (1991). Introduction to Organizational Behavior (4th edition). New York: HarperCollins Publishers.

Steiger, J.H. (1990). Structural model evaluation and modification: An interval estimation approach. Multivariate Behavioral Research, 25, 173-180.

Stommel, M., Wang, S., Given, C.W. \& Given, B. (1992). Confirmatory Factor Analysis (CFA) as a Method to Assess Measurement Equivalence. Research in Nursing \& Health, 15, 399-405.

Stone, E.F. (1974). The moderating effect of work-related values on the job scope-job satistaction relationship. Irvine: University of California.

Stuart, A. (1984). The ideas of sampling. High Wycombe: Charles Griffin.

Sturmans, F. (1986). Epidemiologie: theorie, methoden en toepassing [Epidemiology: theory, methods and application]. Nijmegen: Dekker \& Van de Vegt.

Susman, G. (1976). Autonomy at Work. New York; Praeger.

Taber, T.D. \& Taylor, E. (1990). A review and evaluation of the psychometric properties of the Job Diagnostic Survey. Personnel Psychology, 43, 467-500.

Taylor, F.W. (1911). The Principles of Scientific Management. New York: Harper.

Thierry, H. (1990). Intrinsic Motivation Reconsidered. In: U. Kleinbeck, H.H. Quast, H. Thierry \& H. Häcker (Eds.), Work Motivation (pp. 67-82). Hillsdale, NJ: Ptenum Press.

Thomas, J.G. (1986). Sources of social information: A longitudinal analysis. Human Relations, 39, 855870.

Tiegs, R.B., Tetrick, L.E. \& Fried, Y. (1992). Growth Need Strength and Context Satisfactions as Moderators of the Relations of the Job Characteristics Model. Journal of Management, 18, 3, 575593.

Trist, E.L. (1981). The sociotechnical perspective: The evolution of sociotechnical systems as a conceptual framework and as an action research program. In: A.H. van de Ven \& W.F. Joyce (Eds.), Perspectives on Organizational Design and Behavior (pp. 19-75). New York: Wiley.

Tsui, A.S. \& Ohlott, P. (1988). Multiple assessment of managerial effectiveness: interrater agreement and consensus in effectiveness models. Personnel Psychology, 41, 779-803.

Turner, A.N. \& Lawrence, P.R. (1965). Industrial Jobs and the Worker: An Investigation of Response to Task Attributes. Boston: Harvard University.

U.S. Department of Labor (1981). Selected Characteristics of Occupations Defined in the Dictionary of Occupational Titles. Washington, DC: Department of Labor.

Vancouver, J.B., Millsap, R.E. \& Peters, P.A. (1994). Multilevel Analysis of Organizationai Goal Congruence. Journal of Applied Psychology, 79, 5, 666-679. 
Veen, P.A.F. van (1993). Etymologisch woordenboek [Etymological dictionary]. Utrecht: Van Dale Lexicografie.

Veld, J. in 't (1981). Organisatie-structuur en arbeidsplaats [Organizational structure and workplace]. Amsterdam: Elsevier.

Verbeek, M. (1991). The design of panel surveys and the treatment of missing observations. Nijmegen: NWO.

Vermaat, K. (1994). Flexibele werklastbeheersing in de verpleging [Flexible workload control in nursing]. Maastricht: University of Limburg.

Verschuren, P.J.M. (1991). Structurele modellen tussen theorie en praktijk [Structural models between theory and practice]. Meppel: Het Spectrum.

Vogeldar, A.L.W. \& Vlist, R. van der (1995). Het Job Characteristics Model en taakontwerp [The Job Characteristics Model and job redesign]. Gedrag en Organisatie, 8, 2, 65-87.

Wall, T.D. Clegg. C.W. \& Jackson, P.R. (1978). An evaluation of the Job Characteristics Model. Journal of Occupational Psychology, 51, 183-196.

Wall, T.D. \& Martin, R. (1987). Job and Work Design. In: C.L. Cooper \& I.T. Robertson (Eds.), International Review of Industrial and Organizational Psychology (pp. 61-91). Chichester: Wiley \& Sons.

Warr, P. (1986). A Vitamin Model of Jobs and Mental Health. In: G. Debus \& H.-W. Schroiff (Eds.), The Psychology of Work and Organization (pp. 157-164). Amsterdam: Elsevier Science Publishers.

Warr, P. (1987). Work, Unemployment, and Mental Health. Oxford: Clarendon Press.

Warr, P. (1990a). The measurement of well-being and other aspects of mental health. Journal of Occupational Psychology, 63, 193-210.

Warr, P.B. (1990b). Decision latitude, job demands, and employee well-being. Work and Stress, 4, 4, 285-294.

Warr, P. (1992). Age and Occupational Well-Being. Psychology and Aging, 7, 1, 37-45

Warr, P. (1994). A conceptual framework for the study of work and mental health. Work and Stress, 8 , 2. 84-97.

Watson, D. \& Clark, L.A. (1984). Negative affectivity: The disposition to experience aversive emotional states. Psychological Bulletin, 96, 465-490.

Watson, D. \& Tellegen, A. (1985). Toward a Consensual Structure of Mood. Psychological Bulletin, 98, 2, 219-235

Weaver, C.N. (1980). Job satisfaction in the United States in the 1970s. Journal of Applied Psychology, $65,3,364-367$.

Westman, M. (1992). Moderating effect of decision latitude on stress-strain relationship: Does organizational level matter? Journal of Organizational Behavior, 13, 713-722.

Wikman, A. (1991). Att utveckla sociala indikatorer: en surveyansats belyst med exemplet arbetsmiljö (The development of social indicators: a survey development on the basis of a work environment example]. Stockholm: Statistika centralbyrån.

Williams, L.J., Cote, J.A. \& Buckley, M.R. (1989). Lack of Method Variance in Self-Reported Affect and Perceptions at Work: Reality or Artifact? Journal of Applied Psychology, 74, 3, 462-468.

Windt, W. van der (1992). De arbeidsmarkt: ontwikkelingen en prognoses [The labour market: developments and prognoses]. In: J.K. van Dijk, J.E. Grunveld \& J. Pool (Eds.), Personee/smanagement in de gezondheidszorg: theorie en praktijk (pp. 43-62). Houten: Bohn Stafleu Van Loghum.

Yates, F. (1981). Sampling Methods for Censuses and Surveys. New York: MacMillan Publishing. 


\section{Appendices}




\section{Appendix 1}

LST OF ABBREVIATIONS

$\begin{array}{ll}\text { 2SLS } & \text { Two-Stage Least Squares } \\ \alpha & \text { Coefficient alpha } \\ \text { A } & \text { Appendix } \\ \text { AD } & \text { Additional Decrement } \\ \text { AGFI } & \text { Adjusted Goodness-of-fit Index } \\ \text { aggr } & \text { aggregated } \\ \text { anx } & \text { Anxiety } \\ \text { AR } & \text { Action Research } \\ \text { AUT, or a } & \text { Autonomy } \\ \text { BE } & \text { Beta } \\ \text { BSN } & \text { Bachelor of Science Degree in Nursing } \\ \text { CE } & \text { Constant Effect } \\ \text { CFA } & \text { Confirmatory Factor Analysis } \\ \text { Chi-2, or } \chi^{2} & \text { Chi-square } \\ \text { CLPC } & \text { Cross-lagged Panel Correlational Analysis } \\ \text { COL } & \text { Colleague } \\ \text { CVD } & \text { Cardiovascular Diseases } \\ \text { CVI } & \text { Cross-Validation Index } \\ \text { D } & \text { Deviance } \\ \text { DCS } & \text { Demand-Control-Support } \\ \text { DEM, or d } & \text { Demand } \\ \text { df } & \text { Degrees of freedom } \\ \text { DOT } & \text { Dictionary of Occupational Titles } \\ \Delta & \text { Delta (Greek), which means "difference" } \\ \text { EFA } & \text { Exploratory Factor Analysis } \\ \text { ECVI } & \text { Expected Cross-Validation Index } \\ \text { emot } & \text { emotional } \\ \text { exh } & \text { Exhaustion } \\ \text { FIML } & \text { Full Information Maximum Likelihood } \\ \text { GA } & \text { Gamma } \\ \text { ger } & \text { geriatric } \\ \text { GNS } & \text { Growth Need Strength } \\ \text { H } & \text { Hypothesis } \\ \text { ICU } & \text { Intensive Care Unit } \\ \text { indiv } & \text { individual } \\ \text { IC } & \text { Job Characteristics } \\ \text { JCI } & \text { Job Characteristics Index } \\ \text { JCM } & \text { Job Characteristics Model } \\ \text { JD-C } & \text { Job Demand-Control } \\ & \end{array}$




\begin{tabular}{|c|c|}
\hline JDS & Job Diagnostic Survey \\
\hline LISREL & Linear Structural Relations \\
\hline M & Mean \\
\hline MAQ & Maastricht Autonomy Questionnaire \\
\hline MBI & Maslach Burnout Inventory \\
\hline MBI-NL & Maslach Burnout Inventory, Dutch version \\
\hline $\mathrm{Ml}$ & Modification Index \\
\hline MLA & Multi-Level Analysis \\
\hline $\mathrm{M}_{0}$ & Null Model \\
\hline mot & Motivation \\
\hline MPS & Motivating Potential Score \\
\hline$M_{t}$ & Whole sample Model \\
\hline$N$ & Number (population) \\
\hline$n$ & Number (sample) \\
\hline NNFI & Non-Normed Fit Index \\
\hline n.s. & Non-significant \\
\hline OD & Organization Development \\
\hline OLS & Ordinary Least Squares \\
\hline$p$ & p-value \\
\hline p. & Page \\
\hline PAR & Participatory Action Research \\
\hline PDM & Participative Decision-Making \\
\hline $\mathrm{PH}$ & Phi \\
\hline PhD & Doctor of Philosophy \\
\hline PO & Psychological Outcomes \\
\hline $\mathrm{pp}$ & Pages \\
\hline PRELIS & Preprocessor for LISREL \\
\hline PS & Psi \\
\hline Q & Question \\
\hline r & Correlation coefficient \\
\hline $\mathrm{R}^{2}$ & $\begin{array}{l}\text { Modelled, or explained, proportion of variance; } \\
\text { Squared multiple correlations }\end{array}$ \\
\hline rel & related \\
\hline$r_{i}$ & average item-item correlation \\
\hline RMSEA & Root-Mean-Square Error of Approximation \\
\hline$r_{t}$ & Test-retest reliability \\
\hline RTA & Requisite Task Attribute \\
\hline sat & Satisfaction \\
\hline SD & Standard Deviation \\
\hline SE & Standard Error \\
\hline SEM & Structural Equation Model(ling) \\
\hline SUP, or S & Supervisor / Support \\
\hline $\mathrm{t}$ & t-value \\
\hline
\end{tabular}


$\mathrm{T}$

TCA

U.S.

VARCL

VIF

VM

VWO

VOS

VOS-D

WLS

$\chi^{2}$, or Chi-2

$y$.

YJI

Z
Target Coefficient

Task Characteristics Approach

United States

Variance Component Analysis by Maximum Likelihood

Variance Inflation Factor

Vitamin Model

Voorbereidend Wetenschappelijk Onderwijs (High School)

Vragenlijst Organisatie Stress (Organizational Stress Questionnaire)

Vragenlijst Organisatie Stress-Doetinchem

(Organizational Stress Questionnaire Doetinchem)

Weighted Least Squares

Chi-square

Year(s)

Yale Job Inventory

Z-value

\section{Appendix 2}

QUESTIONNAIRES'

\section{Job autonomy:}

The opportunity that the work offers:

1) to determine the method of working yourself. (AUT1)

2) to leave your workplace whenever you want. (AUT2)

3) to determine the work goals yourself. (AUT3)

4) to determine the order in which the work is carried out yourself. (AUT4)

5) to evaluate the work yourself. (AUT5)

6) to pause in your work whenever you want. (AUT6)

7) to determine the amount of work to be done during a certain period yourself. (AUT7)

8) to raise or lower the pace of work yourself. (AUT8)

9) to determine your own working-hours. (AUT9)

10) to determine the kind of work to be done yourself. (AUT10)

\section{Job demands:}

In the unit where I work:

1) work is carried out under pressure of time. (DEM1)

2) there are peaks in the work. (DEM2)

3) staff have to work too hard. (DEM3)

4) too much work has to be done. (DEM4)

5) there is too little time to finish the work. (DEMS)

6) the pace of work is too high. (DEM6)

7) the work is mentally exacting. (DEM7)

8) the work is too complicated. (DEM8) 


\section{Social support on the job:}

1a) How is your relationship with your senior nursing officer? (SUP1)

1b) How is your relationship with your colleagues? ( $C O L 1$ )

2a) How often do you have conflicts with your senior nursing officer? (SUIP2; reversed score)

2b) How often do you have conflicts with your colleagues? (COL2; reversed score)

3a) If there are problems at work, can you talk about them with your senior nursing officer? (SUP3)

3b) If there are problems at work, can you talk about them with your colleagues? (COL3)

4a) To what extent can you count on your senior nursing officer, when you have difficulties in your work? (SUP4)

4b) To what extent can you count on your colleagues, when you have difficulties in your work? (COL4)

5a) Do you feel appreciated in your job by your senior nursing officer? (SUP5)

5b) Do you feel appreciated in your job by your colleagues? (COL5)

\section{Work motivation:}

1) My work is challenging. (MOT1)

2) The work stimulates me to perform better all the time. (MOT2)

3) My work stimulates me to be creative. (MOT3)

4) My work is very interesting. (MOT4)

5) My work stimulates me to learn new things. (MOT5)

\section{Job satisfaction:}

1) I am satisfied with my present job. (SAT1)

\section{Einotional exhaustion:}

1) I feel emotionally drained from my work. (EXH1)

2) I feel used up at the end of the workday. (EXH2)

3) I feel fatigued when I get up in the morning and have to face another day on the job. (EXH3)

4.) Working with people all day is really a strain for me. (EXH4)

5) I feel burned out from my work. (EXH5)

6) I feel frustrated by my job. (EXH6)

7) I'eel I'm working too hard on my job. (EXH7)

8) I feel like I' $m$ at the end of my rope. (EXH8)

\section{Job-related anxiety:}

1) I feel nervous. (ANX1)

2) I feel anxious. (ANX2)

3) I feel tense. (ANX3)

4) I feel restless. (ANX4)

\section{NOTE}

1. Translated from Dutch; factorial abbreviation, which was used in chapters 5 and 6 , in parentheses. 


\section{Appendix 3}

LISREL NOTATION IN GREEK SYMBOLS

Table A3.1 LISREL notation, Greek alphabet, and LISREL meaning (cf. Hayduk, 1987)

\begin{tabular}{lll}
\hline LISREL notation & Greek alphabet & LISREL meaning \\
\hline$\beta$ (or B) & beta & structural coefficient (matrix) \\
$\gamma($ or $\Gamma$ ) & gamma & structural coefficient (matrix) \\
$\delta$ & delta & measurement error $x$ variable \\
$\varepsilon$ & epsilon & measurement error y variable \\
$\zeta$ & zeta & structural model error \\
$\eta$ & eta & latent endogenous variable \\
$\Theta$ & theta & measurement error matrix \\
$\lambda$ (or $\Lambda)$ & lambda & factor loading (matrix) \\
$\xi$ & xi, ksi & latent exogenous variable \\
$\Sigma$ & sigma & population covariance matrix \\
$S$ & & sample covariance matrix \\
$\Phi$ & phi & exogenous covariance matrix \\
$\Psi$ & psi & error covariance matrix \\
$x$ & & observed exogenous variable \\
$y$ & & observed endogenous variable \\
\hline
\end{tabular}

\section{Appendix 4}

DESCRIPTINE STATISTICS OF THE STUDY VARIABLES

Table A4.1 Means (M), standard deviations (SD), and empirical ranges of the study variables within the Job Demand-Control Model ( $n=895)$

\begin{tabular}{llll|lll}
\hline \multirow{2}{*}{ Measures } & \multicolumn{4}{l|}{ Individual data } & \multicolumn{3}{l}{ Aggregated data } \\
\cline { 2 - 7 } & $\mathrm{M}$ & SD & range & $\mathrm{M}$ & SD & range \\
\hline job demands & 3.20 & .56 & $1.50-5.00$ & 3.20 & .32 & $2.39-4.09$ \\
job autonomy & 2.72 & .55 & $1.00-4.60$ & 2.72 & .26 & $1.88-3.39$ \\
dem x aut & -.09 & .34 & $-2.33-1.35$ & -.04 & .10 & $-.42-.15$ \\
job satisfaction & 3.90 & .86 & $1.00-5.00$ & & & \\
work motivation & 3.80 & .68 & $1.20-5.00$ & & & \\
emot exhaustion & 1.74 & .87 & $.00-4.75$ & & & \\
job-rel. anxiety & 1.47 & .43 & $1.00-4.00$ & & & \\
\hline
\end{tabular}


Table A4.2 Intercorrelations of the study variables within the Job Demand-Control Model $(n=895)$

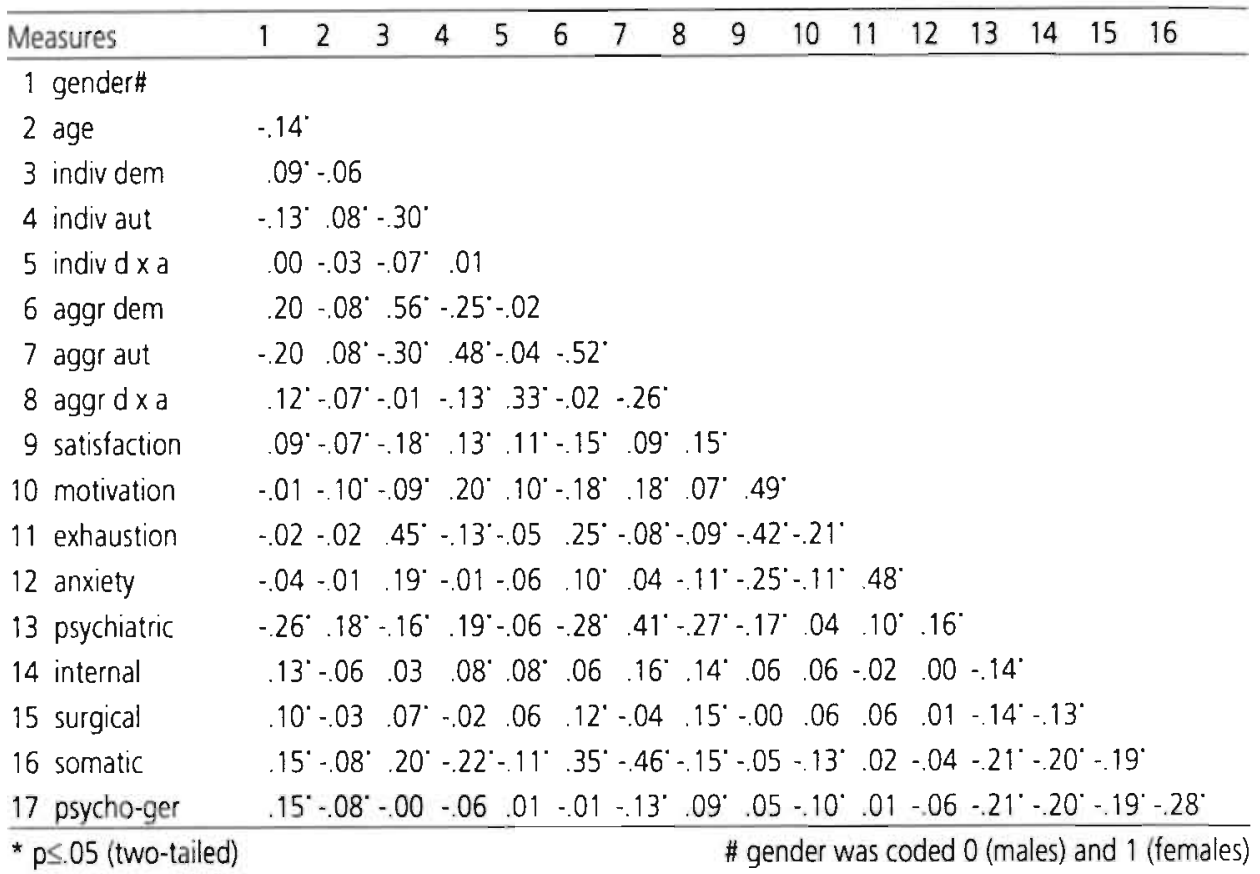

Table A4.3 Means (M), standard deviations (SD), and empirical ranges of the study variables within the Demand-Control-Support Model

\begin{tabular}{llll|lll}
\hline & \multicolumn{3}{l|}{ Calibration sample $(\mathrm{n}=665)$} & \multicolumn{3}{|c}{ Validation sample $(\mathrm{n}=667)$} \\
\cline { 2 - 8 } Measures & $\mathrm{M}$ & SD & range & $\mathrm{M}$ & $\mathrm{SD}$ & \multicolumn{1}{c}{ range } \\
\hline job demands & 3.15 & .60 & $1.00-5.00$ & 3.18 & .58 & $1.38-5.00$ \\
job autonomy & 2.69 & .55 & $1.00-4.60$ & 2.67 & .58 & $1.00-4.40$ \\
social support & 3.29 & .35 & $1.90-4.00$ & 3.32 & .34 & $2.20-4.00$ \\
dem x aut & -.10 & .35 & $-1.74-1.85$ & -.08 & .37 & $-2.37-1.80$ \\
aut x sup & .03 & .20 & $-.72-1.29$ & .03 & .21 & $-.80-1.12$ \\
dem x sup & -.03 & .22 & $-1.26-.96$ & -.03 & .23 & $-1.61-.82$ \\
dem x aut x sup & .01 & .15 & $-1.17-1.24$ & .01 & .17 & $-1.30-1.34$ \\
job satisfaction & 3.94 & .90 & $1.00-5.00$ & 3.95 & .82 & $1.00-5.00$ \\
work motivation & 3.87 & .68 & $1.60-5.00$ & 3.86 & .67 & $1.20-5.00$ \\
emot exhaustion & 1.74 & .88 & $.00-4.75$ & 1.75 & .85 & $.00-4.75$ \\
job-rel. anxiety & 1.50 & .45 & $1.00-4.00$ & 1.48 & .42 & $1.00-4.00$ \\
\hline
\end{tabular}


Table A4.4 Intercorrelations among the study variables within the Demand-Control-Support Model (below diagonal: calibration sample, $n=665$; above diagonal: validation sample, $n=667$ )

\begin{tabular}{|c|c|c|c|c|c|c|c|c|c|c|c|c|c|}
\hline Measures & 1 & 2 & 3 & 4 & 5 & 6 & 7 & 8 & 9 & 10 & 11 & 12 & 13 \\
\hline 1 gender\# & -..- & $-.11^{\star}$ & $.08^{\star}$ & $-.17^{\star}$ & $.10^{*}$ & -.00 & .03 & -.01 & -.03 & .05 & -.01 & -.01 & .04 \\
\hline 2 age & $-.14^{\star}$ & ---- & $.12^{\star}$ & $.09^{*}$ & $-.09^{*}$ & -.04 & .07 & -.01 & .05 & -.06 & $-.17^{\star}$ & -.02 & -.02 \\
\hline 3 job d & .03 & .03 & -.-- & $-.23^{\star}$ & $-.20^{\star}$ & $-.14^{\star}$ & .06 & -.01 & $.21^{\star}$ & $-.18^{\star}$ & $-.12^{\star}$ & $.44^{\star}$ & * .18 * \\
\hline 4 job & $-.16^{\star}$ & .04 & $-.29^{\star}$ & ---- & $.14^{\star}$ & .04 & .05 & .05 & $-.18 *$ & $.15^{*}$ & $.14^{*}$ & .10 & $\star-.05$ \\
\hline 5 sos & $.12^{\star}$ & -.07 & $-.15^{\star}$ & $.16^{*}$ & ---- & .06 & -.02 & $.09 *$ & $-.30^{*}$ & $.35^{\star}$ & $.25^{\star}$ & $-.30^{*}$ & ${ }^{\star}-.20^{\star}$ \\
\hline $6 \mathrm{dem}$ & -.02 & $-.13^{\star}$ & -.06 & $.08^{\star}$ & $.10^{*}$ & ; --..- & $-20^{\star}$ & $.20^{\star}$ & .04 & .07 & .06 & .02 & .04 \\
\hline 7 at & .02 & .01 & $.11^{\star}$ & -.06 & $-.08^{\star}$ & $-.15^{\star}$ & $\ldots$ & $-.34^{\star}$ & $.14^{*}$ & -.03 & -.04 & .05 & -.03 \\
\hline $8 d$ & -.05 & .02 & .06 & $.10^{*}$ & $.13^{*}$ & $.22^{\star}$ & $-.41^{\star}$ & $-\cdots-$ & $-.24^{*}$ & -.00 & .02 & -.01 & -.03 \\
\hline 9 dem & -.00 & -.03 & $.23^{*}$ & $-.16^{\star}$ & $-.37^{\star}$ & .02 & $.27^{\star}$ & $-.25^{\star}$ & ---- & $-.18^{\star}$ & $.09^{\star}$ & $.13^{*}$ & * $.08^{*}$ \\
\hline 10 jobs & $.13^{\star}$ & $-.10^{\star}$ & $-.21^{\star}$ & $.11^{\star}$ & $.35 *$ & $.12^{\star}$ & .00 & -.01 & $-.14^{\star}$ & $\cdots$ & $.44^{\star}$ & & * $-.17^{*}$ \\
\hline 11 work mo & -.02 & $-.13^{\star}$ & $-.10^{\star}$ & $.17^{\star}$ & $.28^{\star}$ & $.10^{\star}$ & $.08^{*}$ & -.02 & -.07 & $.50^{*}$ & -..-- & $.19^{\star}$ & $\star .02$ \\
\hline 12 emot exhaustion & 1.01 & -.02 & $.48^{\star}$ & $-.14^{\star}$ & $-.31^{*}$ & -.03 & .04 & .02 & $.16^{\star}$ & $-.42^{\star}$ & $-.19^{\star}$ & -..- & $.46^{\star}$ \\
\hline 13 job-rel. anxiety & .00 & .01 & $.20^{\star}$ & $-.09^{\star}$ & $.22^{\star}$ & -.03 & .03 & -.01 & $.14^{*}$ & $-.22^{\star}$ & $-.09 *$ & $.45^{*}$ & ....... \\
\hline
\end{tabular}

Table A4.5 Means (M), standard deviations (SD), and empirical ranges of the study variables within the Vitamin Model

\begin{tabular}{llll|lll}
\hline & \multicolumn{3}{l|}{ Calibration sample $(\mathrm{n}=665)$} & \multicolumn{3}{l}{ Validation sample $(\mathrm{n}=667)$} \\
\cline { 2 - 7 } Measures & $\mathrm{M}$ & $\mathrm{SD}$ & range & $\mathrm{M}$ & $\mathrm{SD}$ & \multicolumn{1}{l}{ range } \\
\hline job demands & 3.15 & .60 & $1.00-5.00$ & 3.18 & .58 & $1.38-5.00$ \\
job autonomy & 2.69 & .55 & $1.00-4.60$ & 2.67 & .58 & $1.00-4.40$ \\
social support & 3.29 & .35 & $1.90-4.00$ & 3.32 & .34 & $2.20-4.00$ \\
dem x dem & .36 & .55 & $.00-4.64$ & .34 & .54 & $.00-3.32$ \\
aut x aut & .30 & .45 & $.00-3.66$ & .33 & .46 & $.00-2.98$ \\
sup x sup & .12 & .18 & $.00-1.93$ & .11 & .15 & $.00-1.25$ \\
job satisfaction & 3.94 & .90 & $1.00-5.00$ & 3.95 & .82 & $1.00-5.00$ \\
work motivation & 3.87 & .68 & $1.60-5.00$ & 3.86 & .67 & $1.20-5.00$ \\
emot. exhaustion & 1.74 & .88 & $.00-4.75$ & 1.75 & .85 & $.00-4.75$ \\
job-rel. anxiety & 1.50 & .45 & $1.00-4.00$ & 1.48 & .42 & $1.00-4.00$ \\
\hline
\end{tabular}


Table A4.6 Intercorrelations among the study variables within the Vitamin Model (below diagonal: (alibration sample, $n=665$; above diagonal: validation sample, $n=667$ )

\begin{tabular}{|c|c|c|c|c|c|c|c|c|c|c|c|}
\hline Measures & 1 & 2 & 3 & 4 & 5 & 6 & 7 & 8 & 9 & 10 & 12 \\
\hline 1 gender\# & $\cdots--$ & $-.11^{*}$ & $.08^{\star}$ & $-.17^{\star}$ & $.10^{\star}$ & .05 & -.04 & -.04 & .05 & $-.01 \quad-.01$ & -.04 \\
\hline 2 age & $-.14^{\star}$ & ...-- & $.12^{\star}$ & $.09 *$ & $-.09 *$ & .02 & $.14^{\star}$ & .05 & -.06 & $-.17^{\star}-.02$ & -.02 \\
\hline 3 job demands & .03 & .03 & $\cdots--$ & $-.23^{\star}$ & $-.20 *$ & $.08^{*}$ & .03 & $.08^{*}$ & $-.18^{*}$ & $-.12^{\star} .44^{\star}$ & $.18^{*}$ \\
\hline 4 job autonomy & $-.16^{*}$ & .04 & $-29^{*}$ & ---- & $.14^{*}$ & $-.10^{*}$ & .04 & -.02 & $.15^{*}$ & $.14^{*}-.10^{*}$ & * -.05 \\
\hline 5 social support & $.12^{\star}$ & -.07 & $-.15^{\star}$ & $.16^{*}$ & ---- & -.01 & .04 & $-.14^{*}$ & $.35^{\star}$ & $.25^{\star}-.30^{*}$ & $+.20 *$ \\
\hline 6 dem $x$ dem & .06 & .05 & .04 & -.04 & .04 & $\cdots$ & $.12^{\star}$ & $.18^{*}$ & -.05 & $-.03 \quad .05$ & $.14^{*}$ \\
\hline 7 aut $x$ aut & -.05 & $.19^{\star}$ & .06 & $.10^{*}$ & -.04 & $.09^{*}$ & $-\cdots-$ & $.09^{*}$ & .01 & $-.05-.08^{*}$ & +.06 \\
\hline 8 sup $\times$ sup & .05 & -.00 & $.09^{*}$ & -.06 & $-.22^{\star}$ & .07 & .03 & $-\cdots$ & $-.13^{\star}$ & $-.05 \quad .05$ & .01 \\
\hline 9 job satisfaction & $.13^{\star}$ & $-.10^{*}$ & $-.21^{*}$ & $.11^{*}$ & $.35^{\star}$ & -.06 & .01 & $-.22^{*}$ & $-\cdots$ & $.44^{\star}-.33^{\star}$ & ${ }^{*}-.17^{\star}$ \\
\hline 10 work motivation & -.02 & $-.13^{*}$ & $-.10^{*}$ & $.17^{*}$ & $.28^{*}$ & -.05 & .01 & $-.09^{*}$ & $.50^{*}$ & $-\cdots-.19 *$ & $x-.02$ \\
\hline 11 emot. exhaustion & -.01 & -.02 & $48^{*}$ & $-.14^{*}$ & $-.31 *$ & .02 & -.01 & $20^{\star}$ & $-.42^{*}$ & $-.19^{\star}----$ & $.46^{\star}$ \\
\hline 12 job-rel. anxiety & .00 & .01 & $20^{*}$ & $-.09 *$ & $-.22 *$ & .05 & .07 & $.16^{*}$ & $-.22 *$ & $-.09 * .45 *$ & *....- \\
\hline
\end{tabular}

Table A4.7 Means (M), standard deviations (SD), and empirical ranges of the panel study variables $(n=225)$

\begin{tabular}{llll|lll}
\hline & Time 1 & & & Time 2 & & \\
\cline { 2 - 7 } Measures & $\mathrm{M}$ & SD & range & M & SD & range \\
\hline job demands & 3.16 & .68 & $1.38-5.00$ & 3.16 & .71 & $1.25-5.00$ \\
job autonomy & 2.73 & .59 & $1.50-4.50$ & 2.78 & .58 & $1.60-4.20$ \\
social support & 3.34 & .32 & $2.40-4.00$ & 3.28 & .38 & $2.20-4.00$ \\
job satisfaction & 4.02 & .85 & $1.00-5.00$ & 3.94 & .83 & $1.00-5.00$ \\
work motivation & 3.82 & .69 & $1.60-5.00$ & 3.63 & .66 & $2.00-5.00$ \\
emot. exhaustion & 1.68 & .92 & $.00-4.00$ & 1.61 & .88 & $.00-4.63$ \\
job-rel. anxiety & 1.44 & .41 & $1.00-2.75$ & 1.43 & .45 & $1.00-3.75$ \\
\hline
\end{tabular}


Table A4.8 Intercorrelations of the panel study variables $(n=225)$

\begin{tabular}{|c|c|c|c|c|c|c|c|c|c|c|c|}
\hline Measures & 1 & 2 & 3 & 4 & 5 & 6 & 8 & 10 & $11 \quad 12$ & 14 & 15 \\
\hline \multicolumn{12}{|l|}{1 gender\# (1) } \\
\hline 2 age (1) & -.11 & & & & & & & & & & \\
\hline 3 demands (1) & .08 & .03 & & & & & & & & & \\
\hline 4 autonomy (1) & $-.19^{\star}$ & $.13^{*}$ & $\star-.30^{\star}$ & & & & & & & & \\
\hline 5 support $(1)$ & .08 & -.04 & $-.24^{\star}$ & $\star 24^{\star}$ & & & & & & & \\
\hline 6 satisfaction (1) & .08 & -.09 & -.31 * & * $.25^{\star}$ & * $.46^{\star}$ & & & & & & \\
\hline 7 motivation (1) & -.02 & $-.16^{\star}$ & $x^{*}-.26^{\star}$ & * $.19^{\star}$ & * $34^{\star}$ & $\star 52^{\star}$ & & & & & \\
\hline 8 exhaustion ( 1 ) & -.06 & -.07 & $.52^{\star}$ & $\star-.13$ & $-.25^{\star}$ & $-.40^{\star}-.27^{\star}$ & & & & & \\
\hline 9 anxiety (1) & -.05 & .01 & $.21^{*}$ & $\star-.03$ & $-.19^{\star}$ & $\star-.34^{\star}-.07$ & $.45^{*}$ & & & & \\
\hline 10 demands (2) & -.02 & -.01 & $.72^{\star}$ & ${ }^{\star}-.35^{\star}$ & * $-.21^{*}$ & ${ }^{*}-.28^{\star}-.21^{*}$ & $\star 50^{\star}$ & $.20^{\star}$ & & & \\
\hline 11 autonomy (2) & $-.16^{\star}$ & .04 & $-.27^{*}$ & * $.64^{\star}$ & * $.29^{\star}$ & $.22^{\star} .25^{\star}$ & $\star-16^{\star}$ & $-.04-.43^{\star}$ & & & \\
\hline 12 support (2) & $.13^{\star}$ & -.00 & $-.21^{\star}$ & * $.23^{*}$ & $\star .59 *$ & * $.36^{*} .32 *$ & $\star-26 *$ & $=-.18^{\star}-.34^{\star}$ & $39^{*}$ & & \\
\hline 13 satisfaction (2) & .06 & -.03 & $-.34^{\star}$ & $\star .24^{\star}$ & $\star 38^{\star}$ & * $.55^{*} .43^{\star}$ & ${ }^{*}-.43^{*}$ & $-.26^{\star}-.40^{\star}$ & $.39^{\star} .53^{\star}$ & & \\
\hline 14 motivation (2) & -.11 & -.06 & $-.20^{\star}$ & ${ }^{*} .17^{\star}$ & $.25^{*}$ & * $40^{\star} .62^{\star}$ & * $-.25^{\star}$ & $-.09-.20^{*}$ & $.27^{\star} .42^{\star}$ & $\star .55^{\star}$ & \\
\hline 15 exhaustion (2) & .01 & -.12 & $.33^{*}$ & *.$- .17 *$ & $\star-.24^{\star}$ & $\star-35^{\star}-.25^{\star}$ & $\star 66^{\star}$ & $.37^{*} .50^{*}$ & $-.33^{*}-.44^{*}$ & $\star-.54^{\star}-.36 *$ & \\
\hline 16 anxiety (2) & .04 & .01 & $.17^{*}$ & $\star \star . .04$ & $-.15^{\star}$ & $-.21 *-.07$ & $.36^{*}$ & $.59^{\star} .26^{\star}$ & $-.16^{*}-34^{*}$ & $\star-.37^{\star}-.18^{*}$ & $.53^{*}$ \\
\hline
\end{tabular}




\section{Appendix 5}

ESTIMATED PARAMETER COEFFICIENTS OF THE ULTIMATE MODELS

Table A5.1 Parameter estimates (Full Information Maximum Likelihood) of the linear additive model (Standard Errors in parentheses; $n=1,332$ )

\begin{tabular}{|c|c|c|c|}
\hline parameter\# & estimates (SE) & parameter\# & estimates (SE) \\
\hline $\mathrm{BE}(1,5)$ & $-.19 *(.04)$ & $P S(6,6)$ & $31 *(.01)$ \\
\hline $\mathrm{BE}(2,5)$ & $-.03(.03)$ & $\operatorname{PS}(7,7)$ & $.12^{\star}(.00)$ \\
\hline$B E(3,5)$ & $.64 \star(.04)$ & $\mathrm{PS}(8,8)$ & $.13^{\star}(.01)$ \\
\hline $\mathrm{BE}(4,5)$ & $.12^{\star}(.02)$ & $\operatorname{PS}(9,9)$ & $.04 \quad(.00)$ \\
\hline$B E(1,6)$ & $.10 *(.04)$ & $P S(10,10)$ & $.05 \quad(.00)$ \\
\hline $\operatorname{BE}(2,6)$ & $.14^{\star}(.03)$ & $P S(11,11)$ & $.02 \quad(.00)$ \\
\hline$B E(3,6)$ & $.05 \quad(.04)$ & $\operatorname{PS}(1,2)$ & $.21^{\star}(.02)$ \\
\hline$B E(4,6)$ & $.00 \quad(.02)$ & $\operatorname{PS}(1,3)$ & $-.17^{\star}(.02)$ \\
\hline $\mathrm{BE}(1,7)$ & $.77^{\star}(.07)$ & $P S(1,4)$ & $-.04 *(.01)$ \\
\hline $\operatorname{BE}(2,7)$ & $.46^{\star}(.05)$ & $\operatorname{PS}(2,3)$ & $-.06 *(.01)$ \\
\hline $\mathrm{BE}(3,7)$ & $-.59^{\star}(.06)$ & $\operatorname{PS}(2,4)$ & $.00 \quad(.01)$ \\
\hline$B E(4,7)$ & $-.24^{*}(.03)$ & $P S(3,4)$ & $.12 *(.01)$ \\
\hline $\mathrm{GA}(1,1)$ & $.17 *(.06)$ & $\operatorname{PS}(5,6)$ & $-.09^{\star}(.01)$ \\
\hline $\mathrm{GA}(2,1)$ & $-.07 \quad(.05)$ & $P S(5,7)$ & $-.04^{\star}(.01)$ \\
\hline $\mathrm{GA}(3,1)$ & $-.03(.06)$ & $P S(5,8)$ & $-.02 *(.01)$ \\
\hline $\mathrm{GA}(4,1)$ &. $.01 \quad(.03)$ & $\operatorname{PS}(5,9)$ & $.01 *(.00)$ \\
\hline $\mathrm{GA}(5,1)$ & $.10^{\star}(.04)$ & $\operatorname{PS}(5,10)$ & $.00 \quad(.00)$ \\
\hline$G A(6,1)$ & $-.26^{\star}(.04)$ & $P S(5,11)$ & $.02^{\star}(.00)$ \\
\hline $\mathrm{GA}(7,1)$ & $.09 *(.02)$ & $\operatorname{PS}(6,7)$ & $.03^{\star}(.01)$ \\
\hline$G A(1,2)$ & $.00 \quad(.00)$ & $P S(6,8)$ & $.01 *(.01)$ \\
\hline $\mathrm{GA}(2,2)$ & $-.01 *(.00)$ & $\operatorname{PS}(6,9)$ & $.00 \quad(.00)$ \\
\hline $\mathrm{GA}(3,2)$ & $-.01 *(.00)$ & $P S(6,10)$ & $.01 *(.00)$ \\
\hline $\mathrm{GA}(4,2)$ & $.00 \quad(.00)$ & $P S(6,11)$ & $-.02 *(.00)$ \\
\hline$G A(5,2)$ & $.00 *(.00)$ & $\operatorname{PS}(7,8)$ & $.01 *(.00)$ \\
\hline $\mathrm{GA}(6,2)$ & $.00 \quad(.00)$ & $\operatorname{PS}(7,9)$ & $.00 \quad(.00)$ \\
\hline $\mathrm{GA}(7,2)$ & $.00 *(.00)$ & $P S(7,10)$ & $.01 *(.00)$ \\
\hline $\mathrm{PH}(1,1)$ & $.13 *(.01)$ & $\operatorname{PS}(7,11)$ & $-.02 *(.00)$ \\
\hline $\mathrm{PH}(2,2)$ & $67.14^{*}(2.60)$ & $\operatorname{PS}(8,9)$ & $-.01 *(.00)$ \\
\hline $\mathrm{PH}(1,2)$ & $-.37^{\star}(.08)$ & $P S(8,10)$ & $.02 *(.00)$ \\
\hline$P S(1,1)$ & $.63^{\star}(.02)$ & $\operatorname{PS}(8,11)$ & $.00 \quad(.00)$ \\
\hline$P S(2,2)$ & $.41 *(.02)$ & $\operatorname{PS}(9,10)$ & $-.02 *(.00)$ \\
\hline $\operatorname{PS}(3,3)$ & $.55 *(.02)$ & $\operatorname{PS}(9,11)$ & $.01 *(.00)$ \\
\hline$P S(4,4)$ & $.18^{*}(.01)$ & $P S(10,11)$ & $-.01 *(.00)$ \\
\hline$P S(5,5)$ & $.34^{*}(.01)$ & & \\
\hline
\end{tabular}


Table A5.2 Parameter estimates (Full information Maximum Likelihood) of the non-linear Vitamin Model (Standard Errors in parentheses; $n=1,332$ )

\begin{tabular}{|c|c|c|c|}
\hline parameter\# & estimates (SE) & parameter\# & estimates (SE) \\
\hline $\mathrm{BE}(1,5)$ & $-.18^{\star}(.04)$ & $\mathrm{GA}(7,2)$ & $.00 *(.00)$ \\
\hline $\mathrm{BE}(2,5)$ & $-.02(.03)$ & $G A(8,2)$ & $.01 *(.00)$ \\
\hline $\mathrm{BE}(3,5)$ & $.64^{\star}(.04)$ & $\mathrm{PH}(1,1)$ & $.13^{*}(.01)$ \\
\hline $\operatorname{BE}(4,5)$ & $.11 *(.02)$ & $\mathrm{PH}(2,2)$ & $67.14^{*}(2.60)$ \\
\hline $\mathrm{BE}(1,6)$ & $.09 *(.04)$ & $\mathrm{PH}(1,2)$ & $-.37^{\star}(.08)$ \\
\hline $\mathrm{BE}(2,6)$ & $.14^{\star}(.03)$ & $P S(1,1)$ & $.62 *(.02)$ \\
\hline $\mathrm{BE}(3,6)$ & $.05 \quad(.04)$ & $P S(2,2)$ & $.41 *(.02)$ \\
\hline $\operatorname{BE}(4,6)$ & $.00 \quad(.02)$ & $P S(3,3)$ & $.54^{*}(.02)$ \\
\hline $\mathrm{BE}(1,7)$ & $.73^{*}(.07)$ & $\operatorname{PS}(4,4)$ & $.18^{\star}(.01)$ \\
\hline $\mathrm{BE}(2,7)$ & $.46 *(.05)$ & $P S(5,5)$ & $.34^{*}(.01)$ \\
\hline $\mathrm{BE}(3,7)$ & $-.57 *(.06)$ & $\operatorname{PS}(6,6)$ & $.31 *(.01)$ \\
\hline $\mathrm{BE}(4,7)$ & $-.23^{*}(.04)$ & $\operatorname{PS}(7,7)$ & $.12^{*}(.00)$ \\
\hline $\mathrm{BE}(1,8)$ & $-.06 \quad(.04)$ & $P S(8,8)$ & $.30 *(.01)$ \\
\hline $\mathrm{BE}(2,8)$ & $-.03(.03)$ & $\operatorname{PS}(9,9)$ & $20 *(.01)$ \\
\hline $\mathrm{BE}(3,8)$ & $.02 \quad(.04)$ & $\operatorname{PS}(10,10)$ & $.03^{\star}(.00)$ \\
\hline $\operatorname{BE}(4,8)$ & $.07 *(.02)$ & $\operatorname{PS}(1,2)$ & $.21^{\star}(.01)$ \\
\hline $\mathrm{BE}(1,9)$ & $.06 \quad(.05)$ & $P S(1,3)$ & $-.16^{\star}(.02)$ \\
\hline $\mathrm{BE}(2,9)$ & $.00 \quad(.04)$ & $P S(1,4)$ & $-.04^{\star}(.01)$ \\
\hline $\mathrm{BE}(3,9)$ & $-.11 *(.05)$ & $\operatorname{PS}(2,3)$ & $-.06 *(.01)$ \\
\hline $\mathrm{BE}(4,9)$ & $-.01 \quad(.03)$ & $\operatorname{PS}(2,4)$ & $.00 \quad(.00)$ \\
\hline$B E(1,10)$ & $-.55^{\star}(.13)$ & $P S(3,4)$ & $.12^{*}(.01)$ \\
\hline$B E(2,10)$ & $-.07(.11)$ & $P S(5,6)$ & $-.09 *(.01)$ \\
\hline $\operatorname{BE}(3,10)$ & $.30 *(.12)$ & $P S(5,7)$ & $-.04^{*}(.01)$ \\
\hline$B E(4,10)$ & $.11 \quad(.07)$ & $\mathrm{PS}(5,8)$ & $.02(.01)$ \\
\hline $\mathrm{GA}(1,1)$ & $.18^{*}(.06)$ & $P S(5,9)$ & $.01 \quad(.01)$ \\
\hline $\mathrm{GA}(2,1)$ & $-.06 \quad(.05)$ & $P S(5,10)$ & $.01 *(.00)$ \\
\hline $\mathrm{GA}(3,1)$ & $-.04 \quad(.06)$ & $\operatorname{PS}(6,7)$ & $.03^{\star}(.01)$ \\
\hline $\mathrm{GA}(4,1)$ & $-.02(.03)$ & $\operatorname{PS}(6.8)$ & $-.02^{\star}(.01)$ \\
\hline$G A(5,1)$ & $.10^{*}(.04)$ & $P S(6,9)$ & $.01 \quad(.01)$ \\
\hline $\mathrm{GA}(6,1)$ & $-.24^{*}(.04)$ & $\operatorname{PS}(6,10)$ & $.00 \quad(.00)$ \\
\hline$G A(7,1)$ & $.10^{*}(.03)$ & $\operatorname{PS}(7,8)$ & $.00 \quad(.01)$ \\
\hline $\mathrm{GA}(1,2)$ & $.00 \quad(.00)$ & $\operatorname{PS}(7,9)$ & $.00 \quad(.00)$ \\
\hline $\mathrm{GA}(2,2)$ & $-.01 *(.00)$ & $\operatorname{PS}(7,10)$ & $-.01 *(.00)$ \\
\hline $\mathrm{GA}(3,2)$ & $-.01 *(.00)$ & $\mathrm{PS}(8,9)$ & $.03^{*}(.01)$ \\
\hline $\mathrm{GA}(4,2)$ & $.00(.00)$ & $\operatorname{PS}(8,10)$ & $.01 *(.00)$ \\
\hline $\mathrm{GA}(5,2)$ & $.01 *(.00)$ & $\operatorname{PS}(9,10)$ & $.00 \quad(.00)$ \\
\hline $\mathrm{GA}(6,2)$ & $.00 \quad(.00)$ & & \\
\hline
\end{tabular}


Table A5.3 Parameter estimates (Full Information Maximum Likelihood) of the longitudinal panel model ( 5 tandard Errors in parentheses; $n=225$ )

\begin{tabular}{|c|c|c|c|}
\hline parameter\# & estimates (SE) & parameter\# & estimates (SE) \\
\hline $\mathrm{BE}(1,9)$ & $-.15^{\star}(.06)$ & $B E(8,10)$ & $.04(.05)$ \\
\hline$B E(1,10)$ & $.23 *(.07)$ & $B E(5,11)$ & $-.20(.15)$ \\
\hline$B E(1,11)$ & $.85^{*}(.11)$ & $B E(6,11)$ & $-.26^{*}(.12)$ \\
\hline $\mathrm{BE}(2,9)$ & $-.07 \quad(.05)$ & $\mathrm{BE}(7,11)$ & $.15 \quad(.15)$ \\
\hline $\mathrm{BE}(2,10)$ & $.10(.06)$ & $\mathrm{BE}(8,11)$ & $.12(.08)$ \\
\hline $\mathrm{BE}(2,11)$ & $.54^{\star}(.09)$ & $\mathrm{BE}(12,1)$ & $-.03 \quad(.05)$ \\
\hline $\mathrm{BE}(3,9)$ & $.52 *(.06)$ & $\mathrm{BE}(12,2)$ & $.01 \quad(.06)$ \\
\hline $\mathrm{BE}(3,10)$ & $-.06 \quad(.07)$ & $\mathrm{BE}(12,3)$ & $.13^{*}(.05)$ \\
\hline $\mathrm{BE}(3,11)$ & $-.53^{\star}(.11)$ & $\mathrm{BE}(12,4)$ & $-.02 \quad(.09)$ \\
\hline $\mathrm{BE}(4,9)$ & $.09 *(.03)$ & $\mathrm{BE}(13,1)$ & $.00 \quad(.05)$ \\
\hline $\mathrm{BE}(4,10)$ & $-.01 \quad(.04)$ & $B E(13,2)$ & $.10^{\star}(.05)$ \\
\hline $\operatorname{BE}(4,11)$ & $-.27^{*}(.06)$ & $\operatorname{BE}(13,3)$ & $-.04 \quad(.04)$ \\
\hline$B E(5,12)$ & $-.15^{\star}(.06)$ & $B E(13,4)$ & $.02(.08)$ \\
\hline $\mathrm{BE}(5,13)$ & $.23^{\star}(.07)$ & $\mathrm{BE}(14,1)$ & $.02(.03)$ \\
\hline$B E(5,14)$ & $.85^{\star}(.11)$ & $B E(14,2)$ & $.06 \quad(.03)$ \\
\hline $\mathrm{BE}(6,12)$ & $-.07 \quad(.05)$ & $\mathrm{BE}(14,3)$ & $-.03 \quad(.03)$ \\
\hline$B E(6,13)$ & $.10(.06)$ & $B E(14,4)$ & $-.03 \quad(.06)$ \\
\hline$B E(6,14)$ & $.54^{\star}(.09\rangle$ & $G A(1,1)$ & $.17(.16)$ \\
\hline $\mathrm{BE}(7,12)$ & $.52^{*}(.06)$ & $\mathrm{GA}(2,1)$ & $-.11 \quad(.14)$ \\
\hline $\operatorname{BE}(7,13)$ & $.06 \quad(.07)$ & $\mathrm{GA}(3,1)$ & $-.10 \quad(.17)$ \\
\hline$B E(7,14)$ & $-.53^{\star}(.11)$ & $\mathrm{GA}(4,1)$ &. $.03 \quad(.09)$ \\
\hline $\mathrm{BE}(8,12)$ & $.09 *(.03)$ & $\mathrm{GA}(9,1)$ & $-.17(.15)$ \\
\hline $\mathrm{BE}(8,13)$ &. $.01 \quad(.04)$ & $\mathrm{GA}(10,1)$ & $-.34^{*}(.12)$ \\
\hline $\mathrm{BE}(8,14)$ & $-.27^{*}(.06)$ & $\mathrm{GA}(11,1)$ & $.08 \quad(.07)$ \\
\hline $\mathrm{BE}(5,1)$ & $.34^{*}(.05)$ & $G A(1,2)$ & $-.01 \quad(.01)$ \\
\hline $\mathrm{BE}(6,2)$ & $.49 *(.05)$ & $\mathrm{GA}(2,2)$ & $-.01 *(.01)$ \\
\hline $\mathrm{BE}(7,3)$ & $.50 *(.05)$ & $\mathrm{GA}(3,2)$ & $-.01 \quad(.01)$ \\
\hline $\mathrm{BE}(8,4)$ & $.56^{*}(.05)$ & $\mathrm{GA}(4,2)$ & $.00 \quad(.00)$ \\
\hline $\mathrm{BE}(12,9)$ & $.65 *(.05)$ & $\mathrm{GA}(9,2)$ & $.00 \quad(.01)$ \\
\hline $\mathrm{BE}(13,10)$ & $.55 *(.05)$ & $\mathrm{GA}(10,2)$ & $.01 \quad(.00)$ \\
\hline $\operatorname{BE}(14,11)$ & $.58 *(.07)$ & $\mathrm{GA}(11,2)$ & $.00 \quad(.00)$ \\
\hline $\mathrm{BE}(5,9)$ & $.07 \quad(.08)$ & $\mathrm{PH}(1,1)$ & $.10 *(.01)$ \\
\hline $\mathrm{BE}(6,9)$ & $.04 \quad(.06)$ & $\mathrm{PH}(2,2)$ & $68.52^{*}(6.50)$ \\
\hline$B E(7,9)$ & $-.36 *(.08)$ & $\mathrm{PH}(1,2)$ & $-.28 \quad(.17\rangle$ \\
\hline $\mathrm{BE}(8,9)$ & $-.04 \quad(.04)$ & $P S(1,1)$ & $.53^{\star}(.05)$ \\
\hline $\mathrm{BE}(5,10)$ & $-.11(.08)$ & $\operatorname{PS}(2,2)$ & $.39 *(.04)$ \\
\hline $\mathrm{BE}(6,10)$ & $-.05 \quad(.07)$ & $\operatorname{PS}(3,3)$ & $.61 *(.06)$ \\
\hline $\mathrm{BE}(7,10)$ & $.04 \quad(.08)$ & $\operatorname{PS}(4,4)$ & $.16^{*}(.02)$ \\
\hline
\end{tabular}


Table A5.3 Continued

\begin{tabular}{|c|c|c|c|}
\hline parameter\# & estimates (SE) & parameter\# & estimates (SE) \\
\hline $\mathrm{PS}(5,5)$ & $.36^{*}(.03)$ & $P S(2,4)$ & $.01 \quad(.02)$ \\
\hline$P S(6,6)$ & $.24^{\star}(.02)$ & $\operatorname{PS}(3,4)$ & $.12^{*}(.02)$ \\
\hline $\operatorname{PS}(7,7)$ & $.34^{\star}(.03)$ & $\operatorname{PS}(5,6)$ & $.09 *(.02)$ \\
\hline $\operatorname{PS}(8,8)$ & $.12^{*}(.01)$ & $\mathrm{PS}(5,7)$ & $-.08 *(.02)$ \\
\hline $\operatorname{PS}(9,9)$ & $.33^{*}(.03)$ & $P S(5,8)$ & $-.04 *(.01)$ \\
\hline $\operatorname{PS}(10,10)$ & $.45^{*}(.04)$ & $P S(6,7)$ & $-.05 *(.02)$ \\
\hline $\operatorname{PS}(11,11)$ & $.10 *(.01)$ & $\operatorname{PS}(6,8)$ & $.01 \quad(.01)$ \\
\hline $\operatorname{PS}(12,12)$ & $.19 *(.02)$ & $\operatorname{PS}(7,8)$ & $.06 *(01)$ \\
\hline$P S(13,13)$ & $.23^{*}(.02)$ & $\operatorname{PS}(9,10)$ & $-.13^{\star}(.03)$ \\
\hline $\operatorname{PS}(14,14)$ & $.09 *(.01)$ & $\operatorname{PS}(9,11)$ & $-.05^{\star}(.01)$ \\
\hline$P S(1,2)$ & $.18^{*}(.03)$ & $\operatorname{PS}(10,11)$ & $.05^{\star}(01)$ \\
\hline$P S(1,3)$ & $-.16^{\star}(.04)$ & $\operatorname{PS}(12,13)$ & $-.07 *(.01)$ \\
\hline$P S(1,4)$ & $-.08^{\star}(.02)$ & $\operatorname{PS}(12.14)$ & $-.04 \star(.01)$ \\
\hline $\operatorname{PS}(2,3)$ & $-.08 *(.03)$ & $\operatorname{PS}(13,14)$ & $.03^{*}(.01)$ \\
\hline
\end{tabular}

Table A5.4 The meaning of variables in matrix elements

\begin{tabular}{ll|ll|ll}
\hline linear additive model & & non-linear model & & panel model & \\
\hline variable & element & variable & element & variable & element \\
\hline gender & $\gamma_{1}$ & gender & $\gamma_{1}$ & gender (1) & $\gamma_{1}$ \\
age & $\gamma_{2}$ & age & $\gamma_{2}$ & age (1) & $\gamma_{2}$ \\
satisfaction & $B_{1}$ & satisfaction & $B_{1}$ & satisfaction (1) & $B_{1}$ \\
motivation & $B_{2}$ & motivation & $B_{2}$ & motivation (1) & $B_{2}$ \\
exhaustion & $B_{3}$ & exhaustion & $B_{3}$ & exhaustion (1) & $B_{3}$ \\
anxiety & $B_{4}$ & anxiety & $B_{4}$ & anxiety (1) & $B_{4}$ \\
demands & $B_{5}$ & demands & $B_{5}$ & satisfaction (2) & $B_{5}$ \\
autonomy & $B_{6}$ & autonomy & $B_{6}$ & motivation (2) & $B_{6}$ \\
support & $B_{7}$ & support & $B_{7}$ & exhaustion (2) & $B_{7}$ \\
& & dem x dem & $B_{8}$ & anxiety (2) & $B_{8}$ \\
[dem x aut & $B_{8}$ l & aut x aut & $B_{9}$ & demands (1) & $B_{9}$ \\
[aut x sup & $B_{9}$ l & sup x sup & $B_{10}$ & autonomy (1) & $B_{10}$ \\
[dem x sup & $B_{10}$ l & & & support (1) & $B_{11}$ \\
[d x x x & $B_{11}$ ] & & demands (2) & $B_{12}$ \\
& & & & autonomy (2) & $B_{13}$ \\
& & & support (2) & $B_{14}$ \\
\hline
\end{tabular}




\section{ACKNOWLEDGEMENTS}

Newton once said that if he saw further than others it was because he stood on the shoulders of giants. Although this noble saying tells a lot about Newton's modesty, if he had stood on the shoulders of midgets, he would also have seen further.

In other words, any elevation seems to help, also in writing this thesis. If I have seen any further, it is because I have stood on the shoulders of many persons who were willing to provide support, encouragement, wisdom and love.

First of all, I would like to thank my supervisor Frans Nijhuis. Frans created all possible conditions for completing the entire project in four years. Additionally, he proved to be a competent coach who stimulated and inspired me whenever necessary.

Ab Landeweerd, the co-supervisor, is acknowledged for his accompaniment during the whole venture. Ab was the one who encouraged me to start a career as a scientist. He put the project on the rails, and showed me the profits of well-structured fundamental as well as applied research.

Furthermore, I am indebted to my colleague Peter Janssen for our lively discussions in the process of performing and writing several articles as well as this dissertation. In addition, Nicolle Boumans is acknowledged for her contribution to the study. Being my PhD predecessor, her PhD work was an important tool and blueprint for the current project. Some activities require more interest, devotion and enthusiasm than do others. So it seems to be with statistics. In many phases of the project, Gerard van Breukelen was so kind to discuss with me various aspects concerning sophisticated statistical techniques. These profound discussions resulted in a firm foundation for the analyses applied.

I am indebted to the members of the PhD committee for their willingness to sit on the committee and for reading the entire manuscript.

Several health sciences students have been very helpful in doing some of the fieldwork and data analysis. I would like to thank, in alphabetical order, Hanneke Boone, Gerbentsje Bruinsma, Sjaak van der Linden, Marice Lusthuis and Kees Vermaat.

Furthermore, I am grateful to my colleagues from the universities of Leiden and Utrecht. In particular Jur Furda, Wilmar Schaufeli and Pascale Le Blanc deserve my thanks for several joint ventures in this field of research.

I would also like to thank the health care staff of the various institutions across the country who have been involved in the various stages of the project. In particular I am indebted to those health care workers who gave up their valuable time to take part in the survey once or twice.

During my period as a PhD student, several colleagues at the Department of Medical Psychology from the University of Limburg created a stimulating and enjoyable research environment. Particularly the discussions with Ad de Jong, my room-mate for the first three years of the project, were important to me. Isel van Noppen, Joyce Angenent and Anny Le Doux are acknowledged for their secretarial support. Finally, the punishing badminton games against my colleague Hans Bosma were major remedies against work stress.

Gerard Houben from the Department of Health Policy and Administration deserves my thanks for the profound dialogues about "job control". Additionally, Lou Lathouwer and 
Math Reintjens from the University of Limburg are acknowledged for their help with offset printing and data-entry, respectively. I also thank Bob Wilkinson for his considerable assistance in correcting my English. Hellmuth van Berlo and Dirk Enzmann are acknowledged for their contribution to the summary in German. Corine Remmers read the last draft of the manuscript and gave valuable comments. Karel van den Hurk is gratefully acknowledged for taking care of the most important last task in this thesis: the lay-out and printing. Special thanks also go to the board members of the PhD association of the University of Limburg. These 'partners in distress' were important advocates of all kinds of social support during my $\mathrm{PhD}$ period. Very important to me was my $\mathrm{PhD}$ companion and former neighbour Charles van Haaster.

I would like to acknowledge my debt to my parents as well as my parents-in-law, who supported me in every possible way, and all other relatives and friends who have knowingly and unknowingly - helped me in performing and writing this study.

Finally, I would like to thank you, Lidian, for the exceptional contributions you made to the realization of my thesis. You gave me the ultimate feelings of job autonomy and wellbeing; that is, the actual opportunities to work continuously on this project for four years, even after working-hours and in the weekends. It was not easy for you to listen to my brainstorming, progress and tribulations time after time. I thank you tor your warm support and love, which I needed in order to finish this job. Lidian, I think we are a great team.

Jan de Jonge 


\section{CURRICULUM VITAE}

Jan de Jonge was born 1 May 1964 in Enschede, the Netherlands. After he finished high school (VWO) in 1983, he served in the Dutch Army for sixteen months. A four-year bachelor's programme at the Hogeschool Enschede resulted in a "cum laude" graduation as a registered nurse (BSN). Subsequently, he studied health sciences at the University of Limburg in Maastricht. In the same period, he worked as a part-time district nurse in several districts.

In November 1991, he started as a PhD student at the Department of Medical Psychology, Work and Health Psychology Section, of the University of Limburg. Alongside his PhD work and teaching health sciences students, he has coordinated a risk assessment project in accordance with the Dutch Work Environment Act on behalf of Dutch work organizations. From 1992 to 1995, he functioned as a board member of the PhD association of the University of Limburg.

Beginning 1 January 1996, the author is working as an assistent professor at the Catholic University of Nijmegen, Department of Social Psychology, Work and Organizational Psychology Section. 
ISBN 90-9008948-9 